Departamento de Lenguajes y Sistemas

Informáticos e Ingeniería de Software

Escuela Técnica Superior de Ingenieros Informáticos

Universidad Politécnica de Madrid

TESIS DOCTORAL

\title{
Dificultades en el aprendizaje del diseño de software orientado a objetos: un estudio cualitativo longitudinal
}

Autor: Pamela Catherine Flores Naranjo

Director: Nelson Medinilla Martínez

Enero 2016 



\section{Abstract}

The software development companies look to reduce costs through the development of designs that will: a) ease the distribution of development work with the least communication between the parties; b) changeability, allowing to change a module without disturbing the other parties and; c) understandability, allowing to study a system module at a time.

These basic software design features are achieved through the design of quasidecomposable systems, whose theoretical model was introduced by Simon in his search for a general theory of systems. In the field of software design, Parnas offers a practical way to achieve quasi-decomposable systems, called The Information Hiding Principle.

The Information Hiding Principle is different criterion for decomposition into modules, whose implementation achieves the desirable characteristics of an efficient design at the development and maintenance level. The Principle and the object-oriented approach are related because the object-oriented approach facilitates the implementation of The Principle, which is why when objects begin to take hold, also appear alongside the difficulties in learning an object-oriented software design, which remain to this day, as reported in the literature.

Difficulties in learning object-oriented software design has a great impact both in the classroom and in the profession. The detection of these difficulties will allow teachers to correct or route them before they move to the industry. On the other hand, the industry can be warned of potential problems related to the software development process.

This thesis aims to investigate the difficulties in learning the object-oriented design, through an empirical study. The study was conducted through a qualitative case study, which consisted of three parts. The first, an initial study was aimed to understand the knowledge of the students around The Information Hiding Principle before they start the instruction. The second part, a study was conducted during the entire period of instruction in order to obtain the difficulties of software design and their level of persistence. Finally, a third party, whose purpose was to study the essential difficulties of learning and their possible sources.

Participants in this study belonged to the field of Software Design of the European Master in Software Engineering at the Escuela Técnica Superior de Ingenieros Informáticos of Universidad Politécnica de Madrid. The qualitative data used for the analysis came from the observations in class time and exhibitions, performed interviews with students and exercises sent over the period of instruction.

The difficulties presented in this thesis, in their different perspectives, provided concrete knowledge of a particular case study, making significant contributions in the area of software design, teaching, industry and methodological level. 



\section{Resumen}

Las compañías de desarrollo de software buscan reducir costes a través del desarrollo de diseños que permitan: a) facilidad en la distribución del trabajo de desarrollo, con la menor comunicación de las partes; b) modificabilidad, permitiendo realizar cambios sobre un módulo sin alterar las otras partes y; c) comprensibilidad, permitiendo estudiar un módulo del sistema a la vez.

Estas características elementales en el diseño de software se logran a través del diseño de sistemas cuasi-descomponibles, cuyo modelo teórico fue introducido por Simon en su búsqueda de una teoría general de los sistemas. En el campo del diseño de software, Parnas propone un camino práctico para lograr sistemas cuasi-descomponibles llamado el Principio de Ocultación de Información.

El Principio de Ocultación de Información es un criterio diferente de descomposición en módulos, cuya implementación logra las características deseables de un diseño eficiente a nivel del proceso de desarrollo y mantenimiento. El Principio y el enfoque orientado a objetos se relacionan debido a que el enfoque orientado a objetos facilita la implementación del Principio, es por esto que cuando los objetos empiezan a tomar fuerza, también aparecen paralelamente las dificultades en el aprendizaje de diseño de software orientado a objetos, las cuales se mantienen hasta la actualidad, tal como se reporta en la literatura.

Las dificultades en el aprendizaje de diseño de software orientado a objetos tiene un gran impacto tanto en las aulas como en la profesión. La detección de estas dificultades permitirá a los docentes corregirlas o encaminarlas antes que éstas se trasladen a la industria. Por otro lado, la industria puede estar advertida de los potenciales problemas en el proceso de desarrollo de software.

Esta tesis tiene como objetivo investigar sobre las dificultades en el diseño de software orientado a objetos, a través de un estudio empírico. El estudio fue realizado a través de un estudio de caso cualitativo, que estuvo conformado por tres partes. La primera, un estudio inicial que tuvo como objetivo conocer el entendimiento de los estudiantes alrededor del Principio de Ocultación de Información antes de que iniciasen la instrucción. La segunda parte, un estudio llevado a cabo a lo largo del período de instrucción con la finalidad de obtener las dificultades de diseño de software y su nivel de persistencia. Finalmente, una tercera parte, cuya finalidad fue el estudio de las dificultades esenciales de aprendizaje y sus posíbles orígenes.

Los participantes de este estudio pertenecieron a la materia de Software Design del European Master in Software Engineering de la Escuela Técnica Superior de Ingenieros Informáticos de la Universidad Politécnica de Madrid. Los datos cualitativos usados para el análisis procedieron de las observaciones en las horas de clase y exposiciones, entrevistas realizadas a los estudiantes y ejercicios enviados a lo largo del período de instrucción.

Las dificultades presentadas en esta tesis en sus diferentes perspectivas, aportaron conocimiento concreto de un estudio de caso en particular, realizando contribuciones relevantes en el área de diseño de software, docencia, industria y a nivel metodológico. 



\section{Tribunal de defensa de tesis doctoral}

Angélica de Antonio Jiménez

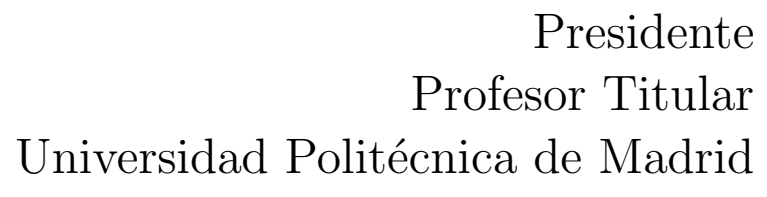

Tomás San Feliu ..........................................

Secretario

Profesor Contratado Doctor

Universidad Politécnica de Madrid

Gonzalo Méndez Pozo .....................................

Profesor Contratado Doctor Universidad Complutense de Madrid

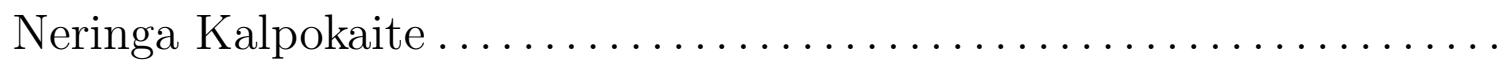

Vocal

Profesor a tiempo completo

IE University

Celia Camilli Trujillo

Vocal

Profesor Asociado

Universidad Complutense de Madrid 



\section{Agradecimientos}

Doy gracias a Dios, porque a pesar de todo, me ha permitido llegar hasta aquí. 



\section{Tabla de Contenidos}

\begin{tabular}{ll}
\hline Parte I: Introducción & 23
\end{tabular}

1. Introducción 25

1.1. Contexto . . . . . . . . . . . . . . . . . . . 25

1.2. Motivación . . . . . . . . . . . . . . . . . . . . . . 25

1.3. Problema de investigación $\ldots \ldots \ldots \ldots \ldots$

1.4. Propósito de la investigación . . . . . . . . . . . . . . . . . . . 26

1.5. Propuesta de investigación $\ldots \ldots \ldots \ldots \ldots$. . . . . . . . . . 27

1.6. Publicaciones y proyectos $\ldots \ldots \ldots \ldots \ldots . \ldots \ldots$

1.7. Estructura de la tesis . . . . . . . . . . . . . . . . . . . . . . . . . . . . . . 29

$\begin{array}{ll}\text { Parte II: Contexto } & 31\end{array}$

$\begin{array}{ll}2 . & 33\end{array}$

2.1. Metodología . . . . . . . . . . . . . . . . . . 33

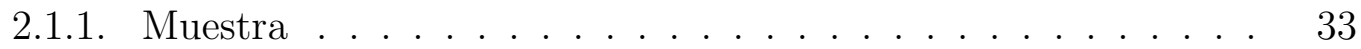

2.1.2. Cadenas de búsqueda . . . . . . . . . . . . . . . . 33

2.1.3. Revisión de literatura . . . . . . . . . . . . . . . . . . 35

2.2. Entendimiento del diseño de software

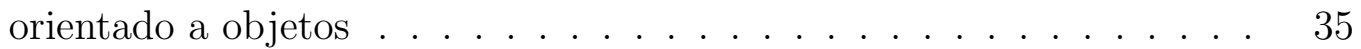

2.2.1. Dificultades de aprendizaje en el diseño orientado a objetos . . 36

2.2.2. Otras dificultades del diseño orientado a objetos . . . . . . . . 39

2.2.3. Misconceptions alrededor del diseño de software

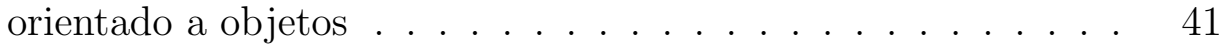

2.2.4. Comprensión alrededor del diseño de software orientado a objetos 41

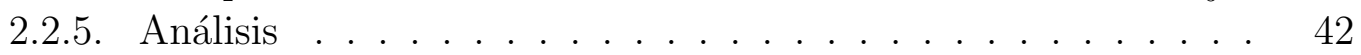

2.3. Entendimiento de programación orientada a objetos . . . . . . . . 44

2.3.1. Dificultades de aprendizaje en la programación orientada a objetos . . . . . . . . . . . . . . . 44

2.3.2. Otras dificultades en la programación orientada a

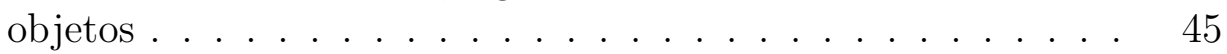

2.3.3. Misconceptions alrededor de la programación

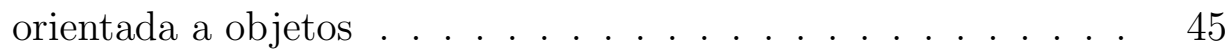

2.3.4. Comprensión alrededor de la programación orientada a objetos 46

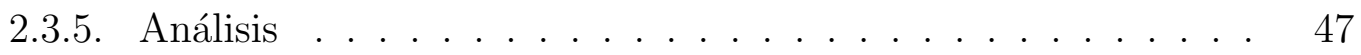


2.4. Entendimiento del Principio de Ocultación de Información . . . . . . 48 2.4.1. Dificultades de aprendizaje del Principio de Ocultación de Información . . . . . . . . . . . . . . . . . . . . 49

2.4.2. Otras dificultades alrededor del Principio de Ocultación de Información . . . . . . . . . . . . . . . . . 49

2.4.3. Misconceptions alrededor del Principio de Ocultación de Información . . . . . . . . . . . . . . . . . . . . 49

2.4.4. Comprensión alrededor del Principio de Ocultación de Informa-

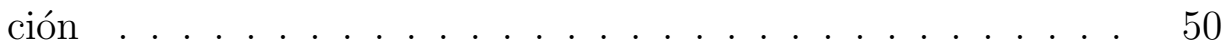

2.4.5. Análisis . . . . . . . . . . . . . . . . . 50

2.5. Resumen del estado del arte . . . . . . . . . . . . . . . . . . 51

2.6. Contexto y originalidad de la tesis . . . . . . . . . . . . . 52

3. Marco teórico 55

3.1. Sistemas cuasi-descomponibles . . . . . . . . . . . . . . . . 55

3.2. Principio de Ocultación de Información . . . . . . . . . . . . . . . . . 56

3.3. Enfoque orientado a objetos . . . . . . . . . . . . . . . . . . 57

3.4. Epistemología de la investigación . . . . . . . . . . . . . . . . . . . 57

3.5. Métodos cualitativos . . . . . . . . . . . . . . . . . . 58

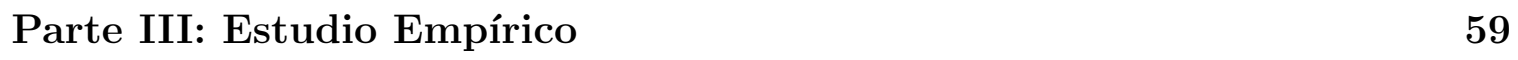

\begin{tabular}{|ll}
\hline 4. Visión general & 61
\end{tabular}

$\begin{array}{ll}\text { 5. Estudios previos } & 63\end{array}$

5.1. Cursos involucrados en el estudio previo . . . . . . . . . . . . . . 63

5.2. Períodos pre-estudio empírico . . . . . . . . . . . . . . . . . 64

5.2 .1$. Febrero - Junio 2012 . . . . . . . . . . . . . . . 64

5.2.2. Noviembre - Diciembre 2012 . . . . . . . . . . . . . 65

$5.2 .3 . \quad$ Febrero - Junio 2013 . . . . . . . . . . . . . . . 65

5.2.4. Noviembre - Diciembre 2013 . . . . . . . . . . . . . . 66

5.2.5. Febrero - Junio 2014 . . . . . . . . . . . . . . . 66

5.3. Períodos post-estudio empírico . . . . . . . . . . . . 66

5.3.1. Noviembre - Diciembre 2014 . . . . . . . . . . . . . . . . . . 67

$5.3 .2 . \quad$ Febrero - Junio 2015 . . . . . . . . . . . . . . . 67

5.4. Lecciones aprendidas . . . . . . . . . . . . . . 67

$\begin{array}{ll}6 . \text { Metodología } & 69\end{array}$

6.1. Metodología cualitativa . . . . . . . . . . . . . . . . . 69

6.2. Entorno y participantes . . . . . . . . . . . . . . . . . 70

6.3. Técnicas para la recolección de datos . . . . . . . . . . . . . . . . . . 71

6.3.1. Observación . . . . . . . . . . . . . . . 71

6.3.2. Entrevista . . . . . . . . . . . . . . . . . . 71

6.3.3. Documentos . . . . . . . . . . . . . . . . 71

6.4. Análisis de datos . . . . . . . . . . . . . . . . . 72 
6.5. Indicadores . . . . . . . . . . . . . . . . . . . . . . . . . 79

$6.6 . \quad$ Integridad de la investigación $\ldots \ldots \ldots \ldots \ldots$

7. Estudio inicial sobre el entendimiento del Principio de Ocultación $\begin{array}{ll}\text { de Información } & 83\end{array}$

7.1. Objetivo . . . . . . . . . . . . . . . . . . . 83

7.2. Preguntas de investigación . . . . . . . . . . . . . . . . . . 83

7.3. Inicio del período de instrucción . . . . . . . . . . . . . . . . . 83

7.4. Análisis de datos del estudio inicial . . . . . . . . . . . . . . . . 84

7.5. Niveles de aproximación al Principio de

Ocultación de Información $\ldots \ldots \ldots \ldots$. . . . . . . . . . . . 85

7.5.1. Nivel de aproximación: Ninguno . . . . . . . . . . . . . . . . 85

7.5.2. $\quad$ Nivel de aproximación: Inadecuado . . . . . . . . . . . . . . 89

7.5.3. Nivel de aproximación: Insuficiente . . . . . . . . . . . . . 95

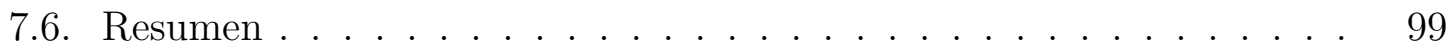

8. Estudio longitudinal de las dificultades de aprendizaje y su nivel de $\begin{array}{lr}\text { persistencia } & 101\end{array}$

8.1. Objetivo . . . . . . . . . . . . . . . . . . . . 101

8.2. Preguntas de investigación . . . . . . . . . . . . . . . . . . . 101

8.3. Período longitudinal de instrucción . . . . . . . . . . . . . . . . . 102

8.4. Análisis de datos del estudio longitudinal . . . . . . . . . . . . . . 102

8.4.1. Creación de tipos de códigos . . . . . . . . . . . . . . . 102

8.5. Niveles de persistencia . . . . . . . . . . . . . . . . . . . . 104

8.5.1. Dificultades con persistencia baja . . . . . . . . . . 105

8.5.2. Dificultades con persistencia media . . . . . . . . . . 106

8.5.3. Dificultades con persistencia alta . . . . . . . . . . 106

8.5.4. Dificultades potencialmente persistentes . . . . . . . . . . 112

8.6. Resumen . . . . . . . . . . . . . . . . . . . . . . . . . . 112

9. Estudio de las dificultades esenciales de aprendizaje y sus orígenes 113

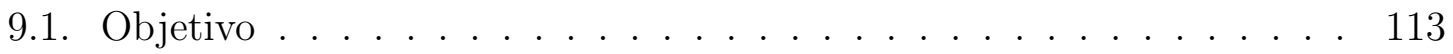

9.2. $\quad$ Preguntas de investigación . . . . . . . . . . . . . . . . . . 113

9.3. Proceso de obtención de dificultades $\ldots \ldots \ldots \ldots$

esenciales . . . . . . . . . . . . . . . . . . . . . . 114

9.4. Taxonomía de las dificultades esenciales. . . . . . . . . . . . . . 114

9.5. Influencia de copiar la realidad en el software. . . . . . . . . . . . 115

9.5.1. Posibles orígenes de la influencia de copiar la realidad en el

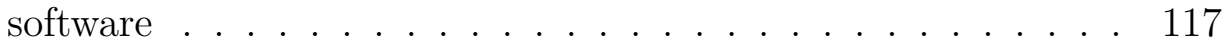

9.6. Influencia del enfoque estructurado . . . . . . . . . . . . . . . . 119

9.6.1. Posibles orígenes de la influencia del enfoque

estructurado . . . . . . . . . . . . . . . . . 120

9.7. Insuficiencia en la concepción de conceptos y sus responsabilidades. . 123

9.7.1. Posibles orígenes de la insuficiencia en la concepción de conceptos y sus responsabilidades . . . . . . . . . . . . . . . . . . 124 
9.8. Malentendidos alrededor del Principio de Ocultación de Información . 125 9.8.1. Posibles orígenes de los malentendidos alrededor del Principio de Ocultación de Información . . . . . . . . . . . . . . . . . 127

9.9. Malentendidos alrededor de la herencia . . . . . . . . . . . . . . . . . 129 9.9.1. Posibles orígenes de los malentendidos alrededor de la herencia 130

9.10. Otros tipos de dificultades . . . . . . . . . . . . . . 132

9.11. Mapa de dificultades esenciales y sus dificultades. . . . . . . . . . . . . . 132

9.12. Dificultades que comparten más de una dificultad esencial . . . . . . . . . . . . . . . . . . . . . . 134

9.13. Resumen . . . . . . . . . . . . . . . . . . . . 138

10.Discusión de resultados 139

10.1. Entendimiento del Principio de Ocultación de Información . . . . . . 139

10.2. Dificultades de aprendizaje y su nivel de persistencia ............................ 142

10.3. Dificultades esenciales de aprendizaje y sus orígenes . . . . . . . . . . 145

Parte IV: Conclusiones y líneas de investigación 149

11. Conclusiones y líneas de investigación futuras 151

11.1. Introducción . . . . . . . . . . . . . . . . . . . . . . . . 151

11.2. Contribuciones en el área de Computer

Science Education Research . . . . . . . . . . . . . . . . . . 152

11.3. Contribución a nivel de educación . . . . . . . . . . . . . . . . . . . . 153

11.4. Contribución a nivel profesional . . . . . . . . . . . . . . . . . . 153

11.5. Contribución a nivel metodológico . . . . . . . . . . . . . . . . . . 153

11.6. Líneas de investigación futuras . . . . . . . . . . . . . . . . . . . . . . 154

$\begin{array}{ll}\text { Parte V: Apéndices } & 165\end{array}$

A. Antecedentes de dificultades en el aprendizaje de diseño de software 167

\begin{tabular}{ll}
\hline B. Ejercicios del estudio de caso & 169
\end{tabular}

B.1. Primer ejercicio individual (JIKEA) . . . . . . . . . . . . . . 169

B.2. Segundo ejercicio individual y grupal

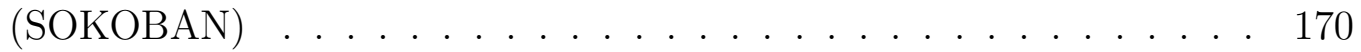

$\begin{array}{ll}\text { C. Códigos ajustados por estudiante } & 171\end{array}$

C.1. Códigos ajustados del primer ejercicio individual (JIKEA) $\ldots \ldots \ldots \ldots \ldots \ldots \ldots \ldots$

\begin{tabular}{ll}
\hline D. Códigos ajustados del segundo ejercicio individual (SOKOBAN) & 177
\end{tabular}

E. Códigos ajustados del primer ejercicio grupal (SOKOBAN) con sus versiones previas 183 
\begin{tabular}{ll}
\hline F. Síntesis de iteraciones del estudio de caso & 187
\end{tabular}

$\begin{array}{ll}\text { G. Formato de consentimiento } & 191\end{array}$

\begin{tabular}{ll}
\hline H. Diccionario de tipos de códigos & 193
\end{tabular}

\begin{tabular}{ll}
\hline I. Extracción de estudiantes por códigos & 199
\end{tabular}

\begin{tabular}{ll}
\hline J. Verificación de tipos de códigos por estudiantes & 205
\end{tabular} 



\section{Lista de Figuras}

6-1. Distribución de ejercicios a lo largo del período de instrucción . . . . 71

6-2. Diagrama del análisis de datos . . . . . . . . . . . . . 73

6-3. Codificación del documento de texto - Página 1 . . . . . . . . . . . . 74

6-4. Codificación del documento de texto - Página 2 . . . . . . . . . . . . 74

6-5. Codificación del documento de texto - Página 3 . . . . . . . . . . . . 75

6-6. Codificación del documento de texto - Página 4 . . . . . . . . . . . 75

6-7. Codificación del documento de texto - Página 5 . . . . . . . . . . . . 76

6-8. Codificación del documento de texto - Página 6 . . . . . . . . . . . 76

6-9. Codificación del audio obtenido de la entrevista . . . . . . . . . . . . 77

6-10. Códigos y citas asociadas a un estudiante . . . . . . . . . . . . . . 77

6-11. Formación de códigos ajustados . . . . . . . . . . . . . . . . 78

6-12. Códigos a justados por estudiante . . . . . . . . . . . . . . . . . 78

6-13. Evolución de códigos y documentos por iteración. . . . . . . . . . . . 79

7-1. Diseño de la investigación del estudio inicial . . . . . . . . . . . . . . 84

7-2. Diagrama del estudiante 2 . . . . . . . . . . . . . . . . . . 85

7-3. Diagrama del estudiante 4 . . . . . . . . . . . . . . . . . . 86

7-4. Diagrama del estudiante 8 . . . . . . . . . . . . . . . . . . . . . . . . . . . . . 87

7-5. Diagrama del estudiante 9 . . . . . . . . . . . . . . . . . . . 88

7-6. Diagrama del estudiante 1 . . . . . . . . . . . . . . . . . . . . . . . . 89

7-7. Diagrama del estudiante 3 . . . . . . . . . . . . . . . . . . . . . . . . . . . . . . . . . . 90

7-8. Diagrama del estudiante 5 . . . . . . . . . . . . . . . . . . . . . . . . . . . . . . . . . . . . .

7-9. Diagrama del estudiante 10 . . . . . . . . . . . . . . . . . . . . . 93

7-10. Diagrama del estudiante 12 . . . . . . . . . . . . . . . . . . . . . . . . . . . . . . . 94

7-11. Diagrama del estudiante 13 . . . . . . . . . . . . . . . . . . . . . . . . . . . . . 94

7-12. Diagrama del estudiante 6 . . . . . . . . . . . . . . . . . . 96

7-13. Diagrama del estudiante 7 . . . . . . . . . . . . . . . . . . . . . . . . . . 97

7-14. Diagrama del estudiante 11 . . . . . . . . . . . . . . . . . . . 98

8-1. Diseño del estudio longitudinal . . . . . . . . . . . . . . . . . . . . . 102

8-2. Agrupación de códigos por tipo . . . . . . . . . . . . . . . . . . 103

8-3. Extracción de estudiantes por tipo de código . . . . . . . . . . . . . . 104

8-4. Verificación de tipos de código por estudiantes . . . . . . . . . . . . 104

8-5. Sobrecarga cohesiva de responsabilidades en un elemento . . . . . . . 107

8-6. Sobrecarga no cohesiva de responsabilidades en un elemento . . . . . 108

8-7. Preferencia a heredar una propiedad en lugar de delegar . . . . . . . 108 
8-8. Resistencia a otorgar propiedades a un concepto que en la vida real no lo tiene. . . . . . . . . . . . . . . . . 109

8-9. Definición de una propiedad invisible para los elementos externos . . 110

9-1. Proceso de obtención de dificultades esenciales . . . . . . . . . . . . . 114

9-2. Taxonomía de las dificultades esenciales de aprendizaje . . . . . . . . 115

9-3. Dificultades relacionadas con la influencia de copiar la realidad en el

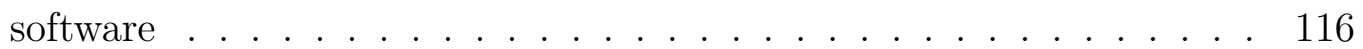

9-4. Dificultades relacionadas a la influencia del enfoque estructurado. . . 120

9-5. Dificultades relacionadas a la insuficiencia en la concepción de conceptos y sus responsabilidades . . . . . . . . . . . . . . . . 124

9-6. Dificultades relacionadas a los malentendidos alrededor del Principio de Ocultación de Información . . . . . . . . . . . . . . . 126

9-7. Dificultades relacionadas a los malentendidos alrededor de la herencia 130

9-8. Sobrecarga de responsabilidades en un elemento . . . . . . . . . . . . 134

9-9. Dependendencia de información de otros elementos para tomar decisiones 135

9-10. Separación de elementos que son similares en el software pero son interpretados como diferentes . . . . . . . . . . . . . 135

9-11. Diseño de un elemento con alto nivel de control . . . . . . . . . . . . 136

9-12. Herencia usada como taxonomía . . . . . . . . . . . . . . . . . . 136

9-13. Preferencia a heredar una propiedad antes que delegarla . . . . . . . 136

9-14. Ausencia del concepto Juego o insuficiencia al definirlo en una aplicación juego . . . . . . . . . . . . . . . . . . . 137

9-15. Ausencia de un elemento que haga de contenedor o insuficiencia en

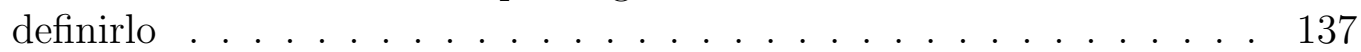

B-1. Imagen de la aplicación Jikea . . . . . . . . . . . . . . . . . . . . . . 169

B-2. Imagen de la aplicación Sokoban. . . . . . . . . . . . . . . . . . . . . 170

C-1. Códigos ajustados primer trabajo individual estudiante 1 . . . . . . . 171

C-2. Códigos ajustados primer trabajo individual estudiante 2 . . . . . . . 172

C-3. Códigos ajustados primer trabajo individual estudiante 3 . . . . . . . 172

C-4. Códigos ajustados primer trabajo individual estudiante 4 . . . . . . . 172

C-5. Códigos ajustados primer trabajo individual estudiante 5 . . . . . . . 173

C-6. Códigos ajustados primer trabajo individual estudiante 6 . . . . . . . 173

C-7. Códigos ajustados primer trabajo individual estudiante 7 . . . . . . . 173

C-8. Códigos ajustados primer trabajo individual estudiante 8 . . . . . . . 174

C-9. Códigos ajustados primer trabajo individual estudiante 9 . . . . . . . 174

C-10.Códigos ajustados primer trabajo individual estudiante 10 . . . . . . 174

C-11.Códigos ajustados primer trabajo individual estudiante 11 . . . . . . 174

C-12.Códigos ajustados primer trabajo individual estudiante 12 . . . . . . 175

C-13.Códigos ajustados primer trabajo individual estudiante 13 . . . . . . 175

D-1. Códigos ajustados segundo trabajo individual estudiante 1 . . . . . . 178

D-2. Códigos ajustados segundo trabajo individual estudiante 2 . . . . . . 178

D-3. Códigos ajustados segundo trabajo individual estudiante 3 . . . . . . 178 
D-4. Códigos ajustados segundo trabajo individual estudiante 4 . . . . . . 179

D-5. Códigos ajustados segundo trabajo individual estudiante 5 . . . . . . 179

D-6. Códigos ajustados segundo trabajo individual estudiante 6 . . . . . . 180

D-7. Códigos ajustados segundo trabajo individual estudiante 7 . . . . . . 180

D-8. Códigos ajustados segundo trabajo individual estudiante 8 . . . . . . 180

D-9. Códigos ajustados segundo trabajo individual estudiante 9 . . . . . . . 181

D-10.Códigos ajustados segundo trabajo individual estudiante 10. . . . . . 181

D-11.Códigos ajustados segundo trabajo individual estudiante 11. . . . . . 181

D-12.Códigos ajustados segundo trabajo individual estudiante 12. . . . . . 182

D-13.Códigos ajustados segundo trabajo individual estudiante 13. . . . . . 182

E-1. Códigos ajustados primer trabajo grupal estudiantes 7-9 . . . . . . . 183

E-2. Códigos ajustados primer trabajo grupal estudiantes 1-2-5 . . . . . . 184

E-3. Códigos ajustados primer trabajo grupal estudiantes 4-10 . . . . . . . 184

E-4. Códigos ajustados primer trabajo grupal estudiantes 3-8-13 . . . . . . 185

E-5. Códigos ajustados primer trabajo grupal estudiantes 6-11-12 . . . . . 185 



\section{Lista de Tablas}

2.1. Cadenas de búsqueda y número de artículos relevantes por base de datos 34

2.2. Entendimiento del diseño orientado a objetos . . . . . . . . . . . . 43

2.3. Entendimiento de la programación orientada a objetos . . . . . . . . 48

2.4. Entendimiento del Principio de Ocultación de Información . . . . . . 51

6.1. Indicadores de la investigación . . . . . . . . . . . . . . . . . 79

A.1. Dificultades de diseño de software reportadas en la literatura . . . . . 168

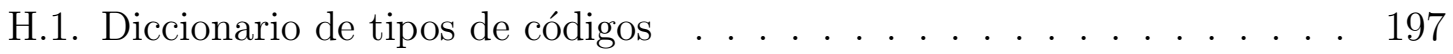



Parte I

\section{Introducción}





\section{Capítulo 1}

\section{Introducción}

Este capítulo tiene como objetivo introducir el tópico central de esta tesis. En este capítulo se describe el contexto en el que se enmarca la tesis. Seguido, se explica la motivación que condujo este trabajo de investigación, después se presenta el propósito del trabajo y la propuesta de investigación. Posteriormente, se da una breve reseña de los proyectos y publicaciones asociados a este trabajo. Finalmente, se muestra la estructura del trabajo presentado.

\subsection{Contexto}

El presente trabajo se ubica dentro del área de Computer Science Education Research. Esta área es de reciente aparición y su principal objetivo es entender cómo mejorar la enseñanza y aprendizaje de disciplinas relacionadas a la computación.

La principal diferencia con el área de Education Research en general, es que investigar alrededor de la educación en Ciencias de la Computación requiere de experiencia en el campo de estudio.

\subsection{Motivación}

La reducción de costes en el desarrollo de software es uno de los principales objetivos de las empresas de software. Una forma de lograr este objetivo es a través de diseños que tengan como propósito la eficiencia del proceso de desarrollo y mantenimiento. Un diseño eficiente debería contar con tres características elementales como: a) poder distribuir el trabajo con la mínima necesidad de comunicación entre las partes; b) poder modificar una parte, sin tener que modificar las demás, o que las demás se afecten menos y; c) poder entender una parte sin tener que entender el resto. Estos beneficios, que para esta tesis, se denominarán facilidad de distribución del trabajo de desarrollo, modificabilidad y comprensibilidad, fueron abordados por Parnas [84] en 1972 al introducir el Principio de Ocultación de Información.

El Principio, es un criterio diferente de descomposición en módulos. Estos criterios permiten crear sistemas cuasi-descomponibles, concepto que fue introducido por Simon [108] en su búsqueda de una teoría general de los sistemas, aunque Parnas, no 
lo tuviera como referencia en el desarrollo del Principio. Con la llegada del enfoque orientado a objetos y su auge en los años noventas, el Principio toma fuerza debido a que los objetos facilitan la implementación del Principio.

En resumen, la línea de diseño que se aborda en esta tesis, es aquella que produce sistemas cuasi-descomponibles que cumplen con las propiedades de facilidad de distribución del trabajo de desarrollo, modificabilidad y comprensiblidad. Hasta la actualidad se reportan dificultades en la obtención de diseños que cumplen con estas características, siendo el reto de este trabajo, precisar las dificultades de aprendizaje que obstaculizan el proceso de desarrollo y mantenimiento eficiente.

\subsection{Problema de investigación}

A lo largo del tiempo y hasta la actualidad, se ha reportado en la literatura las dificultades en el aprendizaje de diseño de software. Una pequeña muestra de esto, se puede ver en una compilación de trabajos que manifiestan esta dificultad (Apéndice A).

Esto conduce a pensar que hasta hoy en día los problemas en el diseño no han sido resueltos, siendo estas dificultades un reflejo de los problemas en los fundamentos del diseño de software, que es un tema clave para la educación en ingeniería de software y su posterior impacto en la profesión. La experiencia y la literatura demuestran que el diseño de software es decisivo en el desarrollo y mantenimiento del software industrial, más allá de las metodologías generalmente sobrevaloradas.

Adicionalmente, algunos criterios que intervienen en la obtención de un diseño con las características de facilidad de distribución del trabajo de desarrollo, modificabilidad y comprensiblidad, también han sido discutido por su dificultad, como por ejemplo, el Principio de Ocultación como uno de los caminos para lograr las características antes mencionadas a través de la creación de sistemas cuasi-descomponibles. En consecuencia, una parte de las dificultades de aprendizaje toma partido con las dificultades alrededor de la implementación y entendimiento del Principio. David Parnas el autor del Principio, en un intercambio de mails con Nelson Medinilla, tutor de esta tesis, ratifica que las dificultades en el aprendizaje y entendimiento del Principio existen y se mantienen hasta hoy en día.

Las dificultades de aprendizaje en el diseño como un problema todavía sin resolver es la base que conduce esta tesis, la cual se centra en investigar las dificultades de aprendizaje en el diseño de software orientado a objetos.

\subsection{Propósito de la investigación}

El propósito general de esta investigación se enmarca en las siguiente pregunta de investigación:

- ¿Qué dificultades de aprendizaje tienen los estudiantes en el diseño de software orientado a objetos? 
Para lograr responder esta pregunta, se han planteado preguntas de investigación con propósitos específicos, las mismas que se exponen a continuación:

- ¿Qué entienden los estudiantes sobre el Principio de Ocultación de Información y cuál es su nivel de aproximación al Principio?

- ¿Cuáles son las posibles causas de ese entendimiento del Principio de Ocultación de Información?

- ¿Qué dificultades de diseño de software tienen los estudiantes y cuál es su nivel de persistencia a lo largo del período de instrucción?

- ¿Cuáles son las dificultades esenciales de aprendizaje?

- ¿Cuáles son los posibles orígenes de dichas dificultades esenciales?

\subsection{Propuesta de investigación}

La propuesta de investigación es establecer un método de investigación adecuado para el descubrimiento de dificultades de aprendizaje en el diseño de software orientado a objetos. La propuesta planteada para este trabajo es la elaboración de un estudio empírico llevado a cabo a través de un estudio de caso cualitativo longitudinal con estudiantes de la materia de Diseño de Software del Máster de la Escuela Técnica Superior de Ingenieros Informáticos de la Universidad Politécnica de Madrid. El estudio empírico establecido es importante por sus resultados y su proceso.

Para conseguir el propósito de investigación planteado se ha buscado un método de investigación que permita aprender y descubrir acerca de ambientes, situaciones y procesos. Las investigaciones de tipo cuantitativo pueden dar una luz sobre muchas de estas situaciones, pero su característica de generalización no permite al investigador centrarse en el individuo y su proceso de aprendizaje. Al ser el aprendizaje un fenómeno social complejo, una metodología cualitativa y en particular un estudio de caso cualitativo permite al investigador que carece de hipótesis estudiar el fenómeno en su contexto sobre el campo de estudio, asegurándose de que los resultados provengan de los involucrados y no de perspectivas del investigador.

Los resultados de este trabajo de investigación aportan y formalizan conocimiento concreto sobre el aprendizaje de los fundamentos del diseño de sistemas software. El reto de la tesis también ha sido adoptar una forma de investigación cualitativa, distinta al enfoque estadístico o numérico usual en el campo de la ingeniería, pero imprescindible cuando se quiere descubrir y obtener conocimiento en ausencia de hipótesis. Los métodos son radicalmente diferentes a los que se aplican para el estudio de leyes o generalizaciones porque se trata de conseguir conocimiento concreto de un caso particular, siguiendo el rigor de un método científico.

\subsection{Publicaciones y proyectos}

En esta sección se presentan las publicaciones y proyectos donde se han publicado gran parte de los resultados obtenidos de esta investigación. Los resultados están pu-

blicados en un congreso y una revista internacional y adicionalmente, fueron aplicados 
en un proyecto de innovación educativa.

\section{Artículos y conferencias}

- Pamela Flores, Nelson Medinilla, y Sonia Pamplona. Persistent Ideas in Software Design Course: A Qualitative Case Study. International Journal of Engineering Education, 2015 (In press).

La revista Internacional de Educación en Ingeniería (IJEE) es una revista que recoge trabajos de investigación científica relacionada con la enseñanza de la ingeniería desde hace más de treinta años. IJEE es una de las pocas revistas dedicadas a la educación en ingeniería que están incluidas en el índice Journal Citations Report (JCR).

El trabajo publicado en esta revista presenta los resultados de el estudio de caso cualitativo longitudinal centrado en buscar las ideas de diseño de software de los estudiantes y su nivel de persistencia a lo largo de un período de instrucción.

- Pamela Flores, Nelson Medinilla, y Sonia Pamplona. What do software design students understand about information hiding?: A qualitative case study. In Proceedings of the 14th Koli Calling International Conference on Computing Education Research, Koli Calling '14, pages 61-70, New York, NY, USA, 2014. ACM.

Koli Calling International Conference on Computing Education Research es una de las conferencias internacionales más importantes dedicadas al intercambio de investigaciones en el campo de la enseñanza y aprendizaje de alto nivel y la investigación en educación de las disciplinas relacionadas a la computación. La conferencia cuenta con la colaboración de la Universidad de Finlandia Oriental, la Universidad de Monash, Australia, y la Universidad de Aalto, Finlandia.

El trabajo presentado en el congreso Koli Calling presenta el estudio de caso cualitativo relacionado al entendimiento del Principio de Ocultación de Información, llevado a cabo con estudiantes de Máster al inicio del período de instrucción. Este trabajo recibió comentarios positivos de un exponente reconocido en la Ingeniería de Software y autor del Principio de Ocultación. Una parte de sus palabras textuales pueden ser vistas en la subsección 2.4.4, perteneciente al estado del arte.

\section{Proyectos}

- Nelson Medinilla, Pamela Flores, y Jaime Ramírez. Mejora del aprendizaje en la disciplina de diseño de software mediante la detección de dificultades de aprendizaje a través de métodos cualitativos, Proyecto de Innovación Educativa, Universidad Politécnica de Madrid, Septiembre 2014 - Septiembre 2015.

Innovación Educativa, es una iniciativa estratégica de la Universidad Politécnica de Madrid, cuyo objetivo es la promoción de los procesos de innovación educativa y el desarrollo de proyectos relacionados con la mejora continua de 
la calidad de sus enseñanzas. Esta iniciativa realiza convocatorias anuales a proyectos institucionales que permitan a su personal la puesta en marcha de acciones dirigidas a la mejora de la calidad de sus enseñanzas en titulaciones oficiales.

El proyecto presentado y aprobado en esta iniciativa estuvo dirigido a aplicar los resultados obtenidos de la investigación presentada en esta tesis. El proyecto estuvo enmarcado al objetivo 1, establecido en la convocatoria 2014. El objetivo 1 es definido como: "Mejorar la eficiencia en los procesos en los procesos de adquisición de los resultados de aprendizaje por parte de los estudiantes, con especial atención a la incorporación de metodologías activas de aprendizaje, y aquellas acciones que favorezcan la interdisciplinariedad y la coordinación curricular de tipo horizontal y vertical".

\subsection{Estructura de la tesis}

A continuación se describen las partes que estructuran esta tesis junto con una breve descripción de los capítulos que lo conforman.

Parte I. La primera parte corresponde a la Introducción de la tesis, donde se describen temas relacionados al tópico central de la tesis, empezando por la motivación que impulsó el trabajo y el problema, propósito, y propuesta de investigación. Además se listan los trabajos publicados y los proyectos ejecutados.

Parte II. Esta parte llamada Contexto, abarca los Capítulos 2 y 3. El Capítulo 2 presenta el estado del arte de los trabajos relacionados a este trabajo de investigación. En este capítulo se describe la metodología realizada para la revisión literaria y los trabajos relacionados relevantes distribuidos en tres grandes áreas: entendimiento de diseño de software orientado a objetos; entendimiento de programación orientada a objetos y; entendimiento del Principio de Ocultación de Información. También presenta un resumen de los trabajos relacionados y una sección dedicada al contexto y originalidad de la tesis presentada. El Capítulo 3 detalla el marco teórico a través de los fundamentos principales que envuelven la tesis, es decir, los sistemas cuasidescomponibles, el Principio de Ocultación de Información y el enfoque orientado a objetos. Además, presenta el marco teórico referido a la epistemología de la investigación y las metodologías cualitativas.

Parte III. Esta parte denominada Estudio Empírico, está conformada por siete capítulos que en conjunto resumen el estudio de caso cualitativo llevado a cabo. El Capítulo 4, es breve y ofrece una visión general de cómo fue concebido el estudio empírico. El Capítulo 5 hace una breve referencia a los estudios previos realizados antes del estudio empírico, explicando de manera resumida las actividades y experiencias recogidas. El Capítulo 6 ofrece a detalle la metodología usada en esta investigación, poniendo especial énfasis en el proceso realizado. Capítulo 7 presenta el punto de partida del estudio empírico a través del estudio inicial que se enfoca en el entendi- 
miento del Principio de Ocultación de Información. El Capítulo 8 presenta el estudio longitudinal dedicado a investigar la persistencia de las dificultades de diseño de software a lo largo del período de instrucción. El Capítulo 9 describe el estudio de las dificultades esenciales y sus orígenes. Seguido, se presenta el Capítulo 10, donde se comunican y discuten los resultados obtenidos de los estudios anteriores.

Parte IV. La cuarta parte corresponde al Capítulo 11, donde se resumen las conclusiones, resaltando las líneas de investigación que deja este trabajo.

Parte V. La parte final del trabajo de investigación está conformada por los apéndices. Se incluyen diez apéndices dirigidos a ampliar la información sobre: los antecedentes en la literatura que reportan dificultades en el diseño de software, los ejercicios envíados a lo largo del período de instrucción, el conjunto de códigos generados por cada estudiante y por cada ejercicio, las iteraciones en el proceso de codificación, el formato de consentimiento que han firmado los estudiantes, el diccionario de los tipos de códigos, la matriz de extracción de estudiantes por código y finalmente la matriz de verificación de tipos de códigos por estudiantes. 
Parte II

\section{Contexto}





\section{Capítulo 2}

\section{Estado del arte}

En este capítulo se presenta un resumen del análisis del estado del arte relacionado a las dificultades en el aprendizaje de diseño de software orientado a objetos. A continuación se muestra la metodología aplicada para la revisión literaria, la muestra y las cadenas de búsqueda empleadas. Además se desarrolla un breve resumen de los trabajos relevantes obtenidos, los mismos que también son representados a través de una tabla junto con sus aspectos relevantes. Un resumen y las contribuciones de esta tesis son presentados al final del capítulo.

\subsection{Metodología}

Los fundamentos y construcción de esta sección sigue los lineamientos generales de una revisión sistemática [45], la cual consiste en definir la muestra, los términos de búsqueda y la revisión de literatura.

\subsubsection{Muestra}

La revisión bibliográfica de los trabajos relacionados corresponden al área de Computer Science Education Research. Las búsquedas bibliográficas se realizaron sobre las bases de datos electrónicas IEEE, ACM, Springer, Elsevier y Taylor\&Francis, acotadas a los años 1990 - 2015, período en el cual se consideraron trabajos relevantes relacionados a los objetivos de la presente investigación.

\subsubsection{Cadenas de búsqueda}

Las cadenas de búsqueda se definieron alrededor del tópico principal de esta tesis, es decir, dificultades en el aprendizaje de diseño de software orientado a objetos.

Los términos difficulties of learning se definieron como cadena principal de búsqueda, pero esta cadena fue variando alrededor de las palabras encontradas en la literatura para referirse a las dificultades, las palabras seleccionadas como variantes fueron: difficulties, misconceptions, comprehension.

Adicionalmente, se definieron términos asociados a la cadena de búsqueda, los cuales están dirigidos a especificar el área de estudio. El área de estudio de este 
trabajo es diseño de software, que en habla hispana es usado frecuentemente, pero su equivalente en inglés "software design" no es utilizado en la literatura científica, por lo que el término asociado definido para este campo fue object-oriented design.

En la búsqueda realizada con los términos object-oriented design se obtuvieron también trabajos relacionados a object-oriented programming, los cuales incluían en sus investigaciones aspectos del diseño. Esto pudiera suceder, porque en el enfoque orientado a objetos no existe una clara y formal separación de la programación y el diseño, algo que si sucede en el enfoque estructurado. Por esta razón muchas veces los términos se mezclan y se usan para los mismos fines. Para no descartar algún trabajo relevante de diseño que se encuentre bajo el paraguas de la programación, se decidió hacer una búsqueda con las cadenas de búsqueda definidas para object-oriented design, pero esta vez, con el término asociado object-orienteded programming. La Tabla 2.1. muestra el detalle de las cadenas de búsqueda utilizadas y el número de artículos relevantes por cada librería científica. En esta tabla no se muestran los artículos repetidos.

\begin{tabular}{llcccccc}
\hline Cadena de búsqueda & $\begin{array}{l}\text { Término } \\
\text { asociado }\end{array}$ & IEEE & ACM & Springer & Elsevier & $\begin{array}{c}\text { Taylor\& } \\
\text { Francis }\end{array}$ & $\begin{array}{c}\text { Sub } \\
\text { total }\end{array}$ \\
\hline \hline difficulties of learning & object & 0 & 6 & 1 & 4 & 2 & 13 \\
difficulties & 1 & 0 & 0 & 1 & 1 & 3 \\
misconceptions & oriented & 1 & 3 & 0 & 2 & 0 & 6 \\
comprehension & design & 1 & 0 & 0 & 0 & 1 & 2 \\
\hline \hline difficulties of learning & object & 1 & 0 & 1 & 0 & 0 & 2 \\
difficulties & 0 & 0 & 1 & 0 & 0 & 1 \\
misconceptions & oriented & 1 & 6 & 0 & 0 & 0 & 7 \\
comprehension & programming & 0 & 0 & 0 & 0 & 1 & 1 \\
\hline \hline difficulties of learning & information & 0 & 0 & 0 & 0 & 0 & 0 \\
difficulties & hiding & 0 & 1 & 0 & 0 & 1 \\
misconceptions & modularity & 0 & 0 & 0 & 0 & 0 & 0 \\
comprehension & & 1 & 0 & 0 & 0 & 1 \\
\hline \hline Número de & & & & & & $\mathbf{3 7}$ \\
trabajos relevantes & & &
\end{tabular}

Tabla 2.1: Cadenas de búsqueda y número de artículos relevantes por base de datos

Como parte de la revisión sistemática, además, se consideró realizar la búsqueda por los términos asociados information hiding modularity, debido a que este es uno de los fundamentos del diseño de software definido para esta tesis. Al término information hiding se le añadió el término modularity, ya que de esta manera se excluyeron aquellos trabajos que usaban las palabras information hiding en el contexto de las redes de información y encriptación; áreas ajenas al objetivo de estudio de esta tesis.

Adicionalmente, se empleó la estrategia de búsqueda backward snowballing, que es una instancia de la revisión sistemática de literatura, la misma que permite identificar artículos relevantes utilizando la lista de referencias de un artículo [55]. De esta estrategia se obtuvieron seis artículos relevantes [9, 67, 98, 20, 74, 92] y además un trabajo doctoral [66].

Otra estrategia utilizada fue la llamada búsqueda oportunista, la cual consta de consultar páginas concretas de conferencias o journals específicos. En esta tesis, una 
de las conferencias consultadas fue la perteneciente a Psychology of Programming Interest Group (PPIG), de la cual se obtuvieron tres artículos relevantes [11, 77, 73]. Adicionalmente, se consultó el repositorio del International Journal of Engineering Education donde se obtuvo un artículo relevante [40].

En total, de la revisión literaria y de las estrategias de búsqueda se obtuvieron 48 artículos, que se consideraron relevantes.

\subsubsection{Revisión de literatura}

En esta sección, se realizó una profunda exploración y revisión de todos los artículos relevantes obtenidos. En cada trabajo se han resaltado los siguientes aspectos:

- Tipo de análisis de datos. Este aspecto se refiere a identificar la manera en que se analizaron los datos obtenidos de cada estudio.

- Técnica. Este aspecto se refiere a resaltar la técnica empleada para la recolección de datos.

- Duración del estudio. Este aspecto se refiere a especificar de cada artículo el tiempo que tomó emplear la técnica en la investigación.

- Nivel de destilación de las dificultades. Este aspecto se refiere a identificar las dificultades según su acercamiento a los hechos observados o recogidos de los individuos. Es decir, una primera destilación es aquella donde las dificultades obtenidas se acercan a presentar los hechos de los individuos, y una segunda destilación se aleja de los hechos y apunta a presentar un nivel de abstracción superior de las dificultades.

- Identificación del origen de las dificultades. Este aspecto corresponde a buscar si el estudio se encarga del estudio del origen de las dificultades de aprendizaje.

A continuación se presenta una breve explicación de los trabajos relevantes obtenidos de la búsqueda literaria.

\subsection{Entendimiento del diseño de software orientado a objetos}

A esta sección se ha denominado entendimiento del diseño de software orientado a objetos, ya que aquí se agruparon aquellos trabajos relacionados a las dificultades en el aprendizaje, dificultades (uso, implementación o mantenimiento), misconceptions y comprensión en el área del diseño. Los trabajos mencionados están descritos en cada sección en orden cronológico. 


\subsubsection{Dificultades de aprendizaje en el diseño orientado a objetos}

Un trabajo encontrado en la década de los noventa fue presentado por [22], donde se realizaron encuestas estructuradas a desarrolladores experimentados en orientación a objetos con el fin de recopilar sus experiencias. Entre los resultados obtenidos se encontraron dificultades relacionadas al uso de la herencia y a la documentación. Una debilidad de este trabajo está en las preguntas de la encuesta, ya que estas estuvieron direccionadas a descubrir problemas relacionados a tópicos antes establecidos, dejando de lados otros tipos de experiencias o dificultades que pudieran tener los participantes. El análisis de las respuestas fue de tipo estadístico, ya que la mayoría de preguntas, excepto una, fueron cerradas, lo que niega la posibilidad de descubrir a profundidad la percepción del encuestado.

En [104, los autores exploran a través del método llamado cognitive mapping, los diversos aspectos que hacen del aprendizaje de las técnicas orientadas a objetos más difícil. El estudio es de carácter cuantitativo, y tiene como objetivo captar las impresiones de los estudiantes, no en el momento mismo en que estas ocurren, si no después de que estas suceden, lo cual puede ser un punto negativo del estudio, debido a que las percepciones de los estudiantes puede cambiar luego de ocurrido el suceso. Tampoco ahonda en abstraer las dificultades encontradas, ni presenta los orígenes de las dificultades, aunque ofrece sugerencias con respecto a la enseñanza.

Se encontraron también trabajos basados en experiencias en el campo de enseñanza como es el caso de [102]. Los autores implantaron en el currículo, la materia de Introducción a la Programación con el fin de enseñar programación orientada a objetos. Esta materia fue posterior a la enseñanza del enfoque estructurado. Entre las experiencias adquiridas de este cambio en el curriculo, y a pesar de que el estudio estuviera enfocado a la programación, se encontraron diversas dificultades relacionadas al diseño de software en los estudiantes, como la sintaxis del lenguaje, el rechazo a trasladarse de un paradigma a otro y la dificultad en entender conceptos como clases y el polimorfismo.

Morris et al. [74], se centra en cuestionar como la experiencia previa ayuda o dificulta el aprendizaje de una nueva. A través de un experimento con dos grupos, uno con sujetos inexpertos en análisis de sistemas y otro con sujetos expertos en metodologías orientado a objetos, los autores analizan si la influencia de la experiencia previa ayuda o dificulta en el desarrollo de sistemas orientado a objetos. Del análisis estadístico realizado, algunos resultados estaban dirigidos a la carga de trabajo necesaria entre un enfoque y otro y la influencia que pudiera tener el orden en que el enfoque fue aprendido.

En [48], el autor describe un método de enseñanza para el diseño y programación orientada a objetos, el cual está basado principalmente en principios constructivistas. La principal motivación de este estudio radica en la falta de entendimiento, malos hábitos de programación y serias misconceptions sobre el desarrollo orientado a objetos, bajo el modelo objetivista. El estudio tiene como objetivo describir un framework pedagógico basado en el modelo constructivista, el cual es usado como herramienta pedagógica para tratar con la transferencia del enfoque procedimental al enfoque 
orientado a objetos, siendo esta la única dificultad mencionada por el autor. El estudio nace a partir de los resultados obtenidos después de un año de instrucción bajo el modelo objetivista en la enseñanza. Los problemas encontrados, no han sido formalmente estudiados y son parte de las percepciones y experiencia de los instructores. La única dificultad explícita es el problema de la influencia del enfoque estructurado en el aprendizaje de enfoques orientado a objetos.

Una investigación cuyo objetivo fue describir la experiencia en migrar del análisis estructurado al modelado orientado a objetos es presentada en [16]. El estudio centra sus esfuerzos en superar la mayor dificultad que conlleva el modelado orientado a objetos, que según sus autores es la abstracción. A través de un proceso formal de enseñanza se muestra la introducción de este aspecto cognitivo en el currículo. Los resultados son recogidos en la examinación al final de la instrucción.

Otra investigación relacionada a la búsqueda de errores realizados en programadores novatos es la Pillay [88], cuyo objetivo del estudio se aleja de errores específicos del lenguaje de programación o implementación y se centra en el diseño orientado a objetos. Este estudio presenta una lista de errores realizados por los estudiantes obtenidos a partir del análisis de ejercicios y pruebas a lo largo de un curso de diseño orientado a objetos. El trabajo se queda corto al mostrar la metodología usada para la investigación y el procedimiento para el análisis de los datos obtenidos de los estudiantes y sus resultados. Tampoco trata el origen de dichos errores.

\section{Desde el punto de vista cognitivo}

En este apartado, se han agrupado aquellos trabajos que tratan las dificultades de aprendizaje desde un punto de vista cognitivo.

Desde el año 90 la preocupación en las consecuencias cognitivas del diseño orientado a objetos aparece con Rosson y Alpert [94]. Los autores aportan en este campo con el análisis de las posible influencia del paradigma orientado a objetos en el diseño. Los autores especulan sobre las posibles consecuencias de este paradigma para los problemas de entendimiento, descomposición y resultado del diseño. El trabajo de Rosson no es sistemático, presenta meras especulaciones con un sentido intuitivo, cuyo principal valor está en las preguntas de investigación y proyectos que pueda inspirar. Una de las principales preguntas que deja este trabajo están alrededor de la naturalidad del paradigma orientado a objetos y sus connotaciones en programadores principiantes, expertos y usuarios finales. También deja abierto el campo para la búsqueda de otros mecanismo que ayuden a definir las relaciones entre objetos, además de la herencia. Rosson finalmente ofrece una alternativa llamada "intelligent agent metaphor" como un mecanismo para extender la funcionalidad de las entidades del problema. Los aspectos cognitivos presentados en este estudio fueron analizados solamente desde el punto de vista naturalista, el cual es el centro de este estudio.

Détienne desarrolla varias publicaciones alrededor de los aspectos cognitivos y el enfoque orientado a objetos. Uno de ellos es [28], donde se reporta una revisión literaria de investigaciones empíricas sobre el diseño de software. Varios aspectos han sido estudiados en esta revisión, por ejemplo, conceptos relacionados a orientación a objetos, reúso de software en orientación a objetos y los beneficios del paradigma 
orientado a objetos y su aplicación en individuos y equipos. El estudio, ofrece una amplia visión del enfoque orientado a objetos desde una perspectiva cognitiva, pero deja de lado temas fundamentales como la descomposición y el Principio de Ocultación de la Información.

Otro trabajo enfocado en la enseñanza pero bajo un enfoque cognitivo, es [98, donde los autores proponen un modelo para el desarrollo de sistemas de entrenamiento para el análisis y diseño orientado a objetos. El modelo parte de la identificación en la literatura de dos dificultades de aprendizaje las cuales son el aprendizaje previo del enfoque estructurado, y los problemas que se originan cuando se traslada la realidad al software. Basados en estas premisas, los autores establecen un modelo que combina aspectos como la racionalidad, la comparativa entre individuos expertos y novatos y las habilidades cognitivas y modelos mentales que participan en el análisis y diseño.

Otro trabajo que se basa en el método de cognitive mapping es el de Tegarden y Sheetz [117, cuyo estudio se centra en extraer de un grupo de estudiantes las percepciones acerca de sistemas orientados a objetos. Los problemas en el área cognitiva que revelan sus respuestas están en su mayoría alrededor de las características cognitivas definidas como la descomposición, seguido de problemas de entendimiento y las solución de problemas. El trabajo toma como punto de partida la afirmación de que la naturalidad es una propiedad inherente de las técnicas orientada a objetos, lo cual podría ser un hipótesis discutible. Además, este estudio se basó en cálculos estadísticos donde los resultados significativos son aquellos en los que la mayoría de estudiantes concordaba. Es importante resaltar la necesidad del autor de enriquecer sus resultados con estudios longitudinales que tomen recursos desde múltiples perspectivas como percepciones de los estudiantes, test, percepciones del profesor, etc.

Otra investigación de los mismos autores trata sobre las dificultades de aprendizaje [105]. Este trabajo se enfoca principalmente en estudiar la relación entre las características del enfoque orientado a objetos y las actividades cognitivas usadas por los desarrolladores de sistemas. Para este objetivo, el primer paso constó de identificar las dificultades de aprendizaje de estudiantes que habían superado un curso de desarrollo orientado a objetos, a través del estudio cualitativo de sus percepciones usando un mapa cognitivo. El aporte principal del trabajo, ha sido definir las relaciones entre las características del enfoque orientado a objetos y las actividades cognitivas. Ambas definidas como fijas por el autor. Este trabajo da una luz sobre la escasez de estudios sobre las causas que subyacen detrás de las dificultades de aprendizaje, aunque de una manera muy generalizada.

Rachel Or-Bach et al. [79], presenta un estudio cualitativo realizado a través del análisis de las soluciones de un ejercicio enviado a los estudiantes y cuyo resultado arrojó una taxonomía centrada en la conceptos de abstracción y herencia. La taxonomía presenta tres categorías de abstracción, basados únicamente en como los estudiantes definieron las clases/métodos abstractos y si aplicaron o no polimorfismo. El estudio de las dificultades de la abstracción en este trabajo tiene un alcance muy corto, pero que puede un eslabón para un estudio más completo sobre la abstracción. Tampoco analiza las posibles causas por la que los estudiantes no logran el nivel máximo de abstracción según la taxonomía dada, aunque analiza las dificultades generales encontradas en la literatura y que pueden tener los estudiantes al momento 
de diseñar.

Estudios más recientes fueron encontrados. Monteiro [73], reporta una investigación donde argumenta basado en la literatura, las posibles raíces cognitivas de la modularidad en el diseño de software, esclareciendo las conexiones entre la descomposición jerárquica y tópicos cognitivos como la memoria, abstracción y categorización conceptual. El estudio presenta aspectos cognitivos interesantes relacionados a la modularidad, sin embargo, el concepto de modularidad que propone el autor puede ser discutido.

Hadar [47] presenta un trabajo relacionado a las dificultades que presentan los desarrolladores de software en el uso y entendimiento de los conceptos y principios del paradigma orientado a objetos. El autor toma prestado un framework teórico de la psicología cognitiva llamado teoría del proceso dual y a través de una investigación cualitativa sugiere que la intuición y el pensamiento lógico podrían llevar a errores en el análisis y diseño de software. El estudio toma como punto de partida los conceptos básicos de objeto, clase, y relaciones entre clases, y como principios, la abstracción y encapsulación. En el estudio no consideran al Principio de Ocultación de Información. Entre las fuentes de las dificultades se menciona a la saliencia, metáforas, experiencia/conocimiento personal y la abstracción. Este trabajo, es uno de los pocos que trata el origen de las dificultades, aunque únicamente bajo los lentes del punto de vista cognitivo.

\subsubsection{Otras dificultades del diseño orientado a objetos}

En esta subsección se presentan aquellos trabajos cuyo objetivo ha sido el estudio de dificultades en otros aspectos que no son el aprendizaje, tal como el uso, implementación o mantenimiento del diseño orientado a objetos. Sin embargo, se los han considerado en la revisión literaria por aportar ideas relacionadas al aprendizaje.

En [26], el autor a través de un experimento estudia el diseño de un programa usando un lenguaje de programación orientada a objetos pero desarrollado por programadores experimentados en lenguajes procedimentales clásicos. El estudio se centra en el análisis de las dificultades en diseñar con un lenguaje orientado a objetos. El estudio propuso a expertos en programación estructurada y expertos en programación orientada a objetos dos tipos de problemas; uno de tipo declarativo, y otro de tipo procedimental. Los resultados analizaron de manera cualitativa los siguientes aspectos: la naturalidad de los objetos, los efectos del tipo de problema y la influencia del conocimiento previo. El investigador tomó estos aspectos como parámetros para el análisis. Entre las principales dificultades que resalta el estudio están las dificultades existentes al definir primero las entidades antes que centrarse en los procedimientos y la influencia tanto positiva como negativa que tiene el conocimiento previo en lenguajes de programación. Como influencia negativa, sugiere que la adaptación de la programación estructurado en la programación orientada a objetos, no fue adecuada. Lo cual es una desacierto, ya que ambos enfoques son totalmente distintos y no pueden ser solamente adaptados.

Sheetz [103], presenta un trabajo enfocado en la identificación de dificultades en el desarrollo orientado a objetos. Este trabajo no se centra en las dificultades 
de aprendizaje, si no en las dificultades de los desarrolladores que usan sistemas orientado a objetos, pero, utiliza las percepciones de los desarrolladores como técnica para entender las dificultades para aprender y usar este enfoque. Diecisiete grupos de desarrolladores completaron un proceso de mapeo cognitivo que permitiera descubrir el modelo mental de los diseñadores y así detectar las dificultades de usar técnicas orientadas a objetos. Mapa cognitivo es una de las maneras de conocer el modelo mental de los participantes, pero tiene ciertas desventajas, por ejemplo, el hecho de que un participante cuando enuncia sus percepciones, comúnmente omite cosas debido a considerarlas irrelevantes o no importantes. Además, está técnica se centra en registrar lo que perciben los estudiantes, pero no en analizar el origen de estas percepciones.

Otra investigación que trata las dificultades en el mantenimiento de sistemas orientado a objetos ha sido presentado en [58]. Se ha considerado importante incluir este trabajo en esta revisión literaria, ya que el mantenimiento de los sistemas orientado a objetos, va de la mano con la propiedad de comprensibilidad en la línea de diseño que aborda esta tesis. Por lo tanto, las dificultades asociadas al mantenimiento repercuten a su vez en el diseño de software y consecuentemente en su aprendizaje. En [58], los autores examinan a través de un experimento las estrategias para la comprensión de un programa y las dificultades de los desarrolladores encargados en mantener un sistema orientando a objetos. Las dificultades expuestas por los desarrolladores mientras realizaban cambios en la tarea, fueron identificadas y categorizadas como dificultades de tipo general y específicas. Las primeras relacionadas al conocimiento general de las interfaces de usuario y las segundas dirigidas a la lógica del programa, la implementación de la interfaz (añadir o remover componentes), entender la estructura de la librería de la aplicación y encontrar las clases afectadas por un cambio, así como la colocación de atributos en clases erróneas. La herencia fue otra dificultad. Las dificultades en el mantenimiento pueden dar una idea de las dificultades que tienen los estudiantes en el aprendizaje.

Blackwell et al. [11] y Nicholson et al. [77], ahondaron sus estudios alrededor de la abstracción y cómo su presencia dificulta o facilita el diseño de software. El primero de ellos, llevó a cabo un estudio cualitativo basado principalmente en la observación del desarrollo de cuatro proyectos diferentes de diseño de software, reuniones con los miembros del proyecto y revisión documental. El estudio presenta el análisis de los problemas que trae consigo el mal uso de la abstracción para los diseñadores de software y sus usuarios finales. Además, en el trabajo se pone énfasis en las posibles consecuencias que trae consigo la abstracción; considerando el hecho de que la abstracción podría ser dañina en ciertos casos. El segundo estudio, toma como hilo conductor el trabajo de Blackwell et al. [11] para defender y discutir la idea de que la utilidad de la abstracción está condicionada a aspectos como el contexto y la forma de uso. Basados en la literatura, los autores hacen un análisis que concluye con cinco habilidades claves para el uso de la abstracción. 


\subsubsection{Misconceptions alrededor del diseño de software orientado a objetos}

Holland et al. [51] ofrece un trabajo con sugerencias de como evitar misconceptions alrededor de los conceptos de orientación a objetos en principiantes. Las sugerencias están basadas en la experiencia adquirida por los autores diseñando y enseñando cursos introductorios. Este trabajo no es sistemático, ya que son meras observaciones de las fallas, con el fin de ofrecer sugerencias para evitarlas.

McCracken et al. [69], realiza un estudio cuantitativo, donde reporta los conceptos y creencias que mantienen los estudiantes de primer año al momento de diseñar. El estudio es realizado a través de una encuesta realizada de forma on-line a 520 estudiantes de primer año. Las preguntas realizadas en la encuesta fueron enfocadas para descubrir qué entienden o relacionan los estudiantes con la actividad de diseñar. El estudio no responde a la pregunta cómo y por qué diseñan los estudiantes.

Uno de los trabajos relacionados a la identificación de misconceptions en el diseño de software es el trabajo [118, el cual es un estudio que adopta metodologías cuantitativas para su desarrollo. Los autores reporta las fallas de los diseños analizados de estudiantes principiantes, basándose en la recolección y análisis de los diseños de los estudiantes con la ayuda de una herramienta informática. El estudio toma como referencia soluciones pre-definidas para comparar los ejercicios realizados por los estudiantes. Un punto que podría ser discutible.

\subsubsection{Comprensión alrededor del diseño de software orien- tado a objetos}

Un estudio interesante, es [67, donde los autores exploran los esquemas de conocimiento que se activan en los programadores procedimentales y como estos intentan mapearlos en los conceptos orientados a objetos que no les eran familiares. Los resultados preliminares son extraídos de un análisis verbal de veinte programadores procedimentales aprendiendo conceptos de orientación a objetos.

Otro trabajo que intenta definir el rol de la experiencia previa en el modelado orientado a objetos es el realizado por [4], cuya investigación estuvo basada en un experimento donde se planteaban dos tipos de ejercicios, uno de tipo procedimental y otro que se centraba en la estructura de un objeto y sus relaciones. Ambas tareas debían ser resueltas por individuos expertos en modelado orientado a los procesos y por individuos inexpertos, ambos tipos de individuos debían modelar los ejercicios con el enfoque orientado a objetos. Los resultados obtenidos del estudio sugieren que tanto la experiencia previa como el tipo de ejercicio juega un rol determinante en el rendimiento. El estudio provee de ideas y fundamentos que podrían ser extendidos a las aulas de clase, como es el hecho de considerar en el aprendizaje, el nivel de experticia de los individuos y el tipo de ejercicio que se les asigna. Este resultado empata con otros estudios que enfatizan la diferencia entre individuos principiantes y experimentados 36,61 .

También se ha creído relevante mencionar en esta sección, un trabajo presentado por Cockburn [20], donde se muestra a través del análisis de un ejercicio la compren- 
sión del enfoque orientado a objetos y donde el autor identifica de manera informal y según su punto de vista, los problemas que tienen los estudiantes cuando se les solicita cambios en un diseño. Aunque el trabajo no presenta sistematicidad, da una luz sobre algunos problemas que emergen de los estudiantes.

En [107], los autores a través de un análisis cuantitativo y usando como técnica un cuestionario, buscaron las percepciones de los estudiantes sobre los conceptos y metodologías correspondientes al análisis y diseño orientado a objetos. El análisis de las respuestas fue evaluado con una escala donde se cuantificaba el acuerdo y desacuerdo de los estudiantes frente al entendimiento de varios conceptos relacionados a la orientación a objetos y cuya referencia fue establecida previamente por los autores. Es importante destacar que el estudio sugiere como trabajo futuro continuar la investigación con metodologías cualitativas.

En busca de las ideas persistentes que tienen los estudiantes de diseño de software, la autora de este tesis, presenta una investigación longitudinal centrada en encontrar las ideas que tienen los estudiantes al momento de diseñar [40]. Como parte de los resultados, se muestran algunas posibles causas por lo que los estudiantes tienen esas ideas. Los resultados fueron clasificados según su nivel de persistencia en bajo, medio, alto y potencial.

\subsubsection{Análisis}

Muchos trabajos de esta sección se centraron en obtener las dificultades de aprendizaje en diseño orientado a objetos, comparándolo con otro enfoque, en particular, con el enfoque estructurado. Sin embargo, este tipo de trabajos presentan algunas limitaciones, como por ejemplo, encontrar ejercicios equivalentes que permitan evaluar ambos enfoques. Otros trabajos centrados en identificar dificultades desde el punto de vista cognitivo, usan metodologías cuantitativas, lo que podría ser insuficiente al momento de tratar con fenómenos complejos como el aprendizaje. Otros estudios fundamentaron sus resultados de manera no rigurosa, basándose en especulaciones o experiencias del investigador. Una síntesis de los trabajos expuestos en esta sección se muestran a continuación en la Tabla 2.2, donde se presenta cada trabajo y sus aspectos relevantes.

\begin{tabular}{|c|c|c|c|c|c|c|c|c|}
\hline Investigación & $\begin{array}{c}\text { Análisis } \\
\text { cuanti- } \\
\text { tativo }\end{array}$ & $\begin{array}{c}\text { Análisis } \\
\text { cualita- } \\
\text { tivo }\end{array}$ & $\begin{array}{l}\text { Análisis } \\
\text { es- } \\
\text { tadísti- } \\
\text { co }\end{array}$ & Técnica & $\begin{array}{c}\text { Estudio } \\
\text { longi- } \\
\text { tudi- } \\
\text { nal }\end{array}$ & $\begin{array}{c}\text { Primera } \\
\text { destila- } \\
\text { ción de } \\
\text { dificul- } \\
\text { tades }\end{array}$ & $\begin{array}{c}\text { Segunda } \\
\text { destila- } \\
\text { ción de } \\
\text { dificul- } \\
\text { tades }\end{array}$ & $\begin{array}{c}\text { Estudia } \\
\text { origen } \\
\text { de difi- } \\
\text { cultades }\end{array}$ \\
\hline $\begin{array}{l}\text { Daly et al. } \\
22]\end{array}$ & & & $\checkmark$ & $\begin{array}{c}\text { encuesta } \\
\text { estructurada }\end{array}$ & & & $\checkmark$ & \\
\hline $\begin{array}{l}\text { Sheetz et al. } \\
104\end{array}$ & $\checkmark$ & & & $\begin{array}{c}\text { mapa } \\
\text { cognitivo }\end{array}$ & & $\checkmark$ & & \\
\hline $\begin{array}{l}\text { Sheard et al. } \\
102\end{array}$ & & & & $\begin{array}{l}\text { experiencia } \\
\text { investigador }\end{array}$ & $\checkmark$ & & $\checkmark$ & \\
\hline $\begin{array}{l}\text { Morris et al. } \\
74\end{array}$ & & & $\checkmark$ & experimento & & & $\checkmark$ & \\
\hline $\begin{array}{l}\text { Hadjerrouit } \\
48\end{array}$ & & & & $\begin{array}{l}\text { experiencia } \\
\text { investigador }\end{array}$ & & & $\checkmark$ & \\
\hline
\end{tabular}




\begin{tabular}{|c|c|c|c|c|c|c|c|c|}
\hline Investigación & $\begin{array}{l}\text { Análisis } \\
\text { cuanti- } \\
\text { tativo }\end{array}$ & $\begin{array}{l}\text { Análisis } \\
\text { cualita- } \\
\text { tivo }\end{array}$ & $\begin{array}{l}\text { Análisis } \\
\text { es- } \\
\text { tadísti- } \\
\text { co }\end{array}$ & Técnica & $\begin{array}{l}\text { Estudio } \\
\text { longi- } \\
\text { tudi- } \\
\text { nal }\end{array}$ & $\begin{array}{c}\text { Primera } \\
\text { destila- } \\
\text { ción de } \\
\text { dificul- } \\
\text { tades }\end{array}$ & $\begin{array}{c}\text { Segunda } \\
\text { destila- } \\
\text { ción de } \\
\text { dificul- } \\
\text { tades }\end{array}$ & $\begin{array}{l}\text { Estudia } \\
\text { origen } \\
\text { de difi- } \\
\text { cultades }\end{array}$ \\
\hline $\begin{array}{l}\text { Box et al. } \\
16]\end{array}$ & & & & $\begin{array}{c}\text { experiencia } \\
\text { investigador }\end{array}$ & & & $\checkmark$ & \\
\hline Pillay 88 & & $\checkmark$ & & $\begin{array}{l}\text { test, análisis } \\
\text { de ejercicio }\end{array}$ & & $\checkmark$ & & \\
\hline $\begin{array}{l}\text { Rosson et } \\
\text { al. 94 }\end{array}$ & & & & especulaciones & & & $\checkmark$ & \\
\hline $\begin{array}{l}\text { Detienne } \\
28 \\
\end{array}$ & & & & $\begin{array}{l}\text { revisión } \\
\text { literaria }\end{array}$ & & $\checkmark$ & $\checkmark$ & \\
\hline $\begin{array}{l}\text { Ryan et al. } \\
98\end{array}$ & & & & $\begin{array}{l}\text { revisión } \\
\text { literaria }\end{array}$ & & & $\checkmark$ & \\
\hline $\begin{array}{l}\text { Tegarden et } \\
\text { al. 117 }\end{array}$ & & & $\checkmark$ & $\begin{array}{c}\text { mapa } \\
\text { cognitivo }\end{array}$ & & $\checkmark$ & $\checkmark$ & \\
\hline $\begin{array}{l}\text { Sheetz et al. } \\
105\end{array}$ & & $\checkmark$ & & $\begin{array}{c}\text { mapa } \\
\text { cognitivo }\end{array}$ & & & $\checkmark$ & \\
\hline $\begin{array}{l}\text { OrBach et } \\
\text { al. } 79\end{array}$ & & $\checkmark$ & & $\begin{array}{l}\text { análisis de } \\
\text { un ejercicio }\end{array}$ & & $\checkmark$ & $\checkmark$ & \\
\hline $\begin{array}{l}\text { Monteiro } \\
73\end{array}$ & & & & $\begin{array}{l}\text { revisión } \\
\text { literaria }\end{array}$ & & & $\checkmark$ & \\
\hline Hadar 47. & & $\checkmark$ & & $\begin{array}{c}\text { teoría del } \\
\text { proceso dual }\end{array}$ & & $\checkmark$ & $\checkmark$ & $\checkmark$ \\
\hline $\begin{array}{l}\text { Detienne } \\
26 \\
\end{array}$ & & $\checkmark$ & & experimento & & & $\checkmark$ & \\
\hline Sheetz 103 & $\checkmark$ & $\checkmark$ & & $\begin{array}{c}\text { mapa } \\
\text { cognitivo }\end{array}$ & & & $\checkmark$ & \\
\hline $\begin{array}{l}\text { Karahasanovic } \\
\text { et al. 58 }\end{array}$ & $\checkmark$ & $\checkmark$ & & experimento & & $\checkmark$ & & \\
\hline $\begin{array}{l}\text { Blackwell et } \\
\text { al. 11] }\end{array}$ & & $\checkmark$ & & observaciones & $\checkmark$ & & $\checkmark$ & \\
\hline $\begin{array}{l}\text { Nicholson et } \\
\text { al. } 77\end{array}$ & & & & $\begin{array}{l}\text { revisión } \\
\text { literaria }\end{array}$ & & & $\checkmark$ & \\
\hline $\begin{array}{l}\text { Holland et } \\
\text { al. } 51\end{array}$ & & & & $\begin{array}{l}\text { experiencia } \\
\text { investigador }\end{array}$ & & $\checkmark$ & & \\
\hline $\begin{array}{l}\text { McCracken } \\
\text { et al. } 69\end{array}$ & $\checkmark$ & & & $\begin{array}{l}\text { encuesta } \\
\text { on-line }\end{array}$ & & & $\checkmark$ & \\
\hline $\begin{array}{l}\text { Thomasson } \\
\text { et al. } 118 \text {. }\end{array}$ & $\checkmark$ & & & ejercicios & & $\checkmark$ & & \\
\hline $\begin{array}{l}\text { Manns et al. } \\
67\end{array}$ & & $\checkmark$ & & $\begin{array}{c}\text { análisis } \\
\text { verbal }\end{array}$ & & & $\checkmark$ & \\
\hline $\begin{array}{l}\text { Agarwal et } \\
\text { al. [4] }\end{array}$ & & & $\checkmark$ & experimento & & & $\checkmark$ & \\
\hline $\begin{array}{l}\text { Cockburn } \\
20 \text { ] } \\
\end{array}$ & & & & $\begin{array}{c}\text { evolución de } \\
\text { un ejercicio }\end{array}$ & & $\checkmark$ & & \\
\hline $\begin{array}{l}\text { Sim et al. } \\
\text { 107 }\end{array}$ & $\checkmark$ & & & cuestionario & & & $\checkmark$ & \\
\hline $\begin{array}{l}\text { Flores et al. } \\
40\end{array}$ & & $\checkmark$ & & $\begin{array}{l}\text { observaciones, } \\
\text { entrevistas, } \\
\text { análisis de } \\
\text { ejercicios }\end{array}$ & $\checkmark$ & $\checkmark$ & & \\
\hline
\end{tabular}

Tabla 2.2: Entendimiento del diseño orientado a objetos 


\subsection{Entendimiento de programación orientada a objetos}

A esta sección se ha denominado entendimiento de programación orientada a objetos, ya que aquí se agrupan aquellos trabajos relacionados a las dificultades en el aprendizaje, dificultades (uso, implementación, mantenimiento), misconceptions y comprensión en el área de programación. Los trabajos mencionados están descritos en cada sección en orden cronológico.

\subsubsection{Dificultades de aprendizaje en la programación orientada a objetos}

En el área de aprendizaje y enseñanza de programación orientada a objetos, está el trabajo [72. Este estudio fue conducido a través de un cuestionario colocado en la web y dirigido a varios estudiantes que cursaban cursos introductorios de programación. El cuestionario ofrecía una serie de preguntas cuya respuesta era el grado de dificultad en ciertos conceptos. Los datos obtenidos fueron analizados estadísticamente y sus resultados mostraron los conceptos que para eran difíciles de entender para los estudiantes. Entre los conceptos estaban la memoria, constructores y funciones virtuales. El estudio no ahonda en el descubrimiento de las razones de por qué ciertos conceptos les parece más difíciles de aprender a los estudiantes.

Un estudio interesante que presenta resultados sobre la enseñanza de programación orientada a objetos en BlueJ es [126], donde se recoge las respuestas de los estudiantes a cuestionarios y las soluciones de los problemas planteados en el curso de programación orientada a objetos a lo largo de un semestre. Los resultados fueron agrupados en dos categorías, por un lado las dificultades atribuidas a las características especiales de la programación orientada a objetos y por otro lado las dificultades correspondientes a las características del ambiente de programación. El estudio carece de explicación acerca de la metodología, por lo que no se puede palpar la rigurosidad del método para la obtención de dificultades.

Otro estudio se centra en las dificultades en el aprendizaje de los conceptos de herencia y polimorfismo 63. El estudio es realizado con un grupo de estudiantes con experiencia en el paradigma procedimental a quienes se les analiza durante todo el período de un curso en el enfoque orientado a objetos. Los resultados se basan en el análisis de observaciones, cuestionario, y examen final. Los resultados fueron clasificados en cuatro categorías: a) modelos alternativos; b) analogías para usar la herencia; c) falta de entendimiento de jerarquías y; d) dificultades en el enfoque de enseñanza.

En [106], los autores muestran un conjunto de dificultades, malentendidos y algunas misconceptions sobre la programación orientada a objetos. El estudio involucró 120 estudiantes de un curso de programación, quienes respondieron un cuestionario con preguntas asociadas a nociones de programación. Sus resultados cuantitativos muestran una categorización y caracterización de los términos que son difíciles de entender por lo estudiantes. La categorización fue realizada a través de los términos 
de expansión y reducción y el análisis de las respuestas de los estudiantes a través de los lentes de esos términos.

Un último estudio centrado en las dificultades en el entendimiento de conceptos de programación orientada a objetos es [10]. Un test presencial sobre conceptos de programación se realizó a un grupo de 30 estudiantes. El test presentaba el código perteneciente a un pequeño programa, asociado a un número de preguntas. El análisis de las respuestas reveló que los estudiantes tienen dificultades en el uso de constructores, así como el entendimiento de encapsulación, objeto y clases. El estudio, otorga un valor cuantitativo a los resultados, descartando aquellos problemas que tuvieron los estudiantes.

\section{Desde el punto de vista cognitivo}

Un estudio centrado en los aspectos cognitivos de la programación orientada a objetos es el presentado por White y Sivitanides [122]. Los autores centran su estudio en las dificultades que trae consigo el traslado del enfoque estructurado al enfoque orientado a objetos. La investigación fue realizada a través de un test de lógica proposicional presentado a los estudiantes y analizado estadísticamente. El estudio concluye afirmando que la dificultad en el traslado del enfoque estructurado y el orientado a objetos no tiene sus raíces en aspectos cognitivos, y propone una posible dificultad relacionada a la interferencia que tiene el aprendizaje previo de estructurado en el aprendizaje de orientación a objetos.

\subsubsection{Otras dificultades en la programación orientada a objetos}

En esta subsección se presentan un trabajo cuyo objetivo ha sido el estudio de dificultades en otros aspectos que no son el aprendizaje, tal como el uso, implementación o mantenimiento de la programación orientada a objetos. Sin embargo, se los han considerado en la revisión literaria por aportar ideas relacionadas al aprendizaje.

En trabajo mencionado es el de Rosson y Carroll [95. Los autores presentan las dificultades que trae consigo un ambiente orientado a objetos como Smalltalk. Las dificultades mostradas en el estudio nacen de la experiencia de los investigadores. El trabajo se centra en la propuesta e implementación una versión minimalista del ambiente de Smalltalk, con el fin de facilitar y motivar a los programadores en el proceso de aprendizaje.

\subsubsection{Misconceptions alrededor de la programación orientada a objetos}

En la búsqueda de misconceptions, quizás el precedente más conocido sea una tesis doctoral dedicada a estudiar el paso de parámetros [66] a través de la investigación cualitativa aplicada a la programación. El trabajo tuvo el mérito de alejarse del familiar camino cuantitativo y adoptar un método cualitativo, como instrumento 
para descubrir. Hace veinte años aquel trabajo fue un desafío; hoy en día se ha extendido algo más el uso de métodos cualitativos de investigación en el aprendizaje de las ciencias de computación.

Otra investigación, pero de tipo longitudinal fue la realizada por Ragonis y BenAri [90], donde los autores realizaron una investigación sobre la comprensión de los conceptos de aprendizaje de programación orientada a objetos en estudiantes de primer año a través del análisis de tareas, notas de campo, observaciones, audio y video. El resultado de este estudio fue una compilación de misconceptions y dificultades alrededor de la programación orientada a objetos.

Sanders et al. [100] presenta un estudio cualitativo sobre los programas realizados por un grupo de estudiantes. El análisis tenía como objetivo la búsqueda de conceptos y misconceptions en la programación orientada a objetos, referidos previamente en la literatura. La investigación ofrece como resultado dos checklists: uno para detectar comprensión y otro para detectar misconceptions.

Clua et al. [19], publica en un trabajo, todavía en desarrollo, el uso de un conjunto de métricas establecidas en la literatura que permitan explorar a través de entrevistas, la calidad del código de estudiantes de posgrado. Este estudio cuantitativo presenta un conjunto de misconceptions alrededor de la programación. Una conclusión del trabajo sugiere emplear análisis cualitativo para sacar a la superficie misconceptions que pudieron ser enmascaradas detrás de las métricas.

En el campo del entendimiento y dificultades del enfoque orientado a objetos, se revisaron varios trabajos en la literatura. En [57], los autores se enfocaron en identificar las misconceptions en programación, teniendo como referencia previa, la construcción de un Concept Inventory para fundamentos de computación, inspirado en el Force Concept Inventory en el campo de la docencia de la física [50. Para este estudio, se condujeron entrevistas formales con el propósito de revelar las misconceptions, las mismas que fueron analizadas de manera cualitativa.

\subsubsection{Comprensión alrededor de la programación orientada a objetos}

Eckerdal propone una investigación distribuida en varios trabajos. Uno de ellos es el de Eckerdal y Thuné [35], el cual es un estudio que está enfocado en realizar una investigación con un enfoque fenomenográfico y bajo la teoría de la variación en la búsqueda del entendimiento de conceptos centrales como objeto y clase. Entre los resultados obtenidos, se encuentran el pensamiento de que un objeto es un tipo de variable y los objetos son tratados como datos. También está la confusión entre objeto y clase. El estudio no presenta posibles orígenes de estas percepciones.

Otro estudio de carácter cuantitativo es [52], cuyos autores conducen un estudio de caso con la finalidad de explorar el modelo mental de los estudiantes principiantes en el campo del diseño y programación orientada a objetos. El estudio se basa en el análisis estadístico de mapas conceptuales, los cuales fueron realizados por los estudiantes durante un período de tiempo. Adicionalmente, se evaluó un examen intermedio donde se permitía aplicar los conceptos aprendidos. El estudio presenta 
las relaciones existentes en los diversos mapas presentados por los estudiantes, pero no ahonda en las motivaciones de los estudiantes para dibujar dichos mapas, ni en conocer a profundidad el entendimiento de los estudiantes.

Un trabajo reciente se presenta en [125] donde el autor se centra en investigar a través de un estudio longitudinal las concepciones que tienen los estudiantes principiantes alrededor de dos conceptos: objetos y clase en el área del diseño y programación orientada a objetos. Los resultados presentados fueron en su mayoría extraídos de manera cuantitativa, aunque una parte del estudio fue analizado también cualitativamente. El autor menciona en el título del articulo, tanto el diseño como la programación, pero los resultados están mayormente enfocados a la programación, por lo que se ha creído pertinente colocarlo bajo esta sección. El trabajo toma como referencia misconceptions recogidas de la literatura, con el fin de comparar los resultados obtenidos. Los datos cuantitativos fueron tomados en cuenta para medir la frecuencia de cada misconception. Este trabajo se limita alrededor de los dos conceptos antes mencionados y no incluye otros descubrimientos realizados en el estudio longitudinal. De los resultados obtenidos, se resalta el pensamiento de los estudiantes a pensar que un objeto es un modelo de algún fenómeno real, resultado que no se ha reflejado en otros trabajos del estado del arte, aunque tampoco se profundiza en este trabajo. Adicionalmente, se aprecia el mayor acercamiento de los estudiantes a la definición de clase, que a la de objeto. Relacionado a la ejecución del programa, resalta la dificultad en comprender la naturaleza estática de las clases y dinámica de los objetos. La reciente publicación (2015) de este trabajo demuestra que hasta la presente fecha existen dificultades alrededor del enfoque orientado a objetos.

\subsubsection{Análisis}

Algunos trabajos relacionados a la programación orientada a objetos están centrados en la comprensión de los conceptos de objeto y clase. Sólo un trabajo se centró en el estudio de la herencia y polimorfismo. Muy pocos trabajos profundizan sus investigaciones en una segunda destilación de dificultades. Una síntesis de los trabajos expuestos en esta sección se muestran a continuación, en la Tabla 2.3, donde se presenta cada trabajo y sus aspectos relevantes.

\begin{tabular}{|c|c|c|c|c|c|c|c|c|}
\hline Investigación & $\begin{array}{l}\text { Análisis } \\
\text { cuanti- } \\
\text { tativo }\end{array}$ & $\begin{array}{c}\text { Análisis } \\
\text { cualita- } \\
\text { tivo }\end{array}$ & $\begin{array}{l}\text { Análisis } \\
\text { es- } \\
\text { tadísti- } \\
\text { co }\end{array}$ & Técnica & $\begin{array}{c}\text { Estudio } \\
\text { longitu- } \\
\text { dinal }\end{array}$ & $\begin{array}{c}\text { Primera } \\
\text { destila- } \\
\text { ción de } \\
\text { dificul- } \\
\text { tades }\end{array}$ & $\begin{array}{c}\text { Segunda } \\
\text { destila- } \\
\text { ción de } \\
\text { dificul- } \\
\text { tades }\end{array}$ & $\begin{array}{c}\text { Estudia } \\
\text { origen } \\
\text { de difi- } \\
\text { cultades }\end{array}$ \\
\hline $\begin{array}{l}\text { Milne et al. } \\
72\end{array}$ & & & $\checkmark$ & $\begin{array}{c}\text { cuestionario } \\
\text { on-line }\end{array}$ & & & $\checkmark$ & \\
\hline $\begin{array}{l}\text { Xinogalos et } \\
\text { al. } 126\end{array}$ & & $\checkmark$ & & $\begin{array}{c}\text { cuestionario, } \\
\text { análisis de } \\
\text { ejercicios }\end{array}$ & $\checkmark$ & $\checkmark$ & & \\
\hline $\begin{array}{l}\text { Liberman et } \\
\text { al. 63 }\end{array}$ & & $\checkmark$ & & $\begin{array}{c}\text { observaciones, } \\
\text { cuestionario } \\
\text { y test } \\
\end{array}$ & $\checkmark$ & $\checkmark$ & $\checkmark$ & \\
\hline $\begin{array}{l}\text { Shmallo et } \\
\text { al. 106 }\end{array}$ & $\checkmark$ & & & cuestionario & & $\checkmark$ & & \\
\hline
\end{tabular}




\begin{tabular}{|c|c|c|c|c|c|c|c|c|}
\hline Investigación & $\begin{array}{l}\text { Análisis } \\
\text { cuanti- } \\
\text { tativo }\end{array}$ & $\begin{array}{l}\text { Análisis } \\
\text { cualita- } \\
\text { tivo }\end{array}$ & $\begin{array}{l}\text { Análisis } \\
\text { es- } \\
\text { tadísti- } \\
\text { co }\end{array}$ & Técnica & $\begin{array}{l}\text { Estudio } \\
\text { longitu- } \\
\text { dinal }\end{array}$ & $\begin{array}{l}\text { Primera } \\
\text { destila- } \\
\text { ción de } \\
\text { dificul- } \\
\text { tades }\end{array}$ & $\begin{array}{c}\text { Segunda } \\
\text { destila- } \\
\text { ción de } \\
\text { dificul- } \\
\text { tades }\end{array}$ & $\begin{array}{c}\text { Estudia } \\
\text { origen } \\
\text { de difi- } \\
\text { cultades }\end{array}$ \\
\hline Biju [10] & $\checkmark$ & & & test & & $\checkmark$ & & \\
\hline $\begin{array}{l}\text { White et al. } \\
122\end{array}$ & & & $\checkmark$ & $\begin{array}{c}\text { test de } \\
\text { lógica pro- } \\
\text { posicional }\end{array}$ & & & $\checkmark$ & \\
\hline $\begin{array}{l}\text { Rosson et } \\
\text { al. 95. }\end{array}$ & & & & $\begin{array}{c}\text { experiencia } \\
\text { investigador }\end{array}$ & & $\checkmark$ & & \\
\hline Madison 66 & & $\checkmark$ & & $\begin{array}{l}\text { observaciones, } \\
\text { entrevistas, } \\
\text { análisis } \\
\text { documental }\end{array}$ & $\checkmark$ & $\checkmark$ & & \\
\hline $\begin{array}{l}\text { Ragonis et } \\
\text { al. } 90\end{array}$ & & $\checkmark$ & & $\begin{array}{l}\text { observaciones, } \\
\text { análisis de } \\
\text { ejericicios, } \\
\text { notas de } \\
\text { campo }\end{array}$ & $\checkmark$ & $\checkmark$ & & \\
\hline $\begin{array}{l}\text { Sanders et } \\
\text { al. 100 }\end{array}$ & & $\checkmark$ & & $\begin{array}{l}\text { análisis de } \\
\text { ejercicio, } \\
\text { revisión } \\
\text { literaria }\end{array}$ & & $\checkmark$ & $\checkmark$ & \\
\hline $\begin{array}{l}\text { Clua et al. } \\
19\end{array}$ & $\checkmark$ & & & entrevistas & & & $\checkmark$ & \\
\hline $\begin{array}{l}\text { Kaczmarczyk } \\
\text { et al. 57. }\end{array}$ & & $\checkmark$ & & entrevistas & & $\checkmark$ & & \\
\hline $\begin{array}{l}\text { Eckerdal et } \\
\text { al. } 35\end{array}$ & & $\checkmark$ & & $\begin{array}{l}\text { teoría de la } \\
\text { variación, } \\
\text { entrevistas }\end{array}$ & & $\checkmark$ & & \\
\hline $\begin{array}{l}\text { Hubwieser } \\
\text { et al. } 52 \text { ] }\end{array}$ & & & $\checkmark$ & $\begin{array}{c}\text { mapas } \\
\text { conceptuales }\end{array}$ & & & $\checkmark$ & \\
\hline $\begin{array}{l}\text { Xinogalos } \\
125\end{array}$ & $\checkmark$ & $\checkmark$ & & exámen & & $\checkmark$ & & \\
\hline
\end{tabular}

\subsection{Entendimiento del Principio de Ocultación de Información}

Esta sección se ha denominado entendimiento del Principio de Ocultación de Información, ya que aquí se agrupan aquellos trabajos relacionados a las dificultades en el aprendizaje, dificultades (uso, implementación, mantenimiento), misconceptions y comprensión del Principio. Los trabajos mencionados están descritos en cada sección en orden cronológico. 


\subsubsection{Dificultades de aprendizaje del Principio de Ocultación de Información}

El autor que introduce el Principio de Ocultación de Información, David Parnas [84, presentó treinta años más tarde el artículo llamado The secret history of Information Hiding [86], en el cual, además de narrar el origen del Principio, discute sobre la dificultad del mismo. El autor plantea algunas razones por la que la aplicación del Principio falla. Entre esas razones se encuentra el llamado "The Flow-Chart Instinct", "Reflecting the System Environment in the Software Structure", entre otros. Además el autor deja como línea futura la realización de investigaciones académicas en esta dirección, debido a la dificultad que envuelve el Principio a pesar de sus años de existencia.

\subsubsection{Otras dificultades alrededor del Principio de Ocultación de Información}

No se encontraron trabajos relacionados a otro tipo de dificultades como el uso, implementación o mantenimiento del Principio de Ocultación de Información.

\subsubsection{Misconceptions alrededor del Principio de Ocultación de Información}

En esta sección se presentan dos trabajos relacionados al entendimiento erróneo y confuso del Principio. El primero es de Berard et al. [9], quienes hacen una compilación bibliográfica de definiciones relacionadas a la abstracción, encapsulación y el Principio de Ocultación de Información. Los autores presentan definiciones de los conceptos antes mencionados tomados desde diferentes fuentes y momentos con el fin de compararlos y descubrir las confusiones, contradicciones y malentendidos existentes en la literatura. Aunque el trabajo no presenta un estudio metodológico riguroso, el autor argumenta las confusiones existentes en la literatura alrededor del Principio de Ocultación, mostrando de esta manera la falta de entendimiento y confusión alrededor del Principio.

Años más tarde, Paul Rogers [92], presenta un trabajo publicado en la web, encaminado a aclarar la permanente confusión existente entre encapsulación y Principio de Ocultación de Información. El autor ilustra a través de ejemplos y definiciones, la diferencia entre estos dos conceptos, pero falla al momento de definir el Principio de Ocultación, ya que lo interpreta relacionándolo directamente a la ocultación y no a la división, por lo que ofrece una definición incompleta. Esta fue una de las fuentes mencionadas por un estudiante del estudio de caso a la cual se refirió para aplicar el Principio. 


\subsubsection{Comprensión alrededor del Principio de Ocultación de Información}

Solo un trabajo se ha encontrado centrado en el entendimiento del Principio, el mismo que es realizado por dos investigadores y la autora de esta tesis [39]. En este trabajo se presentó un estudio de caso cualitativo transversal centrado en la búsqueda del entendimiento del Principio de Ocultación de Información en alumnos de Máster y en el punto de partida del período de instrucción. El estudio propone niveles de aproximación al Principio y discute algunas posibles causas de dicho entendimiento. No se ha encontrado ningún otro trabajo semejante, ni tampoco dedicado al aprendizaje del Principio de Ocultación de Información, a pesar de su importancia y de los equívocos que el Principio suscita. El autor del Principio de Ocultación de Información, David Parnas, tuvo comentarios positivos acerca de este artículo, dejando constancia de su aprobación de los resultados por vía mail a uno de los coautores del trabajo. A continuación se puede apreciar parte de sus comentarios.

"I found your paper interesting. What you report is entirely consistent with my own experience. I have learned a few things over the years.

1. It takes at lest two rounds to teach the idea to most students. I used to teach industrial courses on the design issues for software. There would always be a programming problem. They would almost all get the design wrong (exactly as you describe). I would discuss and correct their designs in the class and then give them a second problem. The second time almost all did much better. In the post-course questionnaire they would say the second exercise was not needed. They were wrong. Whenever I skip the second exercise, the outcome is much worse.

2. Information cannot be taught in isolation. I saw in your answers that many did not understand the ideas of layers [...]"

\subsubsection{Análisis}

Muy pocos trabajos se encontraron sobre el estudio del entendimiento del Principio de Ocultación de Información. Una síntesis de los trabajos expuestos en esta sección se muestran a continuación, en la Tabla 2.4. donde se presenta cada trabajo y sus aspectos relevantes.

\begin{tabular}{|c|c|c|c|c|c|c|c|c|}
\hline Investigación & $\begin{array}{c}\text { Análisis } \\
\text { cuanti- } \\
\text { tativo }\end{array}$ & $\begin{array}{c}\text { Análisis } \\
\text { cualita- } \\
\text { tivo }\end{array}$ & $\begin{array}{c}\text { Análisis } \\
\text { es- } \\
\text { tadísti- } \\
\text { co }\end{array}$ & Técnica & $\begin{array}{c}\text { Estudio } \\
\text { longitu- } \\
\text { dinal }\end{array}$ & $\begin{array}{c}\text { Primera } \\
\text { destila- } \\
\text { ción de } \\
\text { dificul- } \\
\text { tades }\end{array}$ & $\begin{array}{c}\text { Segunda } \\
\text { destila- } \\
\text { ción de } \\
\text { dificul- } \\
\text { tades }\end{array}$ & $\begin{array}{c}\text { Estudia } \\
\text { origen } \\
\text { de difi- } \\
\text { cultades }\end{array}$ \\
\hline Parnas 86 & & & & $\begin{array}{l}\text { experiencia } \\
\text { investigador }\end{array}$ & & & $\checkmark$ & \\
\hline $\begin{array}{l}\text { Berard et al. } \\
9\end{array}$ & & & & $\begin{array}{l}\text { revisión } \\
\text { literaria }\end{array}$ & & & & \\
\hline
\end{tabular}




\begin{tabular}{|c|c|c|c|c|c|c|c|c|}
\hline Investigación & $\begin{array}{l}\text { Análisis } \\
\text { cuanti- } \\
\text { tativo }\end{array}$ & $\begin{array}{c}\text { Análisis } \\
\text { cualita- } \\
\text { tivo }\end{array}$ & $\begin{array}{l}\text { Análisis } \\
\text { es- } \\
\text { tadísti- } \\
\text { co }\end{array}$ & Técnica & $\begin{array}{c}\text { Estudio } \\
\text { longitu- } \\
\text { dinal }\end{array}$ & $\begin{array}{c}\text { Primera } \\
\text { destila- } \\
\text { ción de } \\
\text { dificul- } \\
\text { tades }\end{array}$ & $\begin{array}{c}\text { Segunda } \\
\text { destila- } \\
\text { ción de } \\
\text { dificul- } \\
\text { tades }\end{array}$ & $\begin{array}{c}\text { Estudia } \\
\text { origen } \\
\text { de difi- } \\
\text { cultades }\end{array}$ \\
\hline Rogers 92 & & & & $\begin{array}{c}\text { experiencia } \\
\text { investigador }\end{array}$ & & & & \\
\hline $\begin{array}{l}\text { Flores et al. } \\
39\end{array}$ & & $\checkmark$ & & $\begin{array}{c}\text { observación, } \\
\text { entrevista, } \\
\text { análisis de } \\
\text { ejericio }\end{array}$ & & $\checkmark$ & $\checkmark$ & \\
\hline
\end{tabular}

Tabla 2.4: Entendimiento del Principio de Ocultación de Información

\subsection{Resumen del estado del arte}

De la revisión literaria realizada y de los cuarenta y ocho trabajos relevantes escogidos se puede resumir lo siguiente:

- Ocho trabajos tratan las dificultades de aprendizaje de diseño de software sin ningún método formal, basándose únicamente en experiencias del investigador o especulaciones. Dos de ellos relacionados al entendimiento del Principio de Ocultación de Información.

- Siete estudios han sido ejecutados a lo largo de un período de tiempo, es decir son de tipo longitudinal. Seis de ellos involucran análisis cualitativo.

- Cuatro estudios utilizaron como técnica los mapas cognitivos. Cada uno usando diferentes tipos de análisis de datos (cualitativos, cuantitativos y estadístico).

- Cuatro trabajos recopilan dificultades de aprendizaje a través de revisiones literarias.

- Solo un trabajo de tipo cualitativo se ha llevadoa cabo alrededor del entendimiento del Principio de Ocultación de Información.

- Diecisiete trabajos presentan dificultades con un primer nivel de destilación, es decir, presentan dificultades que se acercan a describir los hechos observados o analizados.

- Quince trabajos presentan estudios que presentan dificultades con el segundo nivel de destilación, es decir, describen dificultades con un mayor nivel de abstracción, alejándose de los hechos mismos.

- Cinco trabajos presentan estudios con primer y segundo nivel de destilación de dificultades.

- Solo un trabajo profundiza sus investigaciones en el estudio del origen de las dificultades. Los orígenes mencionados en este trabajo fueron de tipo cognitivo. 
- Siete estudios han usado análisis estadístico para el tratamiento de datos.

\subsection{Contexto y originalidad de la tesis}

La tématica principal de esta tesis es las dificultades de aprendizaje de diseño de software. Varias características diferencian a los trabajos existentes de esta investigación, tal como se muestra a continuación.

- En esta tesis, se presenta el proceso de obtención de dificultades de aprendizaje desde el origen de los datos recogidos de los estudiantes hasta la definición de las dificultades destiladas y sus orígenes. Sólo un trabajo presentado en el 2013 perteneciente a Hadar [47], describe el proceso realizado con la teoría del proceso dual y metodologías cualitativas. El trabajo de Hadar, difiere de esta investigación en dos aspectos, el primero en el enfoque cognitivo centrado en la racionalidad humana y la toma de decisiones usado para explicar sus resultados, y el segundo aspecto relacionado a la duración del estudio. Hadar presenta un estudio temporal, mientras que esta investigación es de tipo longitudinal, lo cual dotó de riqueza y complejidad al estudio.

- Este trabajo de investigación, presenta un segundo nivel de destilación de dificultades llamado dificultades esenciales. Para su obtención, se realizó un proceso de abstracción realizado sobre las dificultades obtenidas de los estudiantes. Las dificultades esenciales a su vez fueron estudiadas a través de una taxonomía de influencias, insuficiencias y malentendidos. No se han encontrado trabajos que presenten este nivel de destilación de dificultades de aprendizaje bajo el punto de vista de esta taxonomía. Haciéndolo pionero en esta área.

- Esta investigación profundiza en el estudio del entendimiento del Principio de Ocutltación a través de un estudio de caso cualitativo. La ausencia de trabajos relacionados a esta área, y la nulidad de trabajos de tipo cualitativo, denota el abandono por parte de los investigadores en este campo y resalta la contribución de esta tesis en el entendimiento del Principio.

- El presente trabajo describe un estudio cualitativo cuyo objetivo se ha centrado en la caracterización de cada uno de los individuos a lo largo de un período de tiempo con el fin de descubrir cómo y por qué hacen lo que hacen los estudiantes con respecto al diseño de software, ofreciendo de esta manera valioso conocimiento concreto en forma de dificultades, dificultades esenciales y sus orígenes. Los trabajos de tipo cuantitativo y estadístico destacatos en la revisión literaria y centrados en búsqueda de dificultades no responden a las preguntas cómo y por qué, ya que estos tienen como objetivo la generalización, ignorando al individuo y apoyando las ideas que tienen representatividad numérica. Por otro lado, existe un trabajo de tipo longitudinal publicado por Ragonis y Ben-Ari [90], que presenta una lista de categorías y sub-categorías que comprenden di-

ficultades y misconceptions, las mismas que responden a las preguntas ¿cómo 
entienden ciertos conceptos de la programación orientada a objetos?, pero no responden al ¿por qué entienden de esa manera? Además, el trabajo se centra en la programación orientada a objetos y a pesar de que topa algunos aspectos de diseño, no es su objetivo central.

- Esta tesis ha mantenido la intencionalidad de objetividad a lo largo del desarrollo de la investigación, dejando de lado cualquier preconcepción por parte del investigador sobre el entendimiento de los estudiantes. Este trabajo se ha centrado únicamente en los descubrimientos que surgieron a lo largo del estudio de caso cualitativo. Otros estudios han tomado como punto de partida ideas preconcebidas o generadas por otros estudios, como por ejemplo el trabajo de Sanders et al. [100] donde se realizó un análisis cualitativo en busca de misconceptions pero bajo el lente de previas misconceptions encontradas en la literatura.

- Principalmente, la originalidad de este trabajo está dada por la combinación de los criterios relevantes que han servido como referencia para esta revisión literaria. Es decir, esta investigación ofrece una combinación única en la literatura científica al presentar un estudio cualitativo basado en técnicas como observación, entrevistas y análisis documental, de tipo longitudinal, que presenta más de una destilación de las dificultades y que además estudia el origen de dichas dificultades. En la búsqueda sistemática efectuada en esta sección, ningún trabajo se ha encontrado con esa combinación de características. 



\section{Capítulo 3}

\section{Marco teórico}

En este capítulo se exponen los conceptos relevantes que enmarcan esta tesis, como los sistemas cuasi-descomponibles, el Principio de Ocultación de Información y el enfoque orientado a objetos. Adicionalmente, se presentan dos subsecciones relacionadas a la metodología y la epistemología que condujo esta investigación.

\subsection{Sistemas cuasi-descomponibles}

Simon introduce el término de sistemas cuasi-descomponibles en su intención de definir una teoría general de los sistemas. El autor enfoca su estudio principalmente en las estructuras jerárquicas y en otorgarle un valor cuantitativo a las relaciones entre las partes. Él apoya la idea de que los sistemas jerárquicos son a menudo, cuasidescomponibles y que a través de este tipo de estructuras se facilita el entendimiento, descripción y visualización de los sistemas y sus partes [109].

El autor defiende en su trabajo, la idea de que las jerarquías facilitan o tienen la propiedad de cuasi descomponibilidad, lo cual puede ser cierto parcialmente. Si bien, las jerarquías facilitan el entendimiento de las partes, no necesariamente las dota de la propiedad de cuasidescomponibilidad. Los sistemas cuasidescomponibles deben tener una gran libertad de concepción y acción para que se pueda disponer de cada una de las partes, para esto, las partes deberían tener la mínima dependencia entre ellas. Simon defiende la idea de que al fraccionar el sistema de manera jerárquica, debilita el control, pero no necesariamente debería ser así, ya que al otorgarle superioridad a uno de sus elementos lo hace dependiente de sus hijos, lo cual lo hace más dependiente. Por esta razón, las jerarquías en el diseño de software, no son recomendables a pesar de que en algún momento fueron definidos como las estructuras que facilitan los sistemas cuasidescomponibles [108, 14].

Según Booch, un mejor manejo de la complejidad en los sistemas de software se puede realizar a través de la descomposición de los sistemas [14]. Sin embargo, descomponer a nivel de software es mucho más que tan solo dividir, por lo que estudiar como descomponer durante el proceso de diseño es muy importante. La descomposición en el software es un amplio tema de estudio. Herbert Simon es uno de los pioneros en hablar sobre la descomposición de los sistemas, específicamente sobre 
sistemas cuasi-descomponibles. Simon define los sistemas "nearly decomposables como aquellos sistemas cuyas interacciones entre los subsistemas son débiles, pero no despreciables [108].

En resumen, los sistemas cuasi-descomponibles propuestos por Simon, por definición, son aquellos sistemas que tienen la mínima dependencia entre las partes, siendo ésta una de las propiedades deseables de los sistemas informáticos. Un camino a nivel de software para lograr este tipo de sistemas, es el Principio de Ocultación de Información, el cual se detalla a continuación.

\subsection{Principio de Ocultación de Información}

El Principio de Ocultación de Información apareció a comienzos de los años setenta del siglo pasado como un criterio diferente de dividir en módulos [84. El objetivo era mejorar la flexibilidad y comprensibilidad de un sistema mientras acortaba su tiempo de desarrollo. Pero era un criterio a contra corriente, desconcertante para su época, siendo un razón para su menosprecio. La explicación resumida del Principio que se presenta a continuación forma parte del análisis del Principio presentado en [70].

El Principio de Ocultación de Información es una técnica de modularización dirigida al aumento de la productividad del desarrollo y mantenimiento del software. Es una técnica clave del diseño software donde se apoyan la orientación a objetos [21], los tipos abstractos de datos [46] e infinidad de patrones de diseño software [41]. Por tanto, debería ser una técnica de dominio general en el universo del desarrollo de software. Sin embargo, no es así.

El Principio de Ocultación de Información al igual que la programación estructurada de Dijkstra [32] y los tipos abstractos de datos comparten la misma intención: ocultar, con el objetivo de debilitar las relaciones entre las partes del sistema. Pero esto no significa "tapar" información después de concebir las partes del sistema. Por el contrario, se trata de concebir las partes del sistema tal que requieran un mínimo de información entre ellas, para que sus relaciones sean débiles. La ocultación resulta una consecuencia de la concepción de las partes del sistema.

El Principio de Ocultación de Información ha sido denostado [17], tergiversado [9] e ignorado durante muchos años [68. "En aquellos tiempos la idea de ocultar información era subversiva" [85]. Hoy en día se reconoce su importancia [18] y se ha extendido su uso implícito [53, 59, 115] pero todavía continua siendo un incomprendido. Parnas, el autor del Principio ha expresado: "Information Hiding is harder than it looks" y además, ha añadido diciendo que la respuesta a este conflicto puede producir descubrimientos interesantes [86].

El Principio de Ocultación de Información se expresa en el trabajo original del siguiente modo: "Every module in the second decomposition is characterized by its knowledge of a design decision which it hides from all others. Its interface or definition was chosen to reveal as little as possible about its inner workings". La intención del Principio es entonces, concebir las partes del sistema de una manera tal que cada una requiera la mínima cantidad de información de otros, debilitando de esa manera las relaciones entre las partes. La ocultación sería una consecuencia del diseño de 
esas partes del sistema. Para lograr esto, Parnas plantea dos reglas: Asignar una sóla función de cada módulo y otra, que especifica cómo debe ser la definición de un módulo. Este tipo de descomposición difiere de la filosofía de flowcharting de la descomposición funcional donde el concepto se basa en la función que transforma datos.

Resumiendo, el Principio de Ocultación de Información es un modo específico de concebir la partición de un sistema software en términos de módulos: es una visión del concepto de modularidad diferente a la idea de funciones y datos. Dada sus características, la implementación del Principio se facilita con el uso del enfoque orientado a objetos, el mismo que se detalla en la siguiente sección.

\subsection{Enfoque orientado a objetos}

Entre los modelos de análisis reconocidos hasta la actualidad, está el modelo de objetos o también llamado enfoque orientado a objetos. Este nuevo enfoque fue introducido a finales de los años 60's, de la mano de los lenguajes de programación Simula I y Simula 67 [21, 7], a pesar de que su auge fue años más tarde. En esta sección se analiza la relación del enfoque orientado a objetos con el diseño de software eficiente tomado como referencia para esta tesis.

Cuando se habla del enfoque orientado a objetos, se incluye el diseño y programación orientada a objetos. El primero centrado en conceptos relacionados a la descomposición y conceptos claves del enfoque como el principio de ocultación, mientras que comunmente la programación se centra en aspectos operacionales, muchas veces direccionados con algún lenguaje de programación.

El enfoque orientado a objetos tuvo varias definiciones, la mayoría de ellas resaltando al objeto software como base del enfoque. Por ejemplo:

- El desarrollo orientado a objetos es un enfoque del diseño de software donde la descomposición del sistema se basa en el concepto de objeto. Un objeto es una entidad cuyo comportamiento está caracterizado por las acciones que recibe y solicita de otros objetos. 13]

- La metodología Object Modeling Technique de Rumbaugh define los objetos como un concepto, abstracción o cosa con frontera y significado débil, perteneciente al problema que se trata. [96]

\subsection{Epistemología de la investigación}

El trabajo presentado en esta tesis se enmarca en la epistemología de la investigación como el entendimiento de la naturaleza del conocimiento y cómo el conocimiento es generado, adquirido y usado [42]. Los tres aspectos epistemológicos que se resaltan en este trabajo de investigación son:

- Definición inclusiva de ciencia. La ciencia concebida más allá de la demostración de hipótesis y experimentos controlados 
- Generación de conocimiento concreto. Obtención de conocimiento desde cada uno de los casos particulares

- Perspectiva de descubrimiento. Concebir la investigación sin ideas preconcebidas, con la intencionalidad de objetividad e intentando obtener información de los sujetos y no de las preconcepciones del investigador

\subsection{Métodos cualitativos}

La metodología escogida ha sido la que se enmarca en la investigación cualitativa, en particular el estudio de caso cualitativo. Taylor and Bodga [116] señala que los métodos de investigación cualitativa fueron diseñados en su mayoría para investigadores de la educación y otros científicos sociales con el fin de estudiar la complejidad del comportamiento humano (e.g., motivación, comunicación, dificultades en el entendimiento, etc). Un estudio de caso es definido como la investigación intensiva de un único objeto de investigación social, por ejemplo un aula de clase [71]. Este tipo de metodología es muy adecuada para diversos tipos de investigación en ingeniería de software, ya que los objetos de estudio son fenómenos contemporáneos, los cuales son difíciles de estudiar aisladamente [97]. Esta investigación está enmarcada en el área del aprendizaje de diseño de software, por lo que hemos creído pertinente hacer uso de metodologías cualitativas para su estudio y entendimiento. 
Parte III

\section{Estudio Empírico}





\section{Capítulo 4}

\section{Visión general}

Un estudio empírico fue diseñado con el objetivo de buscar las dificultades de aprendizaje de diseño de software orientado a objetos. Con el propósito de acercarse al entendimiento que tienen los estudiantes, se buscó un estudio cuyas características permitieran al investigador entender los obstáculos por los que atraviezan los estudiantes al momento de diseñar software y a lo largo de un período de tiempo. Debido a que el proceso de aprendizaje, es un fenómeno complejo de analizar, se decidió realizar un estudio de caso cualitativo de tipo longitudinal.

El estudio de caso permitió el seguimiento de un grupo de estudiantes a lo largo de un período de tiempo, que en esta investigación, se delimitó al período de instrucción. La investigación se realizó por medio de un único estudio de caso, cuyos participantes fueorn los estudiantes de la materia de Diseño de Software del grado de Máster. Se escogieron alumnos de Máster debido a la alta probabildad de que dichos alumnos graduados de carreras afines a la Informática, hubieran tomado cursos relacionados al diseño y también, que al ser graduados pudieran estar listos para vincularse a la industria. De esta manera, los resultados obtenidos de este estudio de caso, tendrán un gran impacto, tanto a nivel académico como profesional.

El diseño del estudio de caso estuvo conformado por tres investigaciones, las cuales cubrían todo el período de instrucción. La primera investigación centrada en el inicio del período de instrucción y relacionada al entendimiento del Principio de Ocultación de Información, la segunda, dirigida a realizar un estudio longitudinal que descubra las dificultades de aprendizaje, y finalmente una investigación dedicada a investigar las dificultades esenciales de los estudiantes de este estudio de caso.

Los datos recogidos a lo largo del estudio de caso, derivaron principalmente de ejercicios realizados por los estudiantes (individuales y en grupo), entrevistas, observaciones en clase y tutorías. Estos datos fueron variando para las distintas investigaciones. Mientras que en la primera investigación, se recolectó el primer ejercicio enviado, una entrevista por cada participante y la observación realizada en clase al inicio del período de instrucción, la segunda investigación añadió a estos datos recogidos, un trabajo individual y grupal, junto con observaciones, tutorías y entrevistas

que se derivaron del período de instrucción. La tercera investigación, por el contrario de las dos primeras investigaciones, no manejó los datos recolectados directamente, y en lugar de eso, se tomó como insumo principal los resultados obtenidos de la primera 
y segunda investigación para su desarrollo. Adicionalmente, es importante mencionar que los participantes e instructor no variaron en ninguna de las tres investigaciones.

La primera investigación buscó conocer el estado inicial al que llegaban los estudiantes, antes de que recibieran algún tipo de instrucción. Debido a que los participantes pertenecían al grado de Máster y su conocimiento sobre el Principio era desconocido, se creyó necesario conocer su entendimiento sobre el Principio de Ocultación de Información. Siendo esta la principal motivación para capturar en un momento temporal el punto de partida de los estudiantes frente al entendimiento del Principio. De este objetivo, emergieron las siguientes preguntas de investigación:

- ¿Qué entienden los estudiantes sobre el Principio de Ocultación de Información y cuál es su nivel de aproximación al Principio?

- ¿Cuáles son las posibles causas de ese entendimiento del Principio de Ocultación de Información?

La segunda investigación se centró en descubrir la persistencia de las dificultades de diseño de software a lo largo del período de instrucción. Siguiendo esta premisa, planteamos la siguiente preguntas de investigación:

- ¿Qué dificultades de diseño de software tienen los estudiantes y cuál es su nivel de persistencia a lo largo del período de instrucción?

Finalmente, con las dificultades obtenidas de las investigaciones previas, se llevó a cabo la tercera investigación. En este estudio se elevó el nivel de abstracción de las dificultades obtenidas en los estudiantes en la búsqueda de las dificultades esenciales de aprendizaje y sus posibles orígenes. Para lograr este objetivo, se plantearon estas dos preguntas de investigación:

- ¿Cuáles son las dificultades esenciales de aprendizaje?

- ¿Cuáles son los posibles orígenes de dichas dificultades esenciales?

La metodología empleada para este estudio empírico se presenta en el Capítulo 6. mientras que los detalles de cada investigación se presentan por separado. En el estudio incial en el Capítulo 7, el estudio longitudinal en el Capítulo 8 y finalmente en el Capítulo 9, el estudio de las dificultades esenciales. 


\section{Capítulo 5}

\section{Estudios previos}

En este capítulo se resume la experiencia adquirida en investigación cualitativa obtenida de los estudios previos al estudio empírico desarrollado para esta tesis. Primero se describen los cursos que estuvieron involucrados en la etapa previa. Luego se presenta una sección dedicada al período pre-estudio empírico. Posteriormente, se detalla el período post-estudio empírico. Finalmente, se sintetizan las lecciones aprendidas del trabajo previo realizado.

\subsection{Cursos involucrados en el estudio previo}

Para la adquisición de experiencia en métodos cualitativos y trabajo de campo se escogieron aquellas materias relacionadas al diseño de software. Los cursos involucrados en los estudios previos se detallan a continuación.

Ingeniería de Software - Matemática. Asignatura dictada a estudiantes de 4to semestre del Grado de Ingeniería Informática - Matemática, correspondiente a 6 ECTS (European Credit Transfer and Accumulation System). La materia fue dictada durante 16 semanas, y fue impartida los días miércoles y jueves en sesiones de dos horas diarias.

Ingeniería de Software - Informática. Asignatura dictada a estudiantes de 4to semestre del Grado de Ingeniería Informática, correspondiente a 6 ECTS (European Credit Transfer and Accumulation System). La materia fue dictada durante 16 semanas, y fue impartida los días miércoles y jueves en sesiones de dos horas diarias.

Software Design. Asignatura dictada en inglés a estudiantes del European Master Software Engineering, correspondiente a 4 ECTS. La materia fue dictada durante 16 semanas y fue impartida los días lunes en una sesión de dos horas diarias.

Proyecto Práctico de Construcción de Sistemas Software. Asignatura obligatoria dictada a estudiantes de último nivel del Grado de Ingeniería Informática, correspondiente a 6 ECTS. La materia fue dictada durante 16 semanas y fue impar- 
tida todos los días martes y viernes en sesiones de dos horas diarias.

Módulo de Ingeniería de Software I. Módulo de la asignatura Ingeniería de Software forma parte de la asignatura obligatoria dictada a estudiantes de 6to semestre del Grado de Ingeniería Informática, correspondiente a 6 ECTS. La materia fue dictada durante 16 semanas, pero el módulo correspondiente a Diseño de Software fue impartido alrededor de un mes, dos días a la semana, dos horas cada sesión.

Curso de formación. Cursos obligatorios organizados por los Servicios Públicos de Empleo. El curso fue dictado a personas relacionadas al ámbito informático que se encontraban en paro. El curso fue impartido durante dos semanas, dos horas diarias de lunes a jueves.

\subsection{Períodos pre-estudio empírico}

Los métodos cualitativos representaron un reto para el investigador, debido a su poca divulgación en el ámbito de las investigación en Ciencias de la Computación. Por esta razón fue necesario la adquisición de conocimiento y experiencia en la aplicación de técnicas y metodologías cualitativas. A continuación se detallan las actividades realizadas por cada período escolar previo al estudio empírico.

\subsubsection{Febrero - Junio 2012}

Este fue el primer período en donde se incursionó con las técnicas de metodologías cualitativas y se comprendió el trabajo de campo. En este período se dictaron cuatro materias relacionadas a diseño de software. Una materia correspondiente al Máster, dos materias de Grado y finalmente un curso de formación.

\section{Software Design}

- Entrevistas abierta a algunos estudiantes sobre las dificultades que tuvieron a lo largo del curso. Lo obtenido en esta entrevista fue muy superficial, aunque dio una idea de la percepción de la materia en general

\section{Ingeniería de Software - Informática}

- Envío de un ejercicio a los estudiantes a través de un enunciado verbal. Clasificación de los estudiantes en cuatro categorías según sus respuestas. Las categorías fueron: A+ para quienes tuvieron una buena apreciación de los objetos e identificaron los objetos principales; A- para quienes estuvieron próximos a la orientación a objetos; $\mathrm{B}+$ para quienes crearon algunos objetos pero se perdieron en las relaciones y B- para quienes tuvieron escasas ideas de la orientación a objetos.

- Observaciones en el aula de clase 


\section{Proyecto Práctico de Construcción de Sistemas Software}

- Entrevistas abierta a cada grupo de estudiantes. Las preguntas estuvieron centradas en aspectos generales del diseño de software

\section{Curso de formación}

- Seguimiento con el profesor de un único ejercicio a lo largo del curso

- Observaciones en la aula de clase

\subsubsection{Noviembre - Diciembre 2012}

En este período se dictó una materia correspondiente al Grado, en el cual se realizaron las actividades que se muestran a continuación.

\section{Módulo de Ingeniería de Software I}

- Cuestionario sobre diseño de software a estudiantes al inicio del período de instrucción y al final. Las preguntas fueron las mismas en ambos cuestionarios y estuvieron dirigidas a aspectos generales del diseño de software, objeto y clase

- Entrevista abierta a estudiantes. Preguntas relacionadas a los temas vistos en el curso y las tareas enviadas

- Entrevista abierta al instructor. La entrevista tuvo como objetivo conocer el perfil del profesor y su concepción sobre el diseño de software.

\subsubsection{Febrero - Junio 2013}

En este período se dictó dos materias correspondiente al Grado y una materia correspondiente al Máster, en las cuales se realizaron las actividades que se muestran a continuación.

\section{Ingeniería de Software - Matemática}

- Cuestionario inicial con opciones múltiples de diseños para que los estudiantes justifiquen la respuesta que han escogido.

- Entrevistas a estudiantes. La entrevista fue realizada a mediados del período y sus preguntas estuvieron enfocadas a conocer la apreciación que tenían los estudiantes sobre temas específicos de diseño enseñados por el profesor, actividades realizadas en clase y sus motivaciones al momento de diseñar

- Observaciones en el aula de clase

\section{Software Design}

- Cuestionario inicial con opciones múltiples de diseños para que los estudiantes justifiquen la respuesta

- Observaciones en el aula de clase 


\section{Proyecto Práctico de Construcción de Sistemas Software}

- Cuestionario inicial con opciones múltiples de diseños para que los estudiantes justifiquen la respuesta

- Envío de un ejercicio grupal escogido por cada grupo

\subsubsection{Noviembre - Diciembre 2013}

En este período se dictó una materia correspondiente al Grado, en el cual se realizaron las actividades que se muestran a continuación.

\section{Módulo de Ingeniería de Software I}

- Cuestionario inicial con dos tipos de preguntas. Las dos primeras preguntas dirigidas a diseñar una aplicación que se les muestra el momento mismo del cuestionario. Las otras dos preguntas se les expone opciones de diseño sobre los ejercicios anteriores, para que justifiquen su respuesta. El análisis cualitativo de las respuestas son procesadas en el programa Microsoft Excel

- Envío de un ejercicio grupal escogido por cada grupo

\subsubsection{Febrero - Junio 2014}

En este período se lleva a cabo el estudio empírico realizado para esta tesis, específicamente en la materia de Diseño de Software perteneciente al Máster. Paralelamente, se realizaron otras actividades en dos de las tres materias dictadas en ese período.

\section{Ingeniería de Software - Matemática}

- Observaciones en el aula de clases

- Actividad de intercambio de trabajos grupales

\section{Software Design}

- Estudio cualitativo longitudinal descrito en esta tesis

\section{Ingeniería de Software - Informática}

- Cuestionario final con una única pregunta que consta de un enunciado escrito y respuestas de diseño de opción múltiple. En esta ocasión se les solicita a los estudiantes justificar por qué han escogido esa opción y por qué han rechazado las otras opciones

\subsection{Períodos post-estudio empírico}

Superado el estudio empírico, se llevaron a la práctica los resultados obtenidos en los períodos de instrucción posteriores. A continuación se detallan las actividades realizadas en los dos períodos post-estudio empírico. 


\subsubsection{Noviembre - Diciembre 2014}

En este período se llevó a la práctica los resultados del estudio empírico como parte del proyecto de innovación educativa propuesto por el tutor de esta tesis, un miembro del Departamento de Ingeniería de Lenguajes y Sistemas e Ingeniería de Software y la autora de esta tesis. Este proyecto se materializó sobre la materia de Grado que se muestra a continuación.

\section{Módulo de Ingeniería de Software I}

- Actividad en el aula de clase que constó de realizar un diseño basado en un enunciado verbal, para posteriormente defenderlo en el pizarrón

- Cuestionario en el intermedio del período de instrucción. Las preguntas estuvieron relacionadas a la descomposición, herencia, Principio de Ocultación de Información y objetos.

- Discusión sobre los resultados del cuestionario

- Cuestionario final. El cuestionario tuvo dos preguntas con un enunciado escrito y respuestas de diseño de opción múltiple, otra pregunta donde se les solicitaba hacer un diseño y responder unas preguntas asociadas a ese diseño, una pregunta abierta sobre los tipos abstractos de datos y tres preguntas donde se les solicitaba hacer explícitos los conceptos o aspectos más complicados de la materia, su apreciación sobre los ejercicios y actividades realizadas y sobre las técnicas usadas por el profesor en la enseñanza.

\subsubsection{Febrero - Junio 2015}

En este período, con la experiencia adquirida, se aplican los resultados obtenidos del estudio empírico.

\section{Ingeniería de Software - Matemática}

- Cuestionario inicial con opciones múltiples de diseños para que los estudiantes justifiquen la respuesta

\section{Software Design}

- Cuestionario inicial con opciones múltiples de diseños para que los estudiantes justifiquen la respuesta

\subsection{Lecciones aprendidas}

- Los cuestionarios con preguntas abiertas ofrecen al estudiante la oportunidad de explicar abiertamente sobre la pregunta realizada, pero la mayoría de las veces la respuesta se desvíaba del tema central, haciendo muy díficil para el investigador poder conocer lo que el estudiante quería transmitir. Una alternativa a esto, fueron los cuestionarios con opciones múltiples de diseño. El estudiante se centra en los diseños y no en la teoría. 
- En el caso de los cuestionarios de opción múltiple, es importante conocer cual es la elección del estudiante y su razonamiento alrededor de su elección. Con este objetivo, solicitar que justifiquen su respuesta, permitió al investigador conocer detalles, más allá de conocer si el estudiante acertó o no. Además, solicitar que justifiquen por qué rechazaron las otras opciones, ofrece también un amplió espectro de las razones por las que el estudiante tomó una u otra opción.

- Con respecto a los enunciados de los ejercicios envíados como tareas, se pudo apreciar que aquellos enunciados que eran escritos o verbales causaban ambigüedad en los estudiantes produciendo malintepretaciones. Una alternativa para evitar esos problemas, fue acotar el enunciado, presentándolo como una aplicación funcionando y pidiéndoles a los estudiantes diseñar lo que ven. De esa manera las diferentes interpretaciones se minimizaron y las dudas que nacían por parte de los estudiantes podían ser despejadas en el momento.

- El uso de hojas de cálculo para el tratamiento de los datos cualitativos fue útil, pero insuficiente al momento de manejar una cantidad desbordante de datos cualitativos. Para esto, el uso de herramientas propias para el tratamiento de datos cualitativos como ATLAS.ti [76] fue de mucha utilidad.

- Realizar cuestionarios al inicio y final de un período, permitió hacer una comparativa sobre las apreciaciones particulares del estudiante al principio y al fin del análisis, pero no permitió hacer un seguimiento de esas ideas, ni conocer las razones por la que mantuvo o cambió de idea en el transcurso del tiempo. Se pudo obtener más información relevante cuando se centraron diferentes técnicas como entrevistas u observaciones alrededor de un determinado fenómeno.

- Con respecto al tipo de ejercicios. Cuando se les dejó a los estudiantes la libre elección de escoger el ejercicio para su tarea, los ejercicios expuestos por los estudiantes eran diversos en cuanto a su dificultad y su alcance. Este procedimiento dificultó al profesor y al investigador en el momento de explicar y analizar cada ejercicio. Una alternativa fue elegir un mismo ejercicio para todos los estudiantes, de esta manera se enriqueció la explicación del profesor, centrándose en ciertos aspectos en los que todos los estudiantes estaban involucrados. Por otro lado, para el investigador, estandarizar el ejercio le permitió centrar su capacidad de análisis en un recurso a la vez. 


\section{Capítulo 6}

\section{Metodología}

En este capítulo se presentan los detalles relacionados a los aspectos metodológicos que guiaron esta tesis. Primero se define el tipo de metodología empleada, después se detalla el contexto donde se llevó a cabo el estudio, describiendo el entorno y sus participantes. Posteriormente, se definen lás técnicas usadas para la recolección de datos y se explica el proceso de análisis de los datos a través de un ejemplo. Luego se presentan los indicadores de la investigación y finalmente se describen los criterios de calidad que condujeron la investigación.

\subsection{Metodología cualitativa}

Esta investigación utilizó una metodología de investigación cualitativa, en particular un estudio de caso. Se escogió una metodología cualitativa, ya que este tipo de metodología ayuda a comprender y explicar el significado de los fenómenos sociales con la menor modificación posible del entorno natural en el cual ellos ocurren [71]. Debido a que los procesos relacionados al aprendizaje son fenómenos sociales complejos, una investigación cualitativa centrada en el individuo, permitie estudiar desde distintos ángulos, diversas situaciones alrededor del fenómeno de estudio, alejándonos de las generalizaciones que caracterizan a las estudios cuantitativos.

En particular, el estudio de caso es definido como la investigación intensiva de un único objeto de indagación social, por ejemplo un aula de clases [114]. Este estudio de caso adoptó técnicas como observaciones, entrevistas y análisis documental que fueron aplicadas a lo largo del período de instrucción. Todo el proceso fue documentado, discutido y analizado entre el investigador y el profesor.

Conducir ésta metodología en el área de diseño de software ha representado un reto, debido a su poca propagación en el área de la informática. Por esta razón fue necesario la adquisición de experiencia previa en la implementación de la metodología a través de trabajo de campo y estudios previos realizados en colaboración con otros investigadores [39, 81, 82]. Una descripción resumida del trabajo previo puede ser vista en el Capítulo 5 . 


\subsection{Entorno y participantes}

El grupo estuvo caracterizado por estudiantes de diferentes nacionalidades que han completado el grado en Ciencias de la Computación o Informática, por ende con diferentes planes de estudio. Trece estudiantes de la materia de Diseño de Software del European Master in Software Engineering de la Escuela Técnica Superior de Ingenieros Informáticos de la Universidad Politécnica de Madrid - España participaron en el estudio de caso cualitativo. El número total de estudiantes matriculados en la materia fueron de diecisiete, sin embargo, cuatro estudiantes fueron descartados para el estudio, debido a problemas de inestabilidad durante el período escolar. El estudio de caso se implementó en la materia de Diseño de Software del período del semestre académico Febrero - Junio de 2014, la cual fue dictada en idioma inglés. El plan de estudios del curso estuvo centrado en el diseño de software orientado a objetos y tanto su alcance como su contenido no fue modificado por la investigación. Los detalles del contenido de la materia se muestran a continuación:

1. Chapter I: Software Engineering two-dimensional complexity Software engineering complexity concept evolution. Software engineering needs a holistic approach; Uncertainty as tool; Relationships between software, design and process models in the uncertainty dimension. Evolutionary approach

2. Chapter II: System software design features

Software as design. Review of software design concept; Software Design from the system point of view. Relationships between software and other kinds of systems. Software Design based on the system general theory. System structures; Divide and Conquer as systems simplification tool; Ambiguity as powerful systems simplification tool; Information Hiding Principle. The Ambiguity or indifferent dependent relationship; Design simplification by decrease the quantity of information using abstractions, symmetries, monotonic structures, and others similar techniques; Influence of design structure on design properties.

3. Chapter III: Object oriented review Contrast between object and structured models; Ambiguity in: object, message, class and heritage. Substitution Liskov Principle; Evolutionary design using objects; Use cases technique review

4. Chapter IV: Design and dominion patterns

Theoretical foundations of patterns; Analysis of design patterns; Domain patterns

5. Chapter V: Design documentation

Documentation reasons; Software design legibility using objects. Suitable use of abstractions and their structure; Design diagram simplification using abstractions, patterns, symmetries and monotonic structures; Evolutionary documentation 


\subsection{Técnicas para la recolección de datos}

La recolección de datos estuvo enmarcada a diversas fuentes y técnicas, las mismas que se explican a continuación.

\subsubsection{Observación}

Según [64], las observaciones directas abastecen al investigador de experiencias del tipo "aquí y ahora" en profundidad. Las observaciones en este estudio de caso tuvieron como fuente principal las horas de clase y algunas tutorías entre el profesor y el estudiante. Como producto de estas observaciones se recolectaron audios y videos que fueron material de análisis.

\subsubsection{Entrevista}

Dexter [6], define a una entrevista como una conversación con un propósito. El propósito de las entrevistas en este estudio de caso se centró en captar las motivaciones de los estudiantes, la identificación de obstáculos y la verificación de información obtenida de otras fuentes. La entrevista realizada a cada estudiante fue abierta y fue realizada a todos los estudiantes al menos una vez y máximo tres veces a lo largo del período de instrucción.

\subsubsection{Documentos}

Los documentos son singularmente fuente útil de información, aunque ellos son a menudo ignorados [64]. En este estudio de caso, los documentos recolectados se refieren a los ejercicios que se les mandó a hacer a los estudiantes como tarea. Durante la investigación se hablará de documentos al material físico recolectado que abarca tanto texto como gráficos. En este estudio de caso, los gráficos son en su mayoría diagramas de distinto tipo, como diagramas de clases, secuencia, flujos de datos, entidad-relación, etc.

A lo largo del período de instrucción se enviaron tres ejercicios a los estudiantes. Dos de ellos fueron individuales y el tercero, en grupo. El ejercicio final que fue realizado en grupo, estuvo compuesto de versiones previas a la entrega final, las que también fueron analizadas. La distribución de ejercicios se pueden ver en la Figura 6-1.

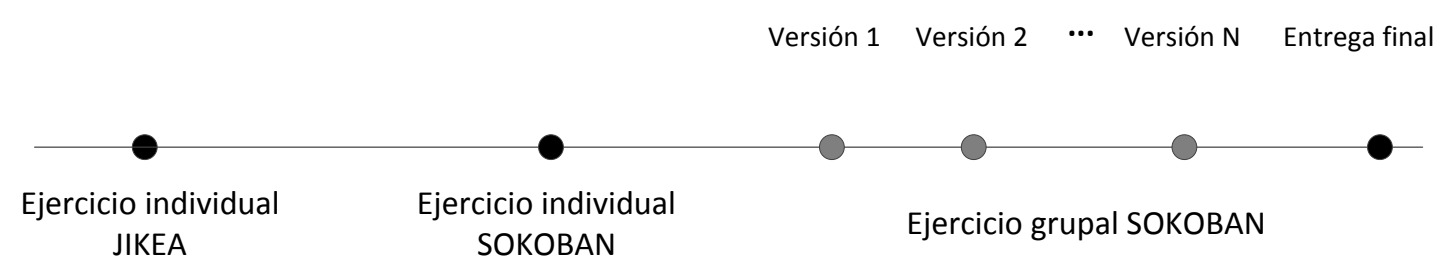

Figura 6-1: Distribución de ejercicios a lo largo del período de instrucción 
La descripción de los ejercicios se muestra a continuación, el detalle de los mismos puede ser visto en el Apéndice B.

- JIKEA: Aplicación que consta de trasladar muebles a través de varias habitaciones

- SOKOBAN: Juego que consta de empujar cajas hasta un lugar designado como correcto dentro de un almacén. Las cajas pueden ser empujadas solamente por el personaje.

Los ejercicios enviados a los estudiantes, fueron expuestos de manera visual en la clase, de manera que el profesor mostraba a través de una aplicación la aplicación que se quería obtener como resultado. Adicionalmente, se les enviaba el enunciado escrito, donde se les describía el ejercicio que debían diseñar. Los estudiantes al momento de ver la aplicación, podían despejar las dudas sobre el ejercicio planteado, apartando de esa manera la mayoría de malentendidos con respecto al objetivo del ejercicio.

Del aprendizaje de los estudios previos realizado por el investigador, se destacó la importancia de la forma de solicitar los ejercicios a los estudiantes. Cuando los ejercicios eran enviados únicamente como enunciado escrito, algunos estudiantes interpretaban de manera diferente el enunciado. Se hizo manifiesto, que muchas veces el enunciado podría prestarse para ambigüedades, lo que interfería al investigador en el momento de analizar los ejercicios.

\subsection{Análisis de datos}

El proceso de análisis de datos constó de cuatro etapas y estuvo basado en el modelo propuesto por Seidel [101] y adaptado a este estudio de caso en particular. En la Figura 6-2 se puede apreciar a cada etapa con una reseña de su objetivo y los resultados de cada etapa. El proceso mostrado fue desarrollado sistemáticamente para todas los datos cualitativos recogidos durante el período de instrucción. El tratamiento de los datos fue realizado con la ayuda del software ATLAS.ti [76]. 


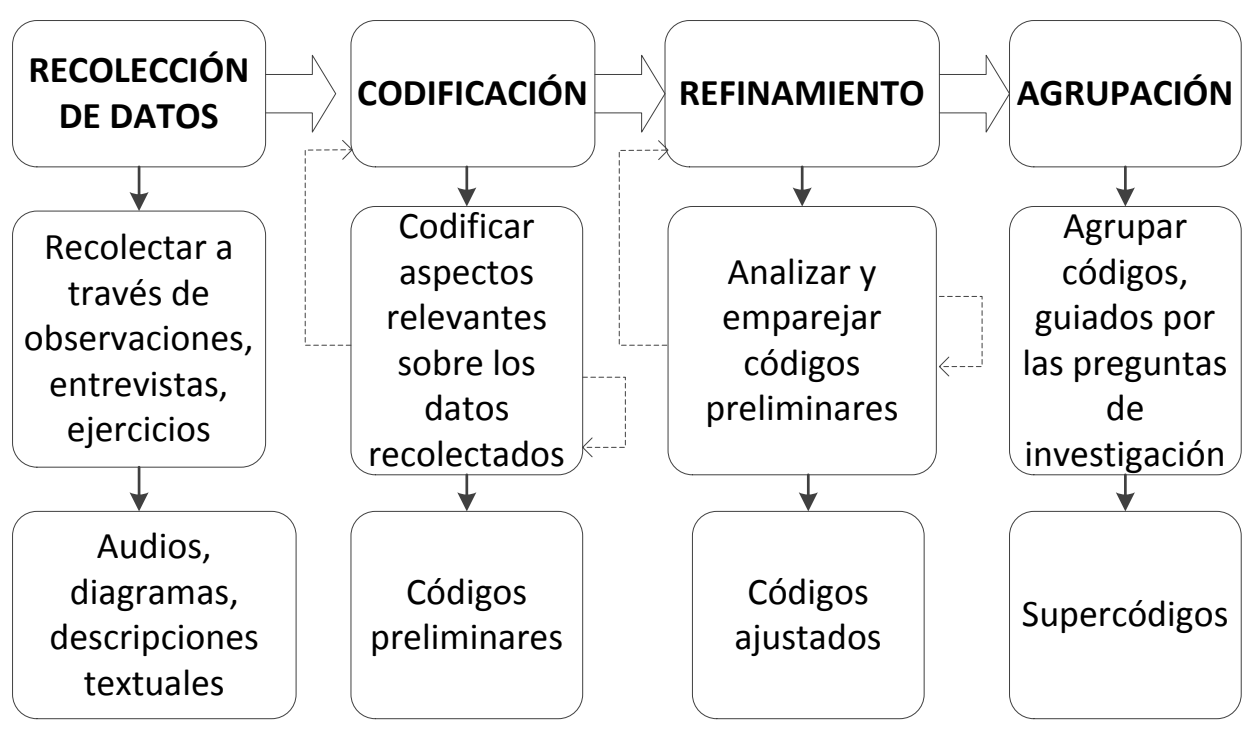

Figura 6-2: Análisis de datos

El proceso de análisis generó una enorme cantidad de información. Para ilustrar este proceso, a continuación se presenta el proceso de análisis de datos realizado al primer ejercicio y entrevista del estudiante 5.

- Recolección de datos

En esta etapa se definieron y ejecutaron las técnicas para la recolección de datos. Para el estudiante en cuestión, los datos recogidos fueron un documento correspondiente al ejercicio individual (textual y gráfico) y una entrevista (formato audio).

- Codificación

En esta etapa se asignaron códigos a cada dato recolectado. Un código en investigación cualitativa es definido como una palabra o frase corta que se asigna simbólicamente a una sumativa, saliente, captura - esencia, y/o atributo evocativo para una porción basado en el lenguaje o en datos visuales [99].

A continuación se muestra el proceso de codificación realizado al ejercicio individual entregado en un documento de texto y la entrevista recogida en formato de audio. Desde la Figura 6-3 hasta las Figura 6-8 se indica el proceso realizado sobre el documento de texto enviado por el estudiante y en la Figura 6-9 se puede ver la codificación realizada sobre el audio. Posteriormente, en la Figura 6-10 se muestra la recopilación de los códigos generados con sus respectivas citas. Las capturas de pantalla fueron tomadas de la herramienta ATLAS.ti 


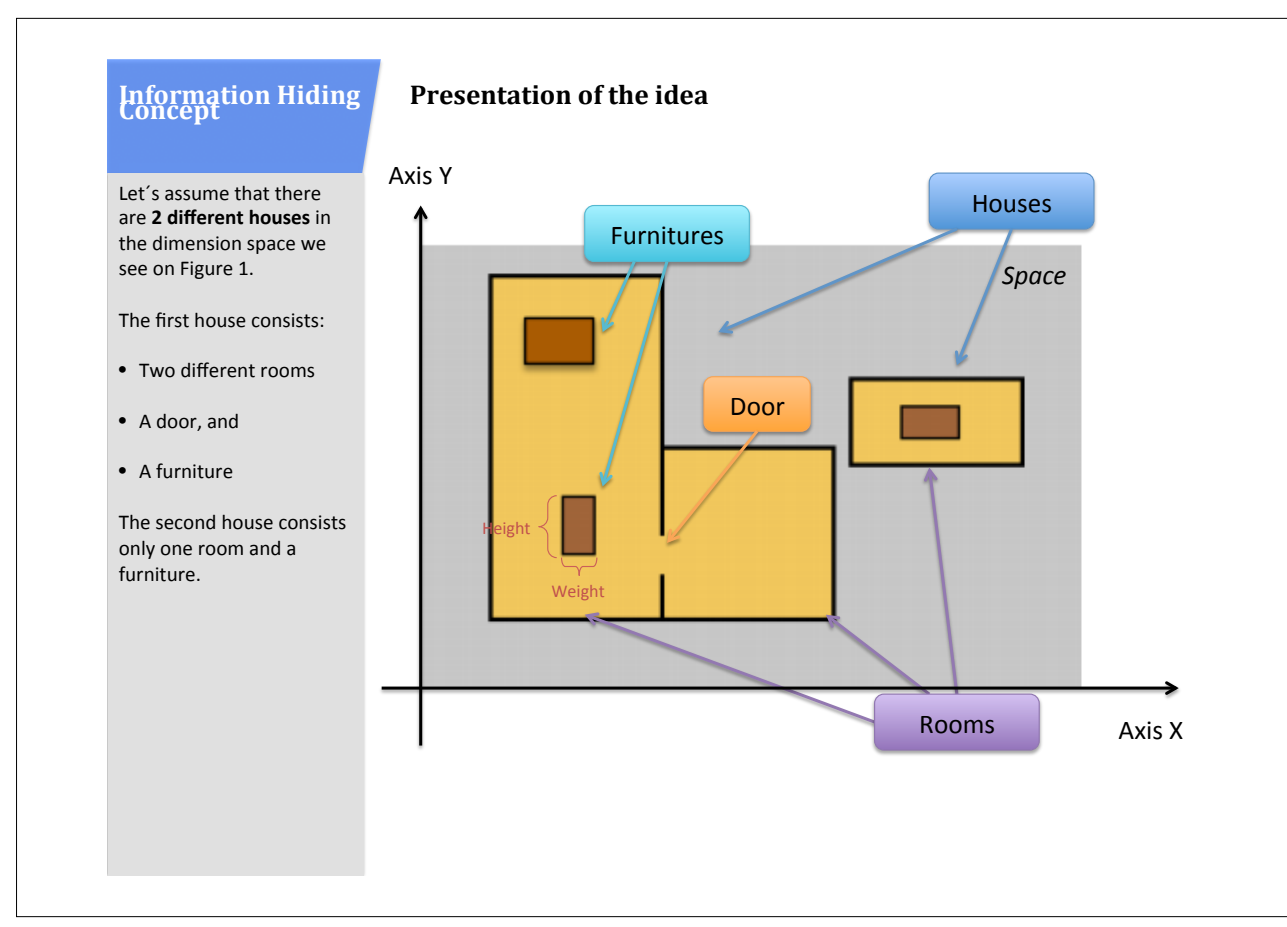

SW05_Asume que la aplicaci.

Figura 6-3: Codificación del documento de texto - Página 1

\section{Unformation Hiding
Loncept}

This is the design of the

application. As it can be seen

on the class diagram there

are two different layers

defined:

- Dimension Layer

- Furniture Layer

The Dimension Layer has 3 entities: House, Doors and

Room, while the Furniture

layer has only 1 entity:

Furniture.

Furniture is inside the

Furniture Layer because it

defines the operation to

move the Furniture.

House, Doors and Room are included into the Dimension Layer and here we have the

logistic to see how the

doors, and the rooms have

been distributed into the

house. This layer defines the

dimension space.

\section{Information Hiding Concept - Meaning of elements}

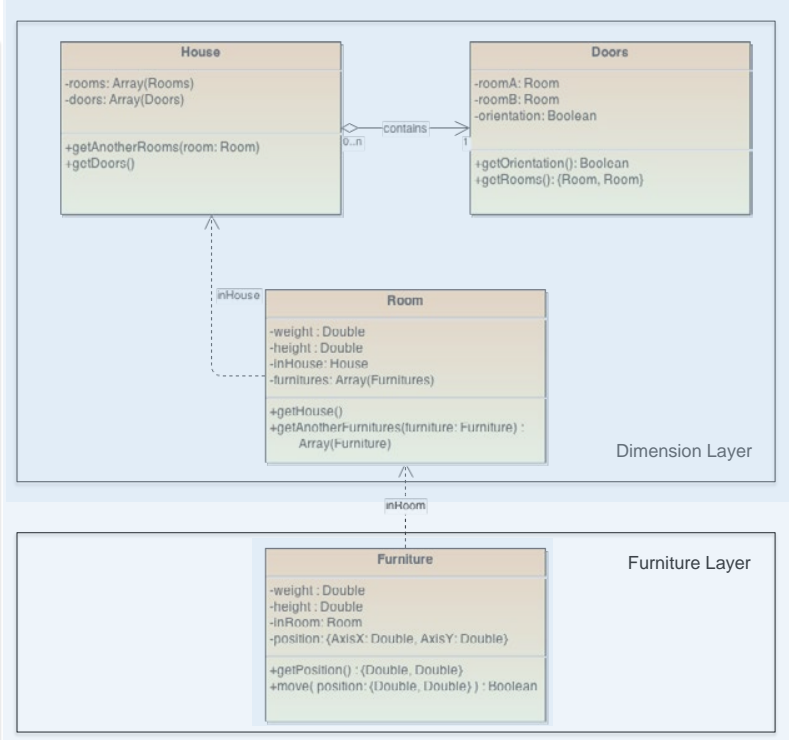

SW05_Descomposición por c SW05_Separación de los ele

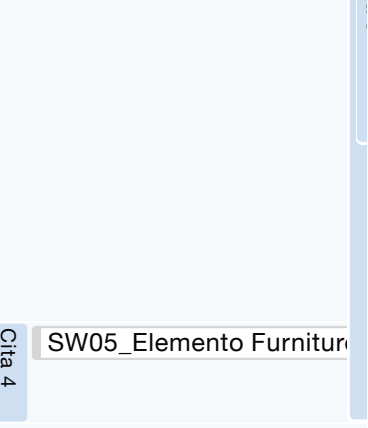

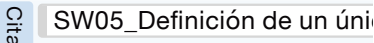

Figura 6-4: Codificación del documento de texto - Página 2 


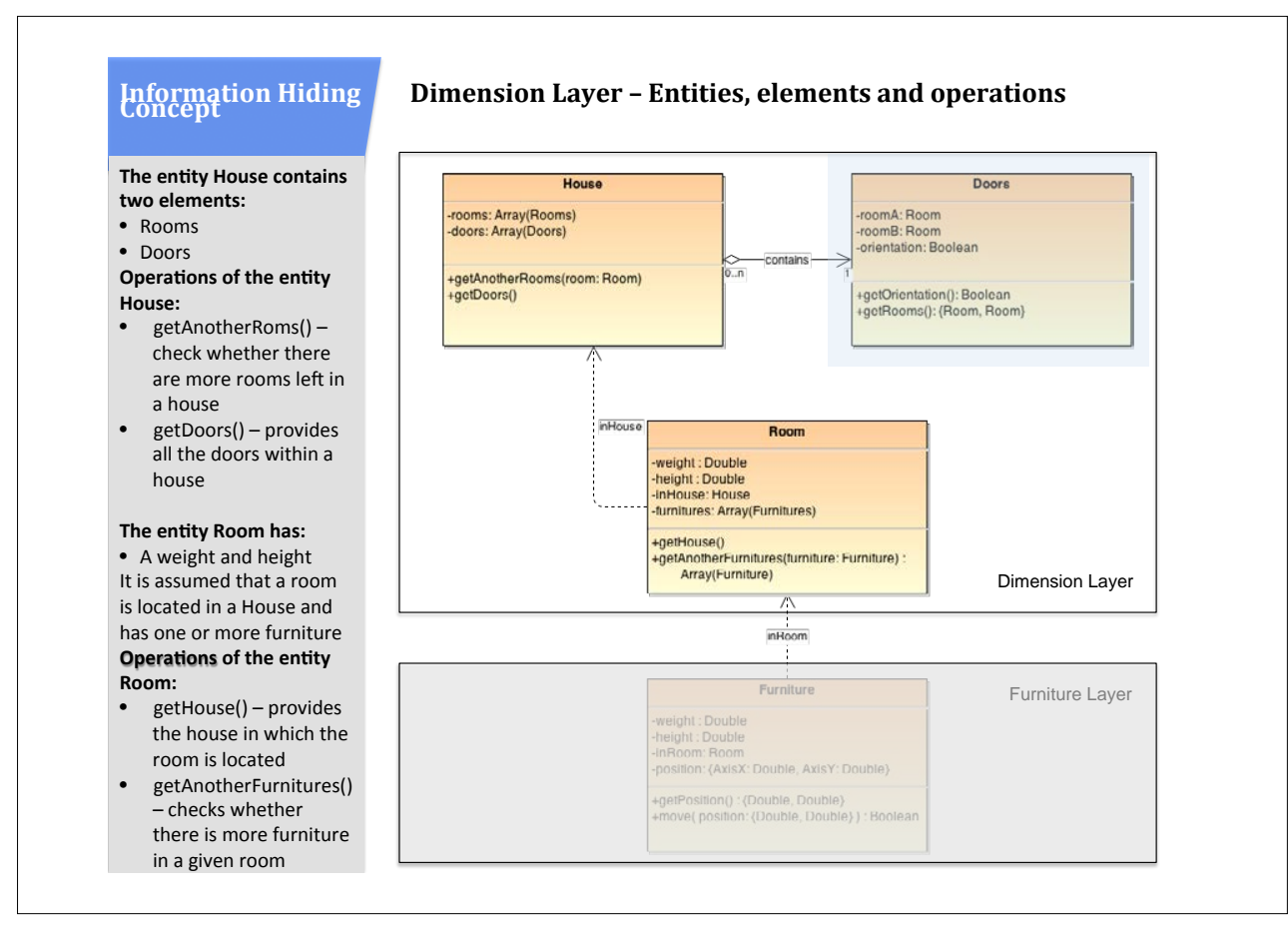

$\stackrel{\rho}{P}$ SW05_Concepto House enun

? SW05_Definición de todos lo $\infty$

Figura 6-5: Codificación del documento de texto - Página 3

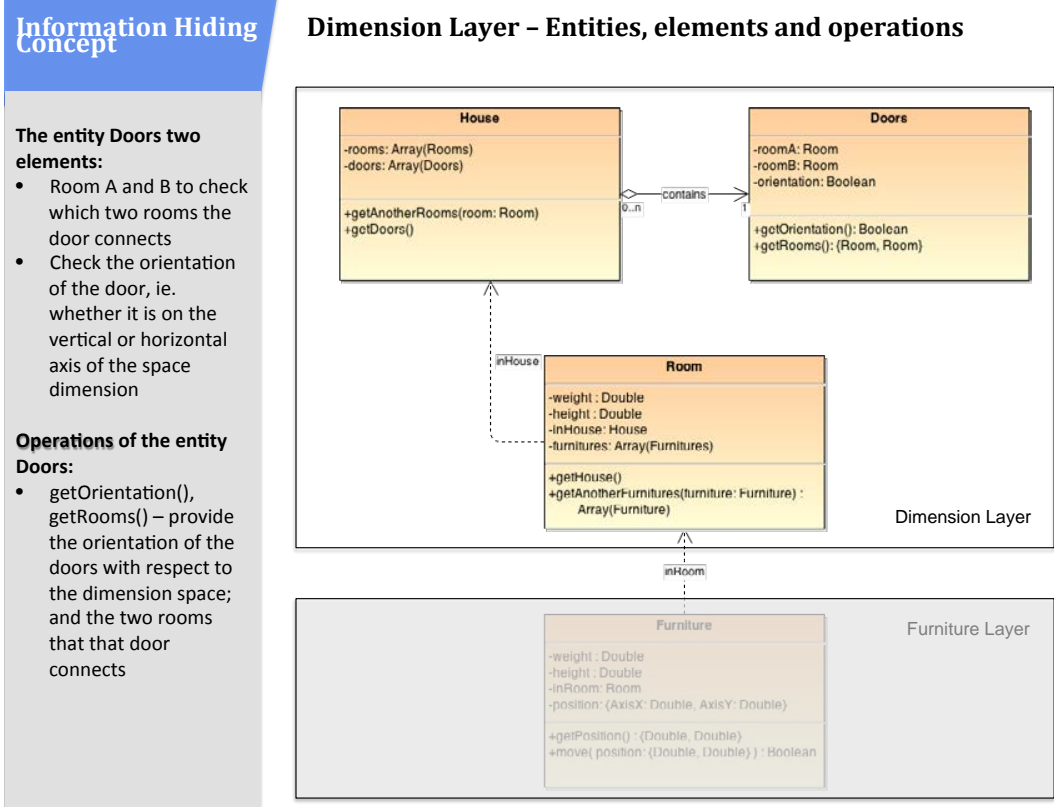

Figura 6-6: Codificación del documento de texto - Página 4 


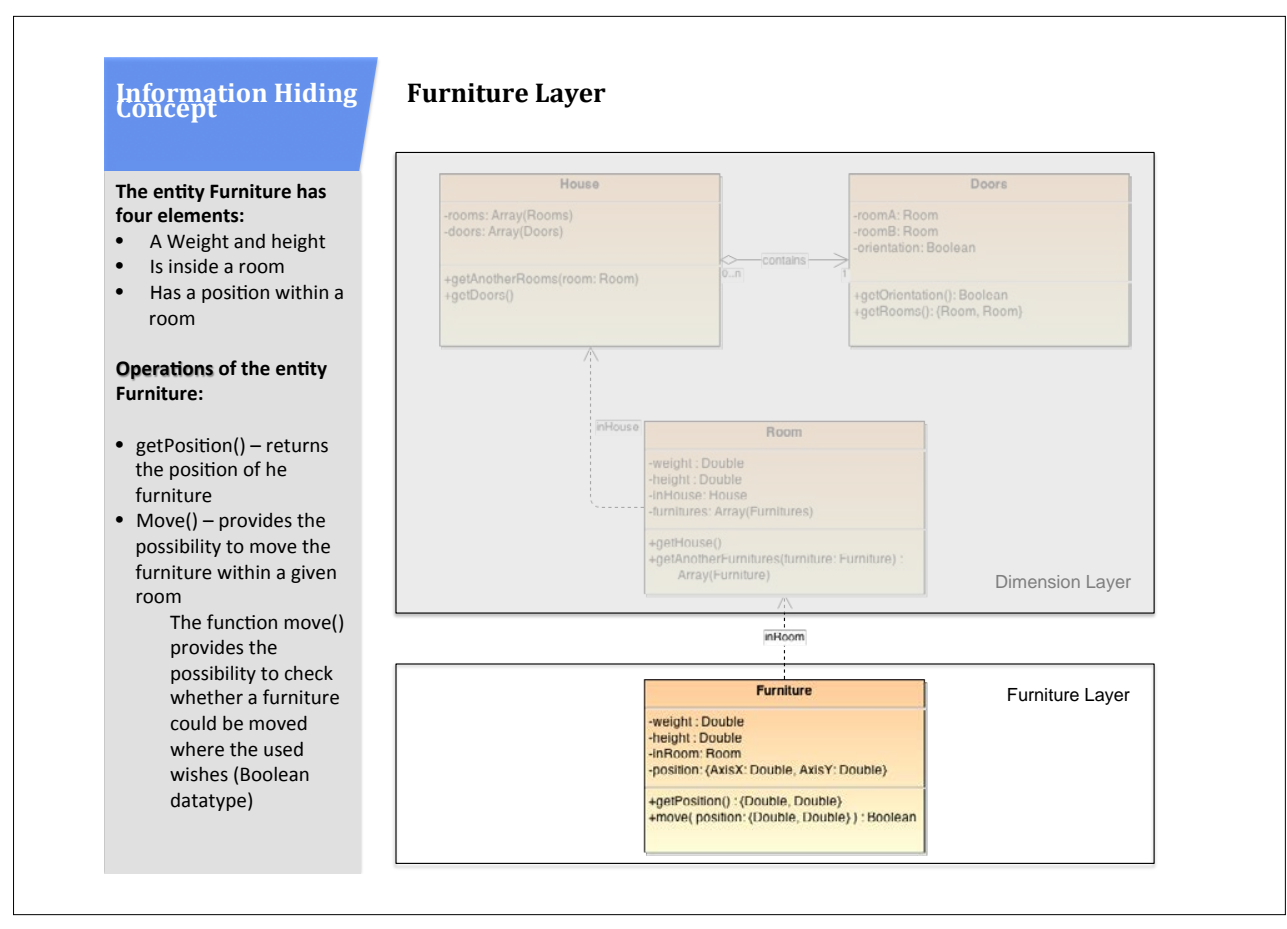

SW05_Definición de un único.

$\exists$

Figura 6-7: Codificación del documento de texto - Página 5

\section{Information Hiding Information hiding principle
Uoncept \\ Explanation of the concept} information hiding

We could assume that the information hiding principle was considered during the design of this software because of the following two reasons:

- The parameters of each entity are hidden (the internal information of each entity remains "invisible")

- The only thing that is known by having designed this design are the required operations that resolve successfully the given problem

The information hiding principle included within this design could reduce the software development risk when implementing changes. The reason behind this is that there is no direct dependency between the entities, a programmer could manage one entity at a time because each entity has been decomposed within two a layer.

Figura 6-8: Codificación del documento de texto - Página 6 


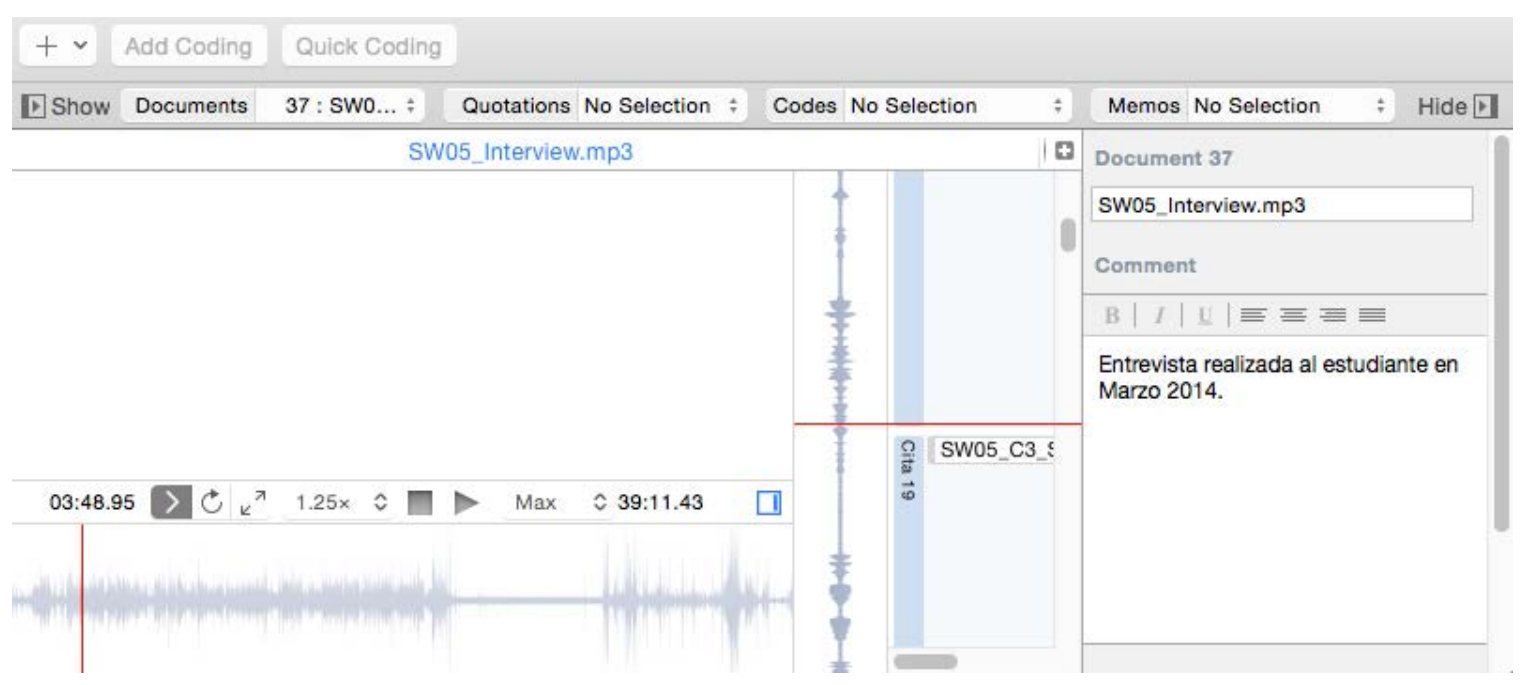

Figura 6-9: Codificación del audio obtenido de la entrevista

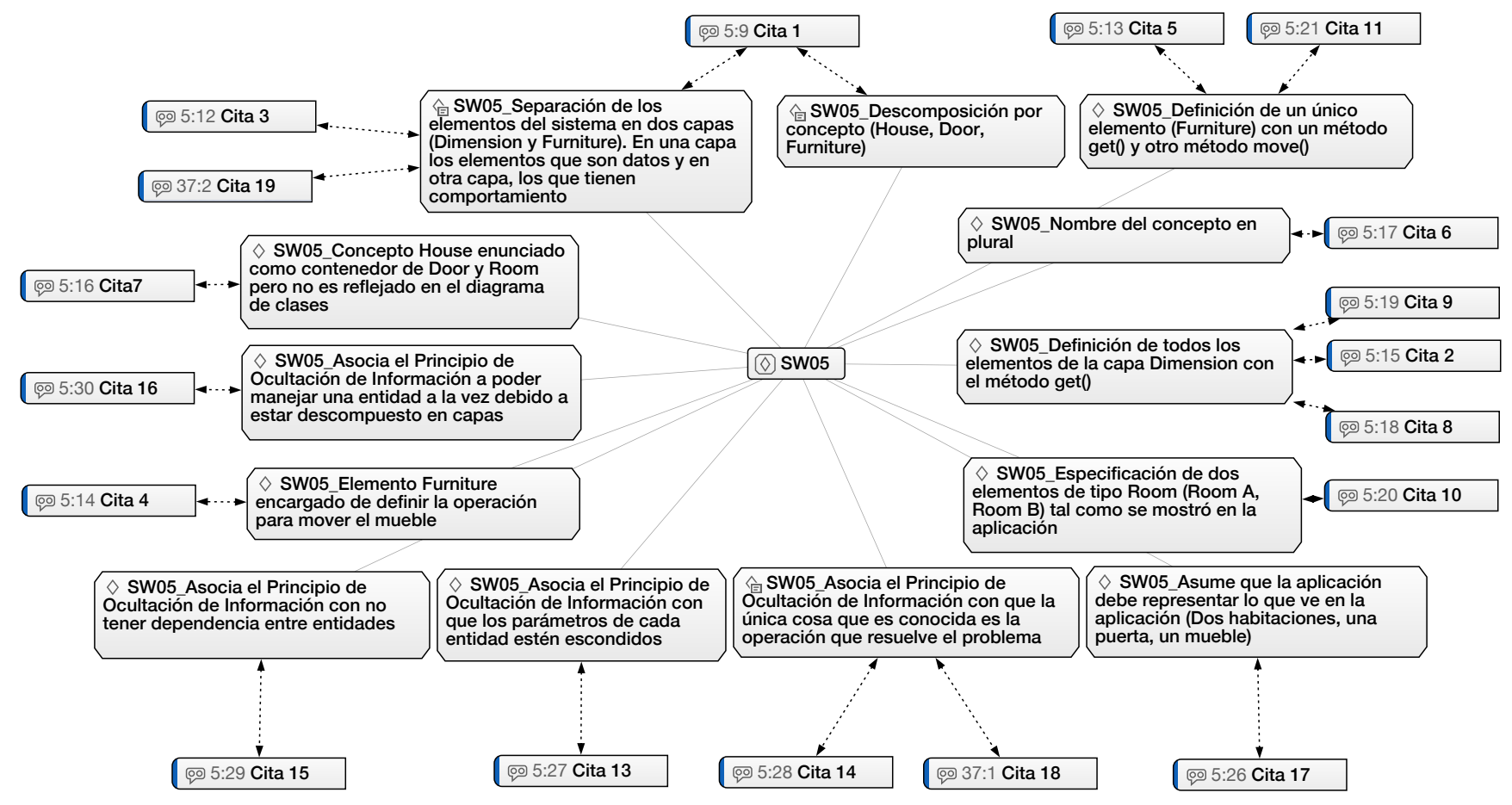

Figura 6-10: Códigos y citas asociadas al estudiante

- Refinamiento

En esta etapa se realizó el análisis de los códigos preliminares de la etapa anterior, emparejando o detallando códigos similares. En este proceso podrían aparecer códigos nuevos. Esta etapa fue realizada de manera iterativa hasta que los códigos se mantuvieron relativamente estables. La Figura 6-11 muestra la formación de los códigos del estudiante 5 en códigos ajustados (color verde). La Figura 6-12 muestra la gráfica del estudiante con sus códigos ajustados. 


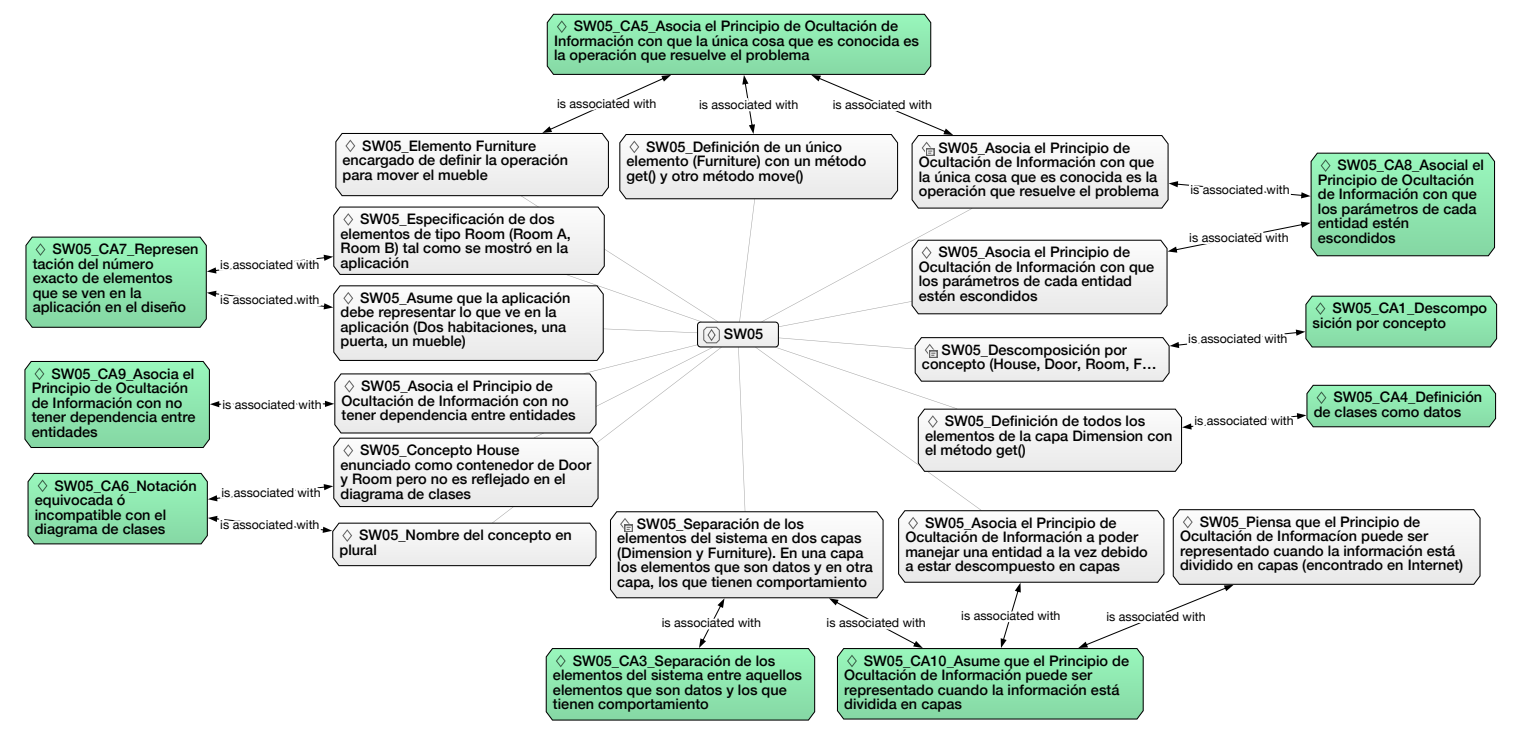

Figura 6-11: Formación de códigos ajustados a partir de los códigos de un estudiante

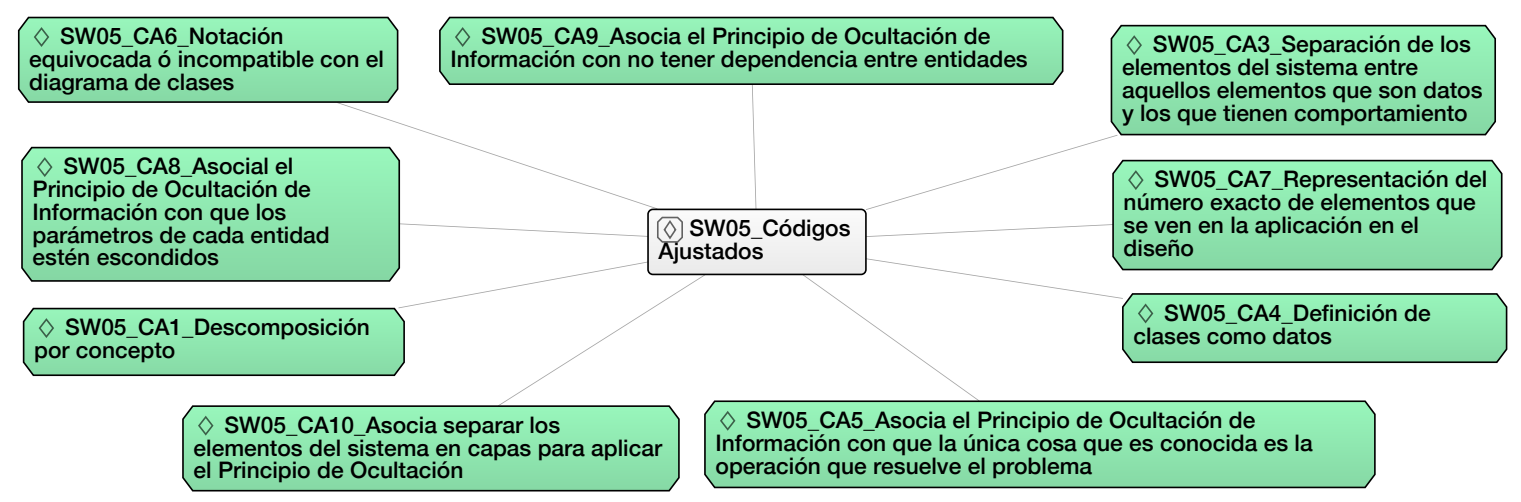

Figura 6-12: Códigos ajustados por estudiante

- Agrupación

En esta etapa se agruparon los códigos generados en la etapa de Refinamiento. La agrupación se realiza siguiendo los criterios de las preguntas de investigación y se busca darle una interpretación a los códigos en forma de resultados.

Debido al número desbordante de iteraciones realizadas en cada etapa del proceso de análisis de datos, ha sido difícil plasmar las variaciones realizadas alrededor de la formación de códigos y la obtención de códigos ajustados finales. El proceso de análisis de datos ilustrado a través del estudiante 5, es solo una muestra sintética y resumida de lo que se ha realizado en el proceso con los trece estudiantes que conformaron el estudio de caso. Los códigos generados por cada estudiante y grupo de estudiantes pueden ser vistos en los Apéndices C, D, E. 


\subsection{Indicadores}

Un resumen de los indicadores se muestran a continuación en la siguiente Tabla.

\begin{tabular}{ccc}
\hline Indicador & Detalle & Descripción \\
\hline \hline \multirow{2}{*}{ Datos sin } & Tareas escritas & 31 documentos $~$ \\
tratamiento & Audio de entrevistas & $\approx 500$ palabras \\
& Audio del profesor & $\approx$ horas \\
& Audio de las clases & $\approx 8$ horas \\
\hline \hline Citas & Textuales, visuales y audibles & 368 \\
\hline \hline Códigos & Códigos preliminares & 220 \\
& Códigos ajustados & 194 \\
& Tipos de códigos ajustados & 48 \\
\hline
\end{tabular}

Tabla 6.1: Indicadores de la investigación

El proceso de codificación realizado entre el profesor e investigador fue iterativo, intenso y constante. En la Figura 6-13 se presenta un resumen de las iteraciones más relevantes, donde se muestra la variación del número de códigos y documentos a lo largo del período de análisis. La línea roja representa el número de códigos, la línea azul representa el número de documentos y en el eje $x$ se representa el número de iteración. Desde la iteración 1 a la 3 , el número de documentos se incrementa, al igual que el número de códigos. Desde la iteración 5 hasta la 12, los números de documentos se mantienen constantes. En la iteración 5 existe un salto en el número de códigos, debido a que se decidió incluir para el análisis las versiones previas del trabajo en grupo. El número de documentos no aumentó en esta iteración debido a que físicamente las versiones previas estuvieron incluidas en el mismo documento final. Una síntesis de las iteraciones más relevantes son descritas en el Apéndice F.

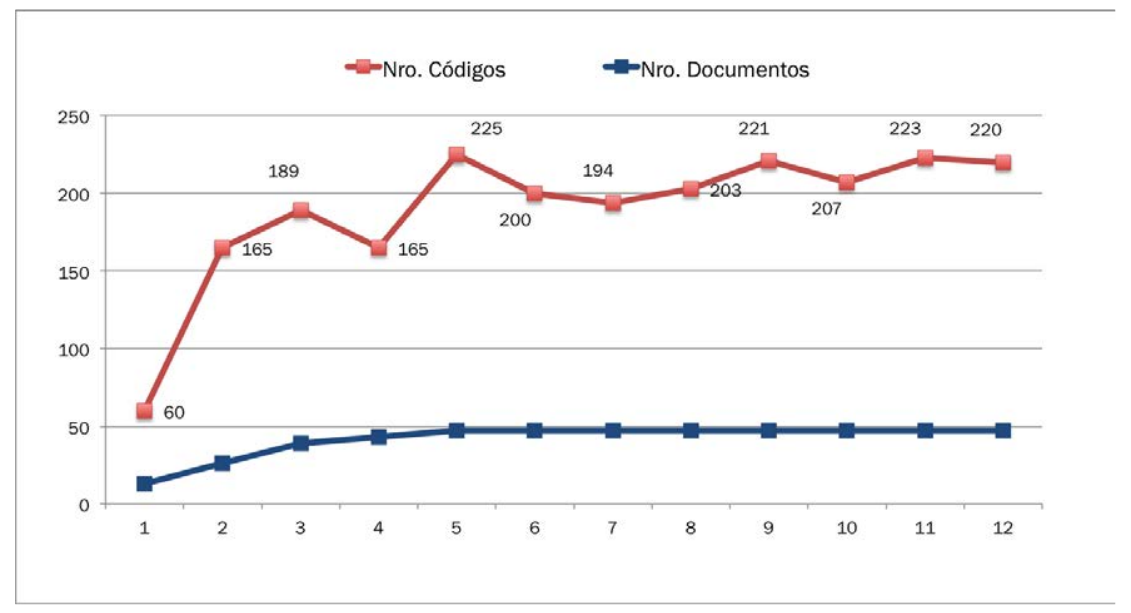

Figura 6-13: Evolución de códigos y documentos por iteración 


\subsection{Integridad de la investigación}

Los resultados de esta investigación estuvieron ceñidos a los criterios de calidad definidos por Lincoln y Guba [64]. Los autores proponen cuatro términos para demostrar la integridad de una investigación de tipo naturalista, los cuales son: credibilidad, transferibilidad, dependabilidad y confirmabilidad. Estos términos reemplazan a los criterios convencionales de validez interna, validez externa, confiablidad y objetividad referenciados por otros autores. A continuación se discuten los criterios de calidad utilizados en esta investigación.

- Credibilidad. La credibilidad se refiere a la existencia de evidencia sobre cómo los datos fueron recolectados y cómo el análisis fue conducido.

Esta investigación provee detalles acerca del entorno en el que se realizó el estudio de caso, sus participantes y perfiles. Adicionalmente, se han descrito en detalle el proceso de recolección de los datos, el proceso de análisis de datos, las herramientas y los criterios usados en la investigación. Las técnicas aplicadas a lo largo de la investigación fueron peer debriefing y triangulación.

Peer debriefing constó de reuniones posteriores documentadas (audio y texto) entre el profesor e investigador luego de cada actividad del estudio de caso y la triangulación se llevó a cabo combinando distintas fuentes de datos, en esta investigación las fuentes de datos fueron las observaciones, entrevistas, y análisis documental, todas apuntando a un solo objetivo, la búsqueda de dificultades de aprendizaje en el diseño de software orientado a objetos.

- Transferibilidad. Este punto se refiere a determinar si la prolongación de los resultados de una investigación en particular tiene aplicabilidad en otros contextos o sujetos. Bajo los lineamientos de Lincoln y Guba, el término transferibilidad difiere del término generalización y se trata de establecer si los resultados pueden ser aplicados bajos ciertas circunstancias; es decir, si son potencialmente aplicables.

Una sugerencia de Lincoln et al. para el investigador es que al desconocer los contextos donde pueden ser aplicables los resultados, la acumulación de evidencia científica acerca del contexto es clave para aquellos interesados en aplicar los resultados en otros contextos.

La responsabilidad de la transferibilidad recae mayormente en la persona que busca la aplicabilidad del estudio, mientras que las responsabilidades del investigador original terminan con en el suministro de datos descriptivos suficientes para que otros hagan tantos juicios de similitud del contexto como sea posible. Esta investigación cumple con presentar de manera científica, descriptiva y rigurosa el entorno, participantes y situaciones para el cual se ha desarrollado el estudio, con el fin de que investigadores encargados de aplicar los resultados, puedan evaluar si es o no aplicable en nuevos contextos.

- Confiabilidad. Este punto también conocido como consistencia, está dirigido a determinar si los resultados de una investigación podrían ser repetidos. La 
repetibilidad en este tipo de estudios no puede ser entendido en el sentido convencional, debido a que es difícil repetir una investigación con el mismo contexto y esperar obtener los mismos resultados; esto por el simple hecho de que el factor más importante en este tipo de estudios está relacionado al comportamiento humano y éste es variable en el tiempo.

Dado esto, confiabilidad está enfocado a la consistencia entre los resultados obtenidos y los datos recolectados. Es decir, el investigador detalla y hace explícito el rastro desde el origen de los datos y su manipulación, hasta la declaración de resultados. En esta investigación, los datos obtenidos desde su recogida, las técnicas de análisis de datos implementadas y las decisiones tomadas por el investigador son expuestas de manera explícita, facilitando su trazabilidad.

- Confirmabilidad. También conocido como neutralidad, se enfoca en establecer el grado para el cual los resultados de una investigación son determinados por los participantes y no corresponden a motivaciones o perspectivas del investigador.

Esta investigación inició y se desarrolló bajo la intencionalidad de objetividad, esto quiere decir, que no se partió de ninguna hipótesis con la intención de rechazarla o aprobarla, ni se prentendió contrarestar ninguna idea preconcebida. Tampoco se tuvo la intencionalidad de ejercer influencia sobre los estudiantes.

Además, para cumplir con este criterio se disponen de transcripciones concretas, citas textuales y la información recogida en video y audio.

Adicionalmente, para evitar conflictos de tipo ético con respecto a la manipulación de los datos recogidos de los estudiantes, en esta investigación se solicitó de manera escrita un consentimiento firmado por los estudiantes, cuyo formato puede ser visto en el Apéndice G. Los puntos principales de este documento apuntan a la voluntariedad en la participación, solicitud de permiso para el análisis de los ejercicios, entrevistas y observaciones realizadas a los estudiantes, compromiso de asegurar el anonimato y confidencialidad de los datos por parte del investigador y petición para poder compartir los resultados obtenidos. 



\section{Capítulo 7}

\section{Estudio inicial sobre el entendimiento del Principio de Ocultación de Información}

En este capítulo se muestra el detalle del estudio realizado al inicio del período de instrucción. Aquí se describe el objetivo del estudio, las preguntas de investigación. Posteriormente, se hace explícito las activiades involucradas en período de instrucción y el proceso de análisis de los datos. Finalmente se muestran los resultados obtenidos y un resumen.

\subsection{Objetivo}

El estudio tuvo como objetivo conocer la "imagen" inicial que tienen los estudiantes respecto al Principio de Ocultación de Información, antes de recibir cualquier tipo de instrucción.

\subsection{Preguntas de investigación}

Las siguientes preguntas de investigación guiaron este estudio:

- ¿Qué entienden los estudiantes sobre el Principio de Ocultación de Información y cuál es su nivel de aproximación al Principio?

- ¿Cuáles son las posibles causas de ese entendimiento del Principio de Ocultación de Información?

\subsection{Inicio del período de instrucción}

El estudio inicial constó de varias sesiones, todas planificadas en coordinación con el profesor y el investigador y realizadas al inicio del período de instrucción. Las sesiones y el proceso realizado se muestran en la Figura 7-1. 
Inicio del período de instrucción

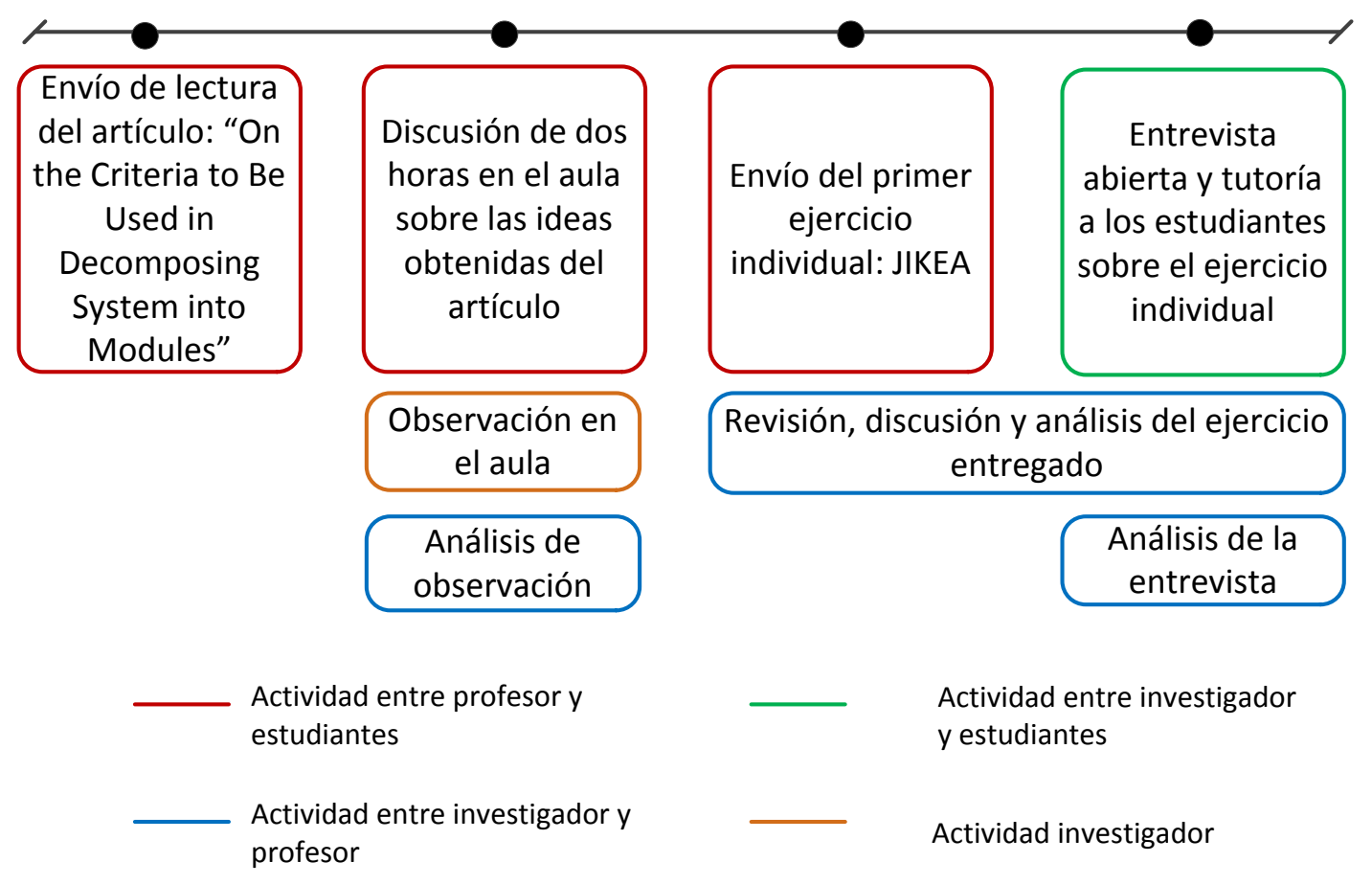

Figura 7-1: Inicio del período de instrucción

La entrevista realizada a los estudianets, fue de tipo abierta, pero estuvo guiada por las preguntas de investigación del estudio, las cuales fueron presentadas en la Sección 7.2. Las principales preguntas realizadas fueron:

- ¿En qué parte del diseño tu piensas que has aplicado el Principio de Ocultación?

- ¿Qué entiendes por Principio de Ocultación?

- ¿Cuál fue la fuente de referencia para implementar el Principio de Ocultación en tu diseño?

\subsection{Análisis de datos del estudio inicial}

Con los datos recogidos para este estudio inicial, se siguió el proceso definido en la Sección 5. Las etapas del proceso de análisis de datos fueron: Recolección de datos, Codificación, Refinamiento y Agrupación. 


\subsection{Niveles de aproximación al Principio de Ocultación de Información}

En esta sección se muestran los códigos ajustados obtenidos de cada estudiante. Además se presentan los supercódigos que representan el nivel de aproximación del estudiante al Principio. Adicionalmente, una pequeña explicación por cada estudiante es presentada a continuación.

\subsubsection{Nivel de aproximación: Ninguno}

En este nivel, se encuentran los estudiantes 2, 4, 8 y 9 y cuyos análisis son mostrados a continuación. Este nivel está conformado por el grupo de estudiantes quienes ignoran el Principio de Ocultación de Información.

\section{Estudiante 2}

El estudiante 2 presenta una clara separación entre los elementos que tienen métodos de los elementos que manejan datos tal como se puede ver en la en la Figure 7-2.

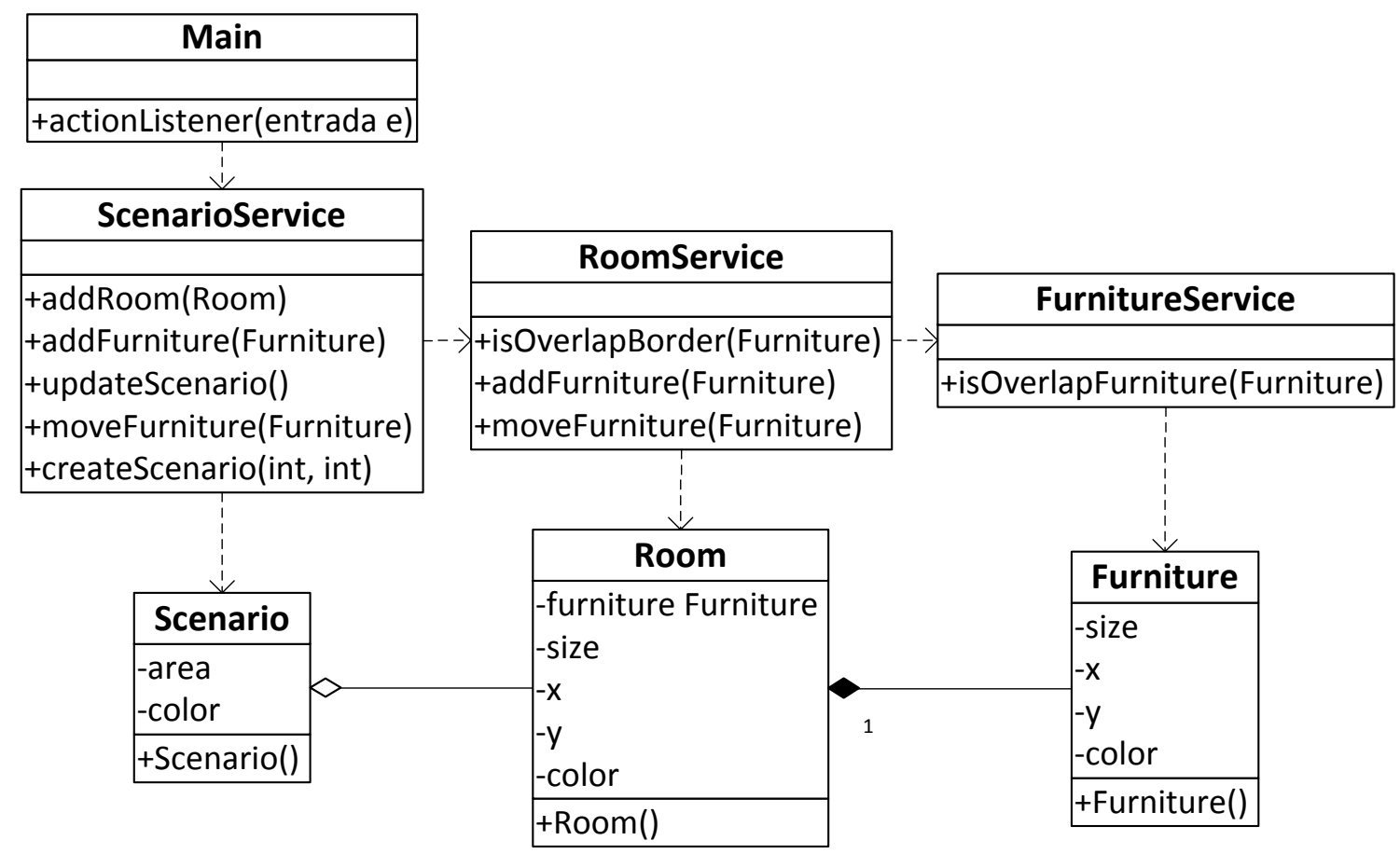

Figura 7-2: Diagrama del estudiante 2

El estudiante no expresa de manera explicita la aplicación del Principio en su ejercicio escrito, pero en su entrevista el estudiante justifica la razón de su diagrama diciendo lo siguiente: "Separo los métodos de los datos, para la persistencia de los datos. Si tengo los datos por separados los puedo cambiar por otros usando los mismos métodos" 
El estudiante da un concepto confuso de persistencia, cambiando un dato por otro, siendo esto un malentendido, ya que la persistencia de datos no está directamente relacionada con la separación de los métodos y los datos. Por otro lado, no es posible cambiar los datos por otros y seguir usando los mismos métodos, como él lo afirma. Se observa que el estudiante trata de asociar el beneficio de flexibilidad, enunciado por Parnas en su artículo, con el concepto que tiene el estudiante de persistencia.

Las ideas principales del estudiante 2 son:

- Falta de entendimiento del Principio de Ocultación de Información. El estudiante diseñó bajo sus propio concepto de persistencia.

\section{Estudiante 4}

El Principio de Ocultación de la Información no fue expresado por el estudiante de manera explicita. Sin embargo, en su ejercicio escrito el estudiante menciona una sección llamada modularización, donde se especula pensando que el estudiante aplica los principios mencionados por Parnas. Adicional a esto, el estudiante también describe las clases y funciones que fueron colocadas en su diagrama. Sin embargo, en la Figure 7-3 no se puede apreciar la relación entre la modularización y la definición de clases y funciones.

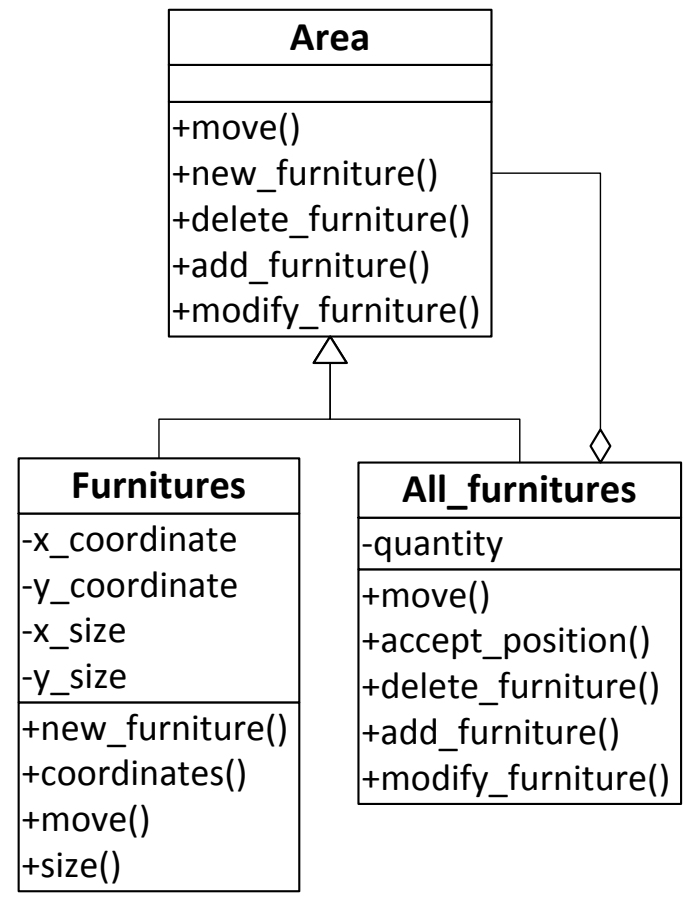

Figura 7-3: Diagrama del estudiante 4

A continuación colocamos las descripciones textuales de algunos módulos: "Module 1: This module contains functions and subroutines whose meaning is invoked by the user of the module. All functions have requirements which are conditions that must be satisfied before the function is executed". 
"Module 3: Based on modules 1 and 2, module 3 will be in charge of the creation of the test case of all the principal functions to be tested. The tester have to follow the requirements of the functions. These tests consist on defining different inputs in order to compare if the outputs are the expected ones or not".

De los módulos citados previamente, el Módulo 1 está dirigido a definir precondiciones, mientras que el Módulo 3 define pruebas para todas las funciones. Esto muestra que los módulos parecen estar enfocados a la seguridad del sistema.

Las ideas principales del estudiante 4 son:

- Falta de entendimiento del Principio de Ocultación de Información. El estudiante separa diseño de modularización. Para el estudiante, diseño es la definición de de clases y funciones y modularización es la definición de módulos responsables de la seguridad del sistema.

\section{Estudiante 8}

El estudiante 8 dispone del diagrama mostrado en la Figure 7-4 y explica el Principio de Ocultación de Información en la entrevista de la siguiente manera: "Según yo, la parametrización es la ocultación". "Siempre estuve acostrumbrado a pensar en que tengo que parametrizar todo, entonces si hay objetos voy a parametrizar los objetos y que tienen en común en este caso: ancho y largo".

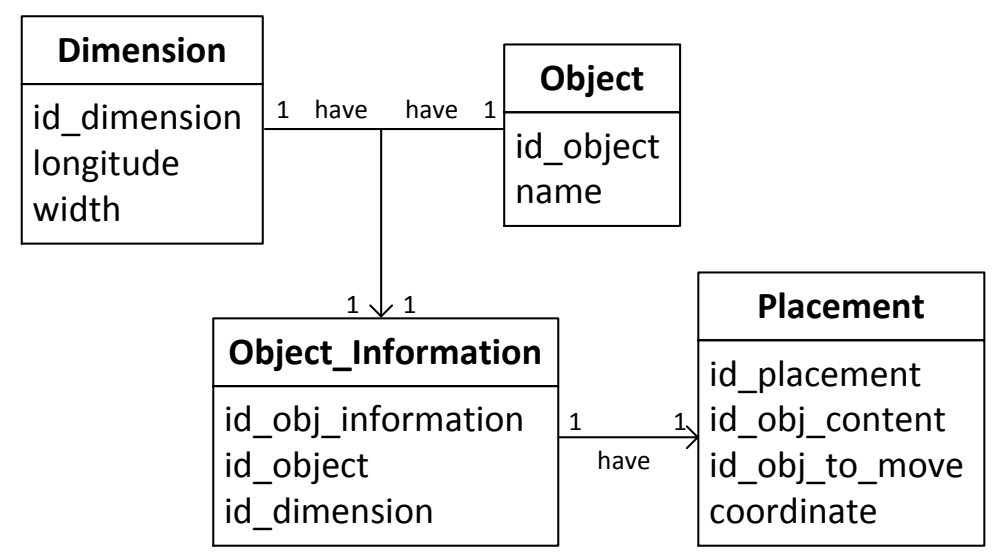

Figura 7-4: Diagrama del estudiante 8

Adicionalmente, se le preguntó en qué parte del diseño él creía que aplicaba el Principio de Ocultación de la Información: "Yo hice un modelo entidad - relación y yo trataba de hacer una base de objetos, estos objetos podrían ser el cuarto o el mueble, y cada uno tiene sus dimensiones, entonces yo quería tener en un sólo lugar los objetos con su dimensión y de acuerdo a eso tratar de moverlos a una posición (... En teoría yo podría ubicar a cualquier objeto que hubiera y que tuviera cualquier dimension y a cualquier lugar dándole las cordenadas".

Tal parece que la idea de parametrizar es la generalización. Esta idea hace pensar que el estudiante hace una proyección de los objetos a las bases de datos.

Las ideas principales del estudiante 8 son: 
- Falta de entendimiento del Principio de Ocultación de Información. El estudiante entiende parametrizar (entendido como generalizar) como una forma de implementar el Principio.

\section{Estudiante 9}

El Principio de Ocultación de la Información fue expresado por el estudiante en su tarea escrita de la siguiente manera: "The Information Hiding Principle means that the modules only share the necessary information with another one [Module], when there is a need to know the basics to achieve a specific software function. Hiding enforces the procedural constraints to both the module procedural detail in any data structures local to the module. When properly implemented this yields systems with low coupling and high modularity".

El diagrama puede ser visto en la Figure 7-5, pero no es suficiente para ver lo que el estudiante ha escrito en su tarea escrita.

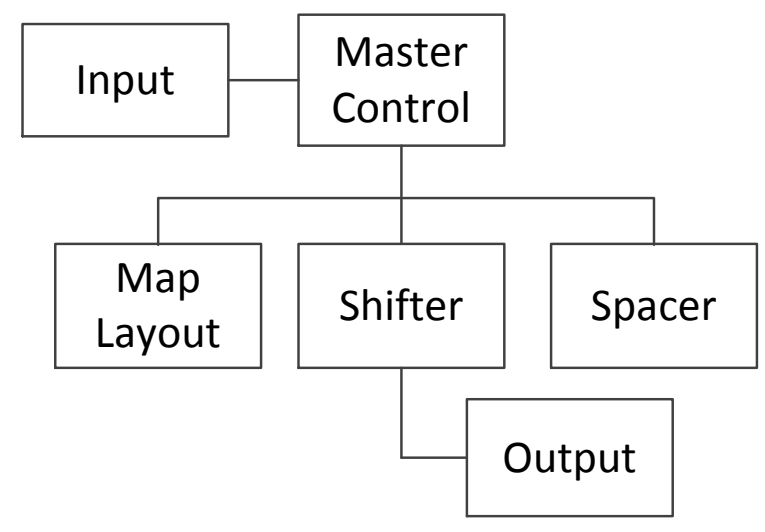

Figura 7-5: Diagrama del estudiante 9

En la descripción de los elementos el estudiante hace su propia adaptación de algunos módulos propuestos por Parnas en su articulo, tal como se muestra a continuación:

"Module 1: Map Layout, this module will contain all the functions or subroutines for drawing the map in which the furniture can be positioned".

"Module 3: Shifter, this module will be used to provide all the functions that allows the furniture to be moved after being added in the map".

Cada módulo parece representar un contenedor de funciones y subrutinas a manera de flowchart, lo cual no es la filosofía del criterio de Parnas. Además el estudiante no es explícito en lo que contiene cada módulo, por lo que es difícil entender su idea del Principio. El estudiante dijo explicitamente en su entrevista: "El artículo era difícil de entender".

Las ideas principales del estudiante 9 son:

- Falta de entendimiento del Principio de Ocultación de Información. Compartir sólo la información necesaria, para realizar una tarea específica, es una manera de implementar el Principio, pero su diseño no muestra esto. 
- Implementar el Principio de Ocultación tiene como consecuencia sistemas con bajo acomplamiento y alta modularidad

- Principio de Ocultación entendido como el traslado de los módulos definidos por Parnas en su artículo

- El paper de Parnas es difícil de entender

\subsubsection{Nivel de aproximación: Inadecuado}

En este nivel, se encuentran los estudiantes 1, 3, 5, 10, 12 y 13 cuyos análisis son mostrados a continuación. Este nivel está conformado por el grupo de estudiantes quienes argumentaron que aplicaron el Principio de Ocultación de Información, pero sus ideas no encabajan con sus diseños.

\section{Estudiante 1}

El Principio de Ocultación de la Información fue entendido por el estudiante 1 como la separación explícita de la información en dominios, tal como se ve en la Figure $7-6$.

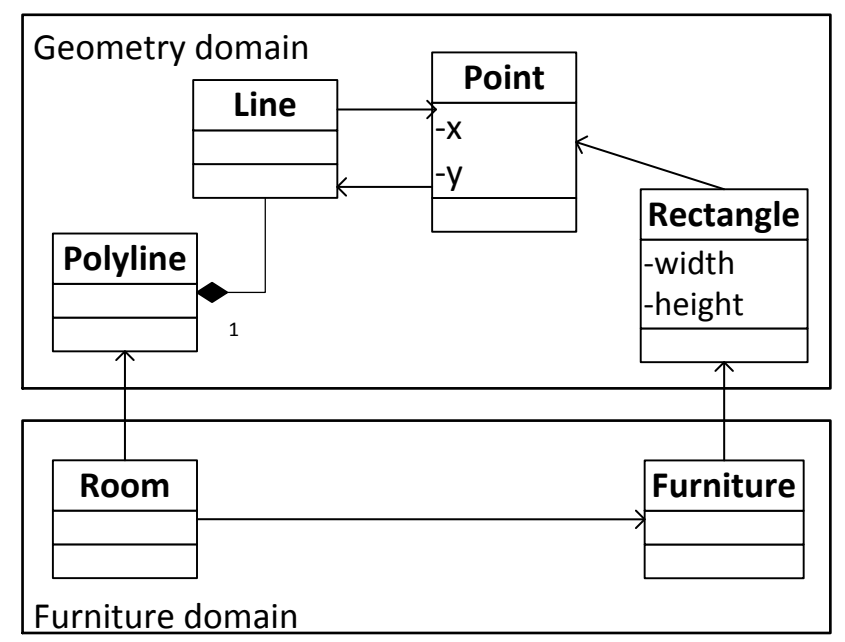

Figura 7-6: Diagrama del estudiante 1

El estudiante además escribe en su ejercicio escrito: "Applying Information Hiding increases understability and flexibility. I have separated the entities according to their domains. So each module has a specialty".

El estudiante separa en dominios según su especialidad: Geometry and Furniture; en concordancia con el pensamiento de Parnas donde el dice que cada módulo debería tener una tarea. En este punto el estudiante identifica este objetivo, sin embargo confunde módulos con dominios, dándole una especialidad a cada dominio en lugar de darle una especialidad a cada módulo.

Adicionalmente, el estudiante coincide que en esta manera de separar hay una clara separación clara entre elementos que son datos (Geometry domain) de los que tienen comportamiento (Furniture domain). 
Las ideas principales del estudiante 1 son:

- Una forma de implementar el Principio es:

- Separar en dominios según su especialidad

- Separar elementos que son datos de los elementos con comportamiento

- Incremento del entendimiento y flexibilidad es una consecuencia de aplicar el Principio

\section{Estudiante 3}

El estudiante 3 aplicó el Principio de Ocultación de Información basado en las siguientes reglas encontradas por el estudiante en Internet, tal como lo expresó en la entrevista: "Yo busqué en Internet como aplicar el Principio de Ocultación y encontré cuatro reglas relacionadas al Principio: 1) do not expose data items; 2) do not expose the difference between stored data and derived data; 3) do not expose a class's internal structure and; 4) do not expose implementation details of a class" [92]. En la Figura 7-7 se muestra su correspondiente diagrama.

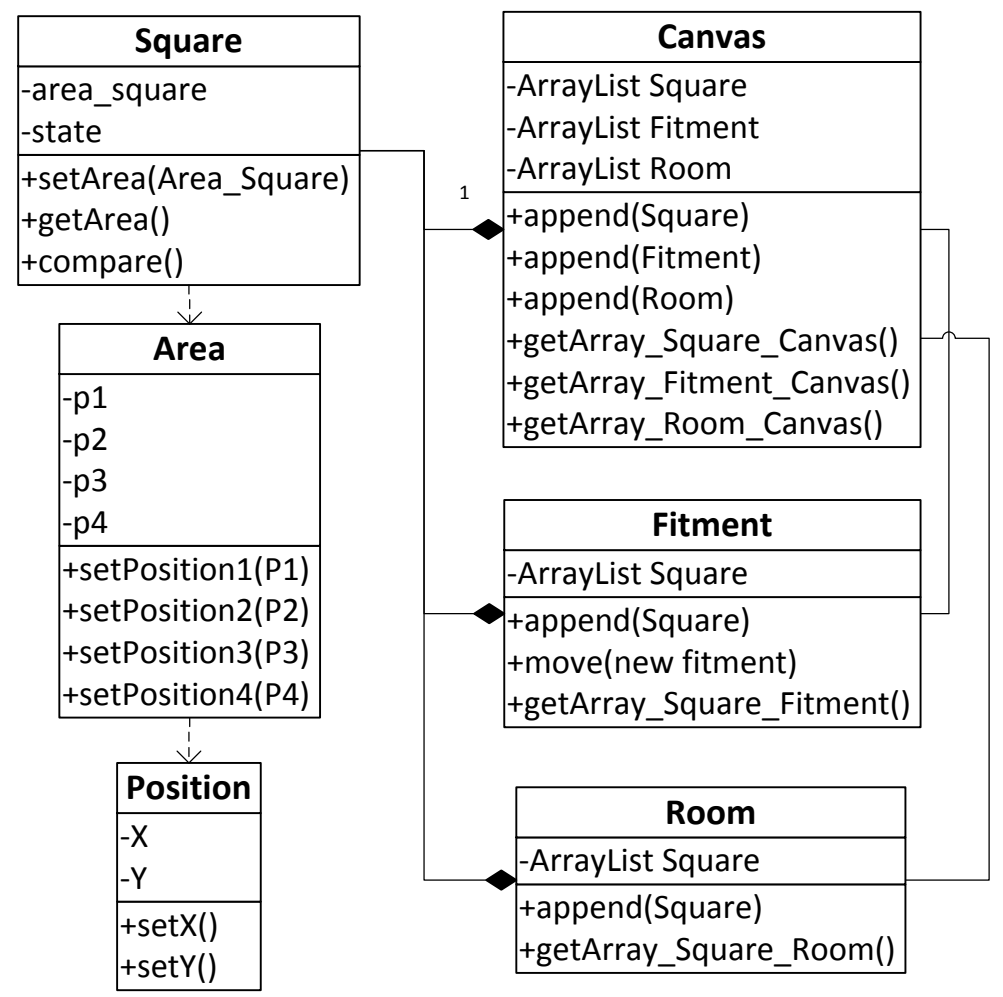

Figura 7-7: Diagrama del estudiante 3

Seguido de esto se preguntó, ¿Si él pensaba que aplicó esas reglas en su diseño?, la respuesta fue la siguiente: "Las tres primeras reglas están relacionadas con programación netamente y las entendí como proteger lo que tienes dentro una clase".

Analizando la Figura 7-7 se puede ver que el estudiante usa get y set en casi todas sus clases, pudiendo ser una manera de proteger sus datos. El enfoque del estudiante 
1 consiste en dividir en capas mientras que el estudiante 3 está centrado en ocultar, este último siendo el enfoque más comun cuando se habla del Principio de Ocultación de Información. El estudiante 3 no se esfuerza en aplicar algún criterio de división para ocultar.

Las ideas principales del estudiante 3 son:

- Proteger lo que está dentro de la clase es una forma de implementar el Principio de Ocultación de Información

\section{Estudiante 5}

El principio de Ocultación de Información fue entendido por el estudiante 5 como la separación explicita de la información en capas, como se puede ver Figure 7-8. Esto coincide con lo dicho por el estudiante en la entrevista: "Yo busqué en el Internet ejemplos de como se representa Information Hiding (...) y encontré que se puede representar con capas (...) En mi opinión, cada capa tiene información diferente y cuando esta [Información] se divide en capas, yo pienso que es ocultación de información".

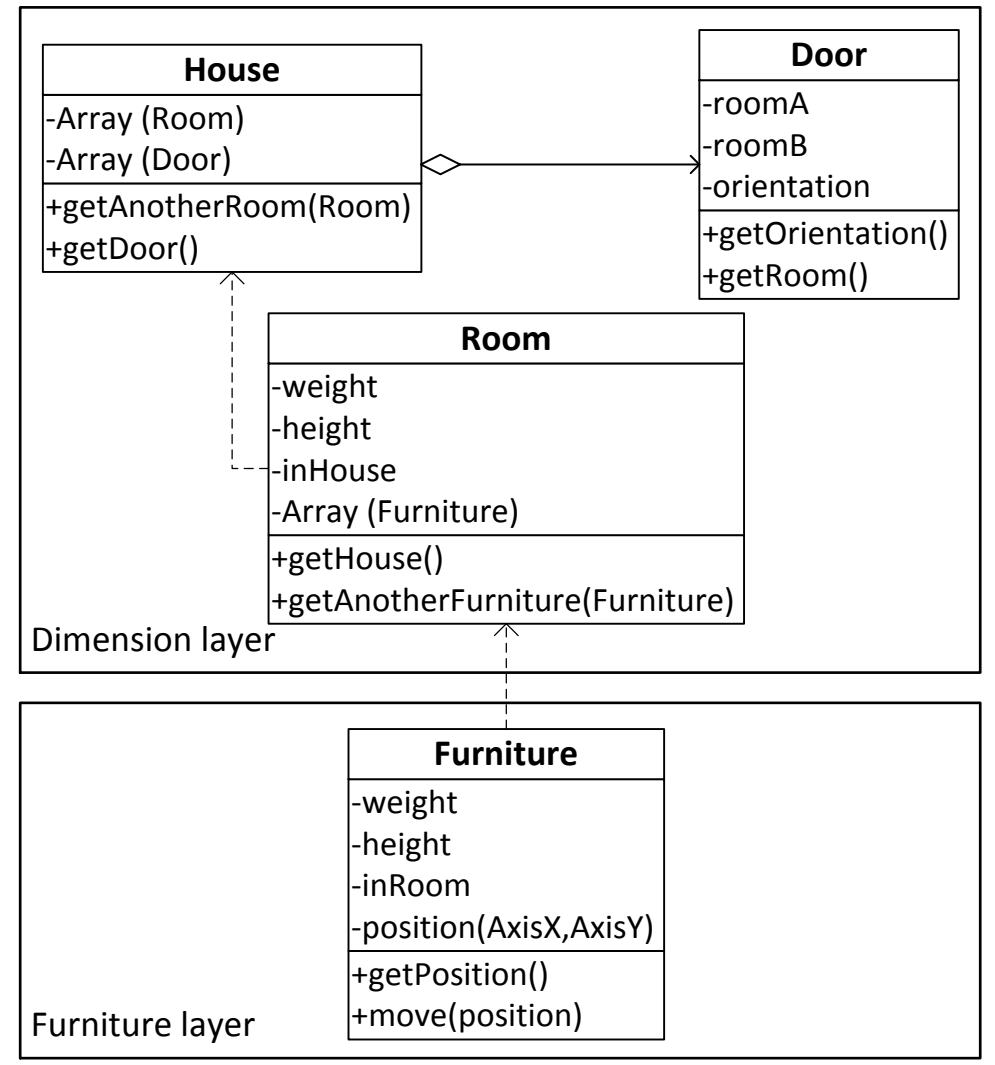

Figura 7-8: Diagrama del estudiante 5

Adicionalmente, en su ejercicio escrito el estudiante justifica la aplicación del Principio en su diseño de la siguiente manera: "The parameters of each entity are hidden; the only thing known by this design are the required operations that resolve successfully 
the given problem". "The Information Hiding Principle included within this design could reduce the software development risk when implementing changes. The reason is that there is no direct dependency between the entities. A programmer can manage one entity at a time because each entity has been decomposed within a layer".

Como se puede apreciar en la Figure 7-8, el estudiante separa en capas para agrupar los elementos que son datos (Dimension Layer), de los elementos que tienen comportamiento ( Furniture Layer).

Los diagramas del estudiante 1 y 5 son semejantes, en ambos se reconoce que el Principio es la separación (dominios o capas), coincidiendo en separar los datos del comportamiento. Es interesante que el concepto que subyace de separar en capas es el mismo pero la fuente de donde tomaron la idea es diferente. Ambos estudiantes provienen de diferentes nacionalidades, permitiendonos pensar que este enfoque está presente en varios lugares y curriculos.

Finalmente este estudiante concluye en la entrevista diciendo: "El paper me pareció un tanto abstracto"

Las ideas principales del estudiante 5 son:

- Una forma de implementar el Principio es:

- Separar los elementos en capas

- Separar los elementos que son datos de los elementos con comportamiento

- Esconder los parámetros de cada entidad

- Mostrar únicamente las operaciones que resuelven el problema

- El articulo de Parnas parece abstracto

\section{Estudiante 10}

El diagrama presentado por el estudiante corresponde a la Figure 7-9. El estudiante explica de manera textual su entendimiento alrededor del Principio de Ocultación: "The core of this principle is the idea that the code can become more flexible and more reliable if it is decomposed into different tasks or related operations that can operate cohesively and independently of the rest of the code in terms of full details. This can provide a simpler handle or interface when needed elsewhere".

El estudiante añade en su ejercicio escrito: "Through applying the concept of Information Hiding, parties can, essentially for interfaces or contracts, determine how behaviour between modules should be. Ensuring that the interface does not itself require any unnecessary complexity. By removing complexity from interfaces, this principle also allows fewer changes when aspects of the interface change".

En descripción escrita, es importante mencionar que el estudiante describe un módulo llamado Input, semejante al mencionado por Parnas en su artículo, de la siguiente manera: "Input: The fundamental layer between the application and whatever input may be fed to it, either through other software modules, through a file, or through user input. The purpose of Input is to gather this information and transform it into arrays of Rooms and Furniture, which the rest of the application will use. This allows the rest of the application to function without regard to the source of the input". 


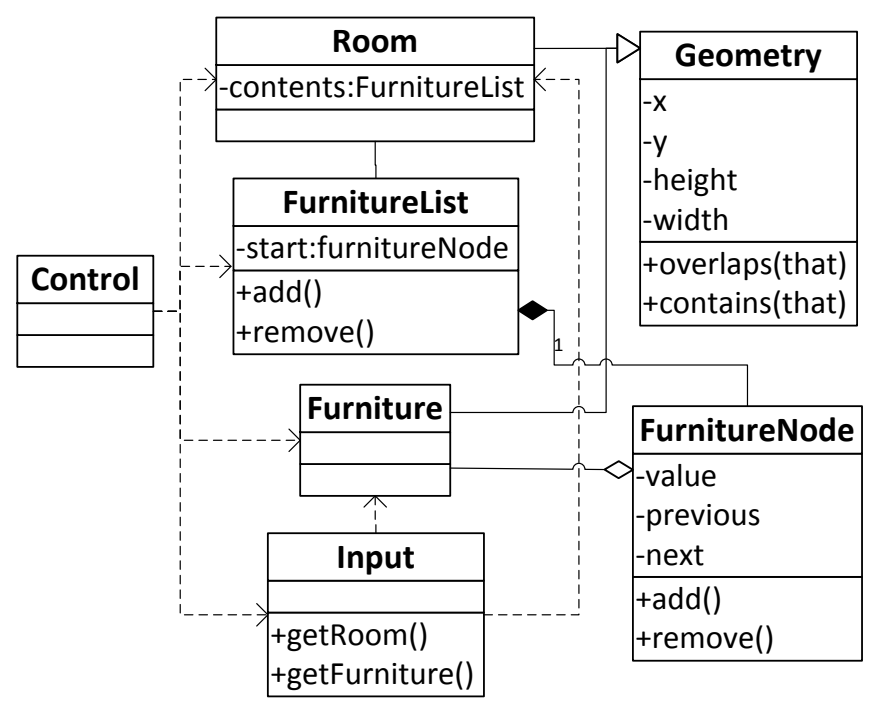

Figura 7-9: Diagrama del estudiante 10

Las ideas principales del estudiante 10 son:

- Implementar el Principio de Ocultación de Información hace el código más flexible y más confiable

- Si el código es descompuesto en tareas y operaciones, es más fácil que se pueda operar más cohesivamente e independientemente del resto del código

- Definir interfaces no complejas para determinar el comportamiento entre módulos

- Trasladar ciertos módulos definidos en el artículo de Parnas es una manera de implementar el Principio

\section{Estudiante 12}

El estudiante 12 no expresa de manera explícita la aplicación del Principio en su ejercicio escrito, sin embargo en su diagrama, mostrado en la Figure 7-10, coloca cada elemento con un comportamiento propio.

Como podemos ver, en el elemento Furniture, este tiene un método mover (), y el elemento Control es el encargado de revisar el movimiento, pero al ver la descripción escrita, se puede apreciar que Control es el encargado de más de una tarea: "When the user wants to move a furniture, the move function of Furniture class is called passing the target $x$ and $y$ position. This function calls checkMove() of Control class with the target $x$ and $y$ and the id of the furniture (...) checkMove() ensures the total size of the furniture is inside the area (...) Also, checkMove() makes sure the furniture is not overlapped with others (...) If everything is ok, checkMove() removes the furniture".

Las ideas principales del estudiante 12 son:

- Definir elementos a través de getters y setters que interactuan con un único elemento que es sobrecargado de responsabilidades, es una forma de implementar el Principio 


\begin{tabular}{|l|}
\hline \multicolumn{1}{|c|}{ Area } \\
\hline -id \\
-height \\
-width \\
$-x$ \\
$-y$ \\
-List of Furniture \\
\hline +getX() \\
+getY() \\
+getHeight() \\
+getWidht() \\
+getFurniture:List of Furniture \\
+addFurniture(furnitureld) \\
+removeFurniture(furnitureld) \\
\hline
\end{tabular}

\begin{tabular}{|l|}
\hline \multicolumn{1}{|l|}{ Furniture } \\
\hline -id \\
-height \\
-width \\
-x \\
-y \\
\hline +move $(x, y)$ \\
+ +getX() \\
+ +getY() \\
+setX(x) \\
+setY(y) \\
+getHeight() \\
+getWidth() \\
\hline
\end{tabular}

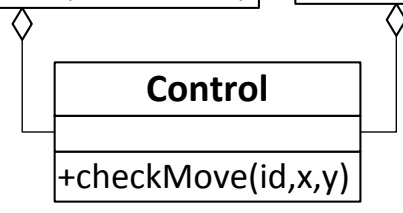

Figura 7-10: Diagrama del estudiante 12

\section{Estudiante 13}

El Principio de Ocultación de la Información fue explicado en la entrevista por el estudiante 13 de la siguiente manera: "I wanted to hide the representation of the object that was going to be moved (...) I think polymorphism is a kind of Information Hiding". Su diagrama relacionado se muestra en Figure 7-11.

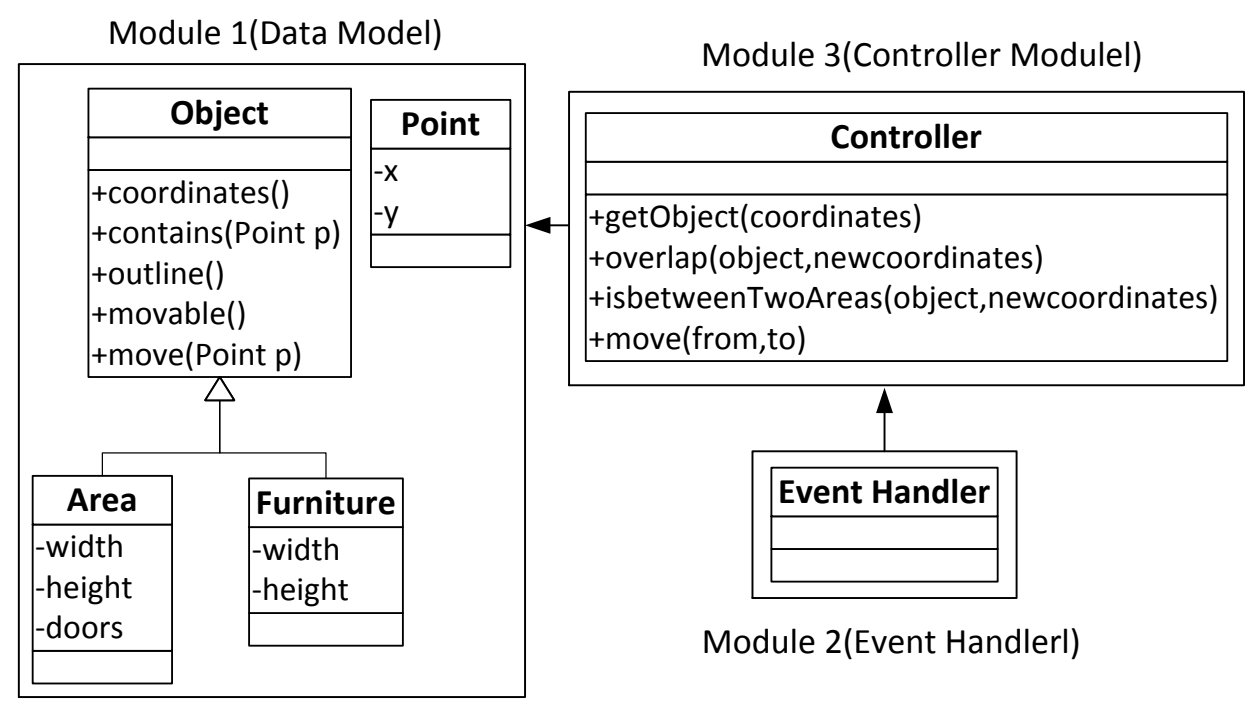

Figura 7-11: Diagrama del estudiante 13

El estudiante menciona la idea de esconder, pero en su diagrama el estudiante no expresa dicha ocultación. La herencia mostrada en la Figure 7-11 con el elemento 
Object, no tiene la estructura polimórfica, al menos eso se ve a nivel de nomenclatura, ya que los métodos del elemento Object no están en los elementos hijos Area y Furniture. Esto quiere decir que todos esos elementos tienen el mismo método con el mismo comportamiento.

Adicionalmente, se pudo observar que Area y Furniture tienen diferentes atributos, lo cual indica que ellos no deberían tener el mismo método, lo cual es una inconsistencia. Con esto, el estudiante sugiere una deficiencia en el manejo de objetos.

Las ideas principales del estudiante 13 son:

- Polimorfismo es una manera de aplicar el Principio de Ocultación

- Insuficiente conocimiento de objetos

\subsubsection{Nivel de aproximación: Insuficiente}

En este nivel, se encuentran los estudiantes 6, 7 y 11 cuyos análisis son mostrados a continuación. Este nivel está conformado por el grupo de estudiantes quienes hicieron diseños con el enfoque del Principio de Ocultación de Información, pero ellos no lograron aplicarlo de manera consistente.

\section{Estudiante 6}

El estudiante 6 explica el Principio de Ocultación de Información en su ejercicio escrito de la siguiente manera: "The decisions taken until now seek to have weak dependencies and not share the internal states between different classes".

Cuando se le preguntó en la entrevista, ¿Cómo aplicó el Principio de Ocultación en su diseño?, la respuesta fue la siguiente : "I focused mainly in the fact that Map is a matrix and only Map knows it. Furniture has attributes x, y, width and height and only Furniture knows it. But then, I realized that when I do authorize() these variables must be shared, which means that at the end I am not hiding, instead, I am sharing them. I did not know how to avoid displaying them, maybe because of the type of design I did."

Lo dicho por el estudiante tiene concordancia con el diagrama expuesto en la in Figure 7-12, Su idea del Principio la enuncia en dos partes: a)dependencia débil entre clases; b) no compartir estados internos. La primera es la idea principal del Principio y el estudiante lo asocia con que "el otro no sepa", expresando esta idea a través de la herencia, en particular con el polimorfismo, tal como se puede ver en la Figure 7-12 con el elemento ObjectInterface. La segunda es una consecuencia de la primera, pero el estudiante no es consciente de eso.

El estudiante también explica en la entrevista, sus ideas relacionadas a la abstracción y polimorfismo. "I understood, for applying the Information Hiding Principle, basically, that under ObjectInterface the elements are unknown, they could be Map or Furniture, any element with the method authorize(), I did not care which was the method. I understood as polymorphism, abstracting all the elements involved in the system. From ObjectInterface, I did not care which element I have to authorize, it can be a Map or it can be a Furniture." 


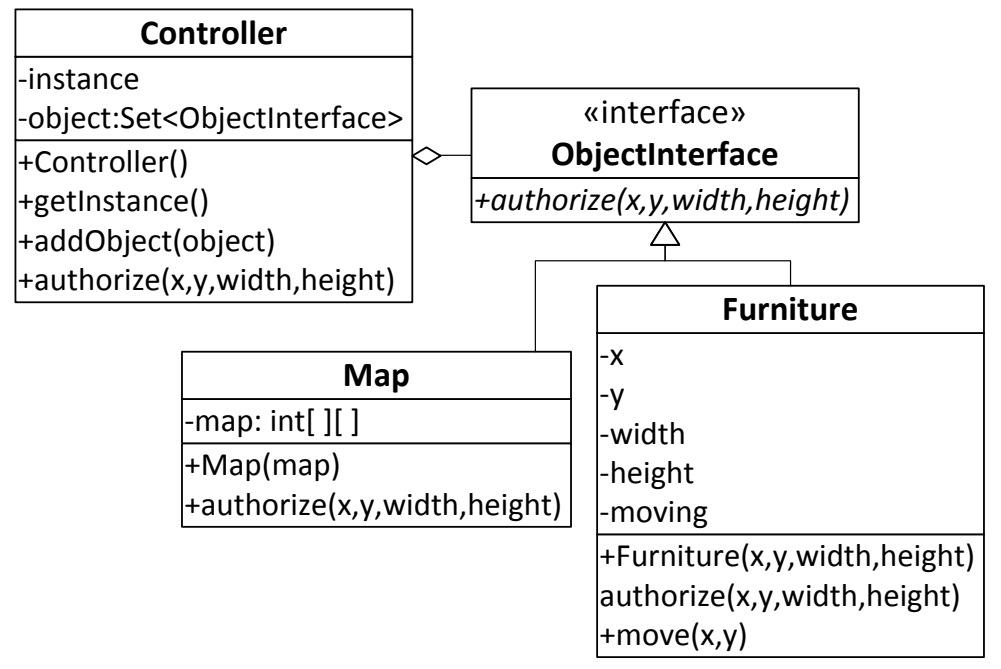

Figura 7-12: Diagrama del estudiante 6

La entrevista con el estudiante finaliza con esta sentencia: "The Information $\mathrm{H} i$ ding Principle is difficult to understand, I do not know how to apply it".

Las ideas principales del estudiante 6 son:

- Una forma de aplicar el Principio es:

- Tener dependencias débiles

- No compartir estados internos de las clases

- Existencia de ideas confusas relacionadas a la abstracción/polimorfismo/herencia y el Principio de Ocultación

- El Principio de Ocultación es dificil de entender y de aplicar

\section{Estudiante 7}

El Principio de Ocultación de la Información fue explicado en su ejercicio escrito por el estudiante 7 de la siguiente manera: "Hiding Information is about not leaking nor sharing internal details, representations between modules. With proper information hiding, modules can be substituted by other modules which satisfy the same contract without changes to modules which depend on them. In practice, that means that one should not retrieve internal information from another module and then act upon it but instead tell the other module to do something".

Lo primero que se resalta es el hecho de no compartir detalles internos. Adicionalmente, el estudiante rescata la idea de que un módulo no debería pedir información interna de otro módulo, si no decirle al otro módulo lo que debe hacer. Con esta forma de proceder, nos está diciendo que presinde de los get y set, lo cual se puede ver en la Figure 7-13.

Además, el estudiante escribe en su ejercicio: "Keeping in mind Information Hiding Principle, one should start with the list of design decisions that are likely to change. In this case things that are likely to change are the following: shape of the furniture, for example circular shaped furniture; shape of areas, for example areas can 


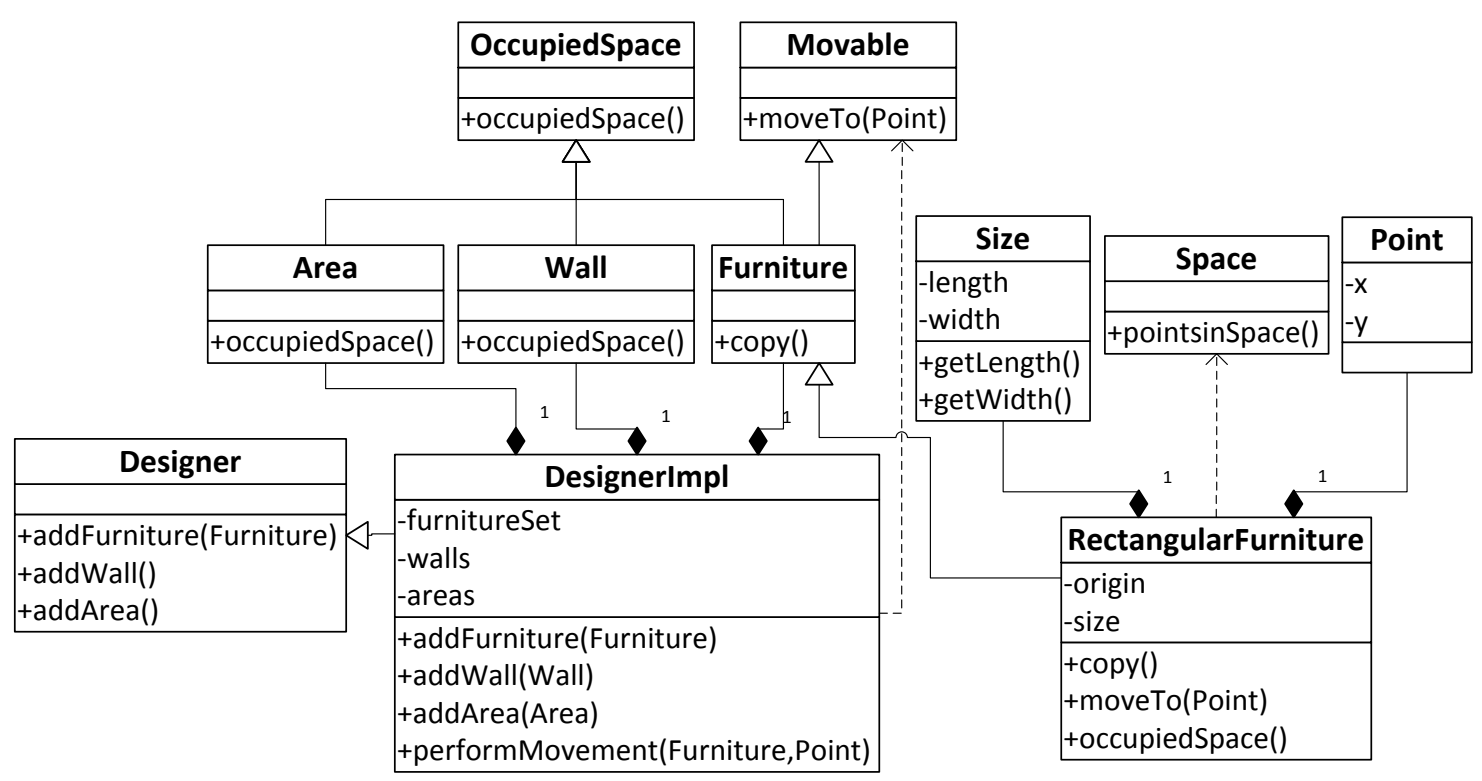

Figura 7-13: Diagrama del estudiante 7

have round corners. The design of the application should be indifferent in terms of furniture's shape as well as area's shape".

Como podemos ver en la Figure 7-13, el estudiante implementa una de las dos decisiones de diseño que el menciona previamente: shape of the furniture; y continúa con el razonamiento escrito sobre la implementación del Principio de la siguiente manera: "However different kinds of furniture can store that information in different way. Rectangular furniture, like table, requires just to have some origin point, width and length to define the space that it occupies. That means that we need some common notion of space which will be consistent across all objects. In this way, we can hide information about placement in the space for each kind of furniture". El estudiante usa la herencia para mostrar esto de una manera practica.

Además el estudiante define poliformismo con el elemento OccupiedSpace, el cual es el encargado del contrato. El polimorfismo definido en este caso es con respecto al método ocuppiedspace(), pero no con el método copy() del elemento Furniture. El estudiante introduce heteregoneidad separando OccupiedSpace y Movable. En cierto sentido, hay una solicitud de información ya que el elemento Movable debería ser identificado. Por otro lado, el elemento DesignerImpl tiene el mismo concepto de heteregeneoidad, al manejar el conjunto de elementos por separado.

La idea de particularizar también está presente con los elementos Size, Space, and Point que están relacionados directamente a RectangularFurniture como se puede ver en la Figure 7-13. De manera textual el estudiante menciona que considera la idea futura de un elemento CircularFurniture, en ese caso los elementos Size, Space and Point deberían estar relacionados a este nuevo elemento; si estos elementos son atributos propios de un concepto entonces deberían pertenecer a OccupiedSpace, para que cualquier nuevo elemento los pueda heredar. 
El estudiante 7 tiene una idea clara del Principio pero cuando lo lleva a la práctica prioriza su percepción de la realidad sobre la del Principio. El estudiante tienen uno de los pensamientos más acertados sobre el Principio entre los otros estudiantes, pero falla al momento de aplicarlo.

Las ideas principales del estudiante 7 son:

- Una forma de aplicar el Principio es:

- No filtrar ni compartir los detalles internos entre módulos

- No solicitar información interna de otros módulos, por el contrario delegar acciones sin el uso de getters y setters

- Sustuir un módulo por otro manteniendo el contrato a través de la herencia es una consecuencia del Principio de Ocultación

- Hacer una lista de las decisiones de diseño que son probables de cambio es parte de aplicar el Principio de Ocultación

- Prioriza la percecpión de la realidad antes que el Principio de Ocultación

\section{Estudiante 11}

Como se puede ver en la Figure 7-14, el estudiante coloca los elementos de manera que sean casi independientes, haciendo una buena distribución de la información a través del uso de objetos, dándole a cada elemento un comportamiento propio. El estudiante menciona la ocultación de los detalles internos de la clase a través de getters y setters, lo cual no va de la mano del Principio.

\begin{tabular}{|c|c|c|}
\hline Map & Furniture & Floor \\
\hline -height & \multirow{6}{*}{\begin{tabular}{|l|}
-id \\
$-x$ \\
$-y$ \\
-height \\
-widht \\
-color \\
\end{tabular}} & \multirow{6}{*}{\begin{tabular}{|l|}
-id \\
$-x$ \\
$-y$ \\
-height \\
-width \\
-color \\
\end{tabular}} \\
\hline -width & & \\
\hline -color & & \\
\hline +resize(height,width) & & \\
\hline +changeColor(color) & & \\
\hline +getHeight() & & \\
\hline +getWidth() & \multirow{10}{*}{$\begin{array}{l}\text { +resize(height, width) } \\
\text { +changeColor(color) } \\
\text { +move(x,y) } \\
\text { +rotateRight() } \\
\text { +rotateLeft() } \\
\text { +getHeight() } \\
\text { +getWidth() } \\
\text { +getColor() } \\
+ \text { getX() } \\
+\operatorname{get} Y()\end{array}$} & \multirow{10}{*}{$\begin{array}{l}\text { +resize(height, width) } \\
\text { +changeColor(color) } \\
\text { +move(x,y) } \\
\text { +rotateRight() } \\
\text { +rotateLeft() } \\
\text { +getHeight() } \\
\text { +getWidth() } \\
\text { +getColor() } \\
\text { +getX() } \\
\text { +getY() }\end{array}$} \\
\hline +getColor() & & \\
\hline \multirow[t]{13}{*}{\rangle} & & \\
\hline & & \\
\hline & & \\
\hline & & \\
\hline & & \\
\hline & & \\
\hline & & \\
\hline & & \\
\hline & 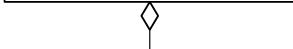 & \multirow[t]{5}{*}{\rangle} \\
\hline & Master Control & \\
\hline & +authorizeMove() & \\
\hline & +authorizeResize() & \\
\hline & +getAllElements() & \\
\hline
\end{tabular}

Figura 7-14: Diagrama del estudiante 11 
El estudiante 11 explica el Principio de Ocultación de Información en su ejercicio escrito, de la siguiente manera: "Finally, designing the application in this way, makes the possibility of adding new elements without modifying the inner behaviour of the existing elements. Furthermore, the elements are independent and only need to interact with MasterControl class through the public methods simplifying in this way the communication. Lastly, each class hides the internal details facilitating the use and understanding with getters and setters".

Las ideas principales del estudiante 11 son:

- Una forma de aplicar el Principio es:

- Definir elementos independientes con su propio comportamiento

- Esconder los detalles internos de cada clase a través de getters y setters

- Añadir nuevos elementos sin cambiar el comportamiento interno de los elementos existentes es una consecuencia de implementar el Principio

\subsection{Resumen}

Las preguntas de investigación formuladas para este estudio de caso fueron respondidas. El estudio ha revelado que cuatro estudiantes ignoraron o malentendieron el Principio; solo tres lo aplicaron, pero con deficiencias. Este resultado nos indica que las dificultades mencionadas por Parnas se mantienen. Además se ha encontrado respecto a la primera pregunta de investigación: ¿Qué entienden y cómo implementan el Principio de Ocultación de Información? dos tipos de interpretaciones: a) la ocultación de información consiste en ocultar el interior de los módulos; b) la división produce ocultación de información, cada uno de estos resultados con diferentes vertientes de interpretación.

Respecto a la segunda pregunta ¿Cuáles son las posibles causas del entendimiento e implementación del Principio de Ocultación? se pudieron identificar varias posibles causas. El pensamiento arraigado a los criterios convencionales de división en términos de funciones que transforman datos y predominio del criterio de copiar la realidad sobre los criterios del Principio son causas que también están reflejadas en las dificultades referidas por Parnas: "Flow Chart Instict" y "Reflecting the system environment in the software structure". Como otra causa está la ausencia de una visión holística de las reglas del Principio. En la base de todas, está, que el enfoque del Principio es radicalmente distinto al paradigma instaurado en los fundamentos de la Ingeniería de Software.

Una consecuencia de los problemas en el entendimiento del Principio de Ocultación se centra en el impacto profesional, ya que la inmensa mayoría de los diseños analizados ofrecen una modularización de baja eficiencia para el desarrollo de software y provienen de graduados universitarios en informática. Estudiar y conocer las ideas de diseño de software que surgen a lo largo del período de instrucción, más allá de las relacionadas al Principio, forma parte del siguiente estudio. 



\section{Capítulo 8}

\section{Estudio longitudinal de las dificultades de aprendizaje y su nivel de persistencia}

En este capítulo se describe el estudio desarrollado a lo largo del período de instrucción. Primero, se definen los objetivos del estudio, seguido de las preguntas de investigación. Seguidamente, se hacen explícitas las actividades realizadas en el período de instrucción y luego el proceso de análisis de los datos. Después, se muestran los criterios de clasificación para la obtención de los resultados. Finalmente, se muestra un resumen.

\subsection{Objetivo}

El estudio tuvo como objetivo conocer las dificultades con las que se enfrentan los estudiantes al momento de diseñar y además, definir su persistencia a lo largo del período de instrucción. El período de instrucción estuvo comprendido desde el inicio del período de instrucción hasta finalizado el mismo. Aquí se incluyó el análisis realizado en el Estudio Inicial sobre el entendimiento del Principio de Ocultación de Información que fue presentado en el Capítulo 1

El término "dificultades" definido para este trabajo, se refiere a aquellas ideas que van contra o que impiden conseguir la línea de diseño de software con las características de facilidad de distribución de trabajo de desarrollo, modificabilidad y comprensibilidad, que ha sido tomado como referencia para esta tesis. En el estudio, también se recogieron algunas ideas que sin ser consideradas dificultades resaltaban por su relevancia y que fueron incluídas como parte del rigor metodológico.

\subsection{Preguntas de investigación}

El estudio longitudinal fue conducido por la siguiente pregunta de investigación: 
- ¿Qué dificultades de diseño de software tienen los estudiantes y cuál es su nivel de persistencia a lo largo del período de instrucción?

\subsection{Período longitudinal de instrucción}

El estudio de caso longitudinal constó de una serie de etapas, todas realizadas en coordinación con el profesor y el investigador. Las etapas y el proceso realizado se muestran en la Figura 8-1.

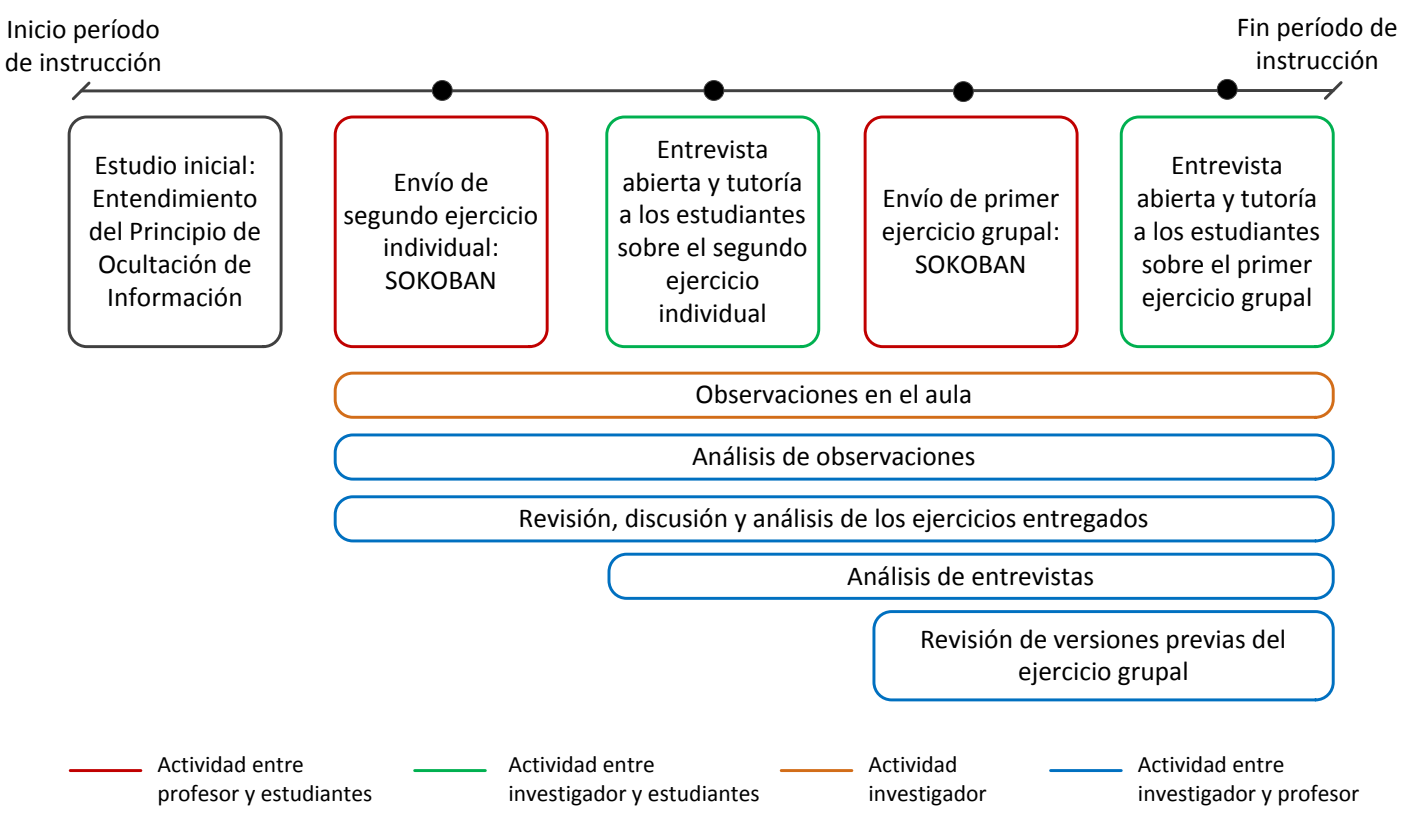

Figura 8-1: Períiodo longitudinal de instrucción

\subsection{Análisis de datos del estudio longitudinal}

Con los datos recogidos para este estudio longitudinal, se siguió el proceso definido en la Sección 5. Las etapas del proceso de análisis de datos fueron: Recolección de datos, Codificación, Refinamiento y Agrupación.

\subsubsection{Creación de tipos de códigos}

Obtenidos todos los códigos ajustados de cada estudiante, se observó la existencia de códigos cuya idea principal se repetía, por lo que los códigos repetidos se agruparon en Tipos. En total cuarenta y ocho tipos de códigos fueron extraídos del análisis. 
Un ejemplo de esta agrupación es ilustrada en la Figura 8-2, donde se puede ver el Tipo11 correspondiente a "Sobrecarga cohesiva de responsabilidades en un elemento", donde el mismo código fue generado por el estudiante 1 en el primer ejercicio individual (verde), por el estudiante 2 en el segundo ejercicio individual (morado), por el grupo conformado por los estudiante 6-11-12 en la versión previa del ejercicio grupal (naranja) y por los dos grupos conformados por los estudiante 6-11-12 y 4-10 en la entrega final del ejercicio de grupo (rojo).

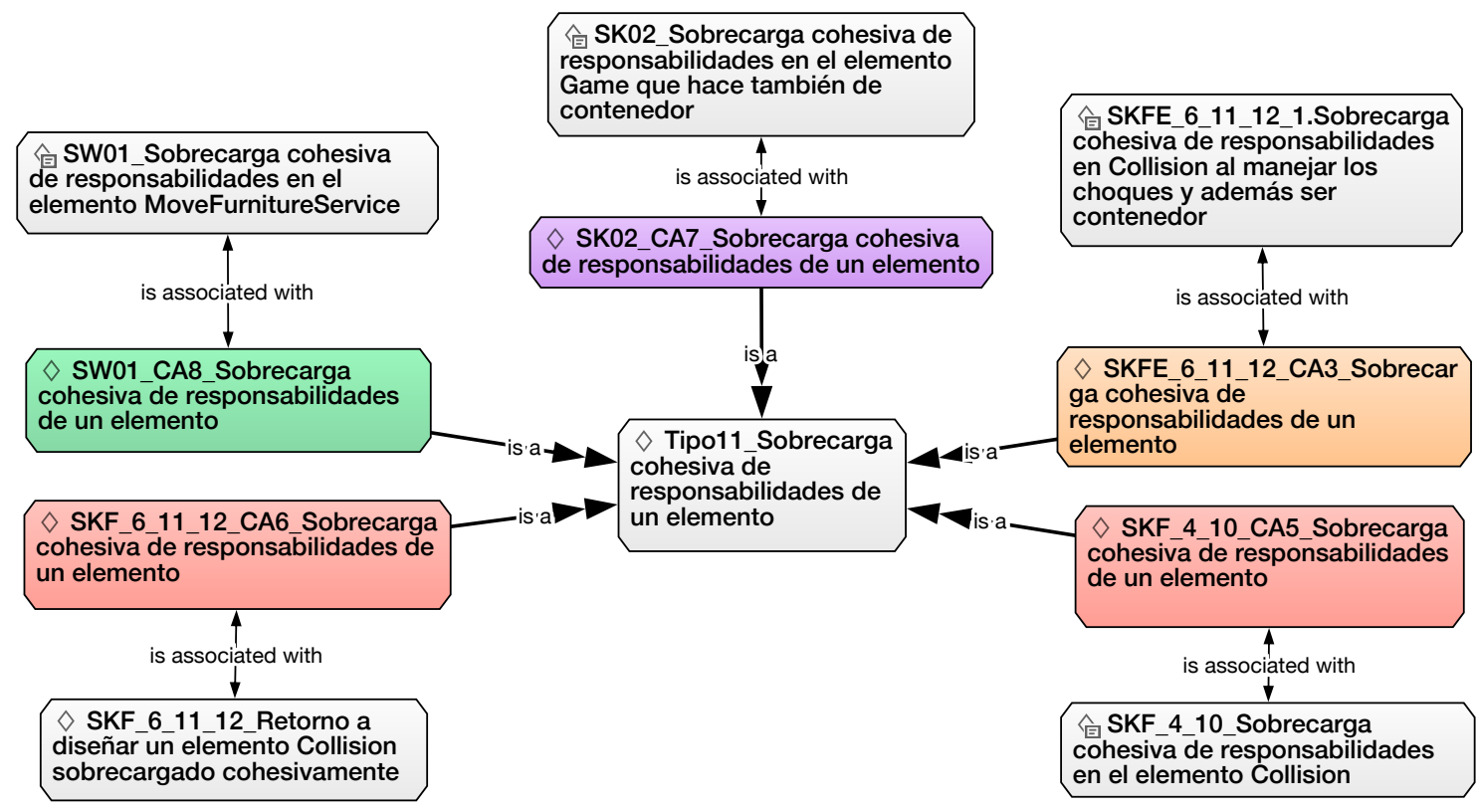

Figura 8-2: Agrupación de códigos por tipo

Esta tipología, ayudó a evitar códigos duplicados en el análisis y permitió sintetizar a cada ejercicio y cada código para todos los estudiantes en una misma línea de tiempo. La definición de cada tipo de código obtenido de este proceso se puede apreciar en el Diccionario de Tipos de Código en el Apéndice H. Este proceso de triangulación por estudiante y por código permitió cumplir con los criterios de calidad definidos por 64] alrededor de la confiabilidad de una investigación. La triangulación fue realizada en varias iteraciones con la validación de estudiantes y códigos como se muestra a continuación:

1. Extracción de estudiantes por tipos de códigos

Luego de un análisis sistemático y varias iteraciones de los documentos de los estudiantes (documentos de texto, diagramas, entrevistas, observaciones), se extrajeron los códigos generados a lo largo de todo el proceso para cada ejercicio en particular, como se muestra en la Figura 8-3. La matriz generada de los tipos de códigos por estudiante se encuentran en el Apéndice I. 


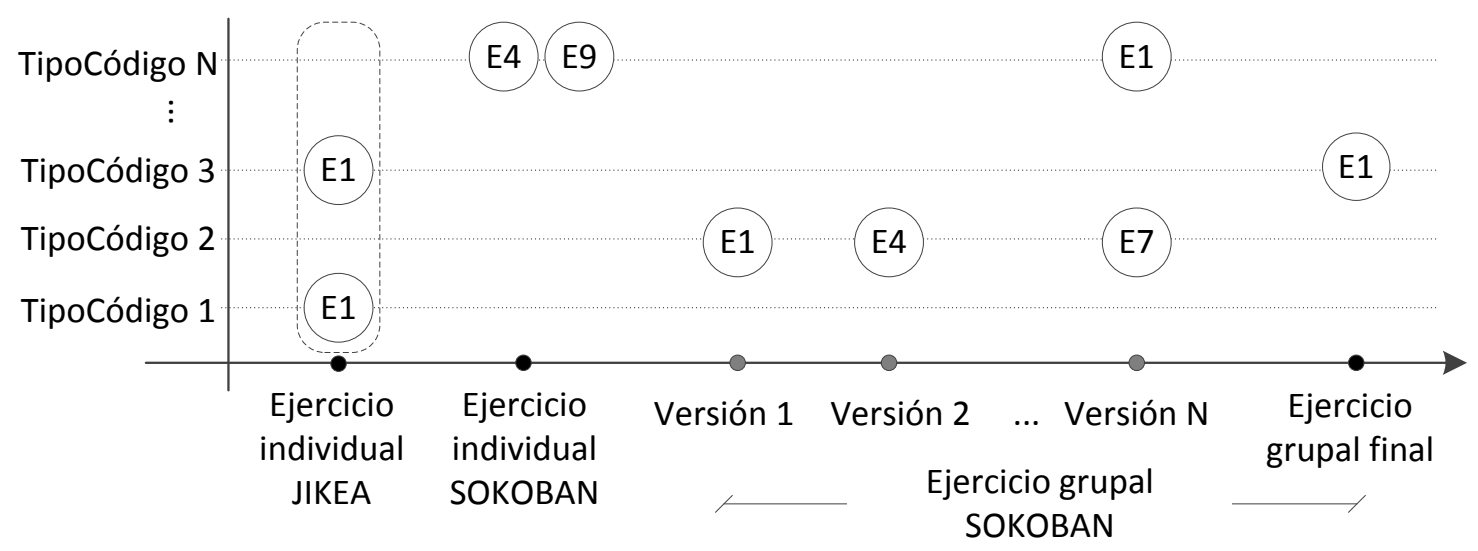

Figura 8-3: Ejemplo de estudiantes por tipos de códigos; (E=Estudiante)

2. Verificación de tipos de código por estudiantes

Subsecuentemente, los códigos generados en el paso previo fueron colocados sobre cada estudiante. Figura 8-4 permitió analizar la evolución de los los tipos de códigos por cada estudiante a lo largo del período académico. La matriz generada de los estudiantes por cada tipo de código se encuentran en el Apéndice J.

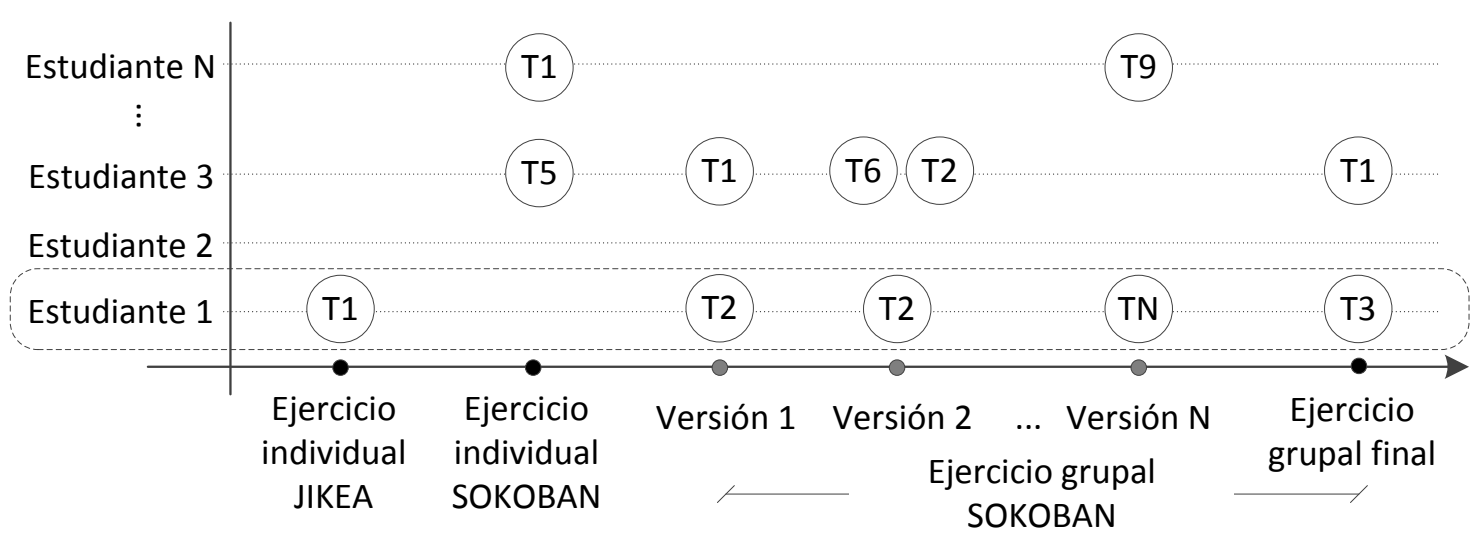

Figura 8-4: Ejemplo de tipos de código por estudiantes; ( $\mathrm{T}=$ Tipo de código)

\subsection{Niveles de persistencia}

Los resultados obtenidos del análisis del proceso de investigación del estudio longitudinal han sido clasificados en cuatro categorías de persistencia: baja, media, alta y potencialmente persistentes. El análisis se centra principalmente en las ideas de alta persitencia debido a su relevancia en el estudio. 


\subsubsection{Dificultades con persistencia baja}

Persistencia baja recoge aquellas dificultades que aparecieron al inicio del período de instrucción, pero que posteriormente han desaparecido. Al estar presentas en algún momento de la línea del tiempo, pudiera ser una señal de que existían antes de iniciada la instrucción. Dentro de esta categoría se han encontrado las siguientes:

- Separación en capas para ocultar información

- Diseño de un elemento que hace de programa principal (Main)

- Identificación de funciones principales y posterior distribución en módulos (Al estilo de Object Modeling Technique [96])

- Separación de cada concepto en dos elementos, uno de datos y otro de funciones, para manejar la persistencia

- Separación de los elementos del sistema en aquellos que son datos de los que tienen comportamiento

- Definición de clases como datos

- Herencia usada como taxonomía

- Herencia usada para reusar código

- Separación de elementos que son similares en software pero que son interpretados como diferentes

- Definición en una herencia de métodos con el mismo nombre pero cuya implementación es impredecible

- Definición de un concepto a través de propiedades que no están relacionadas al concepto

(Ejemplo: Definición de un concepto ObjectInterface a través del único método authorize())

- Principio de Ocultación considerado como no solicitar información o no compartir detalles internos de las clases

- Diseño de un concepto a través de propiedades heredadas

(Ejemplo: Definición de un concepto Furniture con las propiedades heredades de un concepto OccupiedSpace y Movable)

- Elaboración de un modelo entidad-relación

- Definición de una estructura tipo flujo de datos (input-algoritmo-output)

- Uso de get() y set() para esconder los detalles internos de la clase es aplicar el Principio de Ocultación

- Representación del número exacto de elementos que se ven en la aplicación en el diseño

- Notación equivocada o incompatible con el diagrama de clases

En total se encontraron 18 ideas que cumplen con los criterios de persistencia baja, pero 17 fueron consideradas como dificultades, debido a obstaculizar la línea de diseño establecida en esta tesis. La idea que no fue estudiada como dificultad fue "Notación equivocada o incompatible con el diagrama de clases", ya que los problemas con la notación parecieran no estar involucrados con los fundamentos del diseño de software. 


\subsubsection{Dificultades con persistencia media}

Persistencia media recoge aquellas dificultades que aparecen esporádicamente en varios ejercicios a lo largo del período académico, exepto en la versión final del ejecicio grupal. Dentro de esta categoría se han encontrado las siguientes:

- Diseño de un elemento con alto nivel de control

- Definición de un identificador (ID) como atributo de cada elemento

- Diseño de un hijo que hereda un método que no usa

- Descomposición por propiedades

- Descomposición simultánea por conceptos y por propiedades

(Ejemplo: Definición de un concepto Figura como padre y un hijo Movable que representa una propiedad de las figuras)

- Ausencia del concepto Juego o insuficiencia al definirlo en una aplicación de juego

- Ausencia de un elemento que haga de contenedor o insuficiencia al definirlo

- Particularización de un método para los posibles combinaciones (Ejemplo: moveUp(), moveDown(), moveLeft(), moveRight())

- Particularización de las listas (Ejemplo: listBox, listWall, listPlayer)

- Herencia usada para polimorfismo

- Herencia usada para heredar atributos

- Establecer inicialmente una lista de decisiones de diseño para la implementación del Principio de Ocultación de la Información

En total se encontraron 12 ideas que cumplen con los criterios de persistencia media, pero 11 fueron consideradas como dificultades, debido a obstaculizar la línea de diseño establecida en esta tesis. La idea que no fue estudiada como dificultad fue "Herencia usada para polimorfismo", ya que la principal característica de este mecanismo es su capacidad polimórfica, siendo este uso, favorable a la línea de diseño.

\subsubsection{Dificultades con persistencia alta}

Persistencia alta recoge aquellas dificultades que cumplen con los siguientes criterios: a) aparecieron recurrentemente, es decir han desaparecido y reaparecido en la línea del tiempo y; b) aparecieron al final de la línea del tiempo, es decir que podrían estar presentes durante todo el proceso, pero no se manifestaron anteriormente. Dentro de esta categoría, se mencionan las siguientes:

- Sobrecarga cohesiva de responsabilidaes en un elemento

Se usa el término cohesivo cuando se trata de responsabilidades relacionadas entre sí. Figure 8-5 describe un caso interesante donde los estudiantes intentan distribuir la tarea, pero finalmente retoman la idea de sobrecargala. Este es un claro ejemplo del arraigo de esta idea. Figure 8-5 muestra las diferentes versiones del diseño realizado en grupo del ejercicio de Sokoban. 
En la versión 1, existe un elemento Collision que es contenedor y que es encargado de manejar las colisiones mediante el método collide (). En la Iteración 2, Map es contenedor y collide() mantiene el manejo de las colisiones. En la versión 3, los estudiantes dan un salto positivo, añadiendo un método canOverlap(), el cual es el responsable de autorizar el movimiento, evitando dependencias con cada elemento. Finalmente en la Iteración 4, el diseño se mantiene igual que en la versión 3, pero las responsabilidades de cada método vuelven a ser igual que en la versión 2.

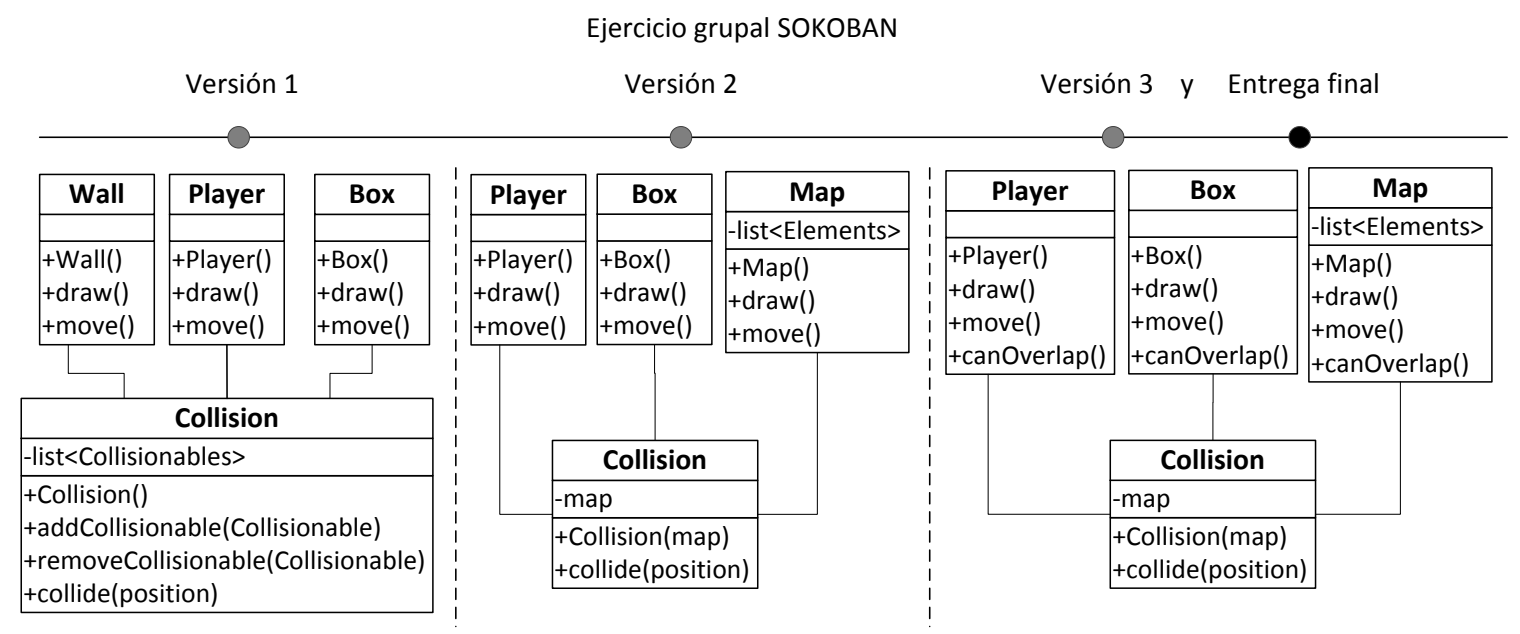

Figura 8-5: Sobrecarga cohesiva de responsabilidades en un elemento

- Sobrecarga no cohesiva de responsabilidades en un elemento

Se usa el término no cohesivo cuando se tratan de responsabilidades inconexas entre sí. Un caso interesante de esta idea, es la evolución de un estudiante en la línea del tiempo, la cual se muestra en la Figure 8-6.

En la parte izquierda de la figura, se encuentra un elemento Game, encargado de tres aspectos (inicializar el Board, ganancia del juego y escuchar el movimiento) para el ejercicio individual del SOKOBAN. En la versión 2 del mismo ejercicio, pero grupal, los estudiantes muestran tres elementos, cada uno encargado de las responsabilidades mencionadas anteriormente. En la entrega final del trabajo en grupo, los estudiantes vuelven a fusionar los elementos en uno solo, con un uso confuso de la herencia. Los estudiantes justifican la sobrecarga no cohesiva de la versión final, de la siguiente manera:"

"Fusioning of Controller and GameRules classes was done because Controller and GameRules finally had the same behavior" 


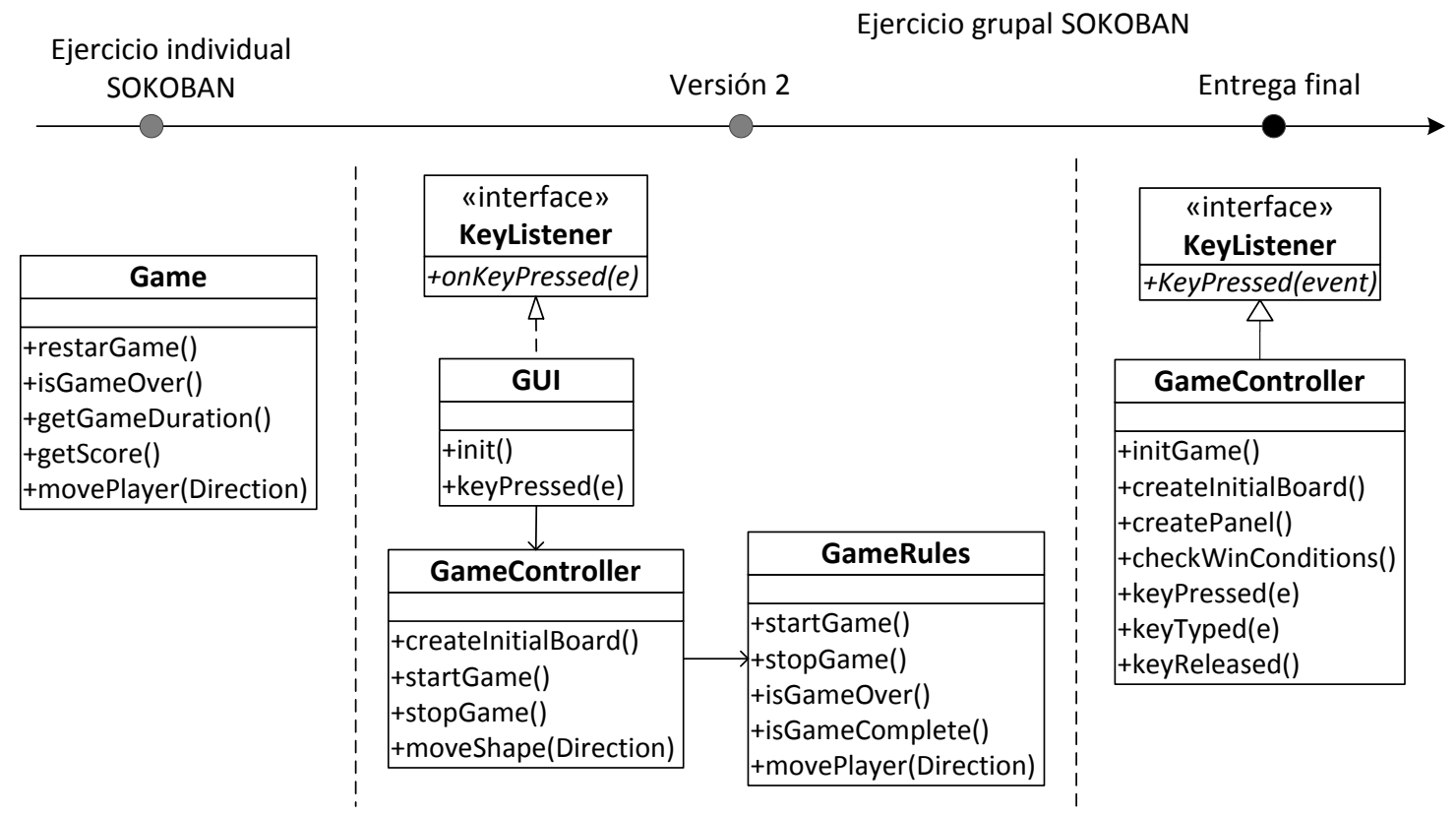

Figura 8-6: Sobrecarga no cohesiva de responsabilidades en un elemento

- Preferencia a heredar una propiedad en lugar de delegar

Para ilustrar este ejemplo, haremos uso de la Figure 8-7. Como se puede ver en la parte izquierda de la figura, los estudiantes definen un elemento llamado Collisionable, el cual es delegado por los elementos que lo usan. En la parte derecha de la figura, el mismo estudiante en su versión final cambia la propiedad Collisionable que antes era delegada a ser un elemento que hereda.

Ejercicio grupal SOKOBAN

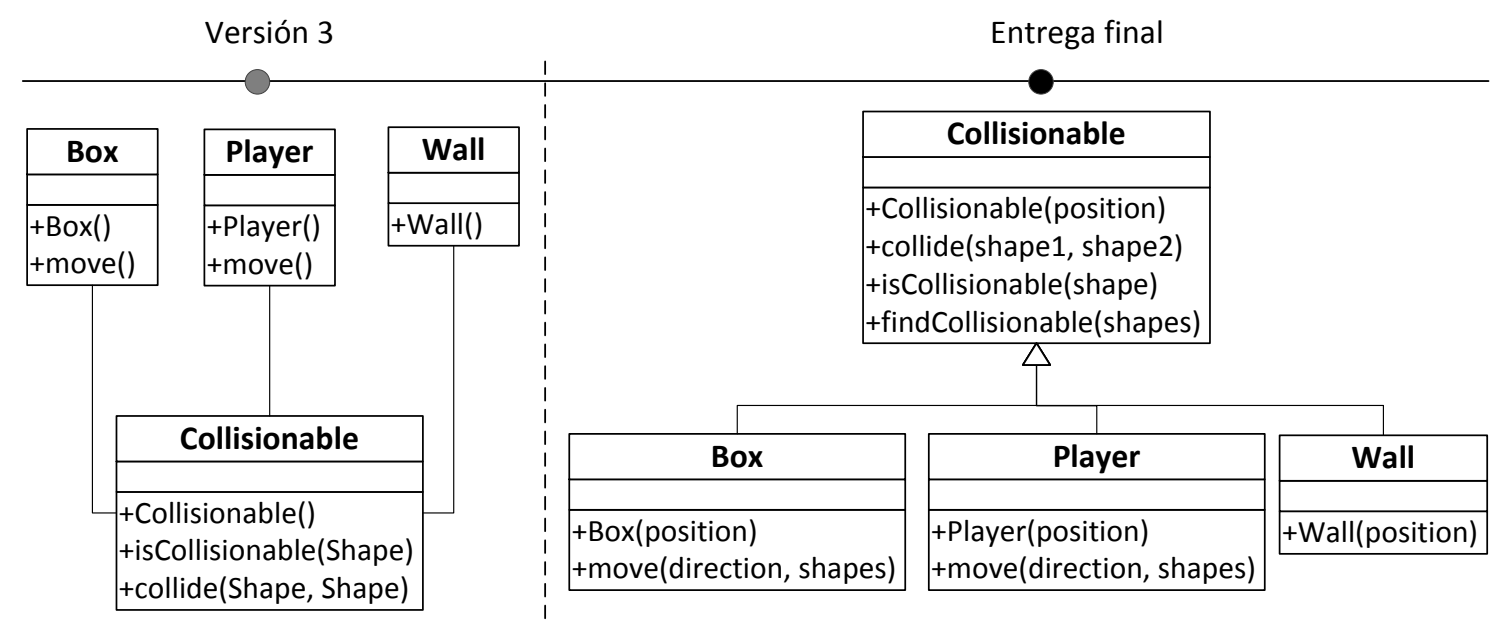

Figura 8-7: Preferencia a heredar una propiedad en lugar de delegar

Los estudiantes justifican la preferencia de la herencia de la siguiente manera: 
"In order to ease this decision, we decided to incorporate the Collisionable property by inheritance, so every figure could implicitly know if the figure next to him was collisionable or not"

- Resistencia a otorgar propiedades a un concepto que en la vida real no lo tiene El ejemplo mostrado a continuación en la Figura 8-8 ilustra como los estudiantes rechazan el asignar al elemento Wall la propiedad "move", justificándolo de la siguiente manera:

"A player and a box can be moved. A wall is the only content type that is not movable" "The problem relies in the conceptual implication on the design. Walls cannot move in the real life"

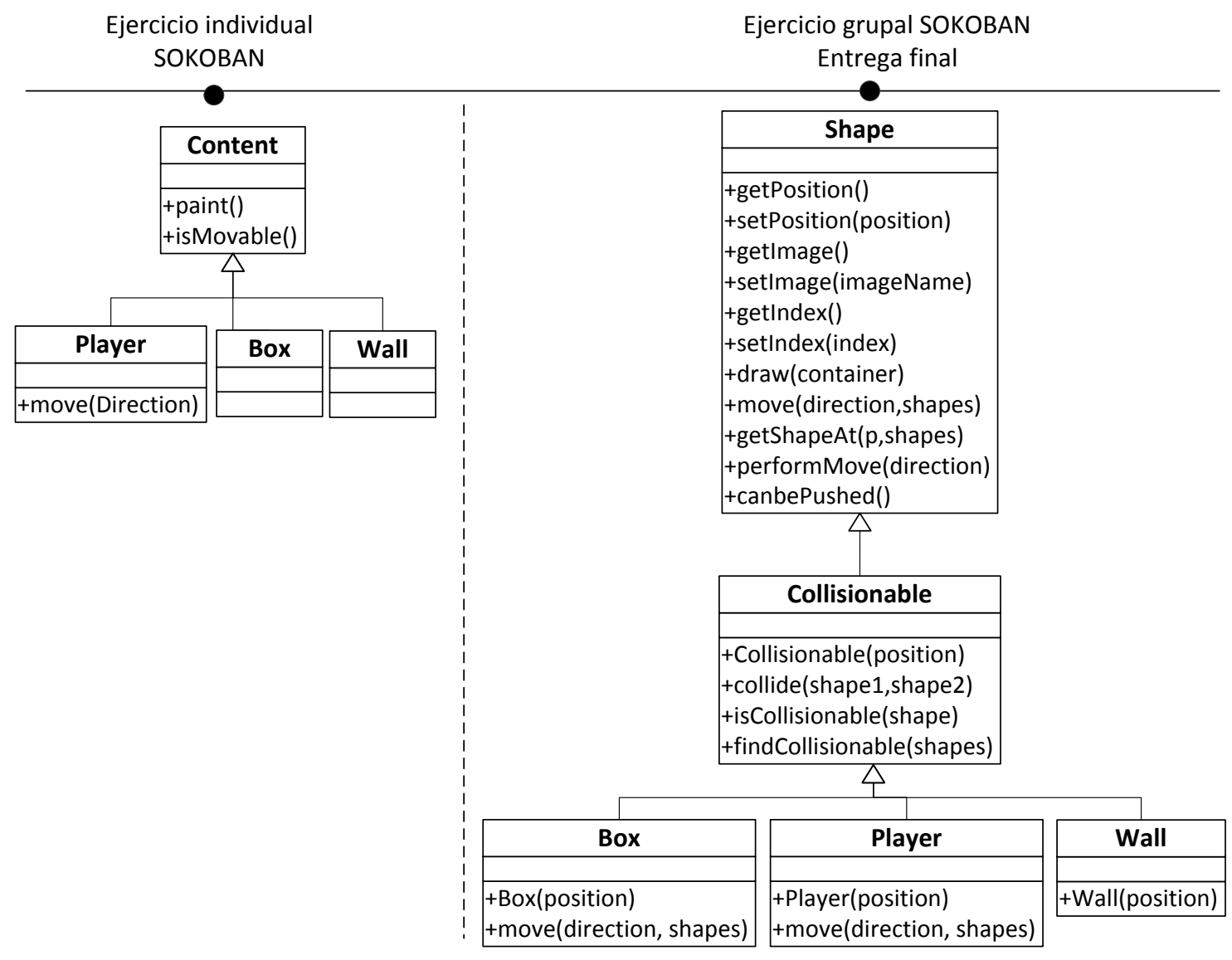

Figura 8-8: Resistencia a otorgar propiedades a un concepto que en la vida real no lo tiene

- Definición de una propiedad que es invisible para los elementos externos

Un ejemplo de esta idea es la evolución de un estudiante con los ejercicios individual y grupal, la cual se muestra a continuación en la Figure 8-9. En la figura, en la parte izquierda se observa como Collision es definido como un elemento, que es consumido de manera interna por los elementos que lo usan. En la figura 
central se puede apreciar dos aspectos, un elemento Movable, explícito para los elementos externos, y un elemento Collision que no lo es. Finalmente, en la versión final del ejercicio en grupo, predomina el uso del elemento Collision como elemento invisible para la herencia.

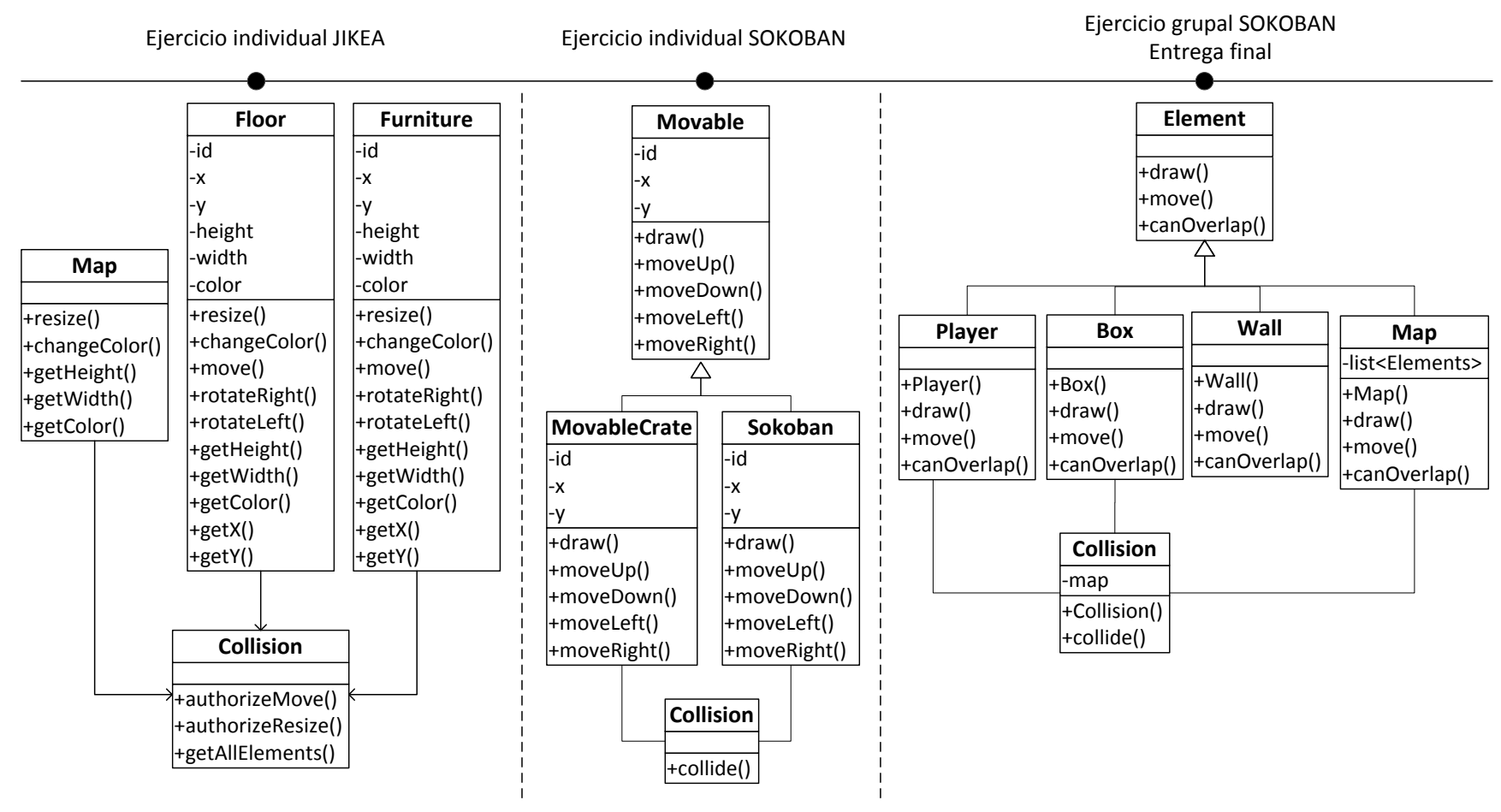

Figura 8-9: Definición de una propiedad invisible para los elementos externos

- Diseño de un elemento que depende de la información de otros elementos para tomar decisiones

Esta idea se manifiesta cuando uno o más elementos dependen de información para poder ejecutar alguna acción o tomar una decisión. Esta idea se caracteriza por preguntar o solicitar información del exterior, a veces de manera unívoca y otras de manera encadenada.

- Acceso a hijos desde el exterior a través de relaciones directas que ignoran al padre y que acceden a métodos particulares que solo tiene el hijo

Esta idea aparece en una estructura de herencia, donde los hijos son accedidos desde el exterior de la estructura a través de métodos particulares que no están presentes en el padre. Es decir se viola el polimorfismo con la adición de métodos en los hijos, ignorando el contrato que debería ser realizado con el padre. 
- Diseño de hijos vacíos iguales a los padres

Esta idea se manteniene a lo largo de la línea de tiempo. Los estudiantes definen una herencia, donde algún hijo está vacío. Eso significa, que tendrá el mismo comportamiento que el padre, comportamiento que pudiera ser motivado con el fin de reusar código.

- Diseño de una interfaz para uniformizar la diversidad y ocultar información

Esta idea apoya la uniformidad a través de la creación de un elemento abstracto como una interfaz, la misma que cubre a los elementos diversos de la aplicación que pertenecen a ese nuevo concepto. Este comportamiento puede formar parte de las ideas que pudieron ser adquiridas previamente al curso, ya que se inició con esta idea y se mantuvo hasta el final.

- No hace explicito cómo ni dónde se manejan las listas

Esta idea se ha manifestado de diversas maneras a lo largo del período de instrucción. Está estrechamente relacionada a la idea de "Ausencia de ùn elemento que actúa como contenedor" que aparece en la categoría de Persistencia Media. Se evidencia cuando los estudiantes colocan métodos tal como getAllElements o getListBox, pero no se sabe dónde o como manejan la estructura de datos correspondiente a las listas.

- Descomposición por concepto

Esta idea se ha mantenido a lo largo del período de instrucción. La definición de conceptos, aunque a veces de manera insuficiente, predominó hasta terminado el período de instrucción.

- Herencia usada para propagar cambios

Este comportamiento predominió en ciertos diseños, donde a pesar de que la herencia podría existir con otros objetivos, los estudiantes la relacionaban con la propagación de cambios. Esta idea está estrechamente relacionada con la idea de rehuso de código.

- Definición de un concepto como un atributo

Definir un concepto como atributo, fue una idea que se mantuvo a lo largo del período de instrucción. A pesar de que la habilidad de descomponer un sistema en conceptos también se mantuvo, muchas veces los estudiantes caían en la tentación de subestimar a un concepto, colocándolo como un atributo y quitándole de esta manera capacidad de decisión y comportamiento.

- Diseño de elementos que están aislados del resto de la estructura

Este comportamiento fue reflejado en aquellos diagramas donde las clases carecían de relación semántica con el resto de la estructura de diseño. 
En total se encontraron 14 ideas que cumplen con los criterios de persistencia alta, pero 10 fueron consideradas como dificultades, debido a obstaculizar la línea de diseño establecida en esta tesis. Las ideas que no fueron estudiadas como dificultades fueron "Definición de una propiedad que está oculta para los elementos externos"; "Diseño de una interfaz para uniformizar la diversidad y ocultar información"; "Descomposición por concepto". Adicionalmente, la idea "Diseño de elementos que están aislados del resto de la estructura", parece haber sido causada por desconocimiento en la nomenclatura y no por estar relacionado a los fundamentos del diseño.

\subsubsection{Dificultades potencialmente persistentes}

Potencialmente persistentes recoge aquellas dificultades que han sido tomadas de frases textuales de los ejercicios o entrevistas de los estudiantes. Sin embargo, están no se han visto reflejadas en los diseños a lo largo del período de instrucción, por lo que no se puede saber si se han mantenido o desaparecido. Dentro de esta categoría, se encuentran las siguientes:

- Principio de Ocultación de la Información asociado a una nula o baja dependencia entre entidades y a no tener relaciones entre clases concretas

- Confusión entre encapsulación y ocultación

- Asocia el Principio de Ocultación con que la única cosa que es conocida es la operación que resuelve el problema

- Asocial el Principio de Ocultación de Información con que los parámetros de cada entidad estén escondidos

En total se encontraron 4 ideas que cumplen con los criterios de persistencia potencial, todas consideradas como dificultades debido a no favorecer la línea de diseño establecida en esta tesis.

\subsection{Resumen}

Las pregunta de investigación planteada para este estudio de caso fue respondida. En total 48 ideas fueron recogidas, de las cuales se identificaron 42 dificultades, agrupadas en cuatro niveles de persistencia: bajo, medio, alto y potencial. Las dificultades encontradas independientemente de su persistencia representan una fuente de problemas a nivel académico, pero también a nivel profesional.

El desafío futuro está en profundizar en el estudio de las dificultades, en busca de dificultades esenciales que agrupan las dificultades observadas en este estudio longitudinal. Estas inquietudes no son respondidas en este estudio, pero dan cabida al estudio posterior. 


\section{Capítulo 9}

\section{Estudio de las dificultades esenciales de aprendizaje y sus orígenes}

En este capítulo se describe el estudio de las dificultades esenciales y sus posibles orígenes. En primer lugar se precisa el objetivo del estudio y sus preguntas de investigación. Después, se presenta el proceso de obtención de las dificultades esenciales y la taxonomía definida para las dificultades esenciales. Posteriormente se detalla cada dificultad esencial obtenida. Seguido, se refleja en un mapa la representación de las dificultades esenciales y su relación con las dificultades obtenidas en el estudio longitudinal previo. En la última sección se discuten las ideas que han sido agrupadas bajo más de una dificultad esencial. Finalmente, se presenta un resumen del estudio.

\subsection{Objetivo}

El estudio de dificultades esenciales tuvo como objetivo analizar las dificultades obtenidas en el estudio longitudinal por parte de los estudiantes y proponer una perspectiva más abstracta de esas dificultades. Adicionalmente, se ofrece algunos posibles orígenes de las dificultades esenciales previamente definidas.

El término "dificultades esenciales"se refiere a aquella dificultad abstraída que cubre a un grupo de dificultades obtenidas desde los estudiantes.

\subsection{Preguntas de investigación}

Las siguientes preguntas de investigación han conducido este estudio:

- ¿Cuáles son las dificultades esenciales de aprendizaje?

- ¿Cuáles son los posibles orígenes de dichas dificultades esenciales? 


\subsection{Proceso de obtención de dificultades esenciales}

Para la obtención de dificultades esenciales se siguió el siguiente proceso. Para cada una de las cuarenta y dos dificultades obtenidas en el estudio longitudinal se aplicó un proceso de abstracción, es decir, se resaltó lo que se consideraba esencial y se dejó de lado lo que no era importante. Posteriormente, esas abstracciones fueron agrupadas según su similitud bajo el nombre de dificultades esenciales. Finalmente, se buscó posibles orígenes para cada dificultad esencial obtenida. Este proceso se puede ver de manera sintetizada en la Figura 9-1.

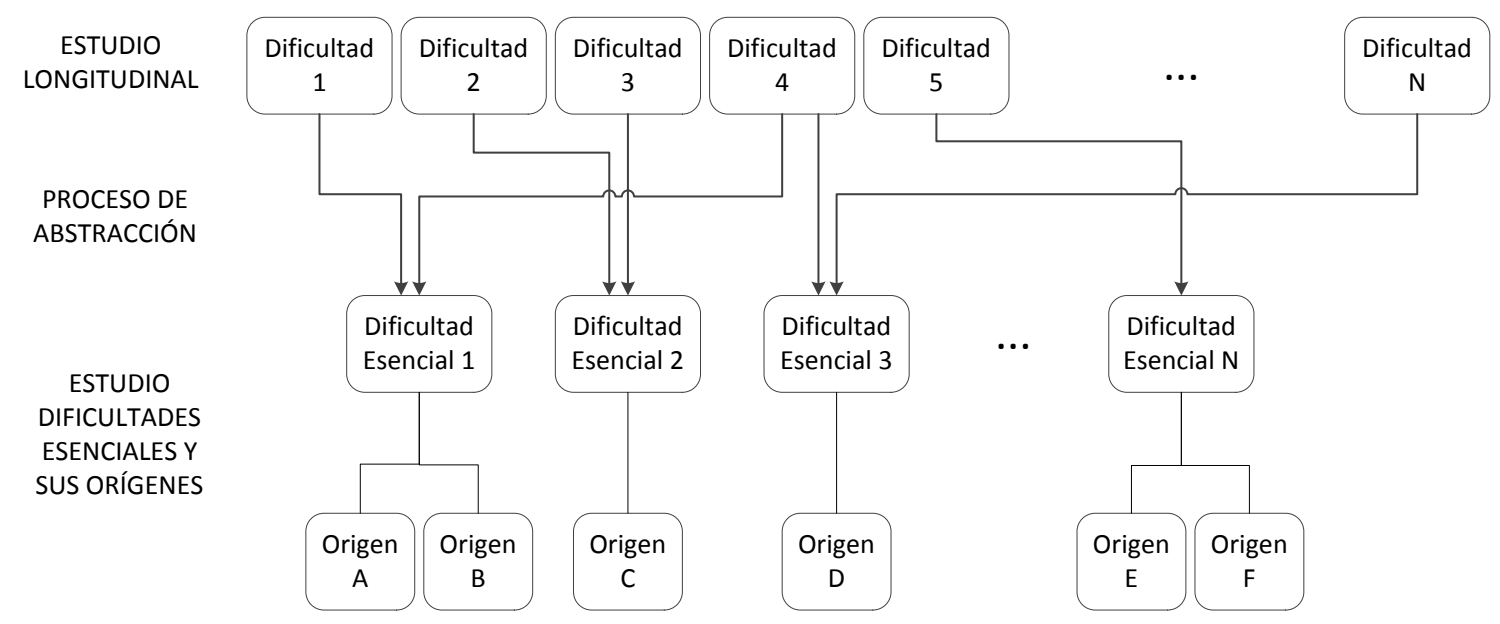

Figura 9-1: Proceso de obtención de dificultades esenciales

\subsection{Taxonomía de las dificultades esenciales}

Las dificultades esenciales fueron a su vez clasificadas bajo los términos influencia, insuficiencia o malentendido, dando lugar a la taxonomía de dificultades esenciales, como se puede ver en la Figura 9-2. Los términos de influencia, insuficiencia y malentendidos fueron usados en el contexto de las definiciones ofrecidos por la Real Academia Española [78] de la siguiente manera:

- Influencia definida como "acción y efecto de influir", y a su vez, Influir como "dicho de una cosa: Producir sobre otra ciertos efectos"

- Insuficiencia será entendido como "cortedad o escasez de algo" y;

- Malentendido, será usado como "mala interpretación, equivocación en el entendimiento de algo". Cabe aclarar que el término malentendido difiere de misconception, ya que por definición misconceptions son concepciones claramente incompatibles con las concepciones aceptadas y que se mantienen de forma persistente, incluso después de la instrucción [1] y en el término malentendido, no se involucra la persistencia 


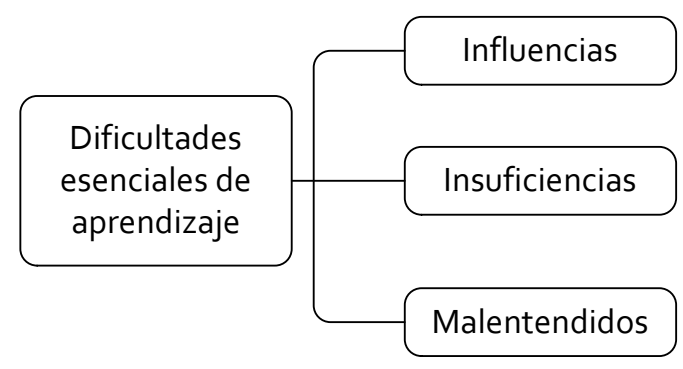

Figura 9-2: Taxonomía de las dificultades esenciales de aprendizaje

En las siguientes secciones, se describe cada una de las dificultades esenciales y las dificultades que lo conformaron. Además, se analizan los posibles orígenes de cada dificultad esencial.

\subsection{Influencia de copiar la realidad en el software}

En el estudio de caso se extrajeron las siguientes dificultades:

- Estudiantes que no imaginaban el concepto Juego cuando se les pidió diseñar un juego, pudiera estar relacionado a que el concepto juego no es algo concreto en la vida real.

- Estudiantes que rechazaron asignar la propiedad mover() a un elemento Pared, pudiera atribuirse a que una pared en la vida real no se mueve.

- Estudiantes que representaban en el diseño el número exacto de elementos que se solicitaba en el ejercicio, pudiera reflejar que lo que ve el estudiante es algo fijo que se mantiene igual, en otras palabras intenta reproducir lo que percibe y se compromete con el problema inmediato (lo que ve en ese momento) y particular (geometría fija).

- Estudiantes que particularizaron las listas y los métodos, pudiera originarse por el pensamiento de querer reflejar y anteponer lo que ven, especificando una lista por cada elemento listbox, listWall o diferentes métodos para cada acción moveup (), movedown, antes que pensar a nivel software.

- Estudiantes que expresaron taxonomías a través de la herencia, pudiera estar relacionado a que la herencia son mecanismos convenientes para capturar la estructura natural de las cosas [94].

- Estudiantes que mostraron dependencia de información de otros elementos y estudiantes que preferían heredar en lugar de delegar, pudiera ser el reflejo del rechazo a asignarle poder de decisión a un elemento software que "representa" un elemento pasivo de la realidad.

- Estudiantes que separaban elementos que eran similares en el software pero que fueron interpretados como diferentes, pudiera tener su motivación en que en la vida real dichos elementos tienen comportamiento diferente. 
Todas estás dificultades parecen tener un fondo común, el apego a la realidad. Esta idea de apego a la realidad parece haber conducido a los estudiantes a comportarse de esa manera, siendo por definición un tipo de influencia. En consecuencia, la dificultad esencial que se abstrae de todas las dificultades antes mencionadas es la Influencia de copiar la realidad en el software. En la Figura 9-3 se puede apreciar la dificultad esencial y sus dificultades relacionadas.

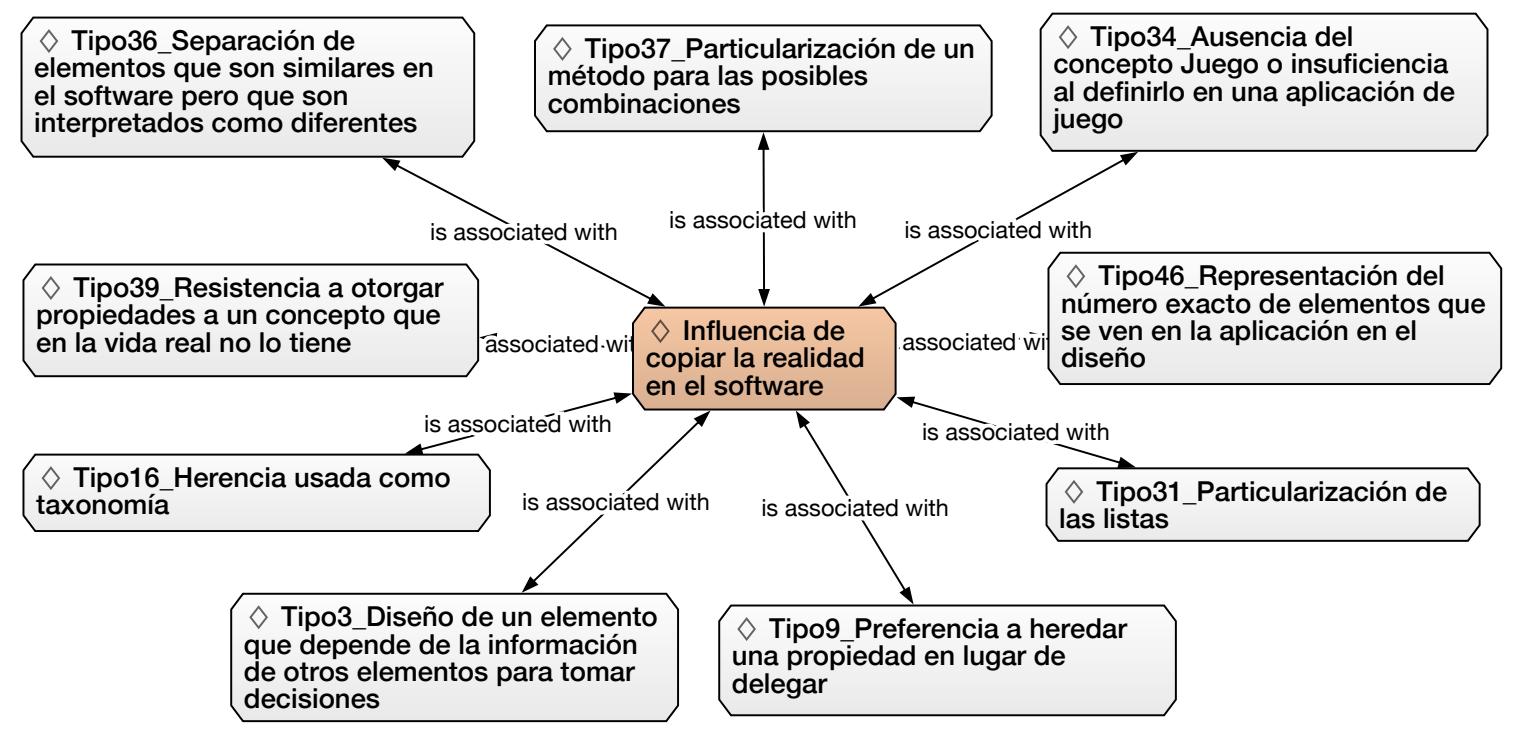

Figura 9-3: Dificultades relacionadas con la influencia de copiar la realidad en el software

Copiar la realidad en el software, puede ser definido como la tendencia de trasladar lo que se ve en el mundo real al mundo software. Esta forma de proceder, ha tenido a lo largo del tiempo sus defensores y detractores. A continuación se presentan algunas de las ventajas encontradas en la literatura sobre la copia de la realidad.

1. Resolución de problemas en el mundo real ofrece un framework para la resolución de problemas en el mundo software [94, 117]

2. Las actividades cognitivas son iguales para resolver el problema en el mundo real como para resolver el problema usando técnicas orientada a objetos 117

3. La facilidad de entendimiento del sistema es alta para los encargados de mantener el software y usuarios, debido a que entender el problema en el mundo real, les permitiría entender el sistema orientado a objetos [117]

4. La concepción del diseño es más fácil para personas que conozcan sobre la estructura del mundo real y que para una persona que conozca dominios particulares de software [117, 94].

Los puntos 1 y 3, pudieran ser discutidos también como desventajas, puesto que parten del supuesto de que en el mundo real la resolución de problemas ya está definido. 
Por otro lado, estan aquellas ideas que desvirtúan la copia de la realidad en el software, a continuación algunas de las desventajas.

1. Transferir el comportamiento de entidades que en el mundo real no tienen comportamiento y que a menudo son un almacén pasivo de información puede obstaculizar el diseño de estas entidades en el mundo software [94]

2. Replicar un concepto de la vida real y obligarlo a comportarse como tal, limita la libertad de un concepto [70, 94]

3. Ignorar entidades debido a que no son concretas en la vida real, da como consecuencia sobrecarga de responsabilidades en otros elementos [40].

En el estudio de caso presentado en esta tesis, se evidenciaron comportamientos concretos que se podrían resaltar. Por ejemplo, si un estudiante omite conceptos de la vida real en el software, las responsabilidades de este concepto ignorado, forzosamente deberán sumarse a otro elemento, modificando directamente la descomposición del sistema y las responsabilidades de cada una de sus partes. Si un estudiante copia conceptos de la vida real y les da las mismas posibilidades y restricciones que tienen en el mundo real, entonces está limitando su potencialidad en el software. Si un estudiante, intenta proyectar la realidad usando la herencia con fines taxonómicos, entonces subestima el poder polimórfico de la herencia. Por lo tanto, copiar la realidad en el software trae consigo consecuencias que van en decremento del desarrollo eficiente del software.

\subsubsection{Posibles orígenes de la influencia de copiar la realidad en el software}

En la búsqueda de posibles orígenes de la influencia de copiar la realidad, se han descubierto dos, los cuales se detallan a continuación.

\section{Amplia aceptación entre autores de renombre y su divulgación en la lite- ratura}

En primer lugar, la influencia de copiar la realidad en el software podría estar originada en la amplia aceptación que tiene esta idea entre varios exponentes renombrados en el área de Ingeniería de Software. Dijkstra fue uno de ellos, quien introdujo el término "Minimizar la distancia intelectual" definida como la distancia entre los problemas del mundo real y la solución computarizada del problema [23]. Tom DeMarco [25], es otro quien sugirió un método de desarrollo de software cuyo modelo de pensamiento estuvo basado en pasar de lo concreto a lo abstracto y a lo concreto. Rumbaugh et al. [96], autor de la metodología para el desarrollo orientado a objetos (OMT), definió la etapa de Análisis sustentando en la idea de crear modelos precisos, concisos y correctos del mundo real. Alan Davis [23], también soportaba la idea de que acercarse lo más que se pueda a la estructura del mundo real debería ser la principal motivación para el diseño orientado a objetos.

Como se puede apreciar, el pensamiento de estos autores, confluye en que copiar la realidad es parte importante del diseño de software. Si estos exponentes han defendido esta idea, no es descabellado pensar que su pensamiento haya sido ampliamente 
difundido en la academia y en la literatura. No obstante, ¿Es posible que todos ellos estuvieran equivocados?, la respuesta es: no del todo; parcialmente, tenían algo de razón. El diseño de software es algo que se construye desde cero, siendo muy difícil de construirlo si se carece de referencias. Por lo tanto, una primera aproximación podría ser tomar como referencia el mundo que conocemos, sin embargo, el problema empieza cuando se trata de copiar la realidad.

Rosson et al. [94, apoya la idea de tomar los aspectos del mundo real como referencia, y propone lo que el llama "extensión metafórica del problema", que en esencia es modificar o extender las entidades del problema que pueden ser de utilidad, tomando el mundo real solamente como impulso inicial. Siendo esta una alternativa para el diseño.

Por otro lado y con menor divulgacion existen aquellos autores que están en contra de copiar la realidad en el software. Aunque parece ser que estos autores, no tuvieron el mismo impacto y divulgación en el pensamiento de los estudiantes, que sus defensores. Por ejemplo, Haythorn [49], critica las metodologías cuyo objetivo inicial es "Modelar los objetos del dominio del problema", argumentando que esto pudiera ser útil para la identificación de objetos, pero no para asignarles comportamiento. Parnas [86], quien introduce el Principio de Ocultación de Información, culpa a lo que el llama "Reflecting the System Environment in the Software Structure", de ser uno de los causantes del fallo en la implementación del Principio, ya que el Principo de Ocultación requiere de una distorsión de la realidad y de renunciar a lo que está impuesto por la percepción y el sentido común.

\section{Propiedad de naturalidad aceptada como inherente del enfoque orientado a objetos}

Como segundo origen, podría estar la aceptación de la propiedad de naturalidad [13, 15, 94], la que ha sido definida como la propiedad más fuerte del enfoque orientado a objetos (OO) y es entendida como la propiedad que tiene un sistema para construir versiones abstractas de cada uno de los elementos existentes en el mundo real, ellas [versiones abstractas] hacen las mismas cosas para resolver sus problemas en el "cyberworld" que sus correspondientes elementos hacen para resolver el mismo problema en el mundo real [117]. Es decir, esto es asumir que el enfoque orientado a objetos es natural, aunque no hay evidencia científica de aquello [26].

A pesar de su nombrada potencialidad, la naturalidad de los objetos también ha sido ampliamente criticada como un obstáculo para el aprendizaje [120, 95] y como una limitación para enriquecer el diseño orientado a objetos [94. Esta limitación puede ser ilustrada con el comportamiento mencionado anteriormente, cuando los estudiantes rechazaban la idea de que una pared en el mundo software pudiera moverse. El problema radica en que la realidad tiene propiedades distintas a las propiedades del software, por lo que intentar conseguir trasladar la realidad al software, sería mutilar los beneficios del software.

Para resumir, la influencia de copiar la realidad en el software, parece originarse en la amplia aceptación de esta idea entre exponentes reconocidos de la Ingeniería de Software y su divulgación en la literatura. Otro afluente de copiar la realidad en el software, puede ser la aceptación como cierta de la propiedad de naturalidad atri- 
buida a los objetos. Ambas razones difundidas extensamente en la academia, parecen haberse introducido en el pensamiento de los estudiantes, como en los instructores, al momento de enseñar y aprender diseño de software orientado a objetos.

\subsection{Influencia del enfoque estructurado}

En el estudio de caso se extrajeron las siguientes dificultades:

- Estudiantes que otorgaban un alto nivel de control y estudiantes que diseñaban un elemento como programa principal tipo Main, parecieran estar motivados por la necesidad de colocar un elemento con un nivel de superioridad sobre el resto, es decir jerarquizar los elementos.

- Estudiantes que separaban los elementos que eran similares en el software pero que eran interpretados como diferentes, estudiantes que definían una estructura de tipo flujo de datos, estudiantes que separaban un concepto en dos, uno para datos y otros para funciones, estudiantes que separaban los elementos que tenían comportamiento de aquellos que eran datos, estudiantes que definían clases como datos y finalmente estudiantes que identificaban funciones principales para luego distribuirlas en los módulos, son ideas que pudieran existir bajo una misma motivación, separar de cualquier manera las funciones de los datos.

- Estudiantes que elaboraron un diagrama entidad relación y estudiantes que colocaban un ID en cada elemento, pudieran tener en mente el aprendizaje previo de los modelos relacionados al análisis estructurado.

- Estudiantes que no hacían explícito dónde y cómo manejaban las listas, estudiantes que no hacían explicito los contenedores y estudiantes que tenían problemas con la herencia, son ideas que pudieran haberse originado por el desconocimiento de este tipo de estructuras, las cuales no existen en el enfoque orientado a objetos.

Todas estas dificultades en su proceso de compresión parecen tener cuatro fondos en común: jerarquización de los elementos, separación entre funciones y datos, desconocimiento de conceptos que no existen en el enfoque estructurado y conceptos relacionados al análisis estructurado. Estas cuatro ideas parecen haber conducido a los estudiantes a comportarse de esa manera, siendo por definición un tipo de influencia. En consecuencia, la dificultad esencial que se abstrae de todas las dificultades antes mencionadas es la Influencia del enfoque estructurado. En la Figura 9-4 se puede apreciar la dificultad esencial y sus dificultades relacionadas.

El enfoque estructurado ofrece un método para el modelado del análisis, el cual está conformado por un conjunto de modelos que dan una representación técnica de un sistema [89]. Varios autores estudiaron alrededor del método que defina al enfoque estructurado, siendo uno de los más reconocidos y aceptados el definido por Tom DeMarco 24], el mismo que tomaremos como referencia para este estudio. DeMarco, estableció tres partes principales como estructura del modelo del análisis, como primero, la descripción de objetos de datos, la especificación del proceso, y la especificación del control; cada una de las descripciones compuestas por sus respectivos diagramas. 


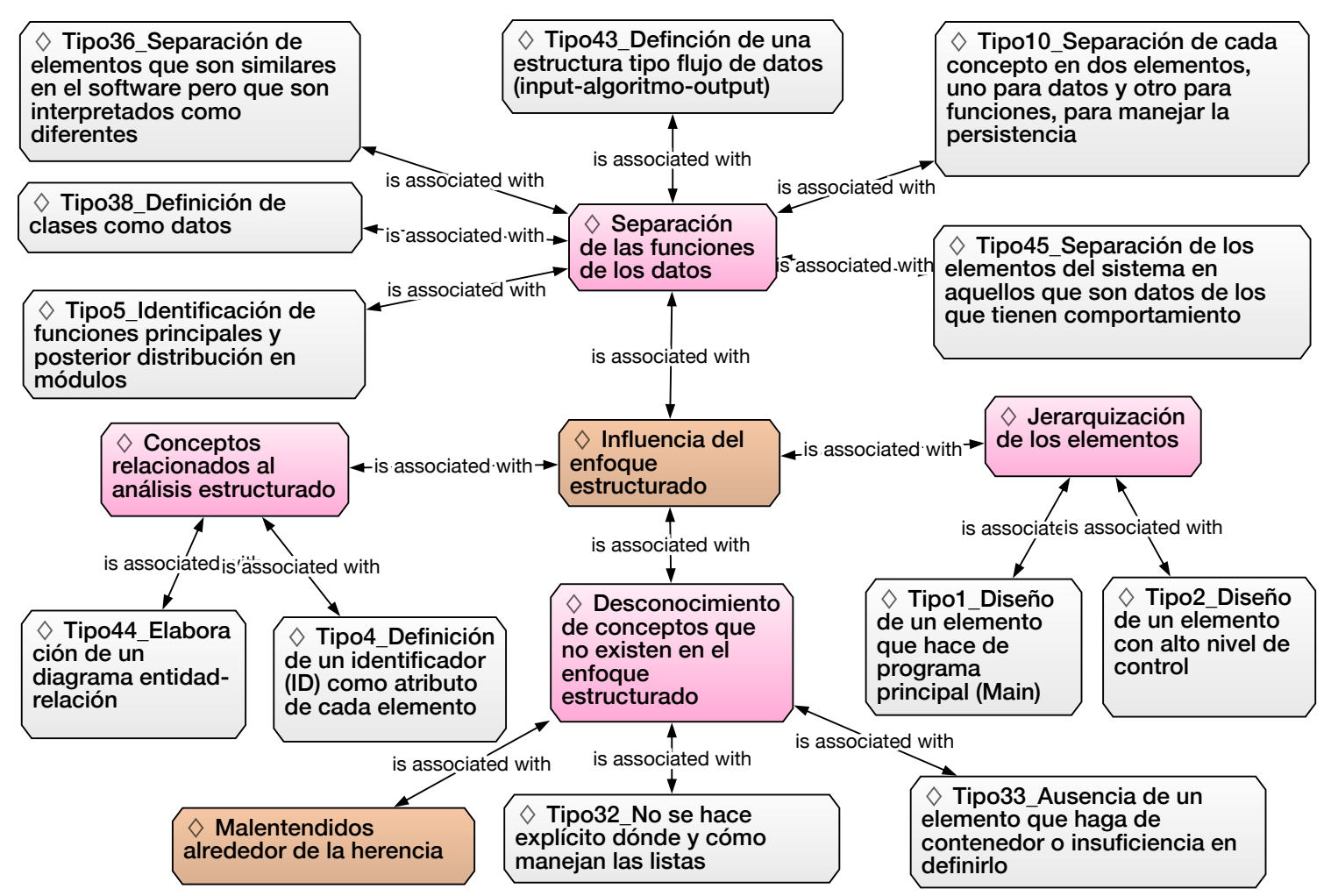

Figura 9-4: Dificultades relacionadas a la influencia del enfoque estructurado

El enfoque estructurado en la academia es comúnmente incluido en el programa de estudios de carreras relacionadas a Ciencias de la Computación e Informática y a lo largo del tiempo ha sido definida como un contenido que es enseñado previo a la enseñanza del enfoque orientado a objetos. En la siguiente sección se describen mayores detalles de este enfoque junto con los posibles orígenes de la influencia del enfoque estructurado.

\subsubsection{Posibles orígenes de la influencia del enfoque estructurado}

En la búsqueda de posibles orígenes de la influencia del enfoque estructurado, se han descubierto dos, los cuales se detallan a continuación.

Intención de trasladar el conocimiento previo del enfoque estructurado al momento de diseñar bajo el enfoque orientado a objetos

Primero, la influencia del enfoque estructurado podría estar originado en la intención de trasladar los conocimientos adquiridos previamente, en particular el conocimiento relacionado al enfoque estructurado. Este traslado ha sido evidente desde distintos aspectos del enfoque estructurado, tal como se explica a continuación.

Uno de los aspectos que pudiera ser tomado como referencia para los estudiantes, es la definición del enfoque estructurado. Para eso nos referiremos a fuentes recono- 
cidas en la literatura como DeMarco [24] y Yourdon [129, 127], quienes lo definen como un modelo para organizar jerárquicamente los módulos de un sistema software. Rumbaugh et al. [96] menciona que este tipo de enfoque hace especial hincapié en especificar y descomponer la funcionalidad del sistema, describiendo aquellos aspectos del sistema que tratan de las transformaciones de valores-funciones, correspondencias, restricciones y dependencias funcionales. Wieringa [123] en 1998, expresaba: "Un sistema software es un sistema que manipula y almacena datos". Medinilla [70], aporta a esta definición expresándolo como el modelo cuyo concepto fundamental está basado en la función que transforma datos.

Medinilla [70], describe al enfoque estructurado como aquel que ofrece el método de desarrollo y los modelos de software. Los modelos establecidos para esta fase están regidos a uno de los principios operativos del análisis, el cual sugiere que el proceso de análisis debería ir desde la información esencial hasta el detalle de la implementación [89], es decir de manera jerárquica. Tanto el modelo funcional, cuya técnica de diagramas de flujo de datos representa el flujo de información (DFD) y el modelo de datos, cuya representación está dada por el diagrama entidad-relación deberían estar establecidos bajo ese principio.

Esto motiva a pensar que tanto la definición del enfoque estructurado. Como se pudo apreciar anteriormente, la organización jerárquica de los módulos como principio operativo del análisis estructurado, pudiera ser el causante de conducir a los estudiantes a colocar módulos en una estructura jerárquica, donde en la parte superior habrá un único módulo que represente el programa global y en los niveles inferiores aparecerá los módulos resultantes de las sucesivas divisiones. Estos resultados coinciden con resultados analizados en [79], donde estudiantes asignaban a la clase Empleado los métodos para calcular el salario de un empleado, cuando estos deberían pertenecer a la clase Recursos Humanos. Este comportamiento muestra un claro diseño procedimental donde la clase Empleado tiene el control y la clase Recursos Humanos es un dato. Detienne [27, 30] también muestra sus hallazgos sobre el proceso al que confluyen los estudiantes principiantes al descomponer grandes procedimientos en unidades funcionales más pequeñas, reflejándose la tendencia de asociar en una sola clase el procedimiento en su conjunto.

Otra parte del enfoque estructurado susceptible a ser transferida al enfoque orientado a objetos son los diagramas correspondientes al modelo de datos y modelo funcional - flujo de información establecido por DeMarco [24] en el enfoque estructurado. Como primero, el diagrama entidad-relación perteneciente al modelo de datos y definido como aquel que representa las relaciones entre los objetos de datos de una manera gráfica, se centra únicamente en los datos independientemente de procesamiento que los transforma [89]. Asociado al modelo entidad-relación está la tabla de objetos de datos, la cual ofrece la especificación del objeto de datos, donde comúnmente el primer campo de esta tabla es un identificador (ID). Tanto el modelo entidad-relación, como el uso de identificadores para cada elemento, fueron comportamientos observados en estudiantes a los que se les pidió un diseño bajo el enfoque orientado a objetos. Tal como puntualizó Rumbaugh estas exigencias no son necesarias en el modelo de objetos [96]. Estos hallazgos, también fueron observados en diseñadores principiantes con experiencia previa en programación estructurada en [28], quienes usaban atributos de 
tipo number en cada clase para relacionar los objetos, en lugar de usar una relación de tipo is-part, haciendo explícito que la solución construida por el sujeto usaba elementos del enfoque relacional de administración de bases de datos. Resultados que empatan con los encontrados en este estudio de caso.

Por otro lado está el diagrama de flujo de datos. Este diagrama tiene dos objetivos: a) proporcionar una indicación de como se transforman los datos a medida que avanza el sistema y; b) representar las funciones que transforman el flujo de datos [89]. Este modelo, parte del análisis estructurado y pudiera ser el origen de la todas las formas de separación en funciones y datos observadas en el estudio de caso. Otros estudios [79, 27, 30] también reflejaron la tendencia de los estudiantes principiantes a crear clases sin pensar en los métodos, resultados que son contrarios a los encontrados en este estudio de caso, donde los estudiantes identificaban las funciones principales para posteriormente distribuirlos en clases. Esto puede deberse a que los estudiantes del estudio de caso presentado en esta investigación podrían no entrar en la categoría de principiantes, debido a que estaban cursando estudios de Máster.

En la misma línea de la intención de los estudiantes a trasladar la definición y modelos del enfoque estructurado, sucede con los mecanismos que no existen en el enfoque estructurado. Los estudiantes al enfrentarse con mecanismos como la herencia, contenedores y listas, propios del enfoque orientado a objetos, no saben como afrontarlos debido a que no les son familiares. Varios problemas con la herencia se identificaron en este estudio de caso, sin embargo, debido a que se encontraron varias manifestaciones del uso de este mecanismo, se decidió tratarlo por separado en la Sección 9.9.

Varios estudios soportan la idea de que el aprendizaje previo de enfoque estructurado es uno de los causantes de las dificultades en el aprendizaje de nuevos enfoques, entre ellos, el orientado a objetos. Rosson et al. 94] dijo en los años noventas una frase que parece definir esta causa: "a designer's past experience will unavoidably influence the ease of generating an object-based problem representation". Por otro lado Argawal et al. 4], mantiene que los estudiantes con experiencia previa en estructurado, mantienen un tipo de sinergia procedimental al momento de resolver nuevos problemas.

\section{Aspectos cognitivos}

Un segundo posible origen de la influencia del enfoque estructurado, pudiera estar relacionado a aspectos cognitivos. Algunos autores [83, 191, 121], defienden que el pensamiento humano y en particular la resolución de problemas pudiera ser innatamente procedimental, por lo que la fijación a tener un pensamiento de este tipo podría tener cabida en el mundo del aprendizaje orientado a objetos, sin embargo, este estudio no ha profundizado en este aspecto. Algunos autores han estudiado sobre la excesiva confianza que los seres humanos tienen en las experiencias previas y que sirven de base para el aprendizaje de cosas nuevas [3, 107] y la influencia (inhibición o motivación) que ejerce este nuevo aprendizaje [4, 74].

En resumen, otra dificultad esencial es la influencia del enfoque estructurado. Entre los orígenes de esta influencia está la intención de querer trasladar los conocimientos previos del enfoque estructurado al momento diseñar bajo el enfoque orientado a objetos. Otro origen pudiera apoyarse en la idea de que el pensamiento humano 
pudiera ser de tipo procedimental.

\subsection{Insuficiencia en la concepción de conceptos y sus responsabilidades}

En el estudio de caso se extrajeron las siguientes dificultades:

- Estudiantes que sobrecargaban de responsabilidades (de manera cohesiva y no cohesiva) pudieron haber cedido a la sobrecarga debido a algún conflicto al momento de asignar responsabilidades o definir los límites de un concepto. Para ilustrar esta idea, mencionamos un ejemplo observado en el estudio de caso, donde una clase llamada Habitación está encargada de los siguientes métodos moverMueble(), añadirMueble(), solapamientoMueble(), colisionPared().

- Estudiantes que omitieron algunos conceptos en el diseño, los definieron de manera insuficiente, pudieron haber tenido problemas al momento de abstraer un concepto y definir sus responsabilidades.

- Estudiantes que colocaron un concepto como un atributo, en lugar de como una clase, pudieran alertarnos de la dificultad que tuvieron los estudiantes al especificar y establecer los objetos involucrados en del diseño.

- Estudiantes que definieron un concepto a través de propiedades que no están relacionadas al concepto, a su vez relacionados con aquellos estudiantes que hicieron descomposición simultánea por propiedades y por concepto, o los estudiantes que hicieron descomposición únicamente por propiedades, pudieran haberse originado por la dificultad en imaginar un concepto o asignar responsabilidades a un concepto demasiado ambiguo. Un ejemplo de esto se vio en el estudio de caso cuando a una clase llamada ObjectInterface se le asignó un único método autorizar()

- Estudiantes que diseñaron un concepto, valiéndose de propiedades heredadas de otros conceptos, para definirlo, pudieran indicar la dificultad de concebir un concepto por si mismo y con comportamiento propio.

Todas estás dificultades parecen tener un fondo común, la concepción de conceptos y sus responsabilidades. Esta idea de concepción de conceptos y sus responsabilidades denotan comportamientos de incompletitud, insuficiencia o ambigüedad en varios aspectos del diseño, siendo por definición un tipo de insuficiencia. En consecuencia, la dificultad esencial que se abstrae de todas las dificultades antes mencionadas es la Insuficiencia en la concepción de conceptos y sus responsabilidades. En la Figura 9-5 se puede apreciar la dificultad esencial y sus dificultades relacionadas.

La concepción de conceptos y responsabilidades, es definida para esta investigación como la incapacidad de los individuos en imaginar un concepto, otorgarle un nombre y definir sus responsabilidades, con sus diferentes variaciones. Una de los posibles orígenes es descrito en la siguiente sección. 


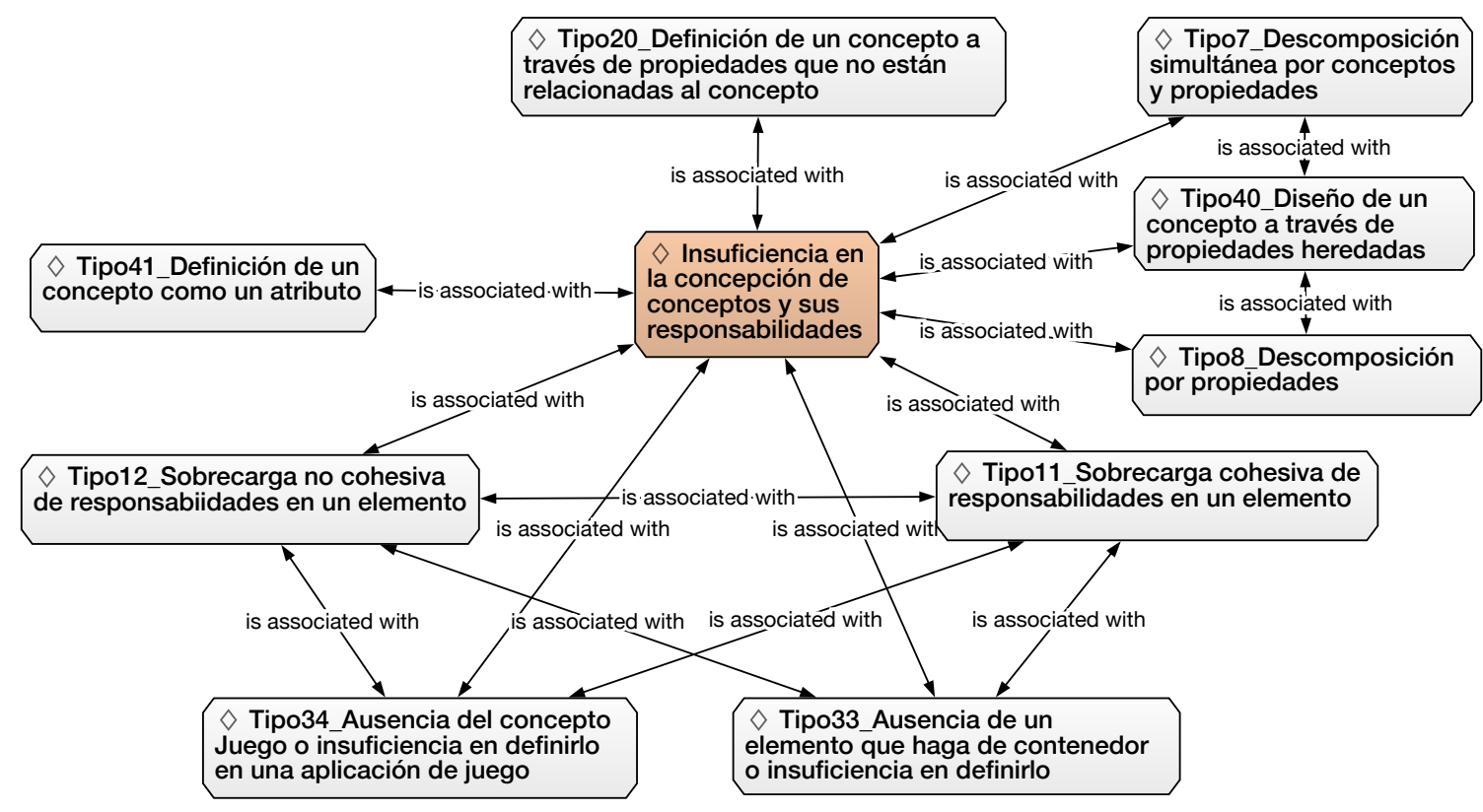

Figura 9-5: Dificultades relacionadas a la insuficiencia en la concepción de conceptos y sus responsabilidades

\subsubsection{Posibles orígenes de la insuficiencia en la concepción de conceptos y sus responsabilidades}

En la búsqueda de posibles orígenes de la insuficiencia en la concepción de conceptos y sus responsabilidades, se ha descubierto una, la cual se detallan a continuación.

\section{Complejidad del proceso de abstracción}

La insuficiencia en la concepción de conceptos y sus responsabilidades pudiera estar originada en la dificultad de abstraer dichos conceptos. En Ingeniería de Software, abstracción es de manera resumida la habilidad de enfocarse en los detalles importantes ignorando los que no lo son [9, 14, 96]. Otra definición de abstracción, está dada según Gray and Tall [44], quienes la definen como "information compression", que es la habilidad de comprimir la información contenida en un sujeto complejo al reducirlo a una sola entidad representativa, la cual en muchos de los casos es un concepto. La propiedad más importante de un concepto es el nombre, el cual debería representar de manera clara y simple lo que subyace detrás del concepto [93].

La abstracción entonces, consiste en un proceso de compresión de información, el cual implica identificar el concepto y distinguir sus límites, con ese conocimiento se podría ser capaz de separar lo que es esencial de lo no esencial. Este proceso que debería, según Booch [14], capturar el objeto en su completitud, sin darle ni más ni menos, sin ofrecer sorpresas ni efectos secundarios que vayan más allá del ámbito de la abstracción, no es una tarea fácil y a pesar de que no se puede hablar de la mejor abstracción, encontrar la abstracción adecuada depende de entre otras cosas, del contexto en el que se encuentre y su finalidad [77]. 
Problemas con la abstracción han sido detectados por otros autores. En [87] el autor advierte que los diseñadores principiantes de orientación a objetos invierten gran parte de su tiempo creando y abandonando entidades en el proceso de definición de clases. Dettiene [28], encontró en sus estudios la dificultad que tienen los principiantes de diseño de software en descomponer en pequeñas unidades funcionales un procedimiento, además de la preferencia de colocarlo todo en una sola clase, siendo un comportamiento que pudiera ir junto con la dificultad de sobrecarga de responsabilidades mostrada en este estudio. En la literatura, otras manifestaciones de los estudiantes relacionados a la abstracción han sido estudiadas, un ejemplo de esto es [79], donde los autores estudian los comportamientos de los estudiantes a través de como definen las clases, métodos abstractos y la implementación del polimorfismo.

Tener dificultades en concebir conceptos y sus responsabilidades tiene varios efectos. Uno de ellos es la definición de términos demasiado ambiguos que provocan desconcierto a quienes son los encargados de mantener el software, ya que no permite una clara visión de la funcionalidad de dicho elemento, ya que ese elemento pudiera ser "cualquier cosa". Este problema también es identificado en [11].

Otro efecto que acarrea la insuficiencia en concebir conceptos radica en la forma de descomponer. Si un estudiante ignora un concepto, o no le da las responsabilidades apropiadas, la descomposición del sistema estará dado en función de elementos sobrecargados con responsabilidades que posiblemente no le corresponden, aumentando de esta manera la dependencia de información entre elementos. La descomposición es tema de estudio, como una de las actividades cognitivas que causa más problemas de aprendizaje de técnicas orientadas a objetos [117].

La dificultad esencial identificada es la Insuficiencia en la concepción de conceptos y sus responsabilidades, que pudiera tener como origen los problemas que envuelven el proceso de abstracción. Imaginar un concepto, darle un nombre y delimitar sus responsabilidades pudiera ser la principal fuente de los problemas al momento de diseñar. Definir un concepto ajustado al contexto software implica un proceso de abstracción que parece ser insuficiente en los estudiantes y cuya consecuencia deriva en la insuficiente o nula definición de las clases y la descomposición de un sistema.

\subsection{Malentendidos alrededor del Principio de Ocul- tación de Información}

En el estudio de caso se extrajeron las siguientes dificultades:

- Estudiantes que asociaban el Principio de Ocultación de la Información a una nula o baja dependencia entre entidades y a no tener relaciones entre clases concretas pudiera provenir de que la dependencia sea tratada como una medida cuantitativa entre relaciones.

- Estudiantes que confundían encapsulamiento con ocultación, pudiera originarse en la equivalencia que se les da a estas dos palabras en la literatura.

- Estudiantes que separaron en capas y estudiantes que establecieron una lista de decisiones de diseño para ocultar información, pudieron haber tenido la idea de 
que aplicar alguna estrategia de división les garantizaba la implementación del Principio

- Estudiantes que usaron get y set para esconder los detalles internos, estudiantes que asociaban esconder los parámetros con el Principio, estudiantes que pensaron que el Principio era mostrar solamente la operación que resuelve el problema o estudiantes que diseñaron interfaces no complejas pudieron haber estado motivados por la idea de que el Principio está relacionado a ocultar el interior de los módulos.

Todas estás dificultades parecen tener cinco fondos comunes: dividir implica ocultar, el Principio de Ocultación de Información relacionado a ocultar el interior de los módulos, confusión entre encapsulamiento y ocultación, el Principio de Ocultación asociado al número de relaciones y la ocultación para debilitar las dependencias. Estas ideas estuvieron descritas en forma de afirmaciones a pesar de estar equivocadas, por lo que todas han sido consideradas por definición como malentendidos. En consecuencia, la dificultad esencial que se abstrae de todas las dificultades antes mencionadas es los Malentendidos alrededor del Principio de Ocultación de Información. En la Figura 9-6 se puede apreciar la dificultad esencial y sus dificultades relacionadas.

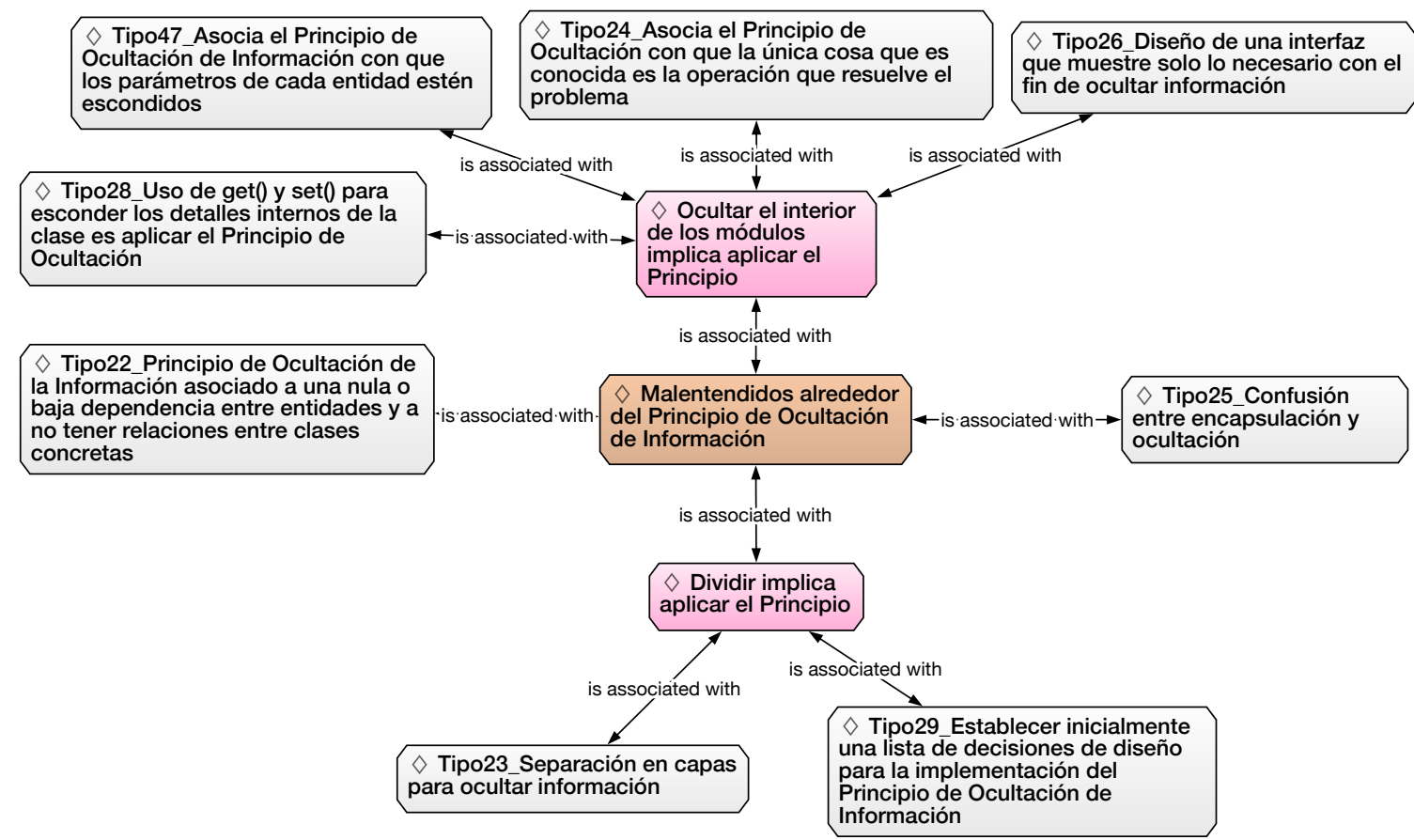

Figura 9-6: Dificultades relacionadas a los malentendidos alrededor del Principio de Ocultación de Información

El Principio de Ocultación de Información, es un criterio diferente de descomposición introducido por David Parnas en 1972. En la siguiente sección se describen mayores detalles de este Principio junto con los posibles orígenes de los Malentendidos 
del Principio de Ocultación de Información.

\subsubsection{Posibles orígenes de los malentendidos alrededor del Principio de Ocultación de Información}

En la búsqueda de posibles orígenes de los malentendidos alrededor del Principio de Ocultación de Información, se han descubierto tres, las cuales se detallan a continuación.

\section{Asociación de los términos cohesión y acoplamiento con la idea de mini- mizar la dependencia}

Antes de ahondar en la discusión de esta origen, se definirá de manera resumida el Principio. El Principio de Ocultación fue introducido por Parnas a inicios de los años 70's como un criterio diferente de descomposición [84]. La intención detrás del Principio de Ocultación de Información es concebir las partes del sistema de manera tal que cada parte requiera la mínima cantidad de información posible de las otras, debilitando de esta manera las relaciones entre ellas. La ocultación entonces viene a ser una consecuencia del diseño de las partes del sistema. El Principio no se trata de "cubrir" información después de concebir las partes del sistema [39].

Cuando el Principio habla sobre disminuir la dependencia de la cantidad de información no se refiere al valor cuantitativo de las relaciones entre elementos o peor aún a no establecer relaciones. Por lo que el origen de esta idea pudiera estar asentada en la asociación que se le da al número de relaciones entre elementos con dependencia. Uno de los autores que atribuyen un valor cuantitativo a las relaciones es Simon [108] quien fue uno de los pioneros en estudiar las interacciones entre y dentro de los subsistemas. Simon estableció la idea de que las relaciones de alta frecuencia es decir las intracomponentes generalmente son más fuertes, que las relaciones intercomponentes que son de baja frecuencia. Booch [14] apoyó esta idea, concluyendo que la definición de estas relaciones hace posible estudiar cada parte del sistema en un relativo aislamiento. Tanto Simon como Booch, direccionaron las relaciones a un valor cuantitativo. Considerar el número de relaciones entre las partes, fue también estudiado por Tom DeMarco [25] en el modelado del sistema. Dicha directriz esta centrada en particionar un sistema en piezas pequeñas y definir sus interfaces, donde se sugiere tener una partición con pocas y simples interfaces a una con muchas y complejas.

Siguiendo esta tendencia cuantitativa, nacen los términos de cohesión y acoplamiento. Cohesión aparece asociado al número de tareas que tiene un módulo, y su cohesión entre ellas. Pressman [89] complementa y confunde el término cohesión denominándolo como una extensión natural del concepto de ocultación de la información. Por otro lado, acoplamiento, es definido como una medida de la interconexión entre los módulos de una estructura de programa. El acoplamiento va dirigido al grado de interdependencia existente entre los módulos [5]. Tanto la cohesión como el acoplamiento son valoradas en un rango establecido. 


\section{Diferentes interpretaciones y definiciones del Principio encontradas en la literatura}

Los malentendidos alrededor del Principio de Ocultación podrían estar originados por las diferentes definiciones e interpretaciones del Principio divulgadas en la literatura. Una de las definiciones más comunes encontradas en la literatura es el uso equivalente de los términos encapsulamiento y ocultación. Este tratamiento equivalente ha sido observado a lo largo del estudio de caso, pero esta apreciación también ha sido encontrada en la literatura [43, 89, 12, 96, 14, 38, 3] y particularmente estudiada en el trabajo de Berard et al. [9] donde se puede ver una compilación bibliográfica de esta confusión.

Pressman [89], menciona entre los beneficios del encapsulamiento, la ocultación de los detalles de implementación interna de datos y procedimientos, además de la reutilización de componentes y la simplificación. Aunque el encapsulamiento potencialmente permite lograr estos beneficios, encapsular no garantiza la ocultación por si misma, a menos que se diseñe pensando lograr este objetivo.

El beneficio de encapsular está en la libertad de creación. En el enfoque estructurado debido a la disociación que existe entre los datos y funciones, el traslado de un concepto no es fácil. Por el contrario, el enfoque orientado a objetos permite agrupar el concepto con sus variables y comportamiento, permitiendo de forma más fácil su creación y traslado.

Los efectos que pueden llevar consigo asociar encapsulamiento con ocultación, es pensar que el encapsulamiento implica ocultamiento. Encapsular no implica ocultar, ya que la cápsula no necesariamente tiene que ser opaca. En el enfoque orientado a objetos, cada objeto puede representar una cápsula, pero esto no garantiza la ocultación; encapsular no es una propiedad particular de los objetos.

Durante el estudio de caso, otro malentendido salió a la luz, relacionado a la asociación del principio de ocultación con la ocultación de los detalles internos de los módulos. Ya se vio anteriormente que Pressman también relaciona el encapsulamiento con la ocultación de los detalles internos. En el estudio de caso, algunas variaciones de esta idea salieron a la superficie, tales como: "mostrar únicamente lo necesarioz "esconder", "dificultar el acceso" o "cubrir" lo menos necesario. Estas interpretaciones muestran la prioridad que se le da a "esconder" por encima de cómo descomponer. Estas ideas se coinciden con las misconceptions del Principio que han sido advertidas años antes por Berard et al. [9] y se mantienen hasta la actualidad [39].

Otra expresión común fue encontrada entre los estudiantes dirigida el uso de get y set para poder "cubrir" de esta manera los atributos de una clase. Este malentendido es por varios estudiantes interpretada como una manera de aplicar el Principio de Ocultación de Información y explícitamente encontrada en la red como una de las reglas para implementar el Principio [92]. Una de las posibles causas que hay detrás del uso del get y set puede estar la costumbre arraigada que tienen los estudiantes a tener el control, solicitando información o preguntando a otros módulos para poder tomar la decisión. Además, la tendencia a pensar que la palabra ocultar expuesta en el Principio de Ocultación de Información, significa esconder o tapar, pudiera ser la otra causa para este maletendido. 


\section{Falta de comprensión del Principio desde un punto de vista holístico}

Finalmente, otro origen es la falta de comprensión del Principio. Por ejemplo, la creencia de que la división convencional produce ocultación. Aunque decir que la división por si misma, implica ocultamiento no necesariamente es un error [39], el malentendido se enfoca en que la división trae consigo la ocultación requerida para decir que el Principio de Ocultación ha sido implementado, lo cual no es verdad. Los estudiantes parecen eludir la división incomprensible del Principio de Ocultación el cual requiere un enfoque holistico que conduce la fuerte dependencia entre ocultación y división. En lugar de eso, aplican divisiones convencionales que traen consigo ocultación, como es el caso de las funciones, procesos y datos.

En resumen, una dificultad esencial de aprendizaje es los maletendidos alrededor del Principio de Ocultación. Los posibles orígenes descansan en el traslado de los términos cohesión y acoplamiento al Principio de Ocultación, las diferentes interpretaciones y definiciones del Principio encontradas en la literatura y la falta de comprensión del Principio.

\subsection{Malentendidos alrededor de la herencia}

En el estudio de caso se extrajeron las siguientes dificultades:

- Estudiantes que definieron la herencia con el propósito de reusar código

- Estudiantes que en lugar de definir un elemento donde delegar responsabilidades, optaron por usar la herencia

- Estudiantes que diseñaban un hijo que heredaba un método que no usaba

- Estudiantes que definieron herencias con el fin de clasificar, siendo una de las consecuencias acceder a hijos desde el exterior a través de relaciones directas ignorando al padre o acceder a métodos particulares que solo tenía el hijo

- Estudiantes que diseñaban hijos vacíos que resultaban ser iguales a los padres

- Estudiantes definieron herencias con el fin de propagar cambios

- Estudiantes que definían herencia para heredar atributos

- Estudiantes que en una herencia definían métodos con el mismo nombre, pero cuya implementación es impredecible

- Estudiantes que preferencia usar la herencia en lugar de delegar a otro elemento

Todas estás dificultades parecen tener un fondo en común, la herencia. Estas ideas estuvieron descritas en forma de afirmaciones a pesar de estar equivocadas, por lo que todas han sido consideradas por definición como malentendidos. En consecuencia, la dificultad esencial que se abstrae de todas las dificultades antes mencionadas es los Malentendidos alrededor de la Herencia. En la Figura 9-5 se puede apreciar la dificultad esencial y sus dificultades relacionadas. 


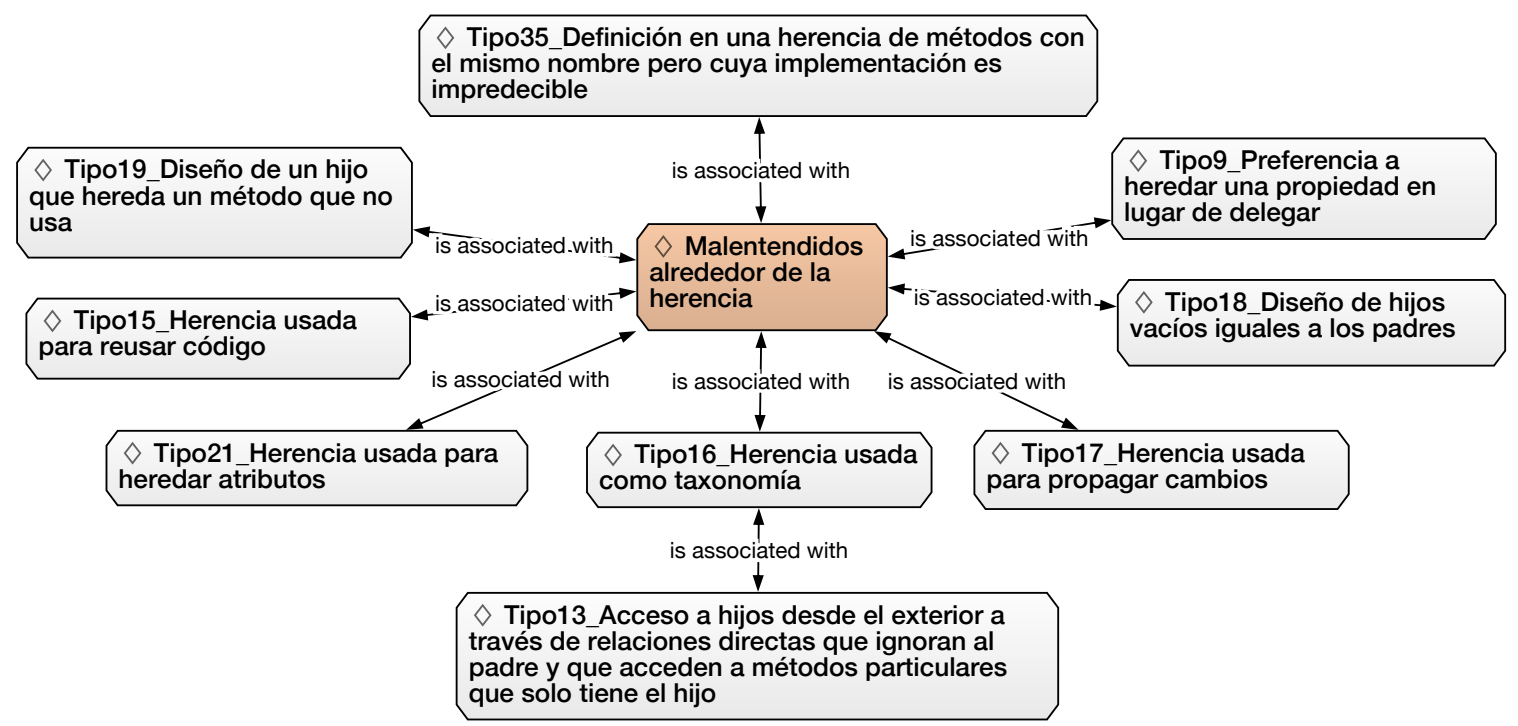

Figura 9-7: Dificultades relacionadas a los malentendidos alrededor de la herencia

\subsubsection{Posibles orígenes de los malentendidos alrededor de la herencia}

En la búsqueda de posibles orígenes de los malentendidos alrededor de la herencia, se han descubierto dos, las cuales se detallan a continuación.

\section{Beneficios realzados de la herencia expuestos en la literatura}

Un posible origen de la mayoría de malentendidos es los beneficios de la herencia expuestos en la literatura y material de enseñanza. Por ejemplo, la herencia como mecanismo de reutilización es una idea que puede ser encontrada de manera repetitiva en la literatura, pudiendo ser la razón de su propagación en la academia. La reutilización ha sido tema de estudio bajo dos enfoques, la primera, como propagador de cambios y la segunda, como mecanismo duplicador de código. De acuerdo a Pressman [89], la ventaja de la reutilización se basa en el poder de propagar cambios directamente a través de la herencia. Sin embargo, esta característica puede ser discutida como desventaja, ya que los estudiantes que trabajaban directamente con las subclases, saltándose el contrato con la superclase, se vieron afectados cuando se realizaban cambios en la superclase, por lo que herencia como mecanismo propagador de cambios no es una ventaja por defecto.

Rumbaugh et al. [96] por otro lado, se alinea con la idea de la reutilización como mecanismo duplicador de código. Es decir una subclase adopta todos los métodos y atributos que ofrece la superclase, pero implementa solo algunos de ellos dejando en la subclase métodos visibles y sin usar que podrián ser utilizados de manera impropia, corrompiendo de esta manera el comportamiento de la subclase. La idea de reutilizar a través de la herencia es ampliamente aceptado y se mantiene hasta el día de hoy, pudiendo ser visible en material de enseñanza, principalmente en la web [75] donde se resalta a la herencia como mecanismo reutilizador. También existen estudios [60, 29] 
que muestran que los esfuerzos de reusar no están únicamente centrados en la herencia, si no también en la copia y modificación literal del código.

Otra idea malentendida en la literatura es la relacionada a preferir heredar en lugar de delegar. La delegación como alternativa a la herencia fue discutida por Rumbaugh veinticinco años atrás por Rumbaugh et al. [96] y se mantiene presente hasta la actualidad, como se demuestra en este estudio de caso. Rumbaugh sugiere rechazar la herencia debido a que la rigidez del mecanismo forza a todas las subclases a adoptar los atributos y métodos de la superclase, dejando métodos visibles que pudieran ser implementados de mala manera en cualquier momento. En lugar de eso, sugiere usar como criterio de descomposición la delegación, donde los métodos pueden ser usados de manera selectiva, ocultando aquellos métodos que no son usados. Aunque Rumbaugh no lo hace explícito, la ocultación es una consecuencia de esta forma de descomposición, el cual es uno de los propósitos del Principio de Ocultación de la Información. En la actualidad, la idea de delegar en lugar de heredar es tema de estudio en diversas investigaciones como por ejemplo [113, 119].

Además de la propagación en la literatura de la herencia como mecanismo reutilizador, se podría considerar otra fuente para este comportamiento. Esta causa podría radicar en los aspectos culturales que condicionan a la persona a comportarse de cierta manera, como por ejemplo, preferir solicitar información para tener el control, en lugar de dejar que otro decida. Este comportamiento es común en nuestro entorno y podría ser el culpable de que los estudiantes tiendan a diseñar elementos que concentran lo necesario para poder tomar la decisión, en lugar de delegar tareas a otros elementos. Los efectos que tiene el mal uso de la herencia son diversos y hasta el día de hoy se reportan estudios sobre misconceptions alrededor de la herencia [28]. Entre los efectos secundarios del mal uso de la herencia se encuentra la dependencia de información que se crea cuando la herencia es usada para cualquier otro efecto que no sea el polimorfismo.

\section{Desconocimiento de mecanismos que no existen en el enfoque estructurado}

Este origen es también discutido como parte de la influencia del enfoque estructurado (Sección 9.6.1), la cual se refiere al desconocimiento de la herencia debido a ser un mecanismo nuevo que no se ha estudiado en otros enfoques, específicamente en el enfoque estructurado. Su desconocimiento y falta de entrenamiento, dota de complejidad al enfoque orientado a objetos.

Para resumir, los malentendidos alrededor de la herencia podrían ser considerados como una dificultad esencial y existen diversas fuentes para su malentendimiento. Una de ellas pudiera estar en los beneficios exclusivos de la herencia propagados en la literatura, además, está el desconocimiento de este mecanismo, debido a ser un mecanismo nuevo y propio del enfoque orientado a objetos. 


\subsection{Otros tipos de dificultades}

En la literatura relacionada, también se han encontrado otras ideas relacionadas a las dificultades en el aprendizaje orientado a objetos, que no han emergido en este estudio de caso, pero que no se ha querido dejarlas de lado.

1. La naturaleza y características del tipo de ejercicio usados en el aprendizaje enfoque orientado a objetos [3, 4, 37, 110, 124]

2. El lenguaje de implementación usado [110, 112

3. La diferencia entre individuos principiantes y experimentados

\subsection{Mapa de dificultades esenciales y sus dificul- tades}

Una representación gráfica de las dificultades esenciales obtenidas en este estudio de caso con sus respectivas agrupaciones, se presentan en esta sección. El mapa puede ser visto en la Figura 9.11 . 


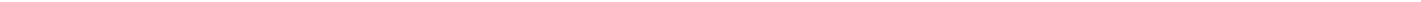




\subsection{Dificultades que comparten más de una dificultad esencial}

Las dificultades esenciales previamente estudiadas, presentaban dentro de sus agrupaciones un conjunto de dificultades. La relación entre las dificultades y su dificultad esencial, pudiera dar la idea de ser una relación de uno a uno, es decir, una dificultad corresponde a una y solo una dificultad esencial. Sin embargo, en el mapa descrito anteriormente, se puede apreciar que una dificultad podría estar relacionada a una o más dificultades esenciales. Más allá de la estructura relacional que pudieran tener las dificultades y dificultades esenciales, se resalta la importancia de que las dificultades pudieran tener diferentes dificultades esenciales que las cubran, por ende, diferentes orígenes. En consecuencia, sería un error tratar las dificultades de manera aislada, puesto que todas forman parte del todo y están relacionadas.

Esta sección se centra en aquellas dificultades que tenían relación con más de una dificultad esencial (color marrón), las mismas que se muestran a continuación.

\section{Sobrecarga de responsabilidades en un elemento}

Las dificultades denominadas sobrecarga de responsabilidades en un elemento (de manera cohesiva y no cohesiva), están relacionadas a la dificultad esencial llamada insuficiencia en la concepción de conceptos y responsabilidades, como se puede ver en la Figura 9-8. Además, las dificultades de sobrecarga son consecuencia de dificultades que tienen como causa la influencia de copiar la realidad en el software y la influencia del enfoque estructurado.

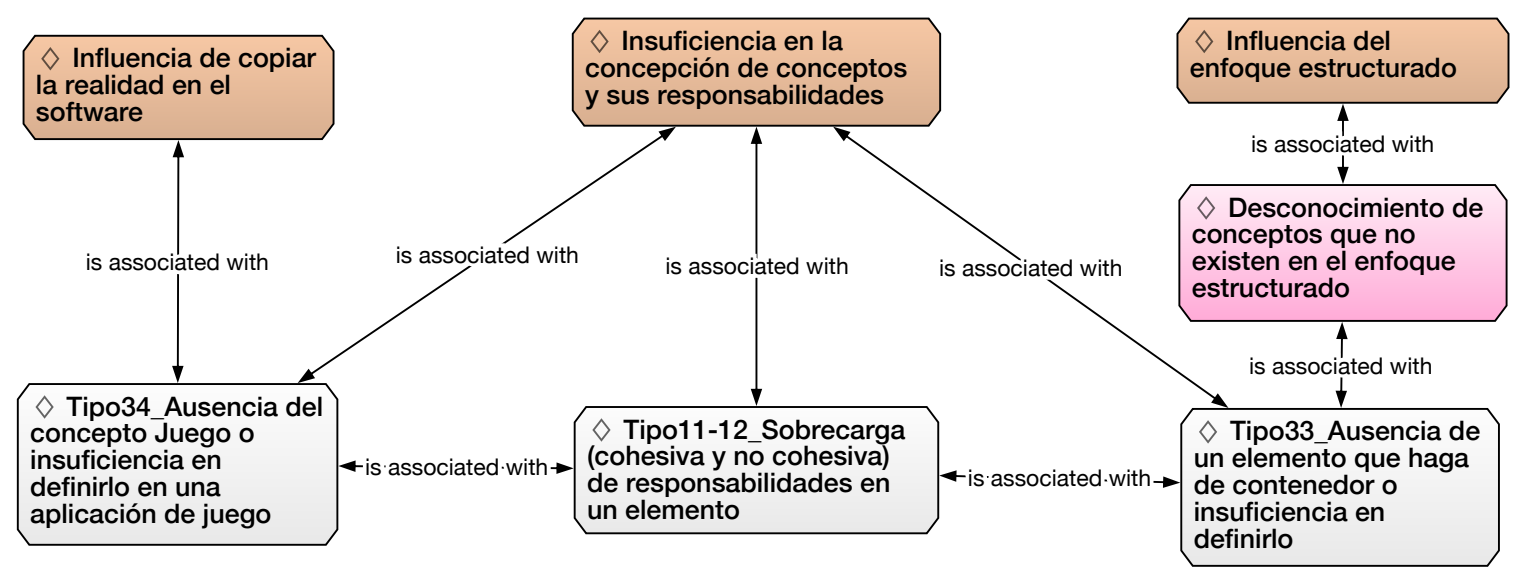

Figura 9-8: Sobrecarga de responsabilidades en un elemento

\section{Dependendencia de información de otros elementos para tomar decisiones}

Esta dificultad está asociada directamente a una dificultad esencial, la influencia de la copia de la realidad. Esta dificultad además, es consecuencia de cuatro dificultades que a su vez tenían como dificultad esencial, la influencia del enfoque estructurado, tal como se puede ver en la Figura 9-9. 


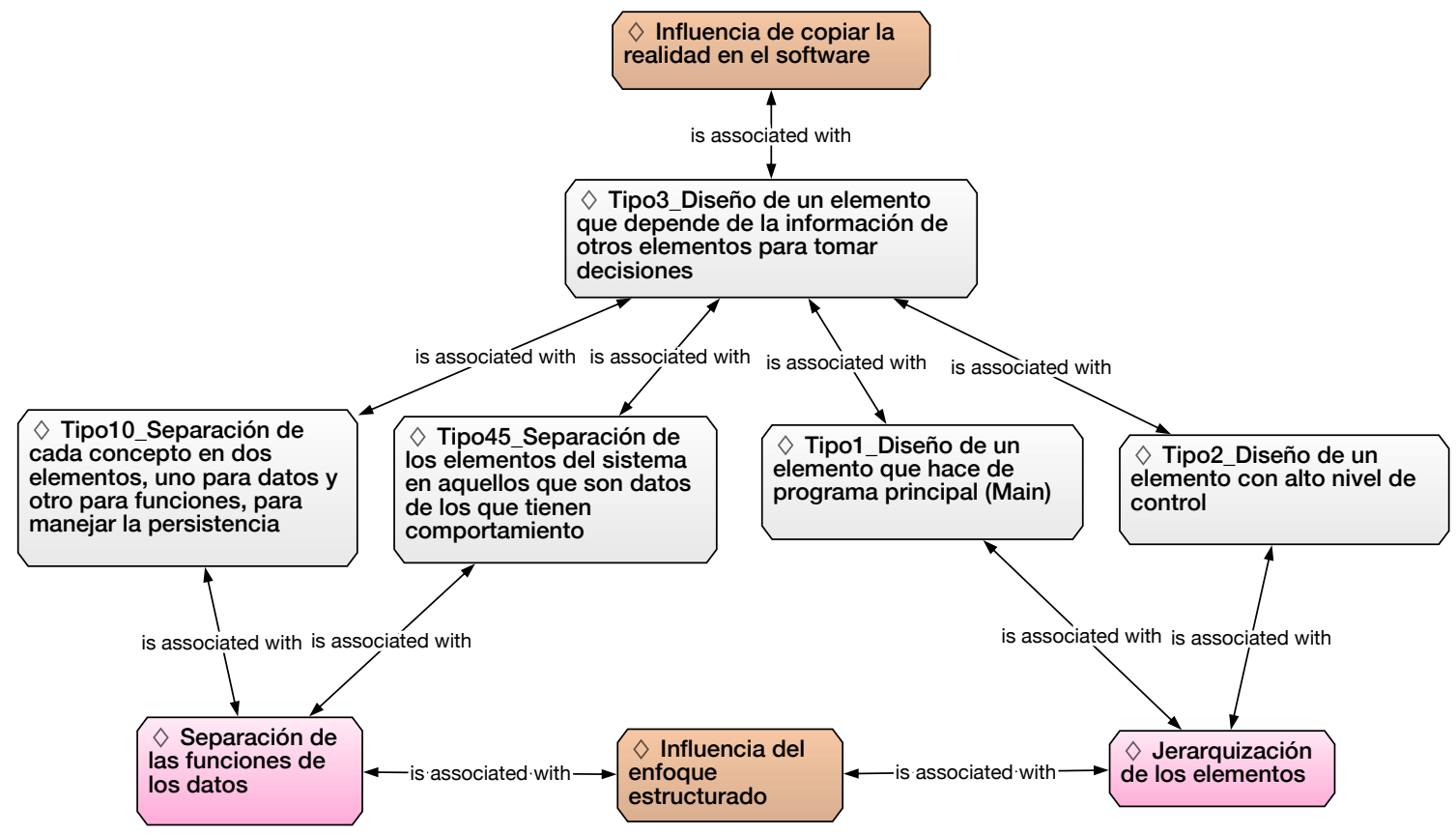

Figura 9-9: Dependendencia de información de otros elementos para tomar decisiones

Separación de elementos que son similares en el software pero son interpretados como diferentes

Este dificultad está asociada a dos dificultades esenciales de manera directa: la influencia de copiar la realidad en el software y la influencia del enfoque estructurado, como se puede apreciar en la Figura 9-10.

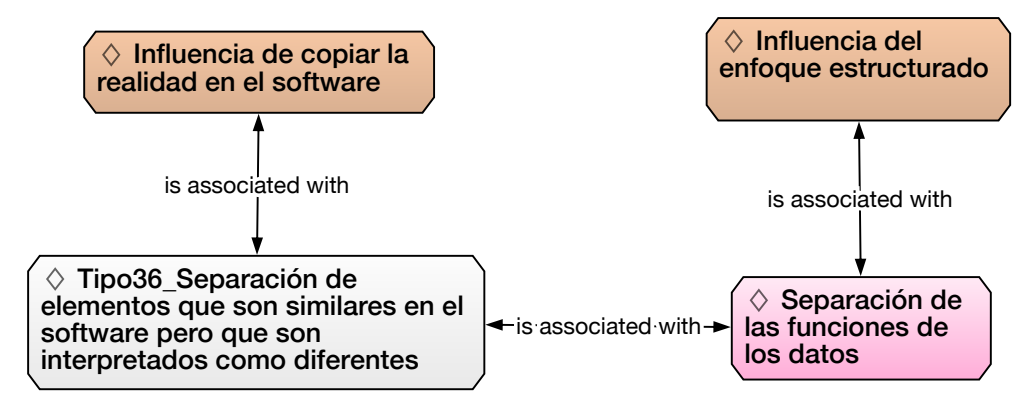

Figura 9-10: Separación de elementos que son similares en el software pero son interpretados como diferentes

\section{Diseño de un elemento con alto nivel de control}

En la Figura 9-11, se aprecia que esta dificultad está asociada de manera directa a una dificultad esencial, la influencia del enfoque estructurado. Además, esta dificultad es consecuencia de otra dificultad que es la sobrecarga (cohesiva y no cohesiva), las cuales a su vez tenían como dificultad esencial, la insuficiencia en la concepción de conceptos y sus responsabilidades. 


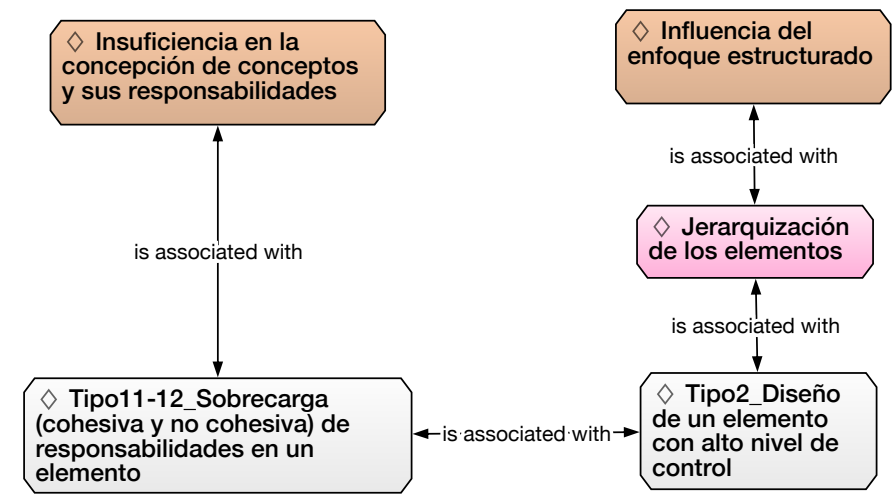

Figura 9-11: Diseño de un elemento con alto nivel de control

\section{Herencia usada como taxonomía}

Esta dificultad está asociada a dos posibles dificultades esenciales. La influencia de copiar la realidad en el software y los malentendidos alrededor de la herencia, tal como se aprecia en la Figura 9-12.

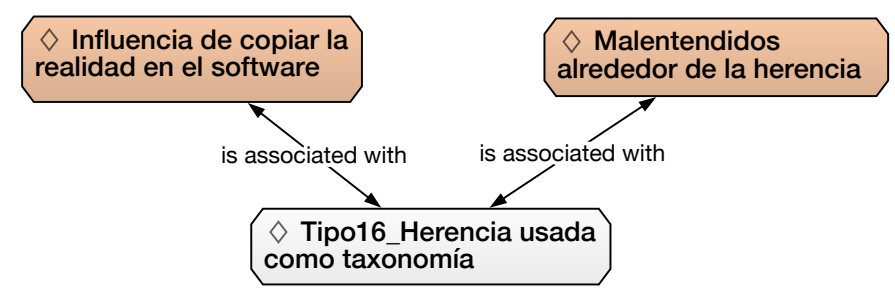

Figura 9-12: Herencia usada como taxonomía

\section{Preferencia a heredar una propiedad antes que delegarla}

En la Figura 9-13, se puede ver que esta dificultad tiene dos dificultades esenciales asociadas: la influencia de la copia de la realidad y el malentendimiento alrededor de la herencia.

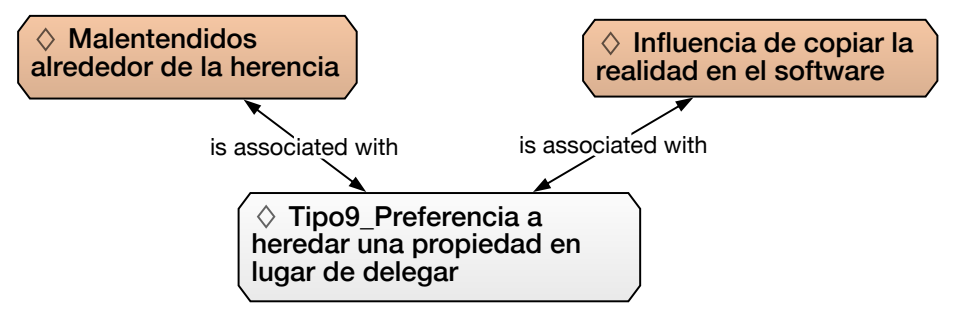

Figura 9-13: Preferencia a heredar una propiedad antes que delegarla

\section{Ausencia del concepto Juego o insuficiencia al definirlo en una aplicación juego \\ Las dificultades esenciales de esta dificultad son la influencia de copiar la realidad en el software y la insuficiencia en la concepción de conceptos y responsabilidades.}


En la Figura 9-14, se aprecia que esta dificultad es también considerada como posible causa para los dos tipos de sobrecarga de responsabilidades en un elemento (cohesiva y no cohesiva), las cuales tienen como dificultad esencial la influencia de la copia de la realidad.

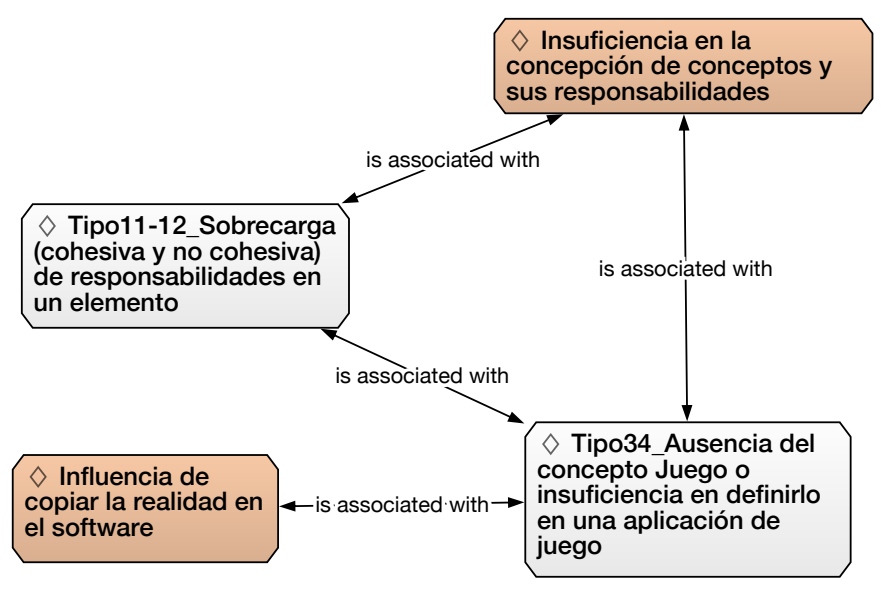

Figura 9-14: Ausencia del concepto Juego o insuficiencia al definirlo en una aplicación juego

\section{Ausencia de un elemento que haga de contenedor o insuficiencia en defi- nirlo}

Esta dificultad esta relacionada a dos dificultades esenciales como se puede ver en la Figura 9-15. Por un lado la insuficiencia en la concepción de conceptos y sus responsabilidades y, por otro lado, la influencia del enfoque estructurado. A su vez, esta idea está relacionada a los dos tipos de sobrecarga descritos en el estudio de caso.

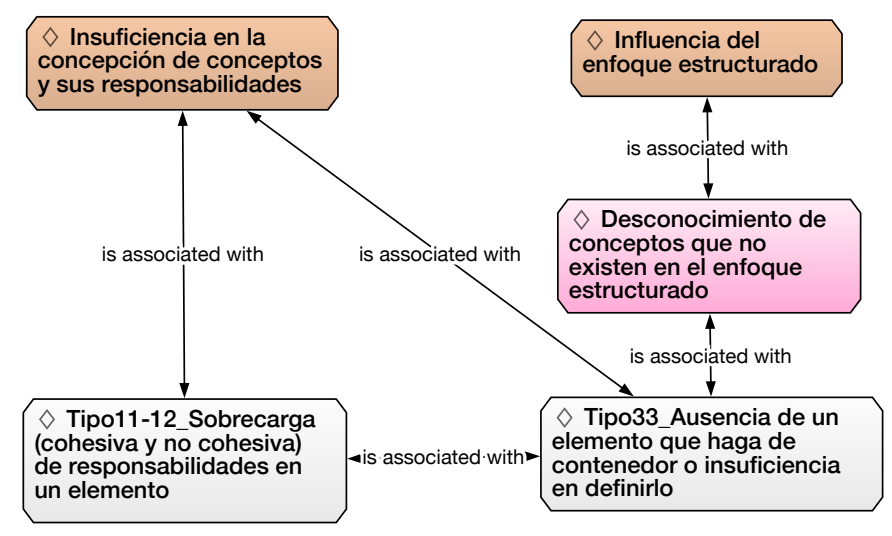

Figura 9-15: Ausencia de un elemento que haga de contenedor o insuficiencia en definirlo 


\subsection{Resumen}

El estudio tuvo como objetivo, identificar las dificultades esenciales de aprendizaje y sus posibles orígenes. El estudio responde las preguntas de investigación planteadas, al definir las dificultades esenciales en forma de influencias, insuficiencias y malentendidos.

Entre las influencias encontradas en el estudio de caso, está la Influencia de copiar la realidad en el software, cuyos orígenes pudieran estar en la amplia aceptación de esta idea entre autores reconocidos de la Ingeniería de Software. Otro origen descansa en aceptar como cierta la propiedad de naturalidad del enfoque orientado a objetos. La segunda influencia presentada es la Influencia del enfoque estructurado, cuyos orígenes pudieran ser atribuidos a factores como la tendencia de los estudiantes a trasladar los conocimientos previos del enfoque estructurado al enfoque orientado a objetos y de tipo cognitivo, relacionado a que el pensamiento humano pudiera ser de tipo procedimental.

Una insuficiencia fue identificada en este estudio, la Insuficiencia en la concepción de conceptos y sus responsabilidades. Esta dificultad esencial pudiera tener su origen en la complejidad del proceso de abstracción.

Finalmente, los malentendidos manifestados en el estudio de caso rondan alrededor del Principio de Ocultación de Información y la herencia. Estos malentendidos pueden estar originados por la asociación de los términos cohesión y acoplamiento a minimizar la dependencia, además de las diferentes interpretaciones y definiciones del Principio encontrados en la literatura y la falta de comprensión del Principio. Con respecto a los malentendidos alrededor de la herencia, rondan alrededor de los beneficios realzados de la herencia que se exponen en la literatura y el desconocimiento del mecanismo de la herencia al ser nuevo y propio del enfoque orientado a objetos.

Las dificultades esenciales presentadas muestran que no pueden ser consideradas de manera aislada, ya que la relación con las dificultades obtenidas de los estudiantes no siempre es de una a una. 


\section{Capítulo 10}

\section{Discusión de resultados}

En este capítulo se comunican y discuten los resultados obtenidos del estudio empírico. En primer lugar se discuten los resultados del primer estudio relacionado al entendimiento del Principio de Ocultación. Posteriormente, la discusión se concentra en las dificultades de aprendizaje y su nivel de persistencia, obtenidos como resultados del estudio de caso longitudinal. Finalmente, se analizan los resultados del tercer estudio, relacionado a las dificultades esenciales de aprendizaje. Finalmente, se presenta un resumen donde se sintetizan los resultados obtenidos.

\subsection{Entendimiento del Principio de Ocultación de Información}

El estudio sobre el Principio de Ocultación de Información tuvo como objetivo contestar las siguientes preguntas de investigación.

- ¿Qué entienden los estudiantes sobre el Principio de Ocultación de Información y cuál es su nivel de aproximación al Principio?

- ¿Cuáles son las posibles causas de ese entendimiento del Principio de Ocultación de Información?

A continuación, se exponen tres secciones donde se responden y discuten las preguntas de investigación planteadas anteriormente.

\section{Entendimiento del Principio de Ocultación de Información}

De la caracterización de cada uno de los trece estudiantes, se pudieron apreciar dos

tipos de entendimiento alrededor del Principio de Ocultación, los cuales se detallan a continuación.

1. "La ocultación de información consiste en ocultar el interior de los módulos"

En algunas respuestas de los estudiantes se apreció que "ocultar" significa: a) "dificultar el acceso o esconder"; aplicar el Principio es sinónimo de combinar 
"privado" con "get" y "set" para "tapar" los atributos de los módulos; b) "ocultar el interior de los módulos" significa "mostrar sólo lo necesario" o "definir interfaces no complejas". Ambos subtipos de ideas, expresadas por los estudiantes ("dificultar el acceso o esconder" y "mostrar sólo lo necesario"), coinciden con interpretaciones equivocadas de diversos autores importantes, advertidas por Berard et al. 9] hace más de cuatro lustros. En esta interpretación se aprecia que subyace la idea de la ocultación como único objetivo del Principio y totalmente aislado de la forma de descomposición.

\section{2. "La división produce ocultación de información"}

Esta interpretación está presente en dos pensamientos distintos. El primer pensamiento, se manifiesta en aquellos estudiantes que han utilizado las divisiones convencionales en módulos. Ellos suponen que la división produce por sí misma la ocultación. No están equivocados porque las divisiones en el software están asociadas con ocultación: por ejemplo, las funciones que ocultan el código en su interior. La conducta de los estudiantes parece eludir la división incomprensible propuesta por el Principio y prefieren aplicar los criterios familiares de división, que produce ocultación por sí misma. Según parece, cuando se les exige ocultar más, ellos optan por "tapar" más. Esta conducta sugiere además, que los estudiantes separaron las dos reglas del Principio: primero, asignaron a cada módulo una decisión de diseño (siguiendo algún concepto convencional: función, proceso, dato) y después, intentaron dotarlo de una interfaz que mostrara lo mínimo de su interior. Posiblemente la idea de la separación de conceptos (dividir y después ocultar) también subyace en la interpretación de "ocultar el interior de los módulos".

El segundo pensamiento, se manifestó en aquellos estudiantes que diseñaron los módulos de forma holística, pero de manera insuficiente. Estos estudiantes consiguieron interfaces que reducían la necesidad de conocer el interior de los módulos a través de la división y renunciaron a representar sus módulos con conceptos convencionales. De hecho cada módulo expresó un concepto distinto y ninguno respondió al concepto de función - proceso - dato. De esta forma debilitaron notablemente la dependencia entre módulos respecto a los diseños de los otros estudiantes. Este pensamiento fue presenciado en pocos estudiantes y fue el más próximo al objetivo del Principio.

Tanto el pensamiento dirigido a que la sola división produce ocultación y el pensamiento dirigido a pensar en dividir para ocultar, pero con insuficiencias, muestra una dificultad fundamental para comprender el Principio. En otras palabras, el Principio requiere de un enfoque holístico que aborde la fuerte dependencia entre ocultación y división.

\section{Niveles de aproximación al Principio de Ocultación de Información}

Como primero, se puede decir que de todos los diseños y respuestas analizadas, ninguno de los estudiantes tuvo un dominio sobre el Principio de Ocultación de Información. De manera más detallada y con respecto a la segunda parte de la primera 
pregunta de investigación, los niveles de aproximación que pudieron ser identificados de los trece estudiantes, fueron tres. El primer nivel conformado por el grupo de estudiantes que "ignoran" el Principio, el segundo nivel conformado por el grupo de estudiantes que tienen una visión "inadecuado" del Principio y finalmente el tercer nivel de aproximación que fueron aquellos estudiantes que tuvieron una "insuficiente" concepción del Principio.

Cuatro estudiantes entraron en el nivel de aproximación "Ignora" el Principio. Uno de ellos intentó aplicarlo a partir de la lectura del trabajo de Parnas, pero no lo consiguió. Otros seis estudiantes argumentaron que aplicaron el Principio pero no acertaron con sus diseños ni con los argumentos, por lo que fueron clasificados bajo el nivel de aproximación "Inadecuado". Y por último, tres estudiantes que realizaron diseños con el enfoque del Principio, pero fueron incapaces de implementarlo completamente, cayendo en el nivel de aproximación "Insuficiente".

Resumiendo, más de las tres cuartas partes de los estudiantes ignoraban o distorsionaban el Principio; solo menos de una cuarta parte lo aplicó, pero con insuficiencias. Este resultado señala que las dificultades respecto al Principio de Ocultación de Información se mantienen, al menos en este estudio de caso. Una consecuencia de este resultado, más allá del aula de clase, es su impacto en la empresa: la inmensa mayoría de los diseños obtenidos en este estudio ofrecen una modularización de baja eficiencia para el desarrollo de software. Es decir, esos diseños, dificultan la distribución del trabajo, la comprensibilidad y la facilidad de cambios. El problema se acentúa porque todos los estudiantes ya son graduados en Informática. Además, estos resultados nos indican que no se trata de un problema local, ya que los estudiantes provienen de siete países diferentes en dos continentes.

\section{Posibles causas del entendimiento del Principio de Ocultación de Informa- ción}

A lo largo del estudio de caso, se pudieron apreciar algunas posibles causas del entendimiento de los estudiantes acerca del Principio de Ocultación. Por ejemplo, un estudiante mostró resistencia a doblegar su percepción de la realidad sobre la forma de división requerida por el Principio. Esta es una posible causa por la que el nivel de aproximación de este estudiante fue "insuficiente", es decir, el estudiante tenía el conocimiento e intención de aplicar correctamente el Principio, pero su apego a la realidad llevada al software dominó sobre cualquier otro criterio. Esta causa es mencionada por Parnas [86], el autor del Principio de Ocultación, como "Reflecting the system environment in the software structure", la cual es para Parnas una de las razones para el fallo en la implementación del Principio. Esto quiere decir en otras palabras, que el Principio requiere una distorsión de la realidad y que el software por ende, debería ser una imagen anamórfica de esta realidad. Es decir, que el software sea capaz de tratar con una imagen que se pinta a si misma o una pared que se mueve, a pesar de que estas ideas no se den en la realidad. El Principio renuncia a lo que la percepción y el sentido común le impone.

Otros estudiantes revelaron una segunda causa, la visión del software en términos de funciones que transforman datos. Parnas la menciona como "The Flowchart 
Instinct". Es decir que los estudiantes diseñaban pensando en los flujos de control. Desafortunadamente, esta visión del software va en contra de la filosofía del Principio, ya que sus fundamentos están caracterizados por dos cualidades: percepción matemática del mundo y organización jerárquica de los sistemas. Ambos podrían ser atribuidos también a la influencia cultural, ya que han sido reconocidos a lo largo de la historia. Sin embargo, existen otras opiniones sobre su origen, como la planteada por Monteiro [73], quien provee una interesante perspectiva cognitiva para la organización jerárquica.

Ambas causas, referidas por Parnas, son razones para el fallo en la aplicación del Principio, entre sí son distintas con respecto al objeto particular, pero son iguales con respecto a la esencia: la dificultad de renunciar a las ideas arraigadas. Es duro imaginar módulos distintos a los convencionales: funciones, procesos y datos, tanto como sobrepasar la propia percepción de la realidad que resulta familiar. Es duro abandonar la conocida y cómoda independencia de las acciones (dividir y ocultar) y tener que trabajar de modo holístico resulta más complicado; siendo esta una tercera causa.

Los estudiantes que estaban dentro del nivel de aproximación del Principio "insuficiente", también revelaron que una de las causas de esta insuficiencia es la falta de la visión holística de los cimientos del Principio, los cuales son radicalmente diferentes al paradigma establecido en los inicios de la Ingeniería de Software. Tal vez esta diferencia es uno de los orígenes de los problemas que hemos observado en el presente estudio de caso y también en una escala global.

Finalmente, se puede mencionar que la dificultad referida en [90] con respecto a la aplicación del Principio dentro de clases compuestas, no se encontró en este estudio. Esta dificultad fue identificada en forma de misconception y estuvo definida bajo la categoría del entendimiento del Principio de Ocultación, como que los atributos de una clase simple deberían ser accedidos directamente desde la clase compuesta en lugar de hacerlo a través de una interfaz. Sin embargo, nuestro estudio no consideró los aspectos de programación en detalle, donde [90] descubrió esta dificultad. Tampoco se ha encontrado en esta investigación, el pensamiento de un estudiante referido en [34], quien dijo: "I think I should know why information hiding is important but I can't think of it now (...)", aunque en este estudio, no hemos encontrado estas puntualizaciones, se cree que estos cuestionamientos estuvieron presentes, pero no fueron observados.

\subsection{Dificultades de aprendizaje y su nivel de persistencia}

La segunda investigación del estudio empírico tuvo como objetivo contestar la siguiente pregunta de investigación.

- ¿Qué dificultades de diseño de software tienen los estudiantes y cuál es su nivel de persistencia?

A continuación, se responden y discuten las preguntas de investigación planteadas anteriormente. 
Luego del análisis realizado a lo largo del período de instrucción, se obtuvieron 48 ideas de diseño de software de los estudiantes, de las cuales 42 fueron consideradas como dificultades, debido a que estas se oponían u obstaculizaban los principios de diseño establecidos para esta tesis. Estas dificultades fueron clasificadas en cuatro niveles de persistencia: persitencia baja, media, alta y potencial.

La persistencia baja se caracterizó por aquellas dificultades fugaces que aparecieron al inicio del período de instrucción y no volvieron a aparecer. La persistencia media se caracterizó por estar conformada por aquellas dificultades que aparecieron esporádicamente en varios ejercios a lo largo del período de instrucción, excepto en la versión final del ejercicio grupal. La persistencia alta fue definida por aquellas dificultades que desaparecieron y volvieron a aparecer y/o, aparecieron en la versión final del ejercicio grupal.

Las dificultades obtenidas del estudio de caso sugieren diversas relaciones entre ellas. Un ejemplo de esto, es la dificultad definida como "Preferencia a heredar una propiedad en lugar de delegar", una dificultad de alta persistencia que fue discutida en [96] veinticinco años atrás y se mantiene aún vigente según se ha detectado en este estudio. Desde el punto de vista del diseño de software, la preferencia a heredar en lugar de delegar tiene dos inconvenientes: establece dependencias muy fuertes y esto puede producir un uso peligroso de la herencia [65]. El último inconveniente, también es una consecuencia de otra dificultad de persistencia baja presentada en el estudio que es la "Herencia usada como taxonomía.

La "Sobrecarga de responsabilidades en un elemento" es una dificultad de persistencia alta, que también ha sido citada en otros trabajos, por ejemplo en el caso de los objetos [73] y en el caso de los Diagramas de Flujo de Datos [128]. Asignar las responsabilidades adecuadas a un elemento software es una tarea difícil. Esto se hizo patente en el caso de la "Definición de un concepto a través de propiedades que no estan relacionadas al concepto", aunque esta dificultad no se mostrara fuertemente a lo largo del estudio. En el presente estudio, también se han encontrado elementos con responsabilidades no cohesivas con el concepto y elementos con más responsabilidades de las que ellos deberían haber tenido. Ambas sobrecargas (cohesiva y no cohesiva) podrían estar relacionadas con la distribución y percepción de la complejidad en el diseño. Se puede llegar a pensar que un solo elemento es más simple que dos elementos a pesar de que dicho elemento sea interiormente muy complejo. Sin embargo, la sobrecarga también podría estar vinculada con la ausencia de un elemento con el cual repartir responsabilidades, lo cual encaja con la dificultad expresada en este estudio y que fue denominada como "Ausencia de un concepto Juego o insuficiencia al definirlo en una aplicación de juego" cuya persistencia fue de tipo media. La sobrecarga no cohesiva o inconexa también podría ser una manifestación de la idea de otorgar un alto nivel de control a un elemento. En cualquier caso, la sobrecarga perjudica los objetivos del desarrollo industrial de software.

La dificultad de "Otorgar un alto nivel de control a un elemento" no se detectó en los ejercicios finales. No obstante, esta idea podría estar encubierta en una sobrecarga no cohesiva según se indicó con anterioridad. Este pensamiento va de la mano de la idea "Uso de un elemento como programa principal (Main)" que apareció explicita- 
mente en las primeros ejercicios, aunque después desapareció o se moderó de forma camuflada. En este estudio de caso, se observó que el nivel de control disminuyó gradualmente a lo largo del curso. Los elementos con alto nivel de control dependen fuertemente de otros elementos y además, son puntos críticos del diseño; en resumen, son perjudiciales.

La "Dependencia de información de otros elementos para tomar decisiones" es una idea de fuerte persistencia. Esta visión apareció notablemente al inicio, por ejemplo con "Separación de cada concepto en dos elementos, uno de datos y otro de funciones", la "Definición de clases como datos" y "Definición de un identificador" ID como atributo de cada elemento", aunque no se mostraron. La visión de separar datos y funciones, se suavizó, aunque permaneció presente la dependencia de la información de otro elemento para tomar decisión o ejecutar algo. La dependencia se hizo más patente en los elementos de alto nivel de control y después, más sutil cuando se redujo el nivel de control.

También resultó interesante que algunos estudiantes aplicaron técnicas para ocultar información usando interfaces o intentando no compartir detalles internos de la clase, con el fin de realizar diseños de dependencia reducida. Sin embargo, no lograron cumplir con ese objetivo. La idea "Uso de get y set para esconder los detalles internos de la clase" posiblemente es otra dificultad para conseguir un diseño software de mínima dependencia entre elementos. Mientras mayor sea la dependencia, menos condiciones tiene el software para ser desarrollado de forma industrial.

La dificultad en el manejo de las listas fue también un problema persistente que se ha manifestado con distintos matices. Por ejemplo, "No se hace explícito cómo ni dónde se manejan las listas", "Ausencia de un elemento que haga de contenedor o insuficiencia al definirlo", de persistencia alta y media respectivamente.

Alrededor de la herencia y el polimorfismo se han encontrado diversas ideas: "Herencia usada como taxonomía", "Herencia usada para reusar código", "Preferencia a heredar una propiedad en lugar de delegar", "Definición en herencia de hijos vacíos iguales a los padres", "Acceso a hijos desde el exterior a través de relaciones directas que ignoran al padre y que acceden a métodos particulares que solo tiene el hijo", "Descomposición simultánea por conceptos y propiedades". Todas ellas delatan dificultades en la comprensión y aplicación de la herencia, que es un medio de descomposición. La herencia y el polimorfismo no existen en el enfoque estructurado, son beneficios, que no obstante, añaden complejidad al enfoque orientado a objetos. En las ideas encontradas, interesantes conflictos se apreciaron entre el tratamiento individual de la diversidad (particularizar) y el tratamiento uniforme de la diversidad.

Además de las ideas perjudiciales mostradas como dificultades, también se han encontrado también ideas positivas: "Definición de una interfaz para uniformizar la diversidad" y "Definición de una propiedad que es invisible para los elementos externos". Ambas conducen al mismo objetivo: ocultar información, es decir, reducir la dependencia de un elemento respecto a otros.

Al final del estudio, algunas ideas han quedado sin determinar su grado de persistencia, debido a que ellas no se han hecho explícitas después, por lo que no se puede asegurar que han desaparecido. Tomando el peor caso, se ha decidido denominarlas Potencialmente persistentes. Estas dificultades fundamentalmente están asociadas con 
el Principio de Ocultación de Información [84] que históricamente ha sido una técnica de difícil comprensión y aplicación [86, 9, 92]. Más reciente, el estudio [90] ha detectado misconceptions alrededor del Principio de Ocultación. También hay una idea relacionada con el concepto convencional de acoplamiento, entremezclada con la herencia, pero no vinculada con el Principio. Esta idea supone que la dependencia resulta de las conexiones directas entre clases concretas y de la cantidad de relaciones entre clases ("Principio de Ocultación de Información asociado a una nula o baja dependencia entre entidades y a no tener relaciones entre clases concretas").

Para resumir, las dificultades concretas sobre el diseño software que han aflorado en el presente estudio son signos o picos de una compleja plataforma interior de los estudiantes, conformada por la visión individual del mundo en general y por el efecto de la instrucción particular.

\subsection{Dificultades esenciales de aprendizaje y sus orígenes}

La última investigación del estudio empírico tuvo como objetivo contestar las siguientes preguntas de investigación.

- ¿Cuáles son las dificultades esenciales de aprendizaje?

- ¿Cuáles son los posibles orígenes de dichas dificultades esenciales?

A continuación, se exponen y se discuten las preguntas de investigación planteadas anteriormente.

Con las dificultades identificadas en el estudio precedente, se obtuvieron las dificultades esenciales, las cuales fueron definidas como aquella dificultad abstraída que cubre a un grupo de dificultades obtenidas desde los estudiantes.

Se identificaron cinco dificultades esenciales, las mismas que fueron clasificadas en influencias, insuficiencias y malentendidos. Adicionalmente, se identificaron posibles orígenes de las dificultades esenciales.

A continuación se discuten cada una de las dificultades esenciales encontradas y se exponen los perjuicios que estas causan al momento de conseguir diseños de software con las características de facilidad de distribución del trabajo de desarrollo, modificabilidad y comprensibilidad.

- Una dificultad esencial identificada en este estudio empírico, es la influencia de copiar la realidad en el software. Sus diversas manifestaciones se dirigen hacia un mismo punto, limitar la libertad de un diseño a comportarse como en la vida real, conduciendo de esta manera a un diseño rígido y poco flexible a los cambios.

Dos posibles orígenes para la influencia de copiar la realidad en el software fueron expuestos en este estudio. El primero, la amplia aceptación de copiar la realidad entre autores de renombre y su divulgación en la literatura y la segunda, la aceptación como cierta de la propiedad de naturalidad atribuida al 
enfoque orientado a objetos; naturalidad entendida como la aceptación de que el enfoque orientado a objetos es natural.

- La segunda dificultad esencial es la influencia del enfoque estructurado. Esta influencia va en contra del diseño de software eficiente de distintas maneras. Como primero, los lineamientos del enfoque estructurado son contrarios al Principio de Ocultación, por ende son perjudiciales al momento de conseguir las propiedades que se espera de un diseño eficiente. Entre otras manifestaciones del enfoque estructurado, la concepción de la "función que transforma datos" llevada al diseño orientado a objetos, promueve el desarrollo de diseños con elementos hegemónicos a nivel jerárquico con alto nivel de control y con fuertes dependencias que impiden a los desarrolladores poder trabajar en grupos separados con la mínima necesidad de comunicación. Negando de esta manera la propiedad de facilidad de distribución del trabajo de desarrollo de un diseño eficiente.

Tanto la influencia de copiar la realidad en el software como la influencia del enfoque estructurado tienen una característica en común, ambas, adquieren un compromiso que les obliga a definir una forma de módulo establecida, limitando la libertad de construir y colocar los módulos de otra manera. El diseño de sistemas cuasi-descomponibles requiere de cierta libertad para poder construir módulos con menor dependencia. El Principio de Ocultación requiere criterios diferentes de descomposición diferentes a los expresados en el enfoque estructurado.

Para conseguir el tipo de diseño que satisfaga las propiedades de facilidad en la distribución de trabajo de desarrollo, modificabilidad y comprensibilidad, se debe renunciar a copiar la realidad y a diseñar bajo los los criterios del enfoque estructurado. Ambas influencias perjudican el objetivo del diseño que cumple con las tres propiedades elementales mencionadas anteriormente.

Dos orígenes fueron propuestos. En primer lugar la intención de trasladar el conocimiento previo del enfoque estructurado al momento de diseñar bajo el enfoque orientado a objetos y la posibilidad de que el pensamiento humano pudiera ser de tipo procedimental.

- La siguiente dificultad esencial, es la insuficiencia en la concepción de conceptos y sus responsabilidades. Si bien esta insuficiencia no atenta de manera directa contra la obtención de las tres propiedades que debería el tipo de diseño que se quiere conseguir, esta dificultad esencial obstaculiza el camino para construir partes del sistema con comportamiento propio que puedan ser estudiadas de manera aislada, y que requieran de la mínima comunicación con otras partes, además, también impide poder separar el trabajo. En consecuencia, si los conceptos tienen más responsabilidades de las que debería tener, o son ajenas al concepto, el entendimiento del diseño se hace más complejo y por ende más costoso.

Esta insuficiencia no está en contra de manera directa, como lo son las influencias de copiar la realidad en el software y la influencia del enfoque estructurado. 
No obstante, la insuficiencia en concebir conceptos y sus responsabilidades representa un obstáculo en el camino hacia el objetivo. Esta insuficiencia, por concepto, demuestra la incapacidad de los individuos al momento de definir los módulos, por lo que su insuficiencia genera problemas en la descomposición del sistema y su posterior distribución de responsabilidades.

Un posible origen de esta insuficiencia se presentó en este estudio, el cual recae directamente en los problemas que conlleva el proceso de abstracción.

- La penúltima dificultad esencial está relacionada a los malentendidos alrededor del Principio de Ocultación. El Principio es uno de los caminos para lograr sistemas cuasi-descomponibles, por lo que su mal entendimiento es claramente un obstáculo. Las manifestaciones de los malentendios como considerar que la ocultación de información es la ocultación de los detalles internos, sabotea el Principio como un criterio que trata la descomposición del sistema, cuya consecuencia es la ocultación y no lo contrario.

De igual manera, otro pensamiento que refleja los malentendidos es la idea de que la división convencional lleva directamente a la ocultación. Esta tendencia en los estudiantes, impide colocar más esfuerzos en una descomposición que favorezca una débil dependencia entre la partes. La interpretación del Principio como ocultación o división, impide lograr sistemas cuasi-descomponibles, por ende, impide lograr sistemas con facilidad de distribución del trabajo de desarrollo, modificales y comprensibles.

Entre los orígenes de los malentendidos alredor del Principio de Ocultaciónen esta el traslado de los términos cohesión y acoplamiento al concepto de minimizar la dependencia usada en el Principio. Otro origen está centrado en las diferentes interpretaciones y definiciones del Principio encontrados en la literatura. El último origen está dirigido a la falta de comprensión del Principio desde un punto de vista holístico.

- La última dificultad esencial apunta a los malentendidos alrededor de la herencia. Los malos uso de la herencia representan un obstáculo de cara a la implementación de mecanismos del enfoque orientado a objeto que facilitan la implementación del Principio de Ocultación. Por ejemplo, la herencia como un mecanismo de descomposición y su mal uso, lleva a distorsionar su verdadera potencialidad como unificador de la diversidad a través de la introducción de incertidumbre.

Uno de los posibles orígenes de los malentendidos alrededor de la herencia pudiera estar en los beneficios exclusivos de la herencia expuestos en la literatura y el desconocimiento de mecanismos que no existen en el enfoque estructurado.

Las dificultades esenciales que emergen de este estudio de caso, muestran como éstas se oponen u obstaculizan la implementación de diseños gestionables, flexibles y comprensibles. Las dificultades esenciales no pueden ser vistas de manera aislada, ya que entre ellas existe una estrecha relación y por ende deberían ser tratas de manera holística. 



\section{Parte IV}

\section{Conclusiones y líneas de investigación futuras}





\section{Capítulo 11}

\section{Conclusiones y líneas de investigación futuras}

En este capítulo se describen las conclusiones y líneas de investigación generadas por el desarrollo de esta tesis. En primer lugar, se describe de manera general las conclusiones de la tesis en una sección de introducción. Posteriormente se especifican de manera resumida las contribuciones de este trabajo de investigación y los beneficios que lleva consigo en los distintos ámbitos de la educación, profesional y metodológico. Finalmente se plantean algunas líneas de investigación y trabajo futuro.

\subsection{Introducción}

El trabajo de investigación presentando en esta tesis responde las preguntas de investigación propuestas. La contribución de este estudio empírico se centra en el aporte que ofrecen las distintas perspectivas de las dificultades de aprendizaje de diseño de software.

Por un lado, se describen con detalle las dificultades que presentan los estudiantes al momento de diseñar, muchas de las dificultades han sido ideas sueltas o especulaciones sin formalizar, siendo las dificultades aquí expuestas valioso conocimiento concreto que refleja la diversidad de ideas obtenidas desde el individuo mismo. Por otro lado, se muestran las dificultades esenciales cuyo desconocimiento es frecuente en el mundo académico y docente, aunque valioso, su aislado conocimiento presenta solo una visión abstraída de la problemática. Este trabajo presenta, ambas perspectivas, empezando desde las dificultades en un grado de granularidad alto, hasta las dificultades esenciales como un paraguas de cada dificultad encontrada. El conocimiento de las dificultades en sus diversas perspectivas, habilita a los docentes corregir desde sus fundamentos las dificultades que salen a la superficie.

Este estudio no ofrece ni pretende generalidades, pero demuestra con rigor científico qué sucede en un caso concreto. 


\subsection{Contribuciones en el área de Computer Science Education Research}

Las contribuciones de este trabajo de manera más detallada se presentan a continuación.

- Precisa el entendimiento sobre el Principio de Ocultación de Información en el marco de un estudio de caso. La primera contribución de esta tesis presenta tres aportaciones alrededor del entendimiento del Principio de Ocultación. La primera aportación, es la caracterización y aproximación de cada estudiante al Principio de Ocultación de Información. El segundo aporte, está centrado en las interpretaciones que tuvieron los estudiantes sobre el Principio, las que se resumen en dos direcciones: a) la ocultación de información entendida como ocultar el interior de los módulos y; b) la división produce ocultación de información. La tercera aportación con respecto al Principio, es el estudio y definición de tres posibles causas del entendimiento mostrado por los estudiantes sobre el Principio, siendo la primera de ellas tendencia a copiar la realidad en el software seguido de los criterios de los flujos de control y la falta de concepción holística del Principio.

- Precisa las dificultades de aprendizaje y su nivel de persistencia en el marco de un estudio de caso. La segunda contribución de esta tesis se presenta en forma de 41 dificultades concretas obtenidas de los estudiantes a lo largo del período de instrucción y repartidas en cuatro niveles de persistencia: bajo, medio, alto y potencial. Además, ofrece un análisis sobre las relaciones entre las dificultades, haciendo explícita la correlación entre ellas.

- Precisa las dificultades esenciales de aprendizaje y sus orígenes en el marco de un estudio de caso. La tercera contribución describe otra perspectiva de las dificultades de los estudiantes agrupandólas según su similitud en dificultades esenciales. Cinco dificultades esenciales fueron obtenidas como resultado: la primera, la influencia de copiar la realidad en el software cuyos posibles orígenes podrían descansar en la proposición de copiar la realidad por autores de renombre y la propiedad de naturalidad atribuída a los objetos. La segunda dificultad esencial analizada, es la influencia del enfoque estructurado originado posiblmente en la tendencia a trasladar los conocimientos previos del enfoque estructurado y la posiblidad de que el pensamiento humano sea de tipo procedimental. La tercera dificultad esencial es establecida como la insuficiencia en la concepción de conceptos y la asignación de sus responsabilidades, cuyo posible orígen radica en la complejidad del proceso de abstracción. Finalmente dos malentendidos se identificaron como dificultades esenciales, el uno con respecto al Principio de Ocultación y el otro dirigido a la herencia. Los orígenes del primero podrían estar en el traslado de los términos cohesión y acoplamiento hacia la idea de "minimizar la dependencia" usada en el Principio, las diferentes interpretaciones y definiciones del Principio encontradas en la literatura y la falta de comprensión desde un punto de vista holístico del Principio. Finalmente, 
los posibles orígenes de la herencia podrían estar arraigados en los beneficios exclusivos de la herencia expuestos en la literatura y el desconocimiento de mecanismos que no existen en el enfoque estructurado.

\subsection{Contribución a nivel de educación}

Esta tesis, al estar relacionada directamente al aprendizaje, trae consigo beneficios en el aspecto académico.

- Resultados como referencia para otros estudios. Los resultados de la tesis pueden servir de referencia para su aplicación en otros contextos similares de enseñanza de diseño de software orientado a objetos. De hecho, los resultados obtenidos fueron aplicados en el Proyecto de Innovación Educativa (IE141510010), concluido con éxito

\subsection{Contribución a nivel profesional}

Los resultados obtenidos de este trabajo de investigación pueden ser considerados como beneficio en el aspecto profesional.

- Advierte de los posibles problemas en el desarrollo de software de una empresa. A nivel profesional, el presente trabajo, advierte a la industria de software sobre las posibles fuentes de los problemas que tienen los estudiantes a pesar de superar el grado o Máster. Siendo una posibilidad que las dificultades identificadas aquí se trasladen a la industria.

\subsection{Contribución a nivel metodológico}

Esta tesis, aporta también en el aspecto metodológico al presentar un proceso metodológico concreto para un estudio de caso.

- Demuestra que la metodología usada es efectiva para la obtención de los objetivos. La metodología usada confirma la eficacia para conseguir los objetivos planteados para este contexto

- Aporta un ejemplo concreto del desarrollo metodológico para un estudio de caso cualitativo. La investigación empleó un proceso metodológico que permitió tener una amplia visión del entendimiento y dificultades de los estudiantes a lo largo de un período de instrucción. El contexto y aspecto metodológico es presentado a detalle desde los datos de origen hasta los resultados obtenidos, permitiendo a otros investigadores buscar otros contextos donde este estudio sea aplicable. 


\subsection{Líneas de investigación futuras}

En esta sección se presentan algunas de las líneas de investigación qué deja el desarrollo de esta tesis.

- Estudiar alrededor del tipo de ejercicio y su relación con el enfoque de diseño. Una posible línea de investigación, está relacionada a conocer los efectos que tienen los tipos de ejercicios sobre un enfoque en particular y su influencia en la estrategia para resolver el problema. Investigar sobre qué dimensiones del ejercicio son relevantes con el fin de determinar qué favorece o perjudica en función del enfoque de diseño, es una línea de trabajo futuro.

- Definir estrategias que ayuden a la transición del enfoque estructurado al enfoque orientado a objetos. Aunque existen propuestas como ObjectFirst, hasta la actualidad muchos planes de estudio mantienen la enseñanza del enfoque estructurado previo al enfoque orientado a objetos. Como se ha visto en este trabajo de investigación, la influencia del aprendizaje previo es una posible dificultad en el aprendizaje del enfoque orientado a objetos. Investigar sobre las herramientas, programas de aprendizaje o actividades que ayuden a los estudiantes a superar la transición y el traslado de lo aprendido anteriormente hacia el enfoque orientado a objetos es un área de estudio potencial. En la literatura pocos estudios han centrado sus esfuerzos a solucionar el problema.

- Investigar sobre la creación de test para la identificación de dificultades. Otra línea de investigación, es el estudio de test que permitan identificar las dificultades de aprendizaje. Un ejemplo de esto en otra área, es el Force Concept Inventory definido para el área de la Física y el cual permite evaluar el entendimiento de la dinámica newtoniana.

- Investigar sobre las estrategias que ayuden a superar las dificultades obtenidas en este estudio de caso. Una posible línea futura, pudiera estar basado en las dificultades obtenidas en este trabajo de investigación, proponiendo soluciones o estrategias para superar dichas dificultades. 


\section{Bibliografía}

[1] Isaac Abimbola. The problem of terminology in the study of student conceptions in science. Science Education, 72(2):175-184, 1988.

[2] Ritu Agarwal, Prabuddha De, Atish Sinha, and Mohan Tanniru. On the usability of oo representations. Commun. ACM, 43(10):83-89, October 2000 .

[3] Ritu Agarwal, Pradipta De, and Atish Sinha. Comprehending object and process models: An empirical study. Software Engineering, IEEE Transactions on, 25(4):541-556, 1999.

[4] Ritu Agarwal, Atish Sinha, and Mohan Tanniru. The role of prior experience and task characteristics in object-oriented modeling: an empirical study. International journal of human-computer studies, 45(6):639-667, 1996.

[5] Fernando Alonso, Loïc Martínez, and Francisco Segovia. Introducción a la ingeniería del software: Modelos de desarrollo de programas. Delta Publicaciones, 2005.

[6] Lewis Anthony Dexter. Elite and specialized interviewing. 1970.

[7] Deborah Armstrong. The quarks of object-oriented development. Communications of the ACM, 49(2):123-128, 2006.

[8] David Bellin. A seminar course in object oriented programming. In Proceedings of the Twenty-third SIGCSE Technical Symposium on Computer Science Education, SIGCSE '92, pages 134-137, New York, NY, USA, 1992. ACM.

[9] Edward Berard and Mark Twain. Abstraction, encapsulation, and information hiding. Essays on Object-Oriented Software Engineering, 1, 1993.

[10] SolyMathew Biju. Difficulties in understanding object oriented programming concepts. In Khaled Elleithy and Tarek Sobh, editors, Innovations and Advances in Computer, Information, Systems Sciences, and Engineering, volume 152 of Lecture Notes in Electrical Engineering, pages 319326. Springer New York, 2013.

[11] Alan Blackwell, Luke Church, and Thomas Green. The abstract is 'an enemy': Alternative perspectives to computational thinking. Submitted to PPIG, 2008. 
[12] Gordon Blair, John Gallagher, David Hutchison, and Doug Shepherd. Object-oriented languages, systems and applications. Halsted Press, 1991.

[13] Grady Booch. Object-oriented development. Software Engineering, IEEE Transactions on, SE-12(2):211-221, Feb 1986.

[14] Grady Booch. Object-oriented Analysis and Design with Applications (2Nd Ed.). Benjamin-Cummings Publishing Co., Inc., Redwood City, CA, USA, 1994.

[15] Alexander Borgida, Sol Greenspan, and Jhon Mylopoulos. Knowledge representation as the basis for requirements specifications. Computer, 18(4):82-91, April 1985.

[16] Roger Box and Michael Whitelaw. Experiences when migrating from structured analysis to object-oriented modelling. In Proceedings of the Australasian Conference on Computing Education, ACSE '00, pages 1218, New York, NY, USA, 2000. ACM.

[17] Frederick Brooks. The mythical man-month, volume 1995. AddisonWesley Reading, MA, 1975.

[18] Frederick Brooks. The Mythical Man-Month, Anniversary Edition: Essays on Software Engineering. Pearson Education, 1995.

[19] Osvaldo Clúa and María Feldgen. Work in progress-object oriented metrics and programmers' misconceptions. In Frontiers in Education Conference, 2008. FIE 2008. 38th Annual, pages F3H-19. IEEE, 2008.

[20] Alistair Cockburn. Object-oriented analysis and design. $\mathrm{C} / \mathrm{C}++$ Users Journal, 1998.

[21] Ole-Johan Dahl. The roots of object orientation: The simula language. In M. Broy and E. Denert, editors, Software Pioneers, pages 78-90. Springer Berlin Heidelberg, 2002.

[22] J. Daly, J. Miller, A. Brooks, M. Roper, and M. Wood. A survey of experiences amongst object-oriented practitioners. In Software Engineering Conference, 1995. Proceedings., 1995 Asia Pacific, pages 137-146, Dec 1995.

[23] Alan Davis. Fifteen principles of software engineering. Software, IEEE, 11(6):94-96, Nov 1994.

[24] Tom DeMarco. Structured analysis and system specification. Yourdon Press, 1979.

[25] Tom DeMarco. Controlling software projects: Management, measurement, and estimation. Yourdon Press, 1982.

[26] Françoise Détienne. Difficulties in designing with an object-oriented language: An empirical study. In Proceedings of the IFIP TC13 Third Interational Conference on Human-Computer Interaction, pages 971-976. North-Holland Publishing Co., 1990. 
[27] Françoise Détienne. Design strategies and knowledge in object-oriented programming: effects of experience. Human-Computer Interaction, 10(23):129-169, 1995.

[28] Françoise Détienne. Assessing the cognitive consequences of the objectoriented approach: A survey of empirical research on object-oriented design by individuals and teams. Interacting with Computers, 9(1):47-72, 1997.

[29] Françoise Détienne. Reasoning from a schema and from an analog in software code reuse. arXiv preprint cs/0701200, 2007.

[30] Françoise Détienne and Frank Bott. Software Design-Cognitive Aspect. Springer Science \& Business Media, 2002.

[31] Edsger Dijkstra. Notes on structured programming, 1970.

[32] Edsger Dijkstra. Ewd 1308: What led to "notes on structured programming". In M. Broy and E. Denert, editors, Software Pioneers, pages 340346. Springer Berlin Heidelberg, 2002.

[33] R Duncan. Power programming. c++: An oopl only a c programmer could love. PC Magazine, 10:441, 1991.

[34] Anna Eckerdal. Novice programming students' learning of concepts and practise. PhD thesis, Uppsala University, 2009.

[35] Anna Eckerdal and Michael Thuné. Novice java programmers' conceptions

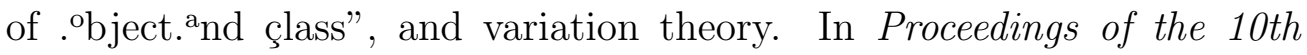
Annual SIGCSE Conference on Innovation and Technology in Computer Science Education, ITiCSE '05, pages 89-93, New York, NY, USA, 2005. $\mathrm{ACM}$.

[36] Dennis Egan and Barry Schwartz. Chunking in recall of symbolic drawings. Memory \& Cognition, 7(2):149-158, 1979.

[37] Hillel Einhorn and Robin Hogarth. Behavioral decision theory: Processes of judgment and choice. Journal of Accounting Research, pages 1-31, 1981.

[38] Davide Falessi, Giovanni Cantone, and Claudio Grande. A comparison of structured analysis and object oriented analysis an experimental study. 2007.

[39] Pamela Flores, Nelson Medinilla, and Sonia Pamplona. What do software design students understand about information hiding?: A qualitative case study. In Proceedings of the 14th Koli Calling International Conference on Computing Education Research, Koli Calling '14, pages 61-70, New York, NY, USA, 2014. ACM.

[40] Pamela Flores, Nelson Medinilla, and Sonia Pamplona. Persistent ideas in software design course:a qualitative case study. International Journal of Engineering Education, in press. 
[41] Erich Gamma, Richard Helm, Ralph Johnson, and John Vlissides. Design patterns: elements of reusable object-oriented software. Pearson Education, 1994.

[42] David Gough, Sandy Oliver, and James Thomas. An introduction to systematic reviews. Sage, 2012.

[43] Ian Graham. Object oriented methods. Addison-Wesley, 1994.

[44] Eddie Gray and David Tall. Abstraction as a natural process of mental compression. Mathematics Education Research Journal, 19(2):23-40, 2007.

[45] Bart Green, Claire Johnson, and Alan Adams. Writing narrative literature reviews for peer-reviewed journals: secrets of the trade. Journal of chiropractic medicine, 5(3):101-117, 2006.

[46] JohnV Guttag. Abstract data types, then and now. In M. Broy and E. Denert, editors, Software Pioneers, pages 442-452. Springer Berlin Heidelberg, 2002.

[47] Irit Hadar. When intuition and logic clash: The case of the object-oriented paradigm. Science of Computer Programming, 78(9):1407 - 1426, 2013.

[48] Said Hadjerrouit. A constructivist approach to object-oriented design and programming. In Proceedings of the 4th Annual SIGCSE/SIGCUE ITiCSE Conference on Innovation and Technology in Computer Science Education, ITiCSE '99, pages 171-174, New York, NY, USA, 1999. ACM.

[49] Wayne Haythorn. What is object-oriented design? JOOP, 7(1):67-78, 1994.

[50] David Hestenes, Malcolm Wells, and Gregg Swackhamer. Force concept inventory. The physics teacher, 30(3):141-158, 1992.

[51] Simon Holland, Robert Griffiths, and Mark Woodman. Avoiding object misconceptions. In ACM SIGCSE Bulletin, volume 29, pages 131-134. ACM, 1997.

[52] Peter Hubwieser and Andreas Mühling. What students (should) know about object oriented programming. In Proceedings of the Seventh International Workshop on Computing Education Research, ICER '11, pages 77-84. ACM, 2011.

[53] S. Huynh, C. Yuanfang, S. Yuanyuan, and K. Sullivan. Automatic modularity conformance checking. In Software Engineering. ICSE '08. ACM/IEEE 30th International Conference on, pages 411-420, May 2008.

[54] Michael Jackson. Principles of program design, volume 123790506. IMA, 1975.

[55] Samireh Jalali and Claes Wohlin. Systematic literature studies: Database searches vs. backward snowballing. In Proceedings of the ACM-IEEE International Symposium on Empirical Software Engineering and Measurement, ESEM '12, pages 29-38, New York, NY, USA, 2012. ACM. 
[56] Robin Jeffries, Althea A Turner, Peter Polson, and Michael Atwood. The processes involved in designing software. Cognitive skills and their acquisition, 255:283, 1981.

[57] Lisa Kaczmarczyk, Elizabeth Petrick, Philip East, and Geoffrey Herman. Identifying student misconceptions of programming. In Proceedings of the 41st ACM Technical Symposium on Computer Science Education, SIGCSE '10, pages 107-111. ACM, 2010.

[58] Amela Karahasanović, Annette Kristin Levine, and Richard Thomas. Comprehension strategies and difficulties in maintaining object-oriented systems: An explorative study. Journal of Systems and Software, 80(9):1541 - 1559, 2007. Evaluation and Assessment in Software EngineeringEASE06.

[59] C. Kästner, S. Apel, and K. Ostermann. The road to feature modularity? In Proceedings of the 15th International Software Product Line Conference, Volume 2, pages 5:1-5:8, New York, NY, USA, 2011. ACM.

[60] Beth Lange and Thomas Moher. Some strategies of reuse in an objectoriented programming environment. In $A C M$ SIGCHI Bulletin, volume 20, pages 69-73. ACM, 1989.

[61] Jill Larkin, John McDermott, Dorothea P Simon, and Herbert A Simon. Expert and novice performance in solving physics problems. Science, 208(4450):1335-1342, 1980.

[62] John Lewis. Myths about object-orientation and its pedagogy. In Proceedings of the Thirty-first SIGCSE Technical Symposium on Computer Science Education, SIGCSE '00, pages 245-249, New York, NY, USA, 2000. ACM.

[63] Neomi Liberman, Catriel Beeri, and Yifat Ben-David Kolikant. Difficulties in learning inheritance and polymorphism. Trans. Comput. Educ., 11(1):4:1-4:23, February 2011.

[64] Yvonna Lincoln and Egon Guba. Naturalistic inquiry, volume 75. Sage, 1985.

[65] Barbara Liskov. Keynote address-data abstraction and hierarchy. ACM Sigplan Notices, 23(5):17-34, 1988.

[66] Sandra Madison. A Study of College Students, Construct of Parameter Passing: Implications for Instruction. PhD thesis, Milwaukee, WI, USA, 1995. UMI Order No. GAX96-10349.

[67] Mary Lynn Manns and Jim Nelson. An exploration of schema development in procedure-oriented programmers learning object-oriented technology. In ICIS, pages 385-386, 1993.

[68] Stephen McConnell. Missing in action: information hiding. Software, IEEE, 13(2):128-, Mar 1996. 
[69] Michael McCracken, Wendy Newstetter, and Jeff Chastine. Misconceptions of designing: A descriptive study. SIGCSE Bull., 31(3):48-51, June 1999 .

[70] Nelson Medinilla. Elementos para el análisis de métodos de ingeniería del software según su complejidad de incertidumbre. PhD thesis, Boadilla del Monte, Madrid, Spain, 2008.

[71] Sharan Merriam. Qualitative Research and Case Study Applications in Education. Revised and Expanded fromÇase Study Research in Education. ERIC, 1998.

[72] Iain Milne and Glenn Rowe. Difficulties in learning and teaching programming\&mdash;views of students and tutors. Education and Information Technologies, 7(1):55-66, March 2002.

[73] Miguel Monteiro. On the cognitive foundations of modularity. 2011.

[74] Michael Morris, Cheri Speier, and Jeffrey Hoffer. An examination of procedural and object-oriented systems analysis methods: Does prior experience help or hinder performance?*. Decision Sciences, 30(1):107-136, 1999 .

[75] Ricardo Moya. Herencia en Java, con ejemplos. http://jarroba.com/ herencia-en-la-programacion-orientada-a-objetos-ejemplo-en-java/, 2014.

[76] Thomas Muhr. ATLAS/ti - A prototype for the support of text interpretation. Qualitative sociology, 14(4):349-371, 1991.

[77] Keiron Nicholson, Judith Good, and Katy Howland. Concrete thoughts on abstraction. In 21st Annual Psychology of Programming Interest Group Workshop (PPIG 2009), University of Limerick, Ireland, 2009.

[78] Real Academia Espa nola. Diccionario de la lengua española. http: //dle.rae.es/?w=diccionario, 2015.

[79] Rachel Or-Bach and Ilana Lavy. Cognitive activities of abstraction in object orientation: an empirical study. ACM SIGCSE Bulletin, 36(2):8286, 2004.

[80] Thomas O'Shea. Panel: The learnability of object-oriented programming systems. object-oriented programming systems, languages and applications. In Proceedings of OOPSLA '86, pages 502-504. ACM, 1986.

[81] Sonia Pamplona, Nelson Medinilla, and Pamela Flores. Exploring misconceptions of operating systems in an online course. In Proceedings of the 13th Koli Calling International Conference on Computing Education Research, Koli Calling '13, pages 77-86, New York, NY, USA, 2013. ACM.

[82] Sonia Pamplona, Nelson Medinilla, and Pamela Flores. Assessment for learning: A case study of an online course in operating systems. International Journal of Engineering Education, 31(2):541-552, 2015. 
[83] Seymour Papert. Mindstorms: Children, computers, and powerful ideas. Basic Books, Inc., 1980.

[84] David Parnas. On the criteria to be used in decomposing systems into modules. Commun. ACM, 15(12):1053-1058, December 1972.

[85] David Parnas. Successful software engineering research. SIGSOFT Softw. Eng. Notes, 23(3):64-68, May 1998.

[86] David Parnas. The secret history of information hiding. In Software pioneers, pages 398-409. Springer, 2002.

[87] Nancy Pennington, Adrienne Lee, and Bob Rehder. Cognitive activities and levels of abstraction in procedural and object-oriented design. Human-Computer Interaction, 10(2-3):171-226, 1995.

[88] Nelishia Pillay. A study of object-oriented design errors made by novice programmers. In Proceedings of the 2009 Annual Conference of the Southern African Computer Lecturers' Association, SACLA '09, pages 101-104, New York, NY, USA, 2009. ACM.

[89] Roger Pressman. Ingeniería del Software: Un enfoque práctico. McGrawHill, 1997.

[90] Noa. Ragonis and Mordechai Ben-Ari. A long-term investigation of the comprehension of oop concepts by novices. 2005.

[91] Bryan Ratcliff and Jawed IA Siddiqi. An empirical investigation into problem decomposition strategies used in program design. International Journal of Man-Machine Studies, 22(1):77-90, 1985.

[92] Paul Rogers. Encapsulation is not information hiding. JavaWorld. com, 5(18):01, 2001.

[93] Eleanor Rosch, Carolyn Mervis, Wayne Gray, David Johnson, and Penny Boyes-Braem. Basic objects in natural categories. Cognitive psychology, 8(3):382-439, 1976.

[94] Mary Beth Rosson and Sherman Alpert. The cognitive consequences of object-oriented design. Hum.-Comput. Interact., 5(4):345-379, Dec 1990.

[95] Mary Beth Rosson and John Carroll. Climbing the smalltalk mountain. SIGCHI Bull., 21(3):76--, January 1990.

[96] James Rumbaugh, Michael Blaha, William Premerlani, Frederick Eddy, William E. Lorensen, et al. Object-oriented modeling and design, volume 199. Prentice-hall Englewood Cliffs, 1991.

[97] Per Runeson and Martin Höst. Guidelines for conducting and reporting case study research in software engineering. Empirical software engineering, 14(2):131-164, 2009.

[98] Caspar Ryan, Ghassan Al-Qaimari, and Janice Langan-Fox. Teaching object-oriented analysis and design: A cognitive approach. In Proc. of SCI'97 World Multi-Conference on Systemics, Cybernetics and Informatics. Citeseer, 1997. 
[99] Johnny Saldaña. The coding manual for qualitative researchers. Number 14. Sage, 2012.

[100] Kate Sanders and Lynda Thomas. Checklists for grading object-oriented cs1 programs: concepts and misconceptions. In ACM SIGCSE Bulletin, volume 39, pages 166-170. ACM, 2007.

[101] John Seidel. Qualitative data analysis. 1998.

[102] Judy Sheard and Dianne Hagan. Experiences with teaching objectoriented concepts to introductory programming students using c++. In Technology of Object-Oriented Languages, 1997. TOOLS 24. Proceedings, pages 310-319, Sep 1997.

[103] Steven Sheetz. Identifying the difficulties of object-oriented development. J. Syst. Softw., 64(1):23-36, October 2002.

[104] Steven Sheetz, Gretchen Irwin, David Tegarden, James Nelson, and David Monarchi. Exploring the difficulties of learning object-oriented techniques. Journal of Management Information Systems, pages 103-131, 1997.

[105] Steven Sheetz and David Tegarden. Illustrating the cognitive consequences of object-oriented systems development. J. Syst. Softw., 59(2):163179, November 2001.

[106] Ronit Shmallo, Noa Ragonis, and David Ginat. Fuzzy oop: Expanded and reduced term interpretations. In Proceedings of the 17th ACM Annual Conference on Innovation and Technology in Computer Science Education, ITiCSE '12, pages 309-314, New York, NY, USA, 2012. ACM.

[107] Edward Sim and George Wright. The difficulties of learning objectoriented analysis and design: An exploratory study. The Journal of Computer Information Systems, 42(2):95, 2001.

[108] Herbert Simon. The architecture of complexity. In Proceedings of the American Philosophical Society, pages 467-482, 1962.

[109] Herbert Simon. The sciences of the artificial, volume 136. MIT press, 1969.

[110] Atish Sinha and Iris Vessey. Cognitive fit: an empirical study of recursion and iteration. Software Engineering, IEEE Transactions on, 18(5):368379, 1992.

[111] Teemu Sirkiä and Juha Sorva. Exploring programming misconceptions: an analysis of student mistakes in visual program simulation exercises. In Proceedings of the 12th Koli Calling International Conference on Computing Education Research, pages 19-28. ACM, 2012.

[112] Elliot Soloway, Jeffrey Bonar, and Kate Ehrlich. Cognitive strategies and looping constructs: An empirical study. Communications of the ACM, 26(11):853-860, 1983.

[113] Savitha Srinivasan. Design patterns in object-oriented frameworks. Computer, 32(2):24-32, 1999. 
[114] Robert Stake et al. Case studies in science education, volume i: The case reports. 1978.

[115] Kevin Sullivan, William Griswold, Yuanfang. Cai, and Ben Hallen. The structure and value of modularity in software design. SIGSOFT Softw. Eng. Notes, 26(5):99-108, September 2001.

[116] Steven Taylor and Robert Bogdan. Introduction to qualitative research methods: The search for meaning. 1984.

[117] David Tegarden and Steven Sheetz. Cognitive activities in oo development. International Journal of Human-Computer Studies, 54(6):779-798, 2001.

[118] Benjy Thomasson, Mark Ratcliffe, and Lynda Thomas. Identifying novice difficulties in object oriented design. In ACM SIGCSE Bulletin, volume 38, pages 28-32. ACM, 2006.

[119] André van der Hoek and Nicolas Lopez. A design perspective on modularity. In Proceedings of the tenth international conference on Aspectoriented software development, pages 265-280. ACM, 2011.

[120] Iris Vessey and Sue Conger. Requirements specification: Learning object, process, and data methodologies. Commun. ACM, 37(5):102-113, May 1994.

[121] Charles Welty and David Stemple. Human factors comparison of a procedural and a nonprocedural query language. ACM Trans. Database Syst., 6(4):626-649, December 1981.

[122] Garry White and Marcos Sivitanides. Cognitive differences between procedural programming and object oriented programming. Information Technology and management, 6(4):333-350, 2005.

[123] Roel Wieringa. A survey of structured and object-oriented software specification methods and techniques. ACM Computing Surveys (CSUR), 30(4):459-527, 1998.

[124] Quanfeng Wu and John Anderson. Strategy choice and change in programming. International journal of man-machine studies, 39(4):579-598, 1993.

[125] Stelios Xinogalos. Object-oriented design and programming: An investigation of novices\&rsquo; conceptions on objects and classes. Trans. Comput. Educ., 15(3):13:1-13:21, July 2015.

[126] Stelios Xinogalos, Maya Sartatzemi, Vassilios Dagdilelis, and Georgios Evangelidis. Teaching oop with bluej: A case study. In null, pages 944946. IEEE, 2006.

[127] Edward Yourdon. Modern Structured Analysis. Yourdon Press, Upper Saddle River, NJ, USA, 1989.

[128] Edward Yourdon and Alexandra Armitage. Análisis estructurado moderno, volume 5. Prentice-Hall, 1993. 
[129] Edward Yourdon and Larry Constantine. Structured design: Fundamentals of a discipline of computer program and systems design, volume 5. Prentice-Hall Englewood Cliffs, NJ, 1979. 


\section{Parte V}

\section{Apéndices}





\section{Apéndice A}

\section{Antecedentes de dificultades en el aprendizaje de diseño de software}

\begin{tabular}{|c|c|c|}
\hline Año & Estudios & Descripción \\
\hline 1970 & Dijkstra 31] & Problemas de diseño de software en general \\
\hline 1975 & Jackson [54 & Problemas de diseño de software en general \\
\hline 1981 & $\begin{array}{l}\text { Jeffries et al. } \\
{[56 \text {. }}\end{array}$ & $\begin{array}{l}\text { Problemas de diseño desde el punto de vista } \\
\text { cognitivo de resolución de problemas }\end{array}$ \\
\hline 1986 & O'Shea[80] & $\begin{array}{l}\text { Dificultades en aprender diseño OO en perso- } \\
\text { nas con experiencia en enfoque procedimental }\end{array}$ \\
\hline 1990 & $\begin{array}{l}\text { Rosson et al. } \\
95 \\
\text { Détienne } 26 \text { ] }\end{array}$ & $\begin{array}{l}\text { Dificultades en el aprendizaje de programa- } \\
\text { ción en ambientes OO (Smaltalk) } \\
\text { Problemas al diseñar con un lenguaje orienta- } \\
\text { do a objetos }\end{array}$ \\
\hline 1991 & Duncan 33. & $\begin{array}{l}\text { Dificultades en el aprendizaje de conceptos de } \\
\text { diseño y programación orientada a objetos }\end{array}$ \\
\hline 1992 & Bellin [8] & $\begin{array}{l}\text { Dificultades en el aprendizaje de conceptos de } \\
\text { diseño y programación orientada a objetos }\end{array}$ \\
\hline 1993 & $\begin{array}{l}\text { Manns et al. } \\
67 \text {. }\end{array}$ & $\begin{array}{l}\text { Dificultades de aprendizaje de OO provenien- } \\
\text { tes del conocimiento previo de estructurado }\end{array}$ \\
\hline 1994 & $\begin{array}{l}\text { Vessey et al. } \\
120\end{array}$ & $\begin{array}{l}\text { Dificultades en el aprendizaje y uso de técni- } \\
\text { cas OO }\end{array}$ \\
\hline 1995 & Brooks [18] & $\begin{array}{l}\text { Dificultades en la incorporación del enfoque } \\
\text { OO en actividades de desarrollo de sistemas }\end{array}$ \\
\hline & $\begin{array}{l}\text { Pennington et } \\
\text { al. } 87 \text { ] }\end{array}$ & $\begin{array}{l}\text { Dificultades que tienen los individuos princi- } \\
\text { piantes y expertos en OO Vs estructurado }\end{array}$ \\
\hline 1997 & $\begin{array}{l}\text { Shettz et al. } \\
{[104 \text {. }}\end{array}$ & Dificultades de aprendizaje de técnicas OO \\
\hline
\end{tabular}




\begin{tabular}{|c|c|c|}
\hline Año & Estudios & Descripción \\
\hline & Ryan et al. 98 & $\begin{array}{l}\text { Dificultades de aprendizaje de técnicas OO en } \\
\text { particular con experiencia previa en estructu- } \\
\text { rado }\end{array}$ \\
\hline & $\begin{array}{l}\text { Holland et al. } \\
\text { [51] }\end{array}$ & Dificultades de aprendizaje de conceptos OO \\
\hline 1999 & $\begin{array}{l}\text { Morris et al. } \\
\text { [74 }\end{array}$ & $\begin{array}{l}\text { Dificultades en la aplicación de técnicas OO } \\
\text { provenientes de la experiencia previa en pro- } \\
\text { cedimental }\end{array}$ \\
\hline & $\begin{array}{l}\text { Hadjerrouit } \\
48\end{array}$ & Dificultades de aprendizaje del enfoque OO \\
\hline 2000 & $\begin{array}{l}\text { Agarwal et } \\
\text { al.[2] }\end{array}$ & $\begin{array}{l}\text { Dificultades en los enfoques OO debido a la no } \\
\text { conjunción entre la metodología y el lenguaje } \\
\text { de programación }\end{array}$ \\
\hline & Lewis 62 & Mitos del enfoque orientado a objetos \\
\hline 2001 & $\begin{array}{l}\text { Sheetz et al. } \\
\text { [105] }\end{array}$ & $\begin{array}{l}\text { Dificultades en el aprendizaje de OO a pesar } \\
\text { de la propiedad de "natural" }\end{array}$ \\
\hline & $\begin{array}{l}\text { Tegarden et al. } \\
\text { 117] }\end{array}$ & $\begin{array}{l}\text { Dificultades relacionadas a } \mathrm{OO} \text { y al desarrollo } \\
\text { de software en general }\end{array}$ \\
\hline 2005 & $\begin{array}{l}\text { Ragonis et al. } \\
{[90]}\end{array}$ & $\begin{array}{l}\text { Dificultades y misconceptions en programa- } \\
\text { ción OO }\end{array}$ \\
\hline 2006 & Armstrong [7] & $\begin{array}{l}\text { Dificultad en el aprendizaje de OO relaciona- } \\
\text { do a la falta de entendimiento de los conceptos } \\
\text { fundamentales }\end{array}$ \\
\hline & $\begin{array}{l}\text { Thomasson et } \\
\text { al. [118] }\end{array}$ & Dificultades en el diseño de software \\
\hline 2007 & $\begin{array}{l}\text { Sanders et al. } \\
{[100 \text {. }}\end{array}$ & $\begin{array}{l}\text { Misconceptions en programas orientados a ob- } \\
\text { jetos }\end{array}$ \\
\hline 2008 & Clúa et al. [19] & $\begin{array}{l}\text { Misconceptions en programadores orientado a } \\
\text { objetos }\end{array}$ \\
\hline 2010 & $\begin{array}{l}\text { Kaczmarczyk } \\
\text { et al. [57] }\end{array}$ & $\begin{array}{l}\text { Misconceptions en programación orientado a } \\
\text { objetos }\end{array}$ \\
\hline 2012 & $\begin{array}{l}\text { Sirkiä et al. } \\
\text { [111] }\end{array}$ & $\begin{array}{l}\text { Misconceptions en programación orientada a } \\
\text { objetos en ejercicios de simulación visual }\end{array}$ \\
\hline 2014 & $\begin{array}{l}\text { Flores et al. } \\
\text { 39] }\end{array}$ & $\begin{array}{l}\text { Dificultades de aprendizaje relacionados al } \\
\text { Principio de Ocultación }\end{array}$ \\
\hline 2015 & $\begin{array}{l}\text { Flores et al. } \\
40\end{array}$ & $\begin{array}{l}\text { Dificultades en el diseño de software orientado } \\
\text { a objetos }\end{array}$ \\
\hline & $\begin{array}{l}\text { Xinogalos } \\
\text { al. [125] }\end{array}$ & $\begin{array}{l}\text { Dificultades en el entendimiento de los objetos } \\
\text { y las clases }\end{array}$ \\
\hline
\end{tabular}

Tabla A.1: Dificultades de diseño de software reportadas en la literatura 


\section{Apéndice B}

\section{Ejercicios del estudio de caso}

\section{B.1. Primer ejercicio individual (JIKEA)}

Taking as reference the concept of "Information Hiding" from the Parnas article, make the design of the application shown below. The purpose of the application is to test the furniture placement in the areas shown. Furniture can be moved, but can not overlap or be placed between two areas.

After seeing the application B-1, describe with words and drawings (class diagram, sequence diagram, etc). How will you make a design that does what has been shown to you. Explain in detail the meaning of the elements, operation and relationships of your design.

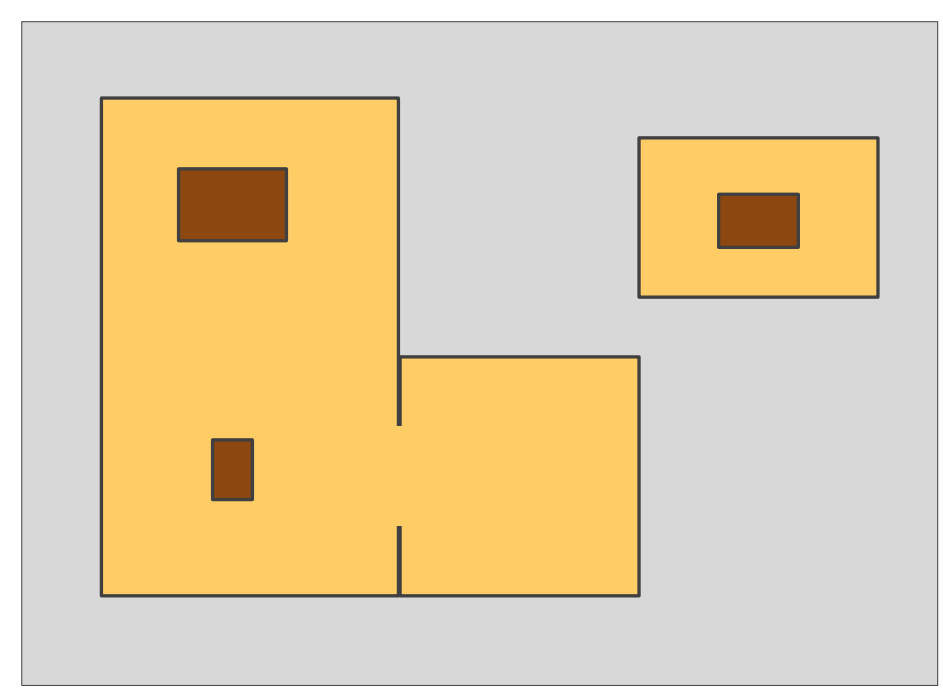

Figura B-1: Imagen de la aplicación JIKEA 


\section{B.2. Segundo ejercicio individual y grupal (SOKOBAN)}

Below (B-2) you can see an application called Sokoban, you can find the description related with this game in the link: https://en.wikipedia.org/wiki/Sokoban Please, make the design for this application and describe what each element does. Use sequence diagram or descriptive text in order to explain your design.

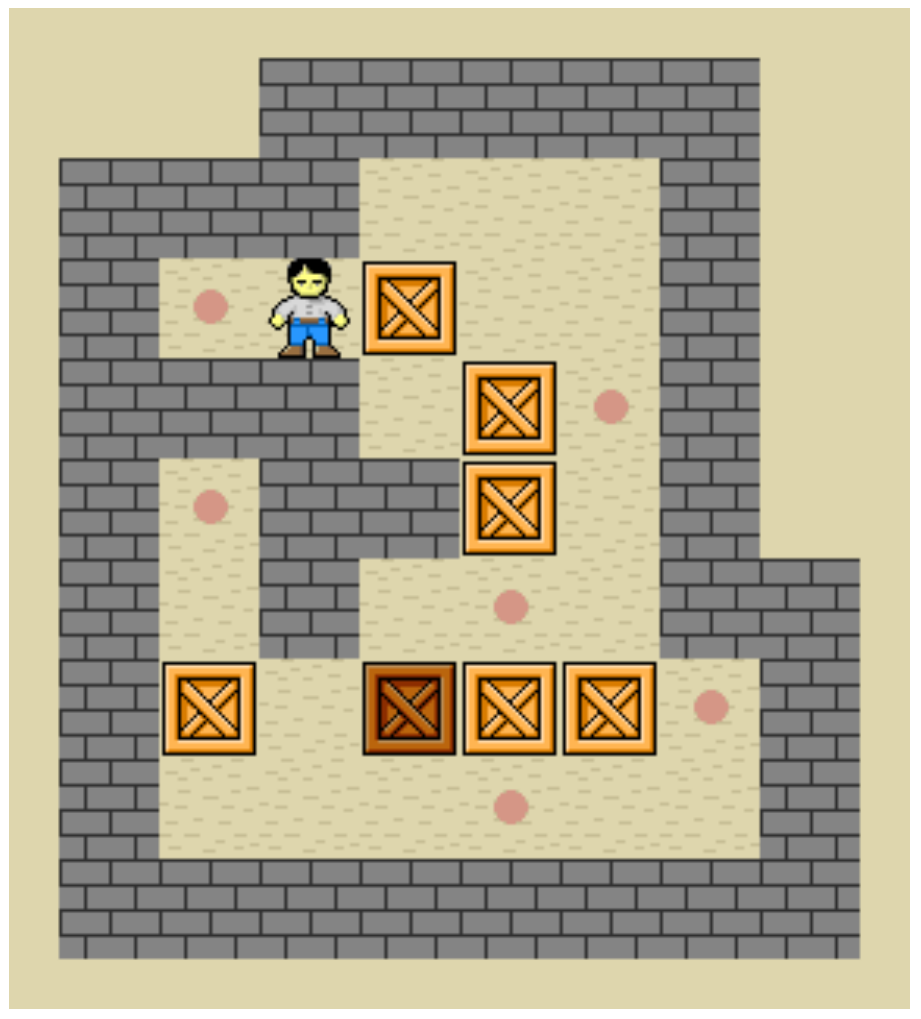

Figura B-2: Imagen de la aplicación SOKOBAN (Tomada de https://en.wikipedia.org/wiki/Sokoban ) 


\section{Apéndice $\mathrm{C}$}

\section{Códigos ajustados por estudiante}

\section{C.1. Códigos ajustados del primer ejercicio individual (JIKEA)}

Las figuras mostradas a continuación, describen los códigos ajustados por cada estudiante y corresponden al primer ejercicio individual envíado al inicio del período de instrucción. Los códigos ajustados se muestran en color verde y los estudiantes en orden ascendente.

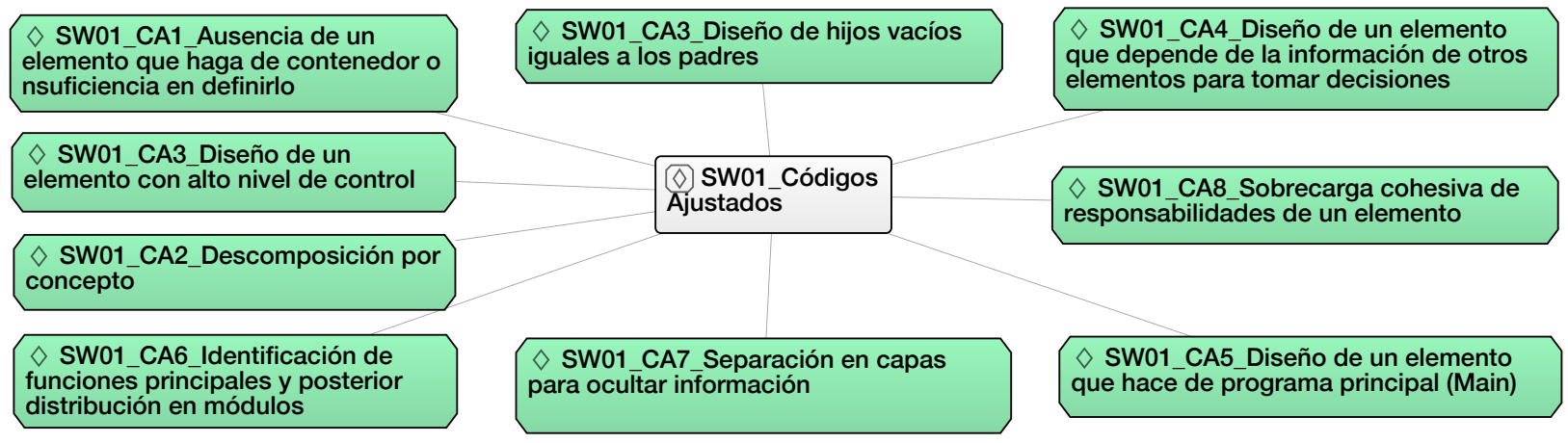

Figura C-1: Códigos ajustados primer trabajo individual estudiante 1 


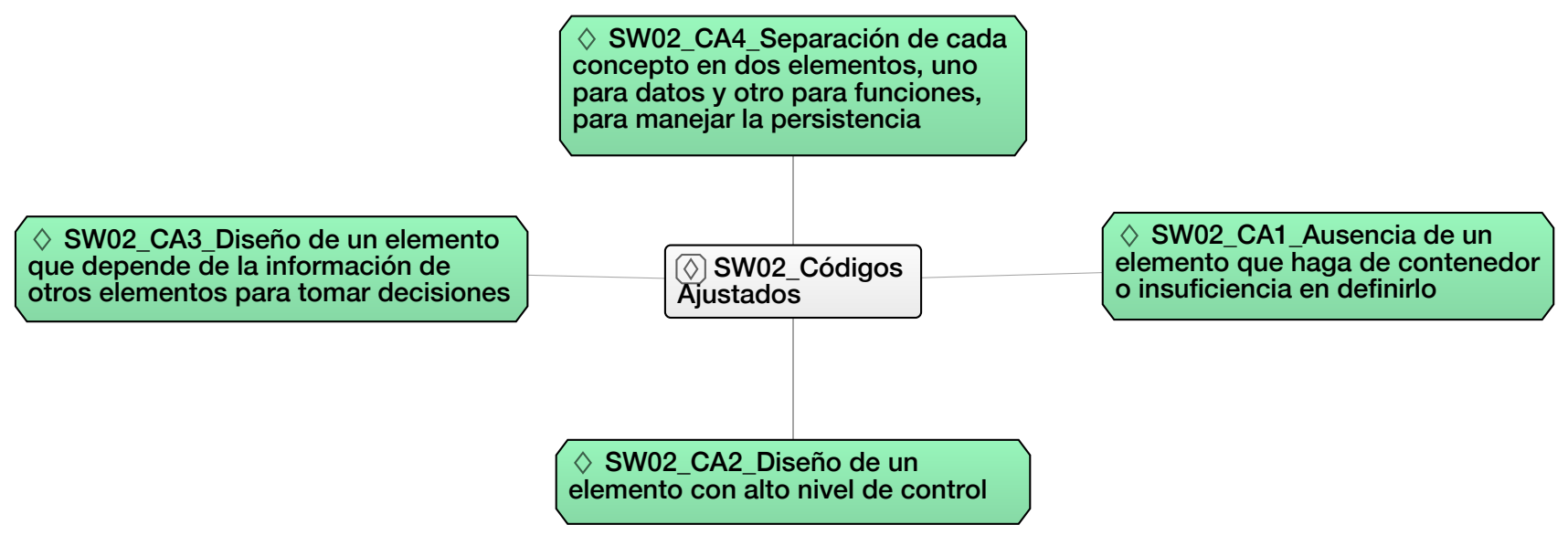

Figura C-2: Códigos ajustados primer trabajo individual estudiante 2

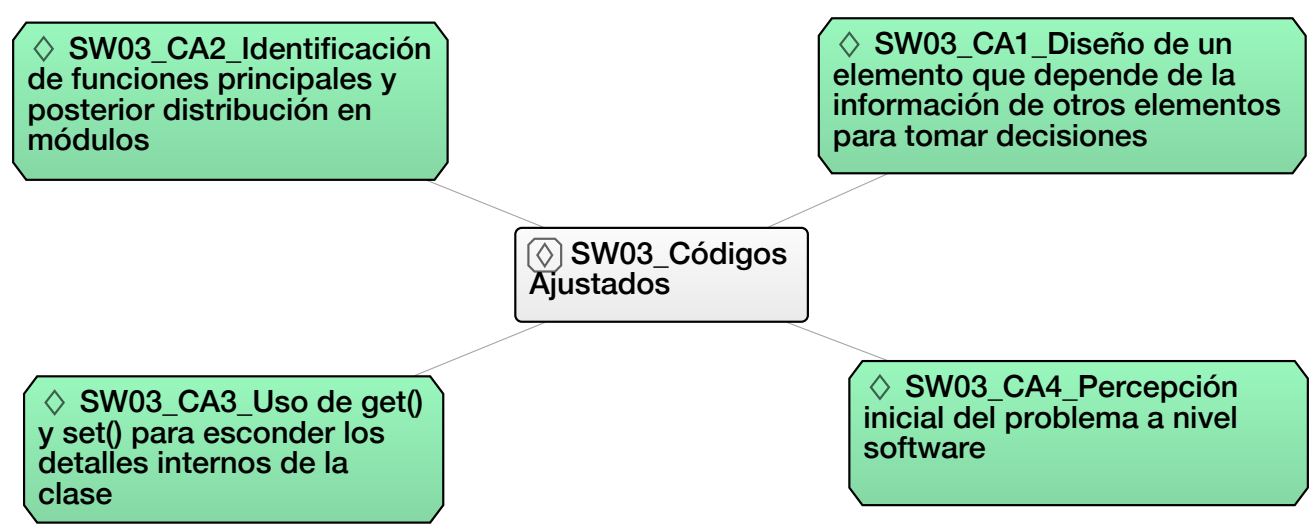

Figura C-3: Códigos ajustados primer trabajo individual estudiante 3

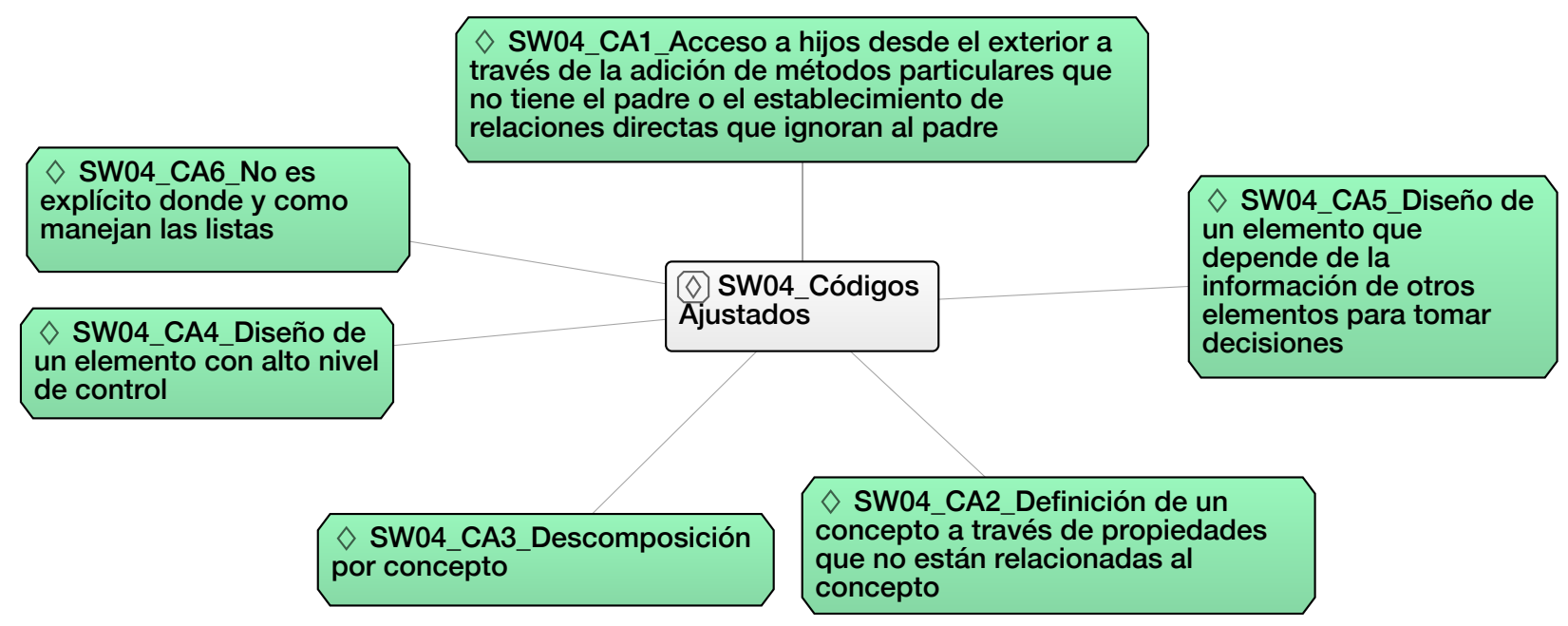

Figura C-4: Códigos ajustados primer trabajo individual estudiante 4 


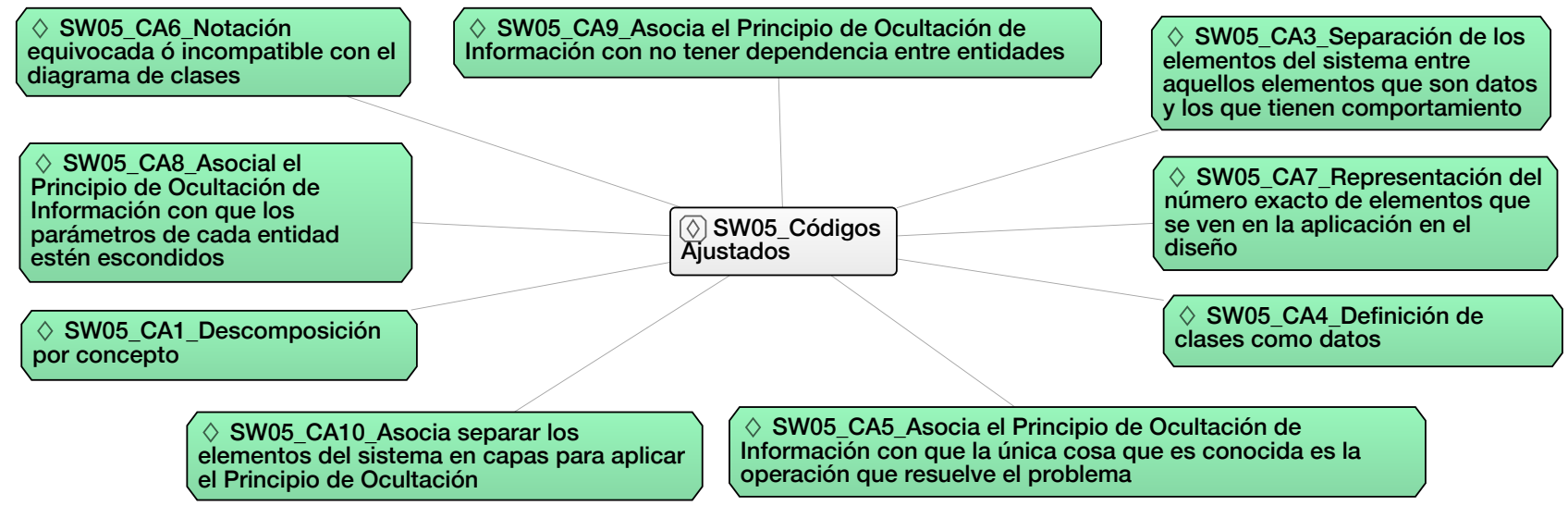

Figura C-5: Códigos ajustados primer trabajo individual estudiante 5

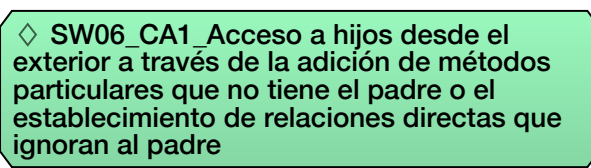

$\diamond$ SW06_CA1_Acceso a hijos desde el exterior a través de la adición de métodos establecimiento de relaciones directas que ignoran al padre

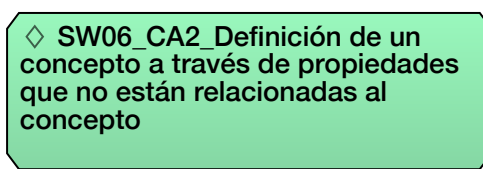

\section{SW06 CA6 Principio}

de Ocultación

considerado como no

solicitar información o

no compartir detalles

internos de las clases
SW06_Códigos Ajustados $\diamond$ SW06_CA3_Descomposición por concepto

Figura C-6: Códigos ajustados primer trabajo individual estudiante 6

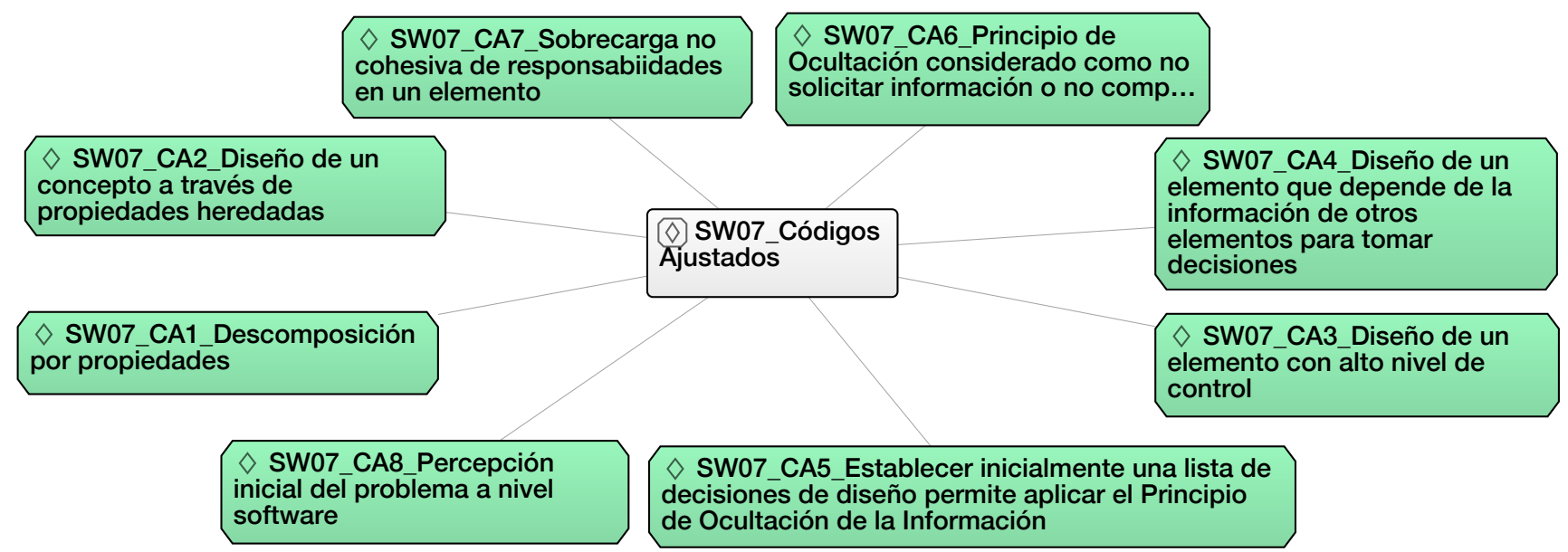

Figura C-7: Códigos ajustados primer trabajo individual estudiante 7 


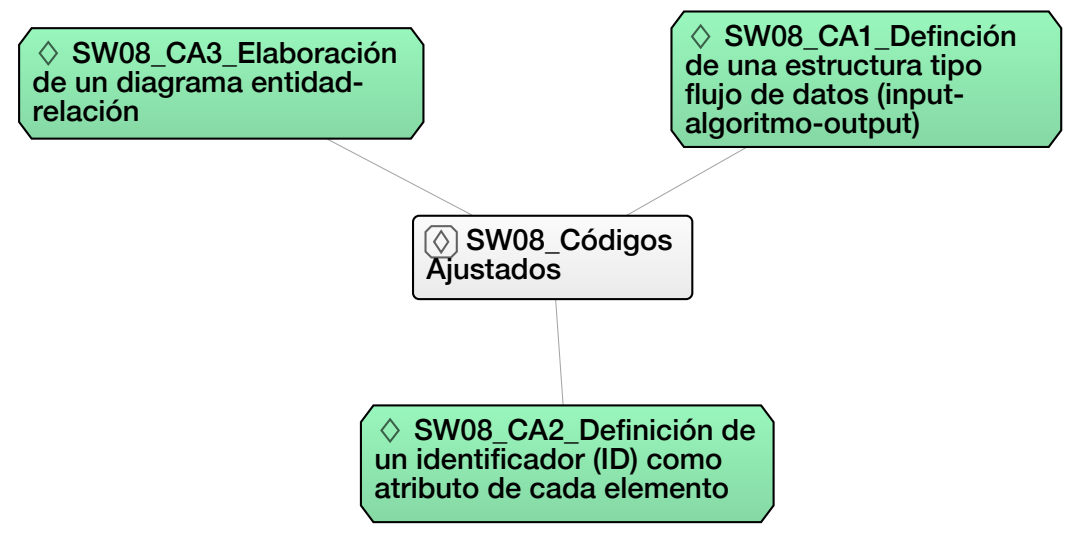

Figura C-8: Códigos ajustados primer trabajo individual estudiante 8

$\diamond$ SW09_CA1_Definción
de una estructura tipo
flujo de datos (input-
algoritmo-output)

SW09_Códigos
Ajustados

$\diamond$ SW09_CA2_Principio de Ocultación
considerado como no solicitar
información o no compartir detalles
internos de las clases

Figura C-9: Códigos ajustados primer trabajo individual estudiante 9

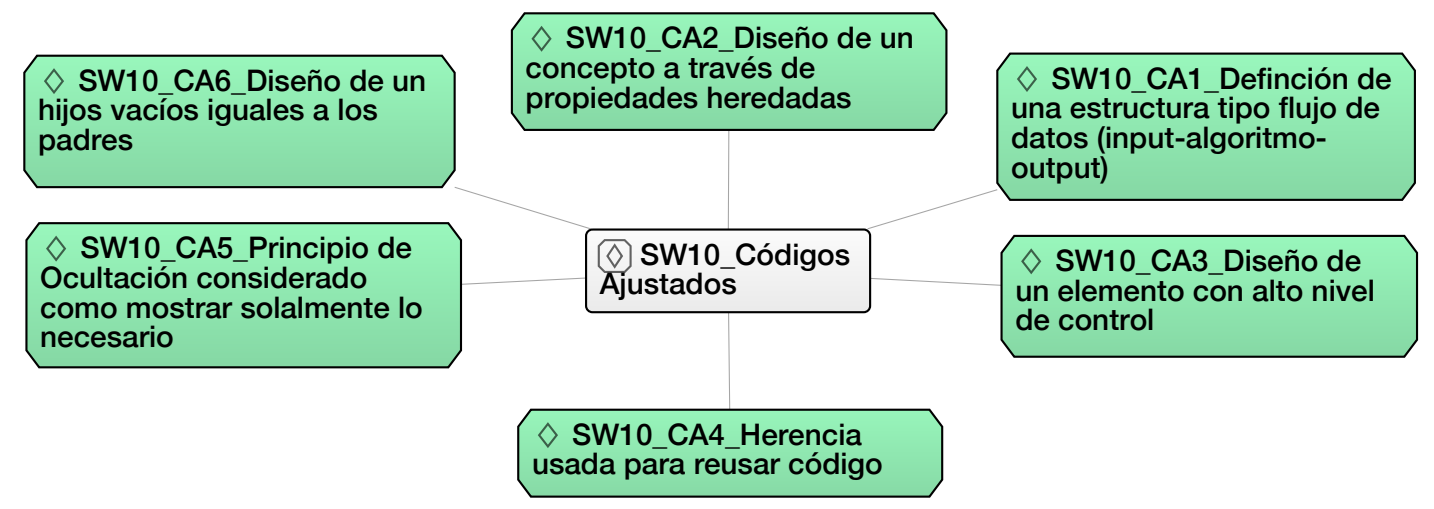

Figura C-10: Códigos ajustados primer trabajo individual estudiante 10

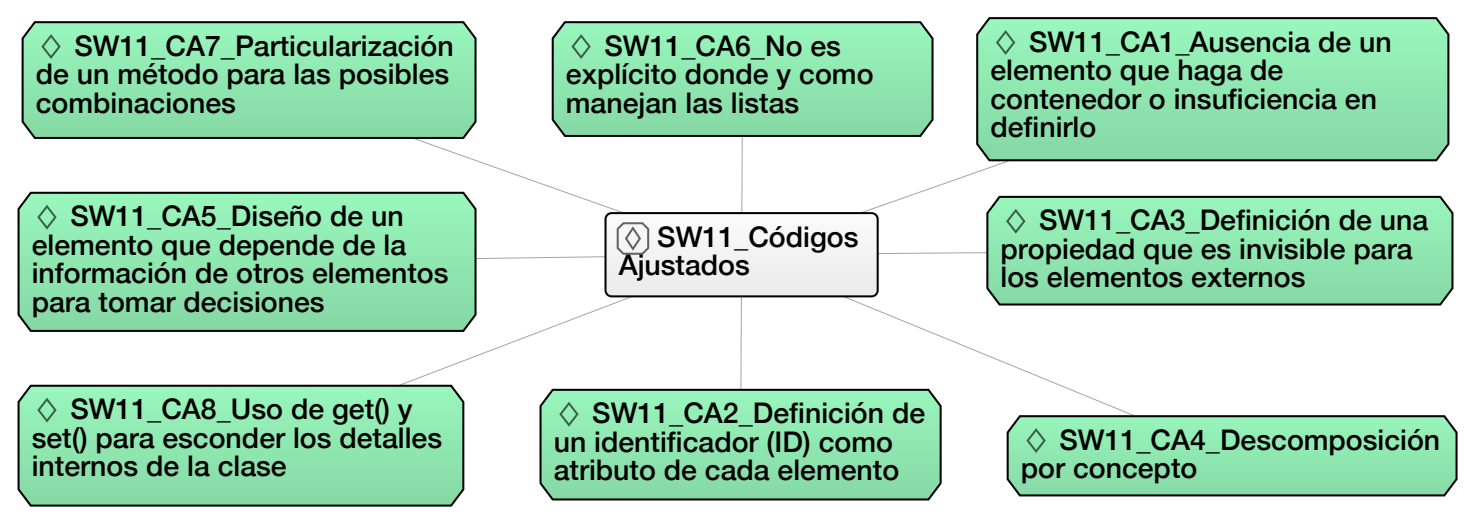

Figura C-11: Códigos ajustados primer trabajo individual estudiante 11 
$\diamond$ SW12_CA2_Diseño de un elemento que depende de la información de otros elementos para tomar decisiones

\section{( $)$ SW12_Códigos} Ajustados
SW12 CA1 Diseño de un elemento con alto nivel de control

Figura C-12: Códigos ajustados primer trabajo individual estudiante 12

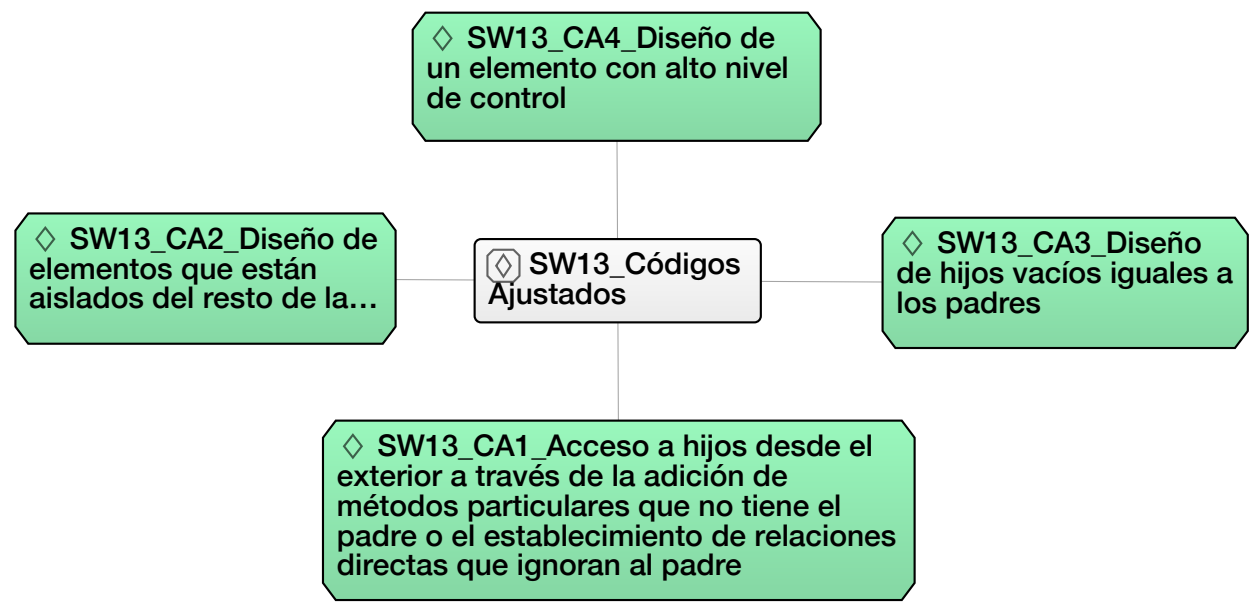

Figura C-13: Códigos ajustados primer trabajo individual estudiante 13 



\section{Apéndice D}

\section{Códigos ajustados del segundo ejercicio individual (SOKOBAN)}

Las figuras mostradas a continuación, describen los códigos ajustados por cada estudiante y corresponden al segundo ejercicio individual envíado durante el período de instrucción. Los códigos ajustados se muestran en color morado y los estudiantes en orden ascendente. 


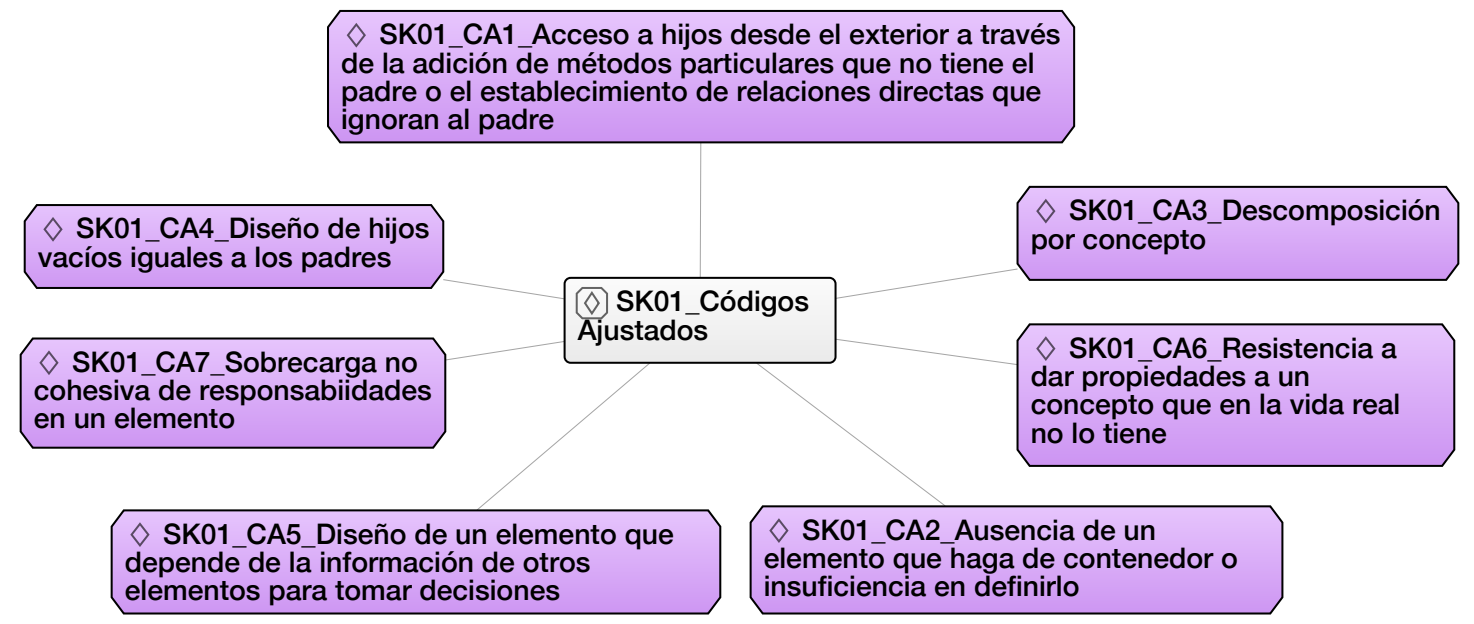

Figura D-1: Códigos ajustados segundo trabajo individual estudiante 1

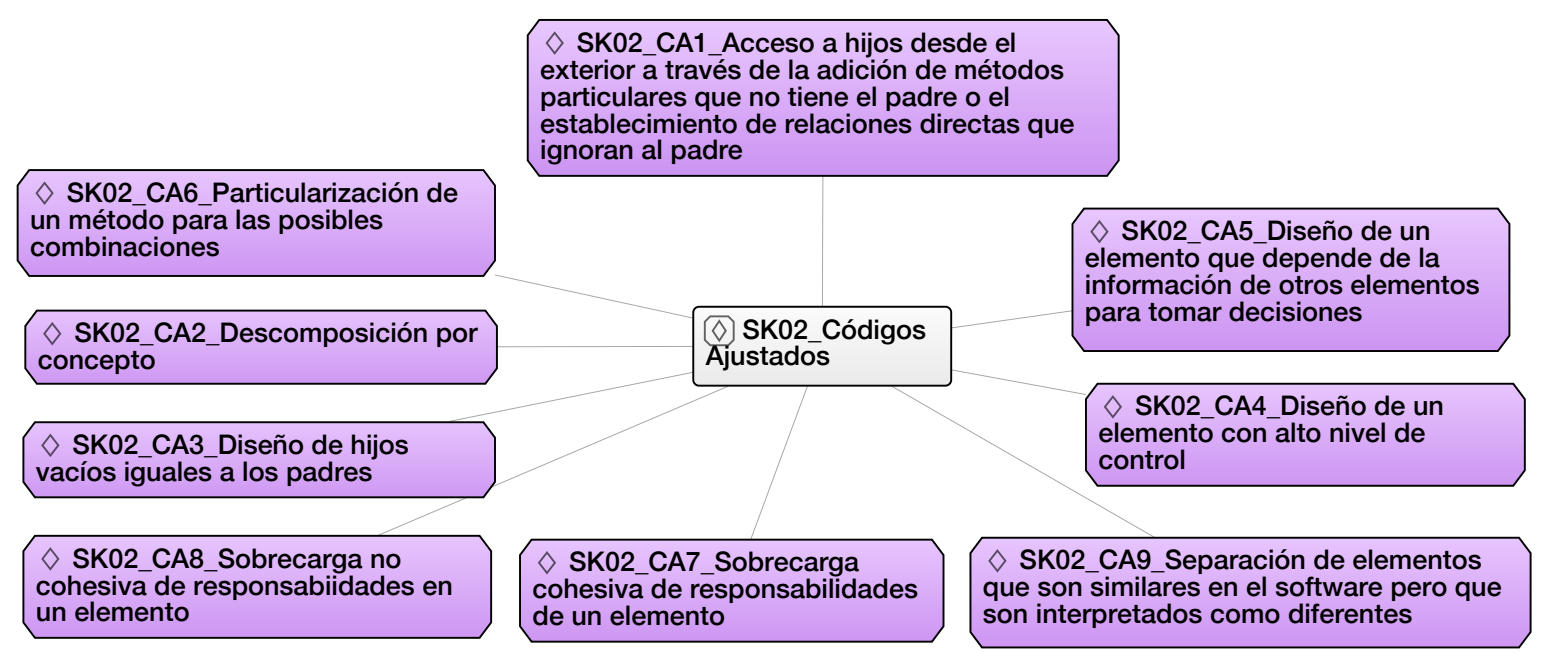

Figura D-2: Códigos ajustados segundo trabajo individual estudiante 2

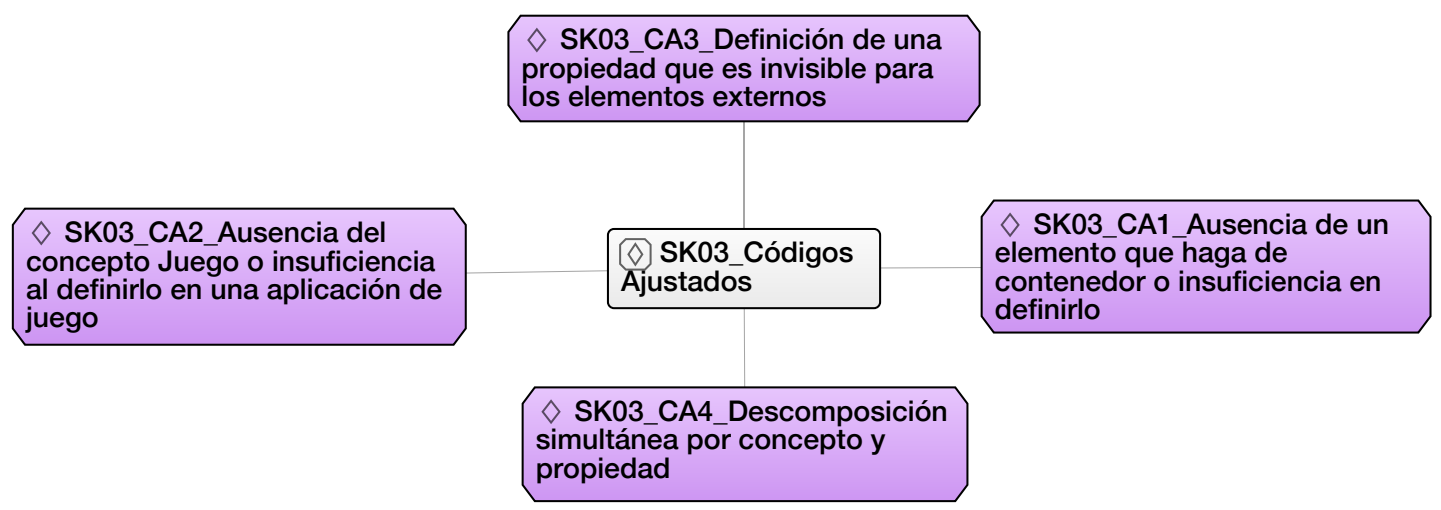

Figura D-3: Códigos ajustados segundo trabajo individual estudiante 3 


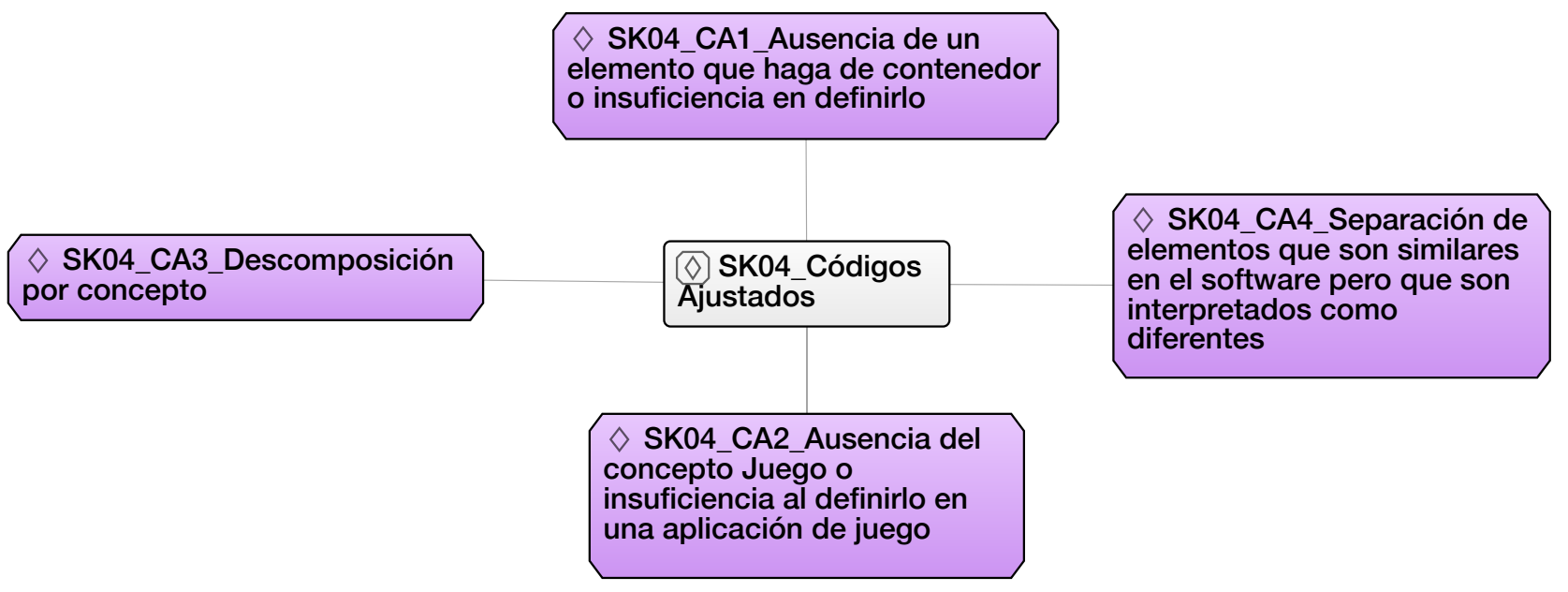

Figura D-4: Códigos ajustados segundo trabajo individual estudiante 4

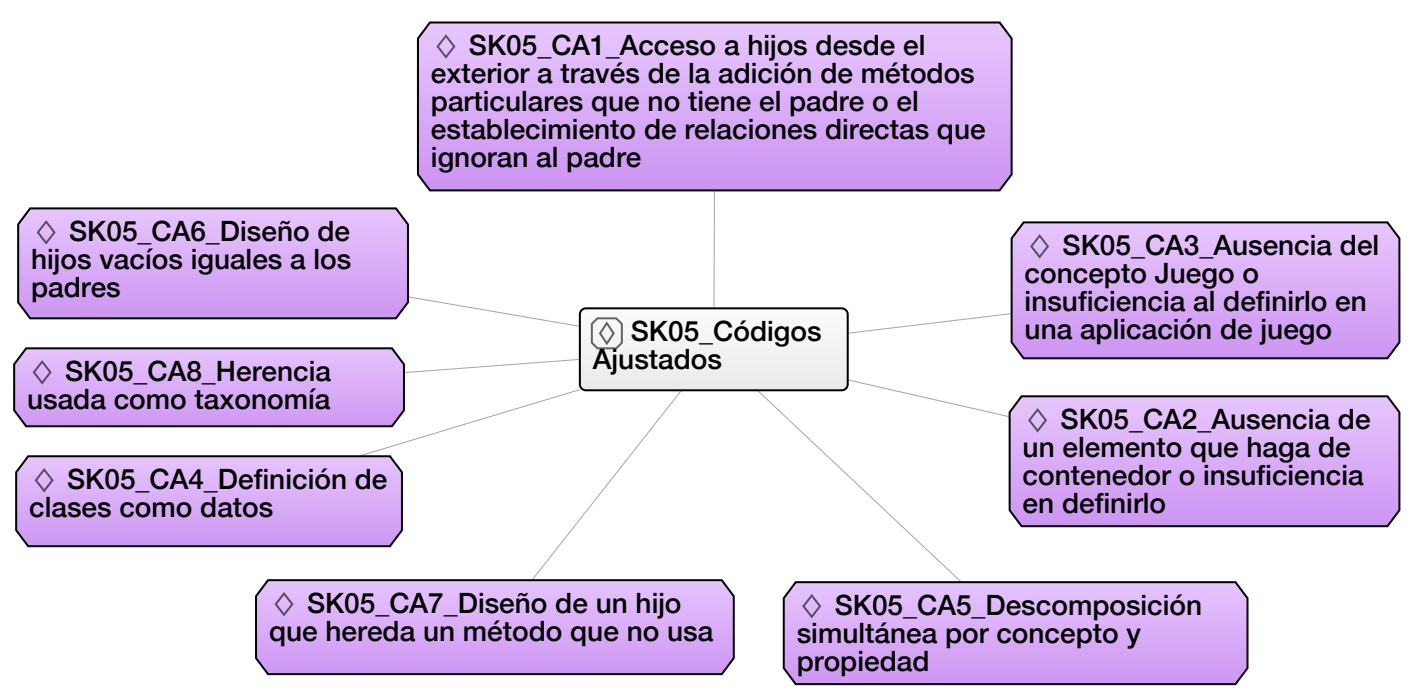

Figura D-5: Códigos ajustados segundo trabajo individual estudiante 5 


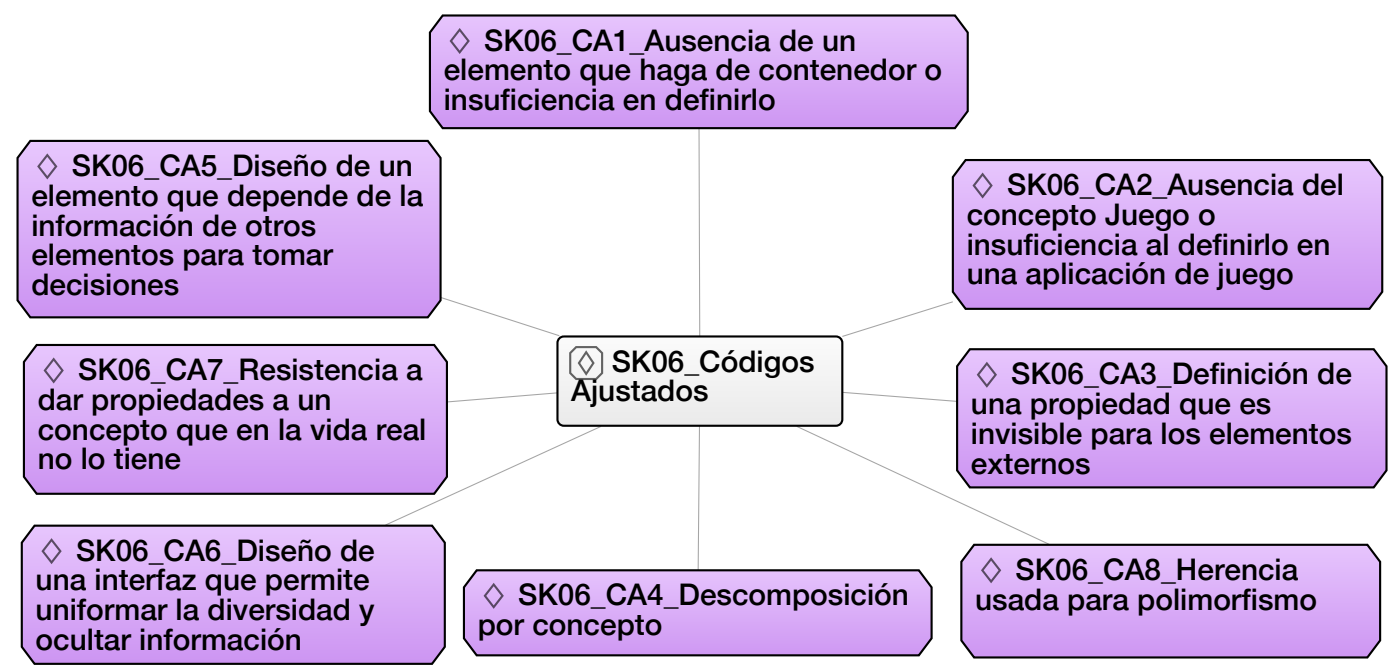

Figura D-6: Códigos ajustados segundo trabajo individual estudiante 6

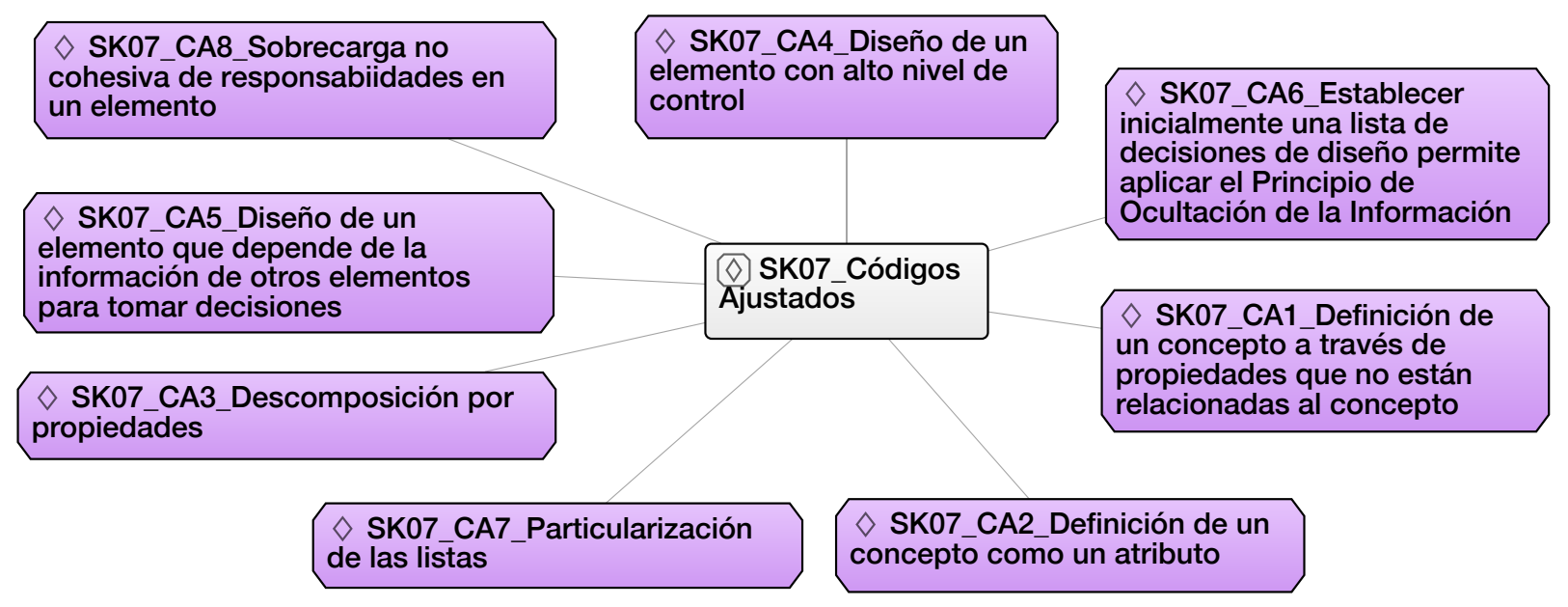

Figura D-7: Códigos ajustados segundo trabajo individual estudiante 7

$\diamond$ SK08_CA1_Ausencia del
concepto Juego o insuficiencia al
definirlo en una aplicación de
juego

Figura D-8: Códigos ajustados segundo trabajo individual estudiante 8 


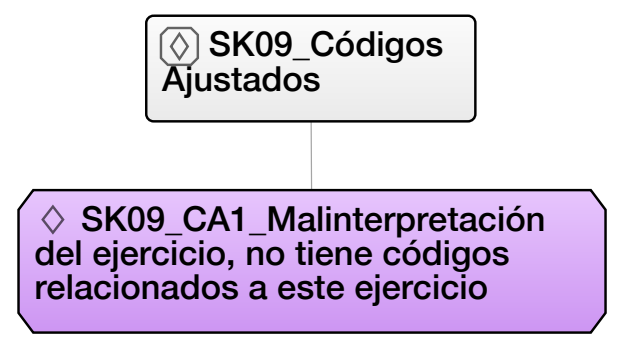

Figura D-9: Códigos ajustados segundo trabajo individual estudiante 9

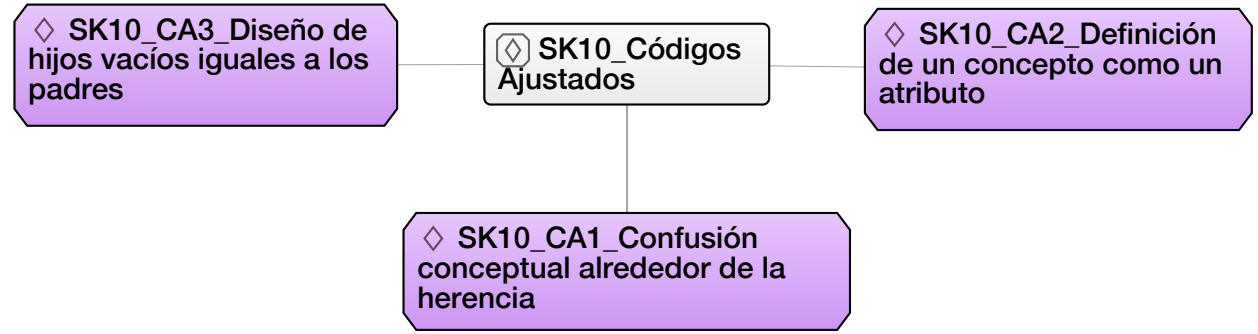

Figura D-10: Códigos ajustados segundo trabajo individual estudiante 10

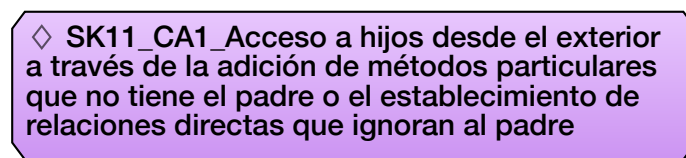

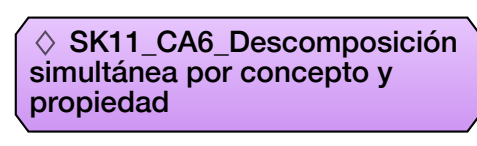

$\diamond$ SK11_CA4_Definición de un identificādor (ID) como atributo de cada elemento

SK11_CA7_Particularización de un método para las posibles combinaciones

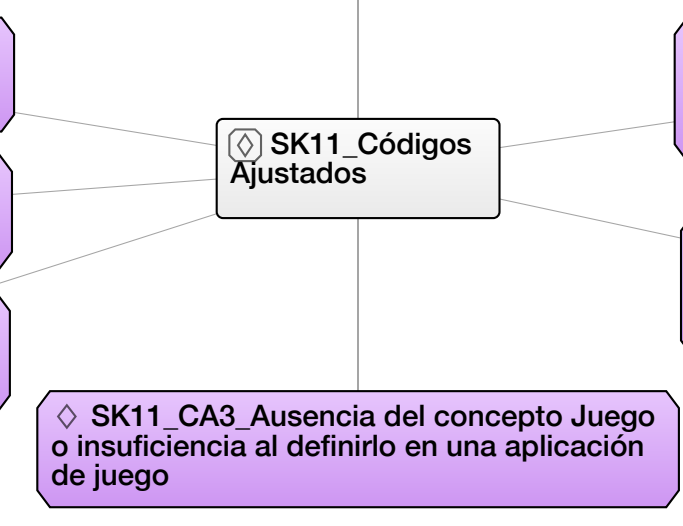

$\diamond$ SK11_CA5_Definición de una propiedad que es invisible para los elementos externos

$\diamond$ SK11_CA2_Ausencia de un elemento que haga de contenedor o insuficiencia en definirlo

Figura D-11: Códigos ajustados segundo trabajo individual estudiante 11 


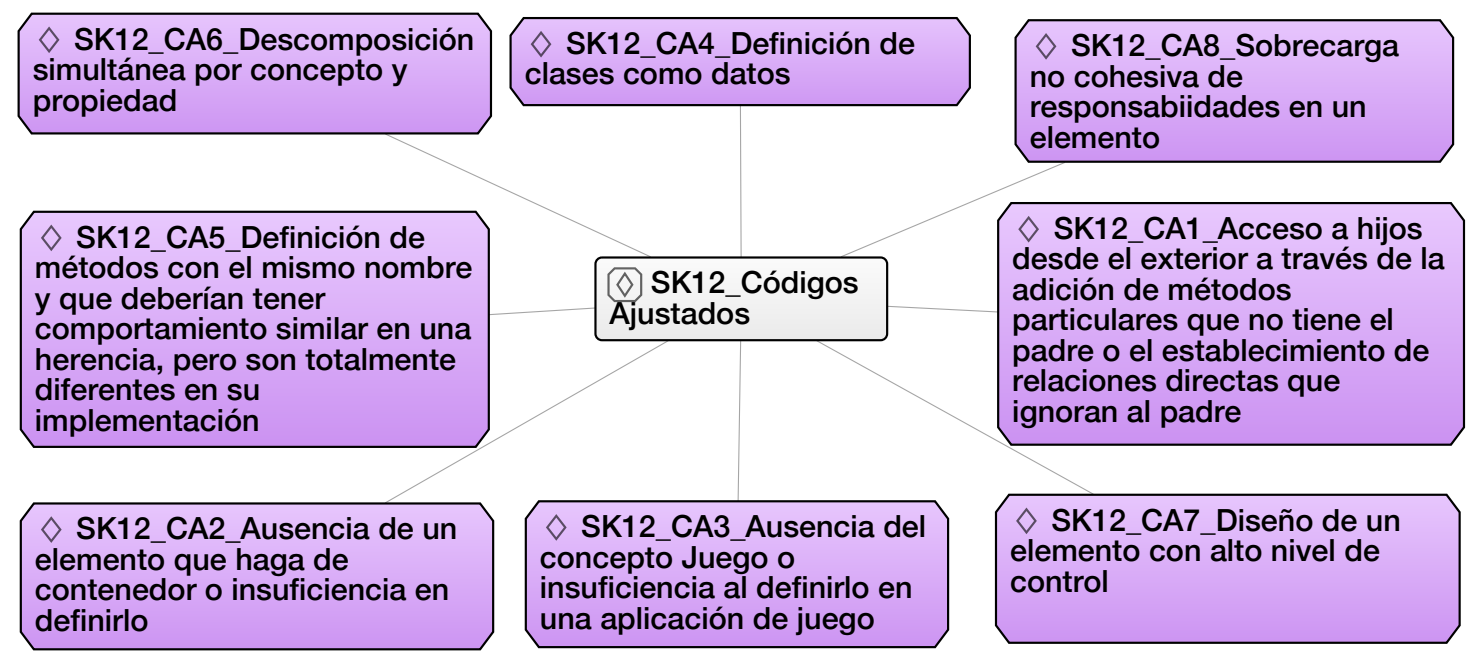

Figura D-12: Códigos ajustados segundo trabajo individual estudiante 12

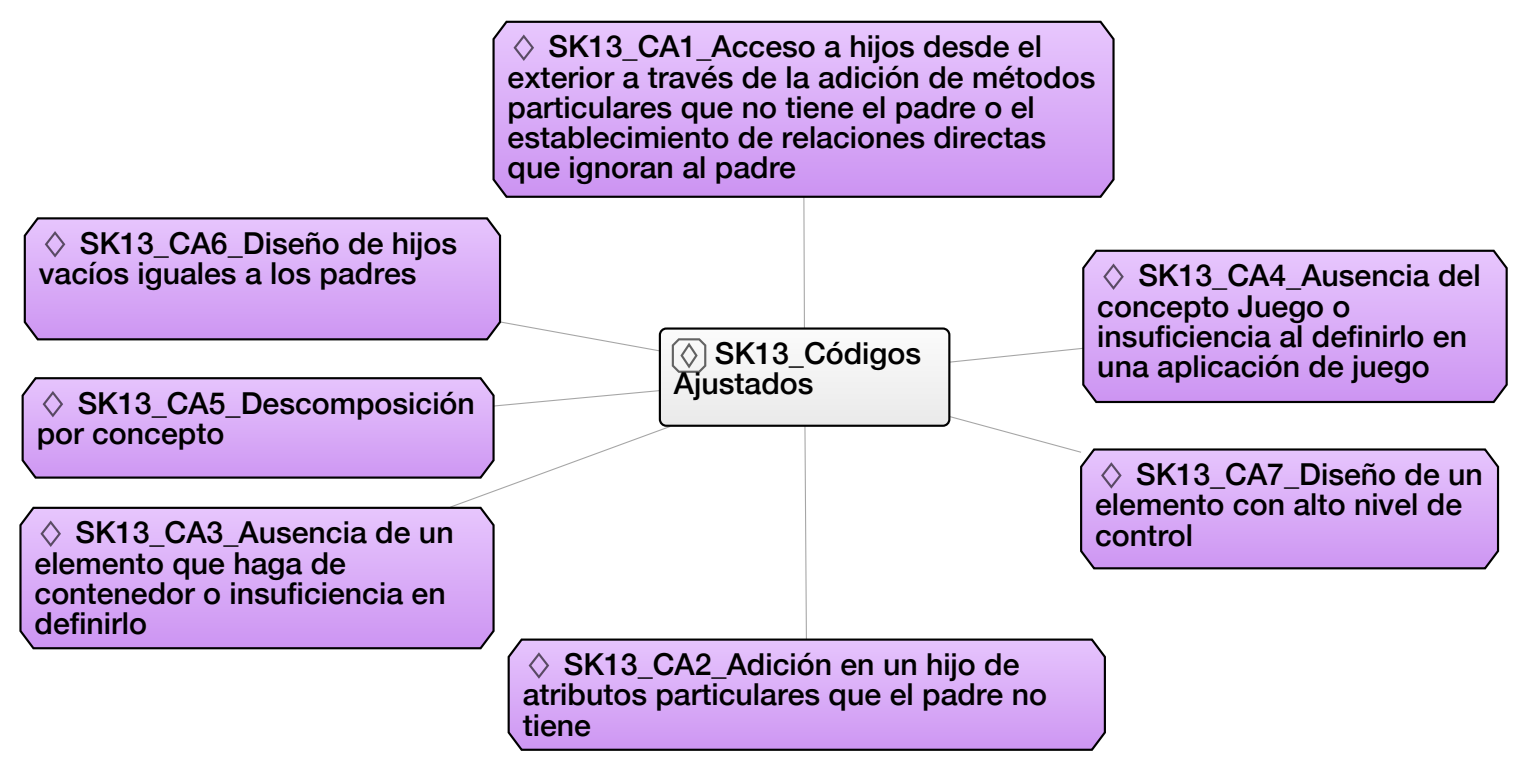

Figura D-13: Códigos ajustados segundo trabajo individual estudiante 13 


\section{Apéndice E}

\section{Códigos ajustados del primer ejercicio grupal (SOKOBAN) con sus versiones previas}

Las figuras mostradas a continuación, describen los códigos ajustados por cada grupo de estudiantes y corresponden al primer ejercicio grupal envíado como trabajo final del período de instrucción. Los códigos ajustados de las versiones previas se muestran en color amarillo y en color rojo los códigos ajustados del trabajo final.

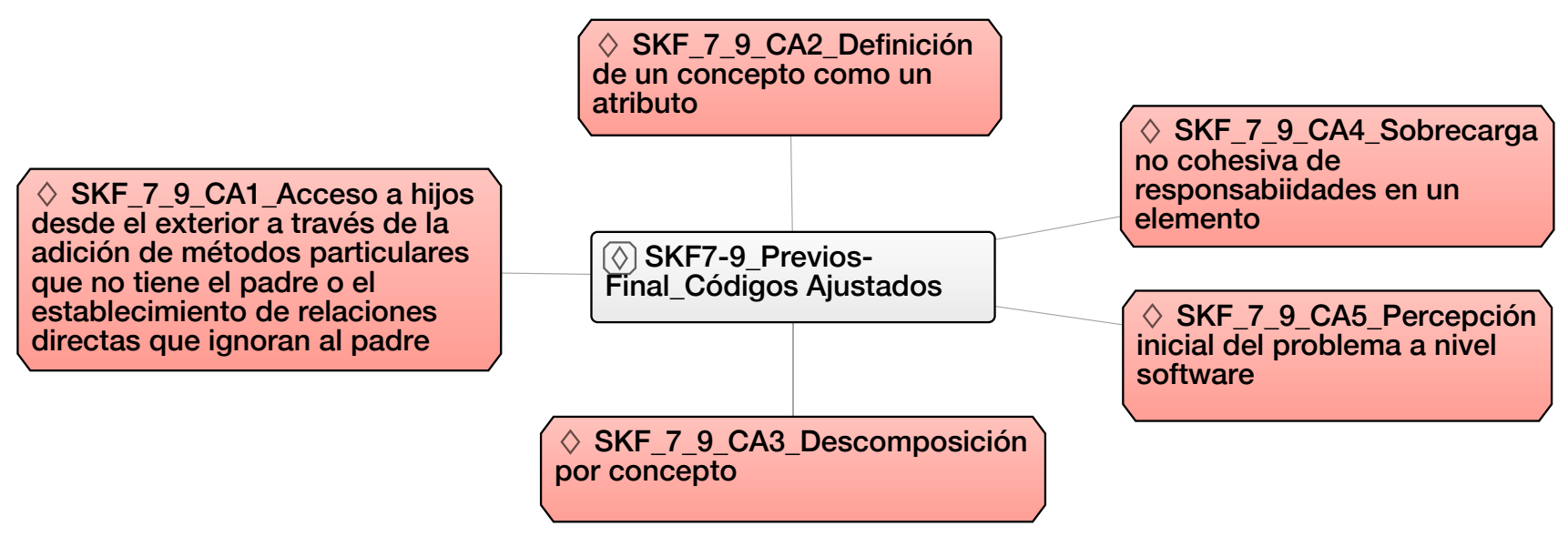

Figura E-1: Códigos ajustados primer trabajo grupal estudiantes 7-9 


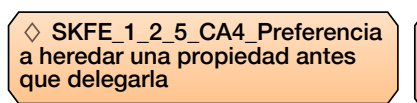

$\triangle$ SKFE 1225 CA5 Principio de Ocultación de la Información asociado a una nula o baja

dependencia entre entidades y a no tener relaciones entre clases concretas

$\diamond$ SKFE_1_2_5_CA3_Diseño de un elemento que depende de la información de otros elementos para tomar decisiones

\section{$\diamond$ SKFE 125 CA7 Confusión entre encapsulación y ocultación}

$\triangle$ SKFE 1_2_5_CA6_Sobrecarga no cohesiva de

responsabiidades en un elemento

$\diamond$ SKFE_1_2_5_CA2_Descompo sición por concepto

\begin{tabular}{l}
\hline SKFE_1_2_5_CA1_Definición \\
de una propiedad que es \\
invisible para los elementos \\
externos
\end{tabular}

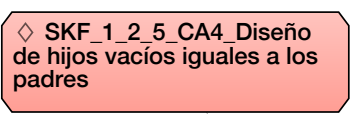

$\diamond$ SKF_1_2_5_CA5_Diseño de un elemento que depende de la información de otros elementos para tomar decisiones 


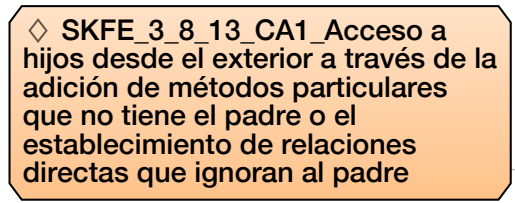

SKFE 3 8 13 CA2 Diseño de elementos que están aislados del resto de la estructura

SKF 38 13 CA6 Sobrecarga no cohesiva de responsabiidades en un elemento $\diamond$ SKF_3_8_13_CA1_Acceso a hijos desde el exterior a través de la adición de métodos particulares que no tiene el padre o el establecimiento de relaciones directas que ignoran al padre
SKF_3_8_13_CA4_Diseño de un elemento que depende de la información de otros elementos para tomar decisiones

SKF_3_8_13_CA3_Diseño de elementos que están aislados del resto de la estructura

Figura E-4: Códigos ajustados primer trabajo grupal estudiantes 3-8-13

$\triangle$ SKF3-8-13 Previos-Final Códigos Ajustados $\diamond$ SKF_3_8_13_CA5_Herencia usada para propagar cambios
SKF 38 13 CA2 Descomposición por concepto $\diamond$ SKFE_6_11_12_CA4_Herencia usada para polimorfismo

$\diamond$ SKFE_6_11_12_CA3_Sobrecar ga cohesiva de responsabilidades de un elemento

$\triangle$ SKFE 61112 CA2 Diseño de un elemento que depende de la información de otros

elementos para tomar decisiones

$\diamond$ SKFE_6_11_12_CA1_Descom posición por concepto $\diamond$ SKF_6_11_12_CA4_Diseño de un elemento que depende de la información de otros elementos para tomar decisiones

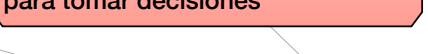

$\begin{aligned} & \otimes \text { SKF_6_11_12_CA3_Diseño } \\ & \text { de un elemento con alto nivel } \\ & \text { de control }\end{aligned}$
de un elem
de control

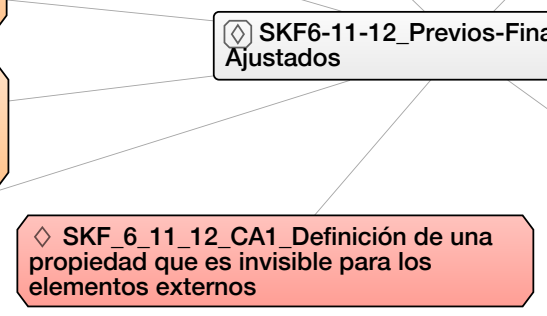

$\diamond$ SKF_6_11_12_CA6_Sobrecarga cohesiva de responsabilidades de un elemento

$\diamond$ SKF_6_11_12_CA2_Descompo sición por concepto

$\triangle$ SKF_6_11_12_CA5_Diseño de una interfaz que permite uniformar la diversidad y ocultar información

Figura E-5: Códigos ajustados primer trabajo grupal estudiantes 6-11-12 



\section{Apéndice F}

\section{Síntesis de iteraciones del estudio de caso}

\section{Iteración: 1}

Nro. recursos: 13

Tipo de recurso: Texto y diagramas

Nro. Códigos: 60

Descripción: En esta iteración se analizó la primera tarea individual (JIKEA) de los trece estudiantes. El propósito de este análisis fue codificar los documentos de texto recogidos de los estudiantes, poniendo especial atención en la a interpretación que tenían del Principio de Ocultación, el cual fue el objetivo de la primera tarea enviada. Los códigos extraídos de esta primera iteración fueron frases descriptivas que representaban de manera general lo que el estudiante había hecho en esa tarea, los códigos fueron etiquetados con el prefijo SW seguido del número de identificación del estudiante (Ejemplo. SW05). Se realizó un comentario en cada código, dónde se explicaba con mayor detalle a cada uno de los códigos.

\section{Iteración: 2}

Nro. recursos: 26

Tipo de recurso: Texto y diagramas

Nro. Códigos: 165

Descripción: En esta iteración se analizó la segunda tarea individual (SOKOBAN) de los trece estudiantes. Al igual que en la iteración anterior, los códigos se extrajeron de los documentos de texto de recogidos de los estudiantes. Los códigos extraídos de esta iteración fueron etiquetados con el prefijo SK seguido del número de identificación del estudiante. Muchos de los códigos generados en la tarea de JIKEA, aparecieron en el análisis de la segunda tarea, pero también aparecieron códigos nuevos. En esta iteración no salieron a la superficie códigos 
nuevos relacionados al Principio de Ocultación.

\section{Iteración: 3}

Nro. recursos: 39

Tipo de recursos: Textos, gráficos, audios

Nro. Códigos: 189

Descripción: En esta iteración se incluye para el análisis las entrevistas de los estudiantes sobre la primera tarea individual JIKEA. La codificación de las entrevistas permitieron triangular códigos generados en los documentos de texto recogidos anteriormente. En esta iteración, dejamos de lado el análisis de las tareas individuales del SOKOBAN y nos centrarnos en analizar la primera tarea, realizando varias iteraciones entre el profesor y el investigador poniéndo especial atención en el entendimiento de los estudiantes con respecto al Principio de Ocultación. Los códigos relacionados al Principio van de la mano de los códigos del diseño en general de cada estudiante, con el fin de entender de manera holística al estudiante. Los códigos no aumentan en número a pesar de las entrevistas analizadas, debido a que en esta iteración también se unen y se refinan códigos.

\section{Iteración: 4}

Nro. recursos: 39

Tipo de recursos: Textos, gráficos, audios

Nro. Códigos: 165

Descripción: En esta iteración se realizaron refinamientos de los códigos obtenidos. Los códigos generados de este refinamiento son llamandos códigos ajustados. Los códigos ajustados se caracterizan por mantener la idea principal del código dejando de lado detalles como nombres de las clases o métodos que estaban incluidos en la primera codificación. Se mantienen los códigos ajustados sin alterar los primeros códigos para que los comentarios hechos sobre cada código no se pierdan. Los códigos ajustados resultantes, su análisis e interpretación son parte de la publicación [39].

\section{Iteración: 5 Nro. recursos: 44}

Tipo de recursos: Textos, diagramas, audios

Nro. Códigos: 225

Descripción: En esta iteración se incluye el análisis del trabajo de grupo (SOKOBAN Grupal). Los códigos extraídos de esta primera iteración, fueron frases simbólicas que representaban de manera general lo que el estudiante había hecho en esa tarea, los códigos fueron etiquetados con el prefijo SKF seguido de los 
estudiantes que conforman el grupo, por ejemplo SKF1-3-5, teniendo en total 5 tareas adicionales.

Iteración: 6 Nro. Documentos: 49

Tipo de documento: Textos, diagramas, audios

Nro. Códigos: 200

Descripción: En esta iteración se añaden al análisis de las entrevistas realizadas con respecto a la segunda tarea y a la tarea grupal. También se incluyen las observaciones de las exposiciones realizadas por cada grupo en clase. En este iteración se pone especial atención a los códigos generados por cada estudiante. En este momento se tienen todos los recursos recogidos del estudiante y se inicia la primera fase del proceso de análisis de los códigos durante todo el período de instrucción en busca de las dificultades de aprendizaje y su nivel de persistencia.

\section{Iteración: 7}

Nro. recursos: 48

Tipo de recursos: Textos, diagramas, audios

Nro. Códigos: 194

Descripción: En esta iteración se muestra uno de las tantas iteraciones del análisis de los recursos generados del período académico. En esta iteración, los códigos se refinaron, haciéndolos más descriptivos de manera que permitieran identificar cada caso particular al que se refería el estudiante. Se agrupan los códigos por colores.

\section{Iteración: 8}

Nro. recursos: 48

Tipo de recursos: Textos, diagramas, audios

Nro. Códigos: 203

Descripción: En esta iteración se agrupan los códigos por estudiante. Las gráficas generadas permiten ver los códigos de cada estudiante en cada tarea. Adicionalmente se realizan las matrices de todos los estudiantes por cada ejercicio, junto con los códigos generados.

\section{Iteración: 9}

Nro. recursos: 48

Tipo de recurso: Textos, diagramas, audios

Nro. Códigos: 221

Descripción: En esta iteración se incluye la codificación de los trabajos previos a la entrega final de la tarea de grupo, ya que aportan al entendimiento 
de la evolución de los estudiantes. Las tareas previas fueron incluidas en el documento del trabajo final, por lo que no se aumentó el número de documentos pero si el número de códigos. Los códigos generados fueron etiquetados con el prefijo SKFE seguido de los estudiantes que conforman el grupo, por ejemplo SKFE1-3-5. Los códigos tienen a estabilizarse, pero se puede ver que aumentan en número debido al aumento de recursos.

Iteración: 10

Nro. recursos: 48

Tipo de recurso: Textos, diagramas, audios

Nro. Códigos: 223

Nro. Códigos ajustados: 207

Descripción: Los códigos presentados en esta iteración están triangulados y revisados por el investigador y el profesor, con la ayuda de la matriz realizada con los códigos, la cual permitió una verificación vertical y horizontal. Se generaron algunos códigos nuevos, debido a que se intentó no descartar nada que pueda ayudar a la interpretación del estudiante.

\section{Iteración: 11}

Nro. recurso: 48

Tipo de recurso: Textos, diagramas, audios

Nro. Códigos: 223

Nro. Códigos ajustados: 211

Descripción: En esta iteración se decide agrupar ciertos códigos similares. Adicionalmente se trabajan con los tipos de códigos generados para mayor facilidad de análisis para el investigador.

Iteración: 12

Nro. Documentos: 47

Tipo de documento: Textos, diagramas, audios

Nro. Códigos: 220

Nro. Códigos ajustados: 194

Descripción: En esta iteración se decide limpiar los códigos ajustados y definir los tipos de códigos para los análisis posteriores. 
Apéndice G

Formato de consentimiento 


\section{Research project about learning in Software Design subject}

Dear

As a PhD student of the Software and Systems Doctoral program of the Universidad Politécnica de Madrid, I am conducting a research on aspects related to the learning of the Software Design subject. The aim of the research is to discover how students learn to design software.

I would greatly appreciate your participation in the study, which will certainly be very valuable. In order to do this, I need your permission to analyze your assignments, assessment tests, final projects and activities done in the Software Design subject.

I guarantee that appropriate measures will be taken to ensure anonymity and confidentiality of the collected data. In any case, no name will be associated with the data. If a quote from a student is published, it will be disclosed in order to ensure the anonymity and confidentiality using general descriptions (one student said “..."). The results of this study will be available for Universidad Politécnica de Madrid, and other institutions interested on learning of Software Design.

Participation in the study is completely voluntary.

Once the study is complete, I will be happy to share the results with you. For any further questions, you can contact me:

Pamela Flores

Computer Languages and Systems and Software Engineering Department

Universidad Politécnica de Madrid, Spain

pamela.flores@fi.upm.es

\section{INFORMED CONSENT}

\section{I} with ID:

understand the objectives of the researcher and I agree to participate to the conditions detailed by this document. I understand that participation in this study is completely voluntary.

Date:

Signature of the participant:

Signature of the researcher:

Participant name:
Researcher name:

Pamela Flores 


\section{Apéndice $\mathrm{H}$}

\section{Diccionario de tipos de códigos}

\begin{tabular}{lll}
\hline Prefijo & Tipos de código & Descripción \\
\hline Tipo1 & $\begin{array}{l}\text { Diseño de un elemento que hace } \\
\text { de programa principal (Main) }\end{array}$ & $\begin{array}{l}\text { Cuando un único elemento contiene las } \\
\text { funciones principales del sistema }\end{array}$ \\
\hline Tipo2 & $\begin{array}{l}\text { Diseño de un elemento con alto } \\
\text { nivel de control }\end{array}$ & $\begin{array}{l}\text { Cuando un elemento contiene la fun- } \\
\text { ción donde se concentra la decisión }\end{array}$ \\
\hline Tipo3 & $\begin{array}{l}\text { Diseño de un elemento que depen- } \\
\text { de de la información de otros ele- }\end{array}$ & $\begin{array}{l}\text { Cuando un elemento se caracteriza por } \\
\text { tener métodos encargados de solicitar } \\
\text { información o preguntar a otros por su } \\
\text { mentos para tomar decisiones }\end{array}$ \\
\hline Tipo4 & $\begin{array}{l}\text { Definición de un identificador antes de tomar la decisión } \\
\text { (ID) como atributo de cada ele- }\end{array}$ & $\begin{array}{l}\text { Sucede cuando los elemento tienen un } \\
\text { atributo encargado de identificar al ele- } \\
\text { mento }\end{array}$ \\
\hline Tipo5 & $\begin{array}{l}\text { Identificación de funciones princi- } \\
\text { pales y posterior distribución en } \\
\text { módulos }\end{array}$ & $\begin{array}{l}\text { Proceso donde se lista las funciones } \\
\text { principales de manera aislada de la } \\
\text { creación de módulos(clases) }\end{array}$ \\
\hline Tipo6 & Descomposición por concepto & $\begin{array}{l}\text { División del sistema en elementos que } \\
\text { representan un concepto }\end{array}$ \\
\hline Tipo7 & $\begin{array}{l}\text { Descomposición simultánea por } \\
\text { concepto y propiedad }\end{array}$ & $\begin{array}{l}\text { División del sistema en elementos que } \\
\text { representan un concepto y otros ele- } \\
\text { mentos que representan una propiedad }\end{array}$ \\
\hline Tipo8 & Descomposición por propiedades & $\begin{array}{l}\text { División del sistema en elementos que } \\
\text { representan propiedades }\end{array}$ \\
\hline Tipo9 & $\begin{array}{l}\text { Preferencia a heredar una propie- } \\
\text { dad antes que delegarla }\end{array}$ & $\begin{array}{l}\text { Acción mediante la cual se prefiere he- } \\
\text { redar una propiedad en lugar de dele- } \\
\text { garla a otro elemento bajo una relación } \\
\text { de asociación }\end{array}$ \\
& &
\end{tabular}

Continúa en la siguiente página 


\begin{tabular}{|c|c|c|}
\hline Prefijo & Tipos de código & Descripción \\
\hline Tipo10 & $\begin{array}{l}\text { Separación de cada concepto en } \\
\text { dos elementos, uno para datos y } \\
\text { otro para funciones, para manejar } \\
\text { la persistencia }\end{array}$ & $\begin{array}{l}\text { Comportamiento en que un elemento es } \\
\text { dividido en dos, colocando en un ele- } \\
\text { mento las funciones y en otro elemento } \\
\text { los datos }\end{array}$ \\
\hline Tipo11 & $\begin{array}{l}\text { Sobrecarga cohesiva de responsa- } \\
\text { bilidades de un elemento }\end{array}$ & $\begin{array}{l}\text { Aquel elemento que se caracteriza por } \\
\text { tener más responsabilidades de las que } \\
\text { debería tener, pero que están relaciona- } \\
\text { das entre ellas }\end{array}$ \\
\hline Tipo12 & $\begin{array}{l}\text { Sobrecarga no cohesiva de respon- } \\
\text { sabilidades en un elemento }\end{array}$ & $\begin{array}{l}\text { Aquel elemento que se caracteriza por } \\
\text { tener más responsabilidades de las que } \\
\text { debería tener, pero que son inconexas } \\
\text { entre ellas }\end{array}$ \\
\hline Tipo13 & $\begin{array}{l}\text { Acceso a hijos desde el exterior a } \\
\text { través de relaciones directas que } \\
\text { ignoran al padre y que acceden a } \\
\text { métodos particulares que solo tie- } \\
\text { ne el hijo }\end{array}$ & $\begin{array}{l}\text { Acción mediante la cual se han estable- } \\
\text { cido relaciones directas entre elementos } \\
\text { externos a la estructura de la herencia, } \\
\text { o uso de métodos definidos en un hijo } \\
\text { que no tiene el padre }\end{array}$ \\
\hline Tipo14 & $\begin{array}{l}\text { Herencia usada para polimorfis- } \\
\text { mo }\end{array}$ & $\begin{array}{l}\text { Acción en la que se usa la herencia con } \\
\text { la intención de dar diferente comporta- } \\
\text { miento al método heredado que lleva el } \\
\text { mismo nombre }\end{array}$ \\
\hline Tipo15 & $\begin{array}{l}\text { Herencia usada para reusar códi- } \\
\text { go }\end{array}$ & $\begin{array}{l}\text { Acción en la que se usa la herencia con } \\
\text { el fin de no repetir el código que tiene } \\
\text { el padre }\end{array}$ \\
\hline Tipo16 & Herencia usada como taxonomía & $\begin{array}{l}\text { Acción en la que se usa la herencia co- } \\
\text { mo un mecanismo para clasificar }\end{array}$ \\
\hline Tipo17 & $\begin{array}{l}\text { Herencia usada para propagar } \\
\text { cambios }\end{array}$ & $\begin{array}{l}\text { Acción en la que se usa la herencia co- } \\
\text { mo un mecanismo para modificar todos } \\
\text { los hijos cuando el padre sea modifica- } \\
\text { do }\end{array}$ \\
\hline Tipo18 & $\begin{array}{l}\text { Diseño de hijos vacíos iguales a los } \\
\text { padres }\end{array}$ & $\begin{array}{l}\text { Cuando un elemento hijo de una heren- } \\
\text { cia no tiene ningún método, lo que im- } \\
\text { plica que es igual al padre }\end{array}$ \\
\hline Tipo19 & $\begin{array}{l}\text { Diseño de un hijo que hereda un } \\
\text { método que no usa }\end{array}$ & $\begin{array}{l}\text { Esto sucede mayormente cuando la he- } \\
\text { rencia es profunda en verticalidad y va } \\
\text { acarreando métodos heredados por de- } \\
\text { finición de herencia, pero no son usados }\end{array}$ \\
\hline Tipo20 & $\begin{array}{l}\text { Definición de un concepto a } \\
\text { través de propiedades que no } \\
\text { están relacionadas al concepto }\end{array}$ & $\begin{array}{l}\text { Esto significa que un concepto tiene } \\
\text { métodos ajenos al nombre del concep- } \\
\text { to, tal vez por ambigüedad en el nom- } \\
\text { bre o por ser nombres de conceptos y } \\
\text { métodos muy genéricos }\end{array}$ \\
\hline
\end{tabular}

Continúa en la siguiente página 


\begin{tabular}{|c|c|c|}
\hline Prefijo & Tipos de código & Descripción \\
\hline Tipo21 & $\begin{array}{l}\text { Confusión conceptual alrededor } \\
\text { de la herencia }\end{array}$ & $\begin{array}{l}\text { Acción en la que se usa la herencia con } \\
\text { el fin de relacionar dos elementos, sin } \\
\text { conocer la relación de hijo y padre }\end{array}$ \\
\hline Tipo22 & $\begin{array}{l}\text { Principio de Ocultación de la In- } \\
\text { formación asociado a una nula o } \\
\text { baja dependencia entre entidades } \\
\text { y a no tener relaciones entre cla- } \\
\text { ses concretas }\end{array}$ & $\begin{array}{l}\text { Pensamiento que relaciona el número } \\
\text { de relaciones con la baja dependencia } \\
\text { y el Principio de Ocultación }\end{array}$ \\
\hline Tipo23 & $\begin{array}{l}\text { Separación en capas para ocultar } \\
\text { información }\end{array}$ & Dividir a los elementos en capas \\
\hline Tipo24 & $\begin{array}{l}\text { Asocia el Principio de Ocultación } \\
\text { con que la única cosa que es cono- } \\
\text { cida es la operación que resuelve } \\
\text { el problema }\end{array}$ & $\begin{array}{l}\text { Pensamiento que relaciona mostrar la } \\
\text { operación más importante al Principio } \\
\text { de Ocultación }\end{array}$ \\
\hline Tipo25 & $\begin{array}{l}\text { Confusión entre encapsulación y } \\
\text { ocultación }\end{array}$ & $\begin{array}{l}\text { Pensar que encapsulamiento es oculta- } \\
\text { ción }\end{array}$ \\
\hline Tipo26 & $\begin{array}{l}\text { Diseño de una interfaz que permi- } \\
\text { te uniformar la diversidad y ocul- } \\
\text { tar información }\end{array}$ & $\begin{array}{l}\text { Cuando un elemento es definido como } \\
\text { interfaz y que cubre otros elementos, } \\
\text { cuya información está oculta }\end{array}$ \\
\hline Tipo27 & $\begin{array}{l}\text { Principio de Ocultación conside- } \\
\text { rado como no solicitar informa- } \\
\text { ción o no compartir detalles in- } \\
\text { ternos de las clases }\end{array}$ & $\begin{array}{l}\text { Pensamiento que relaciona el diseñar } \\
\text { clases que no soliciten ni compartan in- } \\
\text { formación }\end{array}$ \\
\hline Tipo28 & $\begin{array}{l}\text { Uso de get() y set() para esconder } \\
\text { los detalles internos de la clase }\end{array}$ & $\begin{array}{l}\text { Pensamiento que relaciona usar los } \\
\text { métodos get y set para acceder a los } \\
\text { atributos de la clase y de esa manera } \\
\text { ocultar a los atributos }\end{array}$ \\
\hline Tipo29 & $\begin{array}{l}\text { Establecer inicialmente una lista } \\
\text { de decisiones de diseño permite } \\
\text { aplicar el Principio de Ocultación } \\
\text { de la Información }\end{array}$ & $\begin{array}{l}\text { Comportamiento que conduce a identi- } \\
\text { ficar las decisiones de diseño que son } \\
\text { más probables de cambio para poder } \\
\text { aplicar el Principio de Ocultación }\end{array}$ \\
\hline Tipo30 & $\begin{array}{l}\text { Definición de una propiedad que } \\
\text { es invisible para los elementos ex- } \\
\text { ternos }\end{array}$ & $\begin{array}{l}\text { Diseño de un elemento para consumo } \\
\text { interno de los elementos de una heren- } \\
\text { cia }\end{array}$ \\
\hline Tipo31 & Particularización de las listas & $\begin{array}{l}\text { Definición de listas para cada elemento } \\
\text { que tiene más de un elemento }\end{array}$ \\
\hline Tipo32 & $\begin{array}{l}\text { No es explícito donde y como ma- } \\
\text { nejan las listas }\end{array}$ & $\begin{array}{l}\text { Diseño del sistema donde hay una esca- } \\
\text { sa referencia de las listas que maneja el } \\
\text { sistema o no se puede saber cómo estas } \\
\text { son manejadas }\end{array}$ \\
\hline
\end{tabular}

Continúa en la siguiente página 


\begin{tabular}{|c|c|c|}
\hline Prefijo & Tipos de código & Descripción \\
\hline Tipo33 & $\begin{array}{l}\text { Ausencia de un elemento que ha- } \\
\text { ga de contenedor o insuficiencia } \\
\text { en definirlo }\end{array}$ & $\begin{array}{l}\text { Diseño del sistema donde no hay un ele- } \\
\text { mento encargado de manejar las listas o } \\
\text { el elemento pudiera ser potencialmente } \\
\text { un contenedor, pero no contiene listas }\end{array}$ \\
\hline Tipo34 & $\begin{array}{l}\text { Ausencia del concepto Juego o in- } \\
\text { suficiencia al definirlo en una apli- } \\
\text { cación de juego }\end{array}$ & $\begin{array}{l}\text { Cuando se les pidió diseñar un juego, no } \\
\text { hubo un concepto Juego en el diseño }\end{array}$ \\
\hline Tipo35 & $\begin{array}{l}\text { Definición de métodos con el mis- } \\
\text { mo nombre y que deberían tener } \\
\text { comportamiento similar en una } \\
\text { herencia, pero son totalmente di- } \\
\text { ferentes en su implementación }\end{array}$ & $\begin{array}{l}\text { En una estructura de herencia, el estu- } \\
\text { diante parece usar polimorfismo al co- } \\
\text { locar a sus hijos con la misma propie- } \\
\text { dad del padre. La propiedad se refería } \\
\text { a una misma acción que debía tener un } \\
\text { comportamiento similar, pero al ver su } \\
\text { implementación tenían secuencia dife- } \\
\text { rentes y confusas }\end{array}$ \\
\hline Tipo36 & $\begin{array}{l}\text { Separación de elementos que son } \\
\text { similares en el software pero que } \\
\text { son interpretados como diferentes }\end{array}$ & $\begin{array}{l}\text { En las aplicaciones enviadas existían } \\
\text { elementos que en el software podrían } \\
\text { tener las mismas propiedades y por } \\
\text { tal razón podrían ser agrupadas bajo } \\
\text { una misma abstracción. Pero el estu- } \\
\text { diante las consideró como diferentes se- } \\
\text { parándola fuera de la abstracción }\end{array}$ \\
\hline Tipo37 & $\begin{array}{l}\text { Particularización de un método } \\
\text { para las posibles combinaciones }\end{array}$ & $\begin{array}{l}\text { Sucede cuando una clase tiene varios } \\
\text { posibilidades para un mismo método, } \\
\text { por ejemplo cuando el estudiante consi- } \\
\text { deró colocar el método moverArriba(), } \\
\text { moverAbajo() }\end{array}$ \\
\hline Tipo38 & Definición de clases como datos & $\begin{array}{l}\text { Cuando las clases no tienen comporta- } \\
\text { miento }\end{array}$ \\
\hline Tipo39 & $\begin{array}{l}\text { Resistencia a dar propiedades a } \\
\text { un concepto que en la vida real } \\
\text { no lo tiene }\end{array}$ & $\begin{array}{l}\text { Cuando un concepto a nivel de softwa- } \\
\text { re podría tener una propiedad, pero el } \\
\text { estudiante se niega a colocarlo, porque } \\
\text { ese mismo concepto en la vida real ca- } \\
\text { rece de dicha propiedad }\end{array}$ \\
\hline Tipo40 & $\begin{array}{l}\text { Diseño de un concepto a través de } \\
\text { propiedades heredadas }\end{array}$ & $\begin{array}{l}\text { Sucede cuando un concepto del diseño } \\
\text { es creado a partir de propiedades here- } \\
\text { dades de otro conceptos }\end{array}$ \\
\hline Tipo41 & $\begin{array}{l}\text { Definición de un concepto como } \\
\text { un atributo }\end{array}$ & $\begin{array}{l}\text { Esto sucede cuando un concepto podría } \\
\text { ser representado como una clase por te- } \\
\text { ner comportamiento propio, pero en lu- } \\
\text { gar de eso se simplifica a ser un atributo } \\
\text { de otro concepto }\end{array}$ \\
\hline
\end{tabular}

Continúa en la siguiente página 


\begin{tabular}{|c|c|c|}
\hline Prefijo & Tipos de código & Descripción \\
\hline Tipo42 & $\begin{array}{l}\text { Diseño de elementos que están } \\
\text { aislados del resto de la estructura }\end{array}$ & $\begin{array}{l}\text { Clases que a nivel de diagrama no tie- } \\
\text { nen relación con el resto del sistema }\end{array}$ \\
\hline Tipo43 & $\begin{array}{l}\text { Definición de una estructura tipo } \\
\text { flujo de datos (input-algoritmo- } \\
\text { output) }\end{array}$ & $\begin{array}{l}\text { Diseños que han definido una partición } \\
\text { de módulos donde uno de ellas se encar- } \\
\text { ga de la entrada de datos, otro módulo } \\
\text { se encarga del procesamiento, y final- } \\
\text { mente otro de la impresión o salida de } \\
\text { datos }\end{array}$ \\
\hline Tipo44 & $\begin{array}{l}\text { Elaboración de un diagrama } \\
\text { entidad-relación }\end{array}$ & $\begin{array}{l}\text { Cuando se diseña con un diagrama en- } \\
\text { tidad - relación }\end{array}$ \\
\hline Tipo45 & $\begin{array}{l}\text { Separación de los elementos del } \\
\text { sistema en aquellos que son datos } \\
\text { de los que tienen comportamiento }\end{array}$ & $\begin{array}{l}\text { Sucede cuando la descomposición del } \\
\text { sistema se ha realizado de manera que } \\
\text { unas clases tienen comportamiento y } \\
\text { otras son datos }\end{array}$ \\
\hline Tipo46 & $\begin{array}{l}\text { Representación del número exac- } \\
\text { to de elementos que se ven en la } \\
\text { aplicación en el diseño }\end{array}$ & $\begin{array}{l}\text { Esto se refleja cuando el diseño del sis- } \\
\text { tema está enfocado a resolver el proble- } \\
\text { ma inmediato solicitado a los estudian- } \\
\text { tes, es decir si se les mostró una aplica- } \\
\text { ción con dos muebles, entonces los estu- } \\
\text { diantes crean un sistema para dos mue- } \\
\text { bles }\end{array}$ \\
\hline Tipo47 & $\begin{array}{l}\text { Asocia el Principio de Oculta- } \\
\text { ción de Información con que los } \\
\text { parámetros de cada entidad estén } \\
\text { escondidos }\end{array}$ & $\begin{array}{l}\text { Esconder los parámetros a través de co- } \\
\text { locarlos como privados es entendido co- } \\
\text { mo aplicar el Principio de Ocultación }\end{array}$ \\
\hline Tipo48 & $\begin{array}{l}\text { Notación equivocada o incompa- } \\
\text { tible con el diagrama de clases }\end{array}$ & $\begin{array}{l}\text { La descripción textual que da el estu- } \\
\text { diante no coincide con lo que se visua- } \\
\text { liza en en diagrama, estos fallos están } \\
\text { centrados en el desconocimiento de la } \\
\text { notación }\end{array}$ \\
\hline
\end{tabular}

Tabla H.1: Diccionario de tipos de códigos 

Apéndice I

Extracción de estudiantes por códigos 


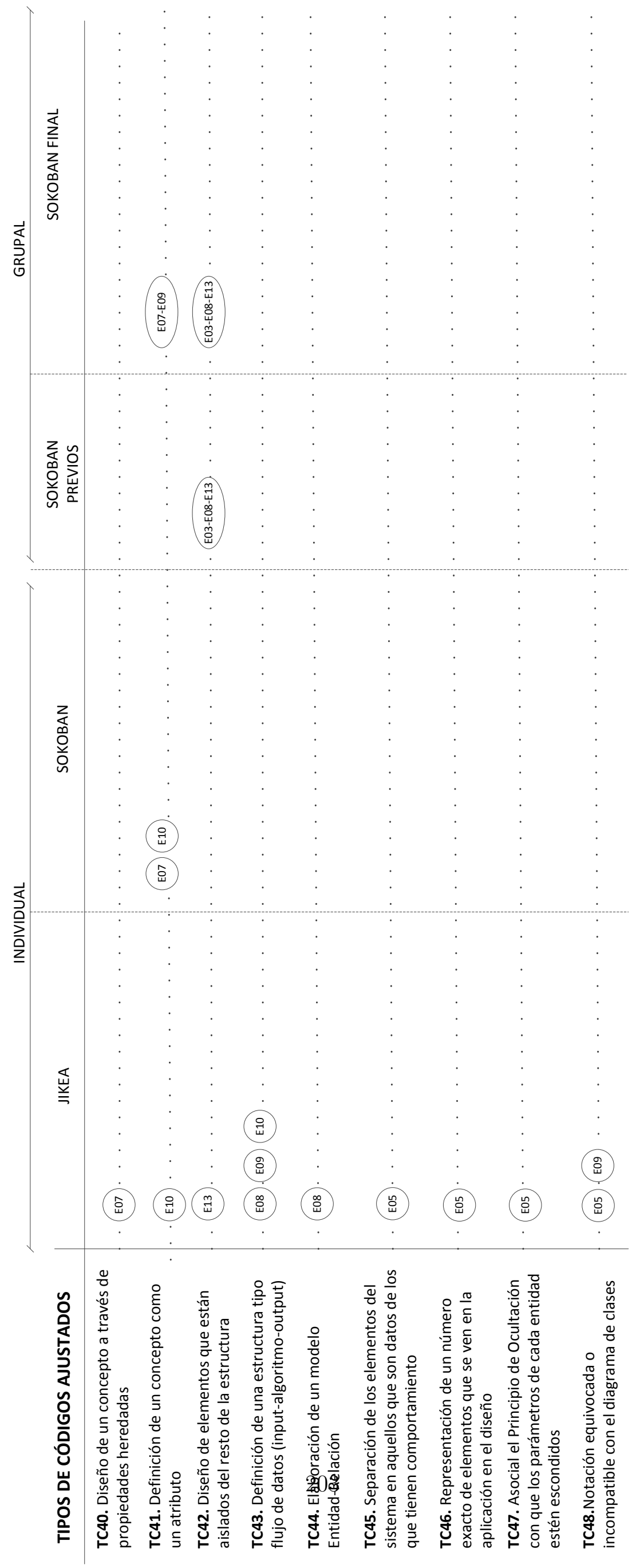



Apéndice $\mathbf{J}$

\section{Verificación de tipos de códigos por estudiantes}




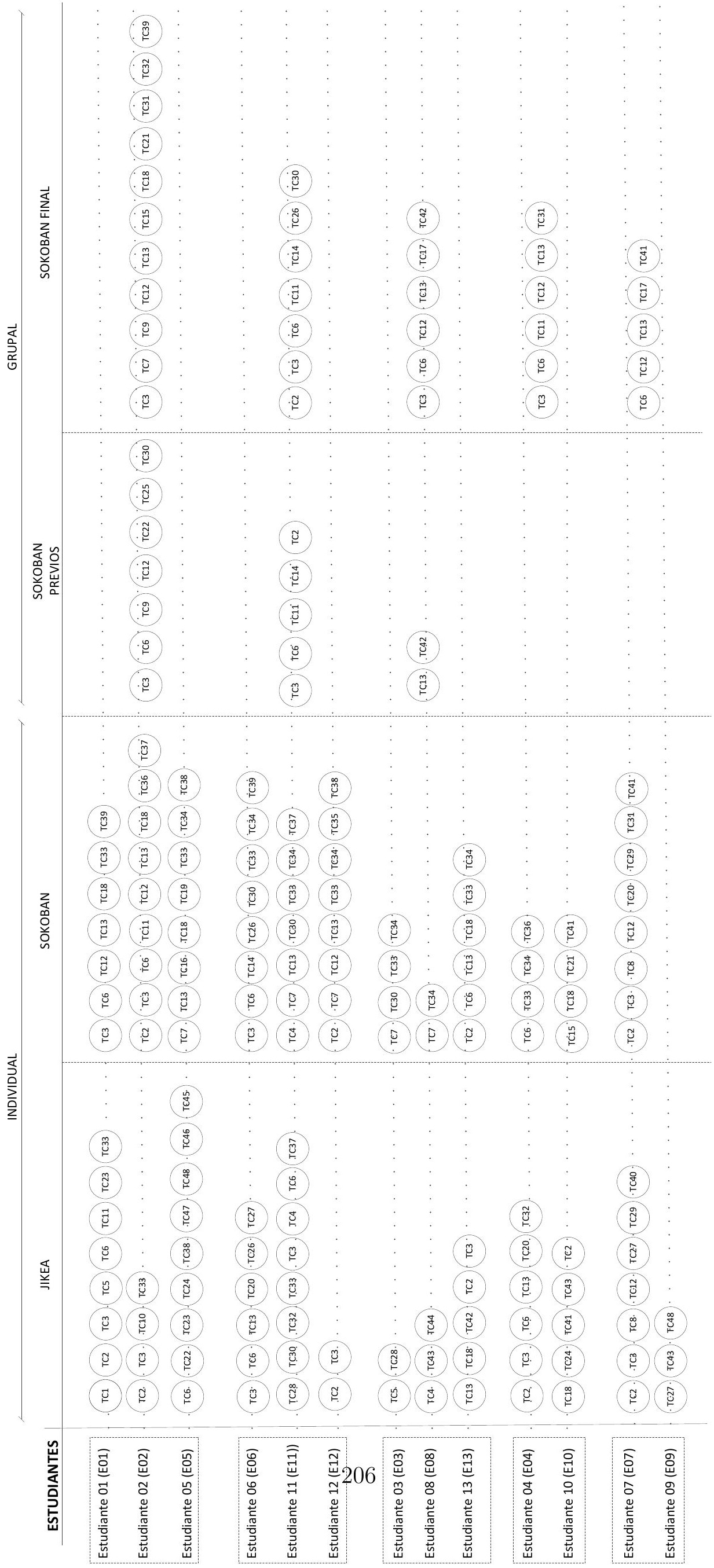

